(1)

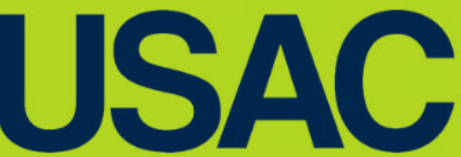

TRICENTENARIA

Universidad de San Carlos de Guatemala
Centra Universitaria de Sur Oriente

\section{CUNSURORI}

\section{NATURALEZA,}
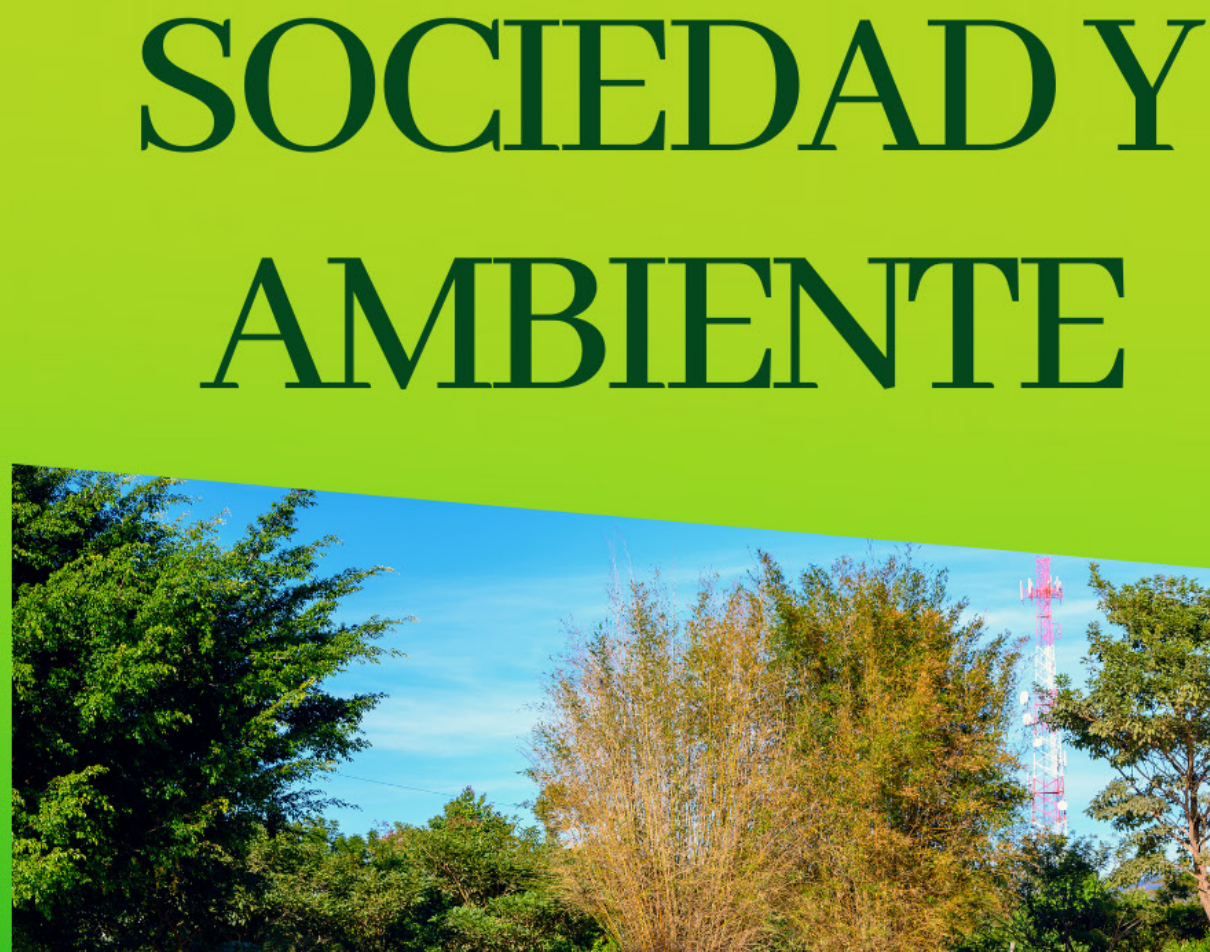

1.7.

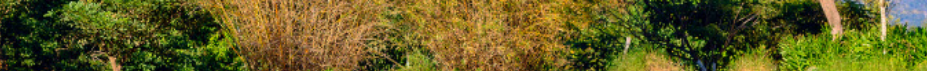

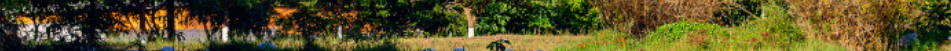

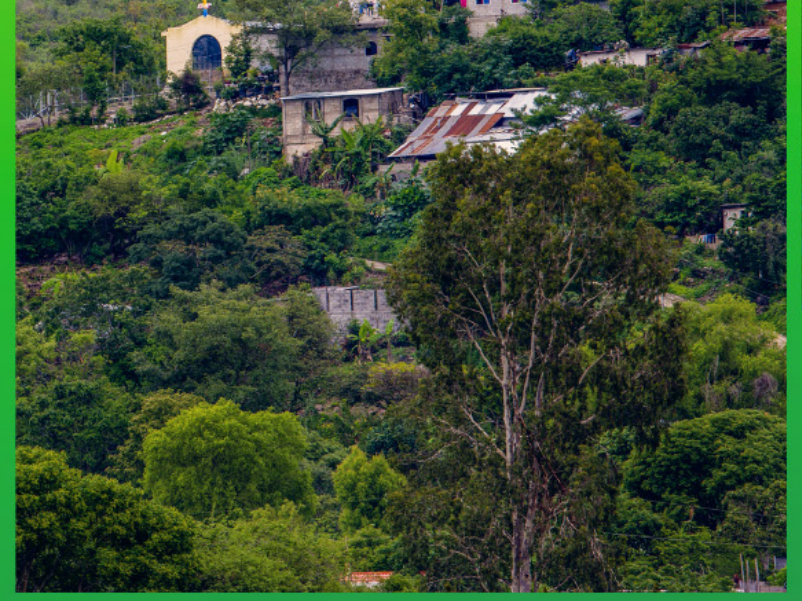

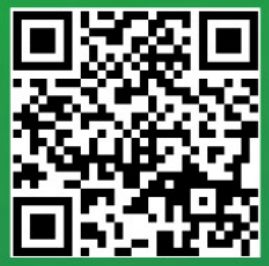

http://revistacunsurori.com/
Publicación catalogada en:

Portal $d$ Portales

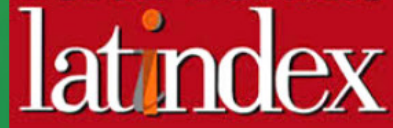

www. latindex.uman.mx

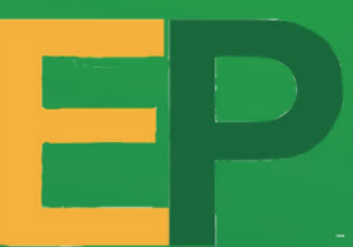

Departamento de Estudios de Postgrado
Revista impresa ISSN 2313-786X Revista digital ISSN: 2707-9643 Año 2020 Vol. 7

ACADÉMICA CIENTÍFICA 


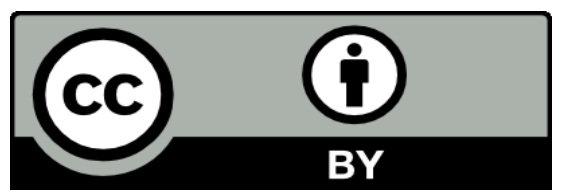

Este texto está protegido por una licencia CreativeCommons 4.0.

Esta licencia permite que otros distribuyan, mezclen, adapten y desarrollen su trabajo, incluso comercialmente, siempre y cuando le den crédito por la creación original.

Fotografía de portada y contraportada: Luis Galicia

Descripción de la fotografía de portada y contraportada: Vistas panorámicas del área rural del municipio de San Pedro Pínula, Jalapa y Puente Chipilapa al paso del rio de Jalapa

Diseño, diagramación y administración de la palataforma OJS: Edvin Méndez.

Centro Universitario de Sur Oriente (CUNSURORI, Universidad de San Carlos de Guatemala, 2020.

Los textos publicados en la revista son responsabilidad exclusiva de sus autores. 


\section{Naturaleza, Sociedad y Ambiente}

\section{Revista Académica y Científica}

Centro Universitario de Sur Oriente -CUNSURORI

Universidad de San Carlos de Guatemala

3a. calle final 1-69, zona 5 Bo. Chipilapa, Jalapa, Guatemala

Teléfono 7922-7908
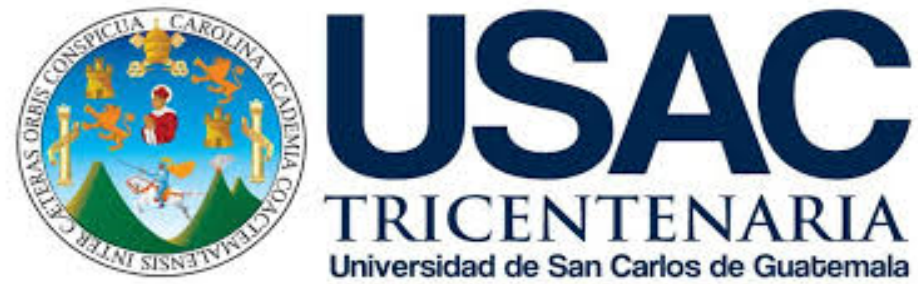

Con el apoyo de:

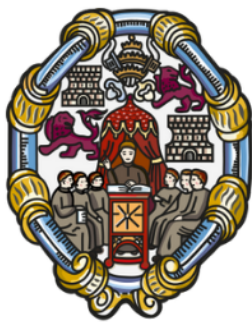

Universidad Pontifica de Salamanca

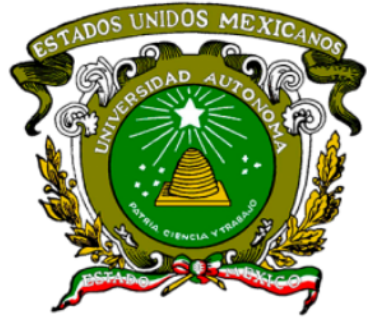

Universidad Autónoma del Estado de México

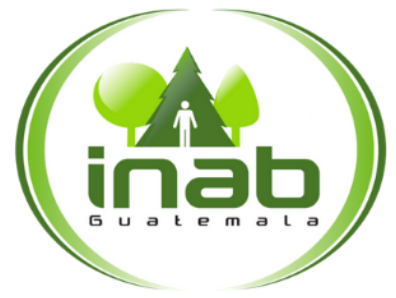

Universidad Nacional de Bosques Más bosques, más vida

\section{경희대학교}

KYUNG HEE UNIVERSITY

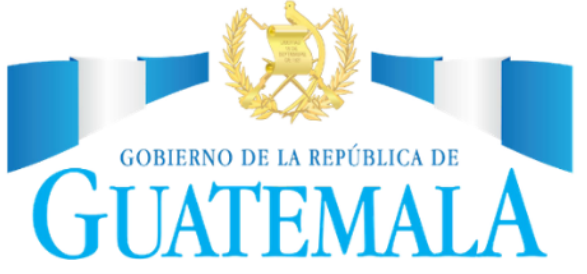

Ministerio de Educación

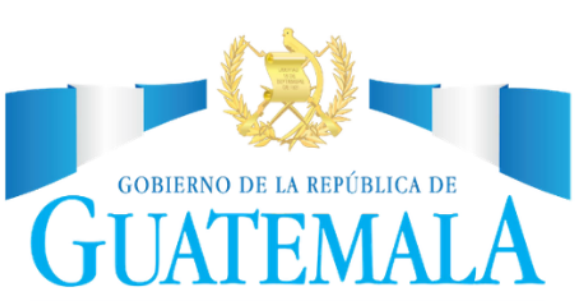

Ministerio de Ambiente y Recursos Naturales

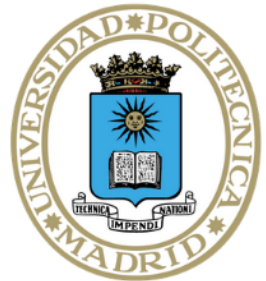

Universidad Politécnica de Madrid

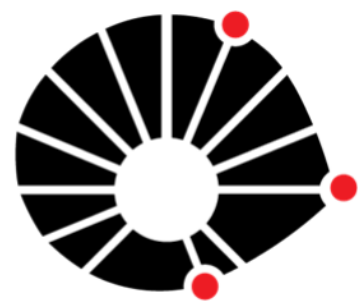

UNICAMP

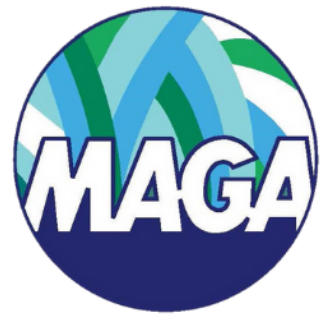

Ministerio de Agricultura, Gandadería y Alimentación 



\section{Autoridades de la Universidad de San Carlos de Guatemala (USAC)}

M.Sc. Murphy Olympo Paiz Recinos

Rector

Arq. Carlos Enrique Valladares Cerezo

Secretario General

Dr. Jorge Ruano Estrada

Coordinador General Sistema de Estudios de Postgrado (SEP)

Dr. Félix Alan Douglas Aguilar Carrera

Director General de Investigación (DIGI)

Licda. Mariaceleste Morales Carrillo

Jefa de Biblioteca Central

\section{Autoridades del Centro Universitario de Sur Oriente (CUNSURORI)}

\section{Consejo Directivo}

Lic. Edwin Wilfredo Contreras Cardona

Director

\section{M.A. Modesto Rustrían \\ Secretario}

M. Sc. Hilda Gissela Ortiz Cruz

Representante Docente

Ing. Agr. Marino Eliázar Reyes Rivadeneira

Representante Docente

M.A. Engelberth Waldemar Palma López

Representante Graduados

Lic. Edgar Antonio Orellana Carillo

Representante Estudiantil

T.P.A. Marvin Iván Castillo López

Representante Estudiantil 



\section{Revista Naturaleza, Sociedad y Ambiente}

Jalapa, Guatemala

\section{Director de la Revista}

Lic. Edwin Wilfredo Contreras Cardona

Director del Departamento de Estudios de Postgrados CUNSURORI-USAC

\section{Comité Científico Editorial}

M.A. Ludwing Enrique Ortíz López

Director Departamento de Estudios de Postgrado

Centro Universitario de Sur Oriente - USAC

Licda. Sara Barrios Montenegro de Cotto

Coordinadora Académica

Centro Universitario de Sur Oriente - USAC

M.A. Hilda Gissela Ortíz

Consejo Directivo de Postgrado

Centro Universitario de Sur Oriente - USAC

M.A. Yadira Abigail Ishlaj Conde

Docente Departamento de Estudios de Postgrado

Centro Universitario de Sur Oriente - USAC

M. Sc. María Carlota Ávila de Palacios

Centro Universitario de Sur Oriente - USAC

Dra. Claudia Esmeralda Villela

Universidad de San Carlos de Guatemala

Centro Universitario de Oriente - CUNORI

Ing. Byron Orozco

Ministerio de Ambiente y Recursos Naturales -MARN-, Guatemala

Ing. Agr. Erick Estuardo Cruz

Ministerio de Agricultura, Ganadería y Alimentación - MAGA-, Guatemala

M.A. Vilma Edith Téllez Lima

Ministerio de Educación - MINEDUC -, Guatemala

M.A. Keneth Federico Salazar Linares

Instituto Nacional de Bosques - INAB-, Guatemala 


\section{Comité de revisión y arbitraje}

Lic. Edwin Wilfredo Contreras Cardona

Director, Centro Universitario de Sur Oriente - USAC

M.A. Ludwing Enrique Ortíz López

Director Departamento de Estudios de Postgrado

Centro Universitario de Sur Oriente - USAC

Licda. Sara Barrios Montenegro de Cotto

Coordinadora Académica

Centro Universitario de Sur Oriente - USAC

M.A. Yadira Abigail Ishlaj Conde

Docente Departamento de Estudios de Postgrado

Centro Universitario de Sur Oriente - USAC

Dr. Pedro Costa Morata

Universidad Politécnica de Madrid, España

Dr. Francisco Salinas Ramos

Universidad Pontificia de Salamanca, España

Ing. Byron Orozco

Ministerio de Ambiente y Recursos Naturales -MARN- Guatemala

Ing. Agr. Erick Estuardo Cruz

Ministerio de Agricultura, Ganadería y Alimentación - MAGA-Guatemala

M.A. Vilma Edith Téllez Lima

Ministerio de Educación - MINEDUC - Guatemala

M.A. Keneth Federico Salazar Linares

Instituto Nacional de Bosques - INAB-Guatemala

M.A. Hilda Gissela Ortíz

Consejo Directivo de Postgrado

Centro Universitario de Sur Oriente - USAC 


\section{Secretaria Administrativa}

M.A. Yadira Abigail Ishlaj Conde de G.

Departamento de Estudios de Postgrado

Centro Universitario de Sur Oriente

Universidad de San Carlos de Guatemala

3a. calle final 1-69, zona 5 Bo. Chipilapa, Jalapa, Guatemala, C.A.

Tel. (502) 7922-7908

http:/revistacunsurori.com

postgradoscunsurori@gmail.com

revistacunsurori@gmail.com 



\section{Presentación / presentation}

Actualmente nos encontramos viviendo una época en medio de una pandemia, que nos ha llevado al confinamiento de muchas actividades y que al mismo tiempo ha permitido incluso el cambio de paradigmas en los procesos de educación y por supuesto en los de investigación. Dicha situación ha conferido el avance acelerado en la implementación de actividades virtuales en todos los campos, lo que ha generado el enriquecimiento de conocimientos en el área de tecnología e informática especialmente, sin embargo, también ha propiciado conocimientos en todas las áreas multidisciplinares.

Nuestro compromiso como Revista Naturaleza, Sociedad y Ambiente, es precisamente difundir ese conocimiento científico producto de investigaciones con distintos énfasis, con la finalidad que puedan ser leídos por todo tipo de público, más allá del mundo estrictamente académico y/o científico. Hoy por hoy, que hemos avanzado en los procesos digitales, también contamos con nuestra revista no solamente impresa sino también electrónica, con lo cual nos permite precisamente difundir con mejores alcances los artículos presentados en cada edición.

El Centro Universitario de Sur Oriente a través del Departamento de Estudios de Postgrados, está comprometido en la búsqueda de espacios que permitan y promuevan los procesos de investigación, incidiendo a mejorar una cultura de conocimiento, decisión y por ende llevar a una mejor calidad de vida en la sociedad en general. Las investigaciones nos llevan a la obtención de respuestas, a la claridad de la comprensión, no solo del fenómeno que se investiga, ni del proceso en el que se construye un objeto de estudio, sino, fundamentalmente del universo interior del propio investigador que crece como conocimiento viviente. Por lo que, lo incentivamos a ser parte de éste equipo multidisciplinar de investigadores, para generar conocimiento y poder divulgar sus artículos en esta revista.

Lic. Edwin Wilfredo Contreras Cardona Director Departamento de Estudios de Postgrado Centro Universitario de Sur Oriente 



\section{Índice}

Presentación. .vii

\section{Artículos / Articles}

Responsabilidad Social Empresarial: experiencia y compromiso con los trabajadores y comunidades; Venezuela

Corporate Social Responsibility: experience and commitment to workers and communities; Venezuela

José Yhovany Bastidas, Jao Leite de Souza, María Rojas, Winston Duque, Wilson de Oliveira Campos, José Gui-

llermos Torres, Darialys Castillo y Ranni Arias

\section{Ordenamiento Territorial en el Municipio de Jalapa}

Territorial Planning in the Municipality of Jalapa

Ariel Oswaldo Reyes Donis

La validez de escalas NEP-R y ECS para medir comportamiento y preocupación ambiental en estudiantes del CUNSURORI, USAC

The validity of NEP-R and ECS scales to measure behavior and environmental concern in students from CUNSURORI, USAC

Jerson Martínez Castro

Estudio de prevalencia de Salmonella sp. en palomas domesticas (Columba livia) en parque zoológico minerva, Quetzaltenango

Prevalence study of Salmonella sp. in domestic pigeons (Columba livia) in minerva zoo, Quetzaltenango

Victor Andrés Amado Soto y Héctor Fuentes Rousselin

Estrategias de enseñanza utilizadas en estudiantes en programas de equivalencias integrales

Teaching strategies used in students in comprehensive equivalency programs

Adán Estrada Chávez

La ficción de método (reconstrucción del pasado) en Jinetes en el cielo del escritor guatemalteco, Mario Roberto Morales

The fiction of method (reconstruction of the past) in Riders in the sky by the Guatemalan writer, Mario Roberto Morales

Daniel Alarcón Osorio

El aumento del uso de los medios de comunicación masivos por crisis del Coronavirus

The increase in the use of mass media due to the Coronavirus crisis

Linda Evelin Espinoza Recinos

El aumento del uso de los medios de comunicación masivos por crisis del Coronavirus

The increase in the use of mass media due to the Coronavirus crisis

Linda Evelin Espinoza Recinos

"El clima laboral en la empresa constructora CARMOR, del municipio y departamento de Jalapa"

"The work environment in the construction company CARMOR, of the municipality and department of Jalapa "

Linda Evelin Espinoza Recinos 



\section{Responsabilidad Social Empresarial: experiencia y compromiso con los trabajadores y comunidades; Venezuela}

\section{Corporate Social Responsibility: experience and commitment to workers and communities; Venezuela}

\section{Como citar el artículo}

Yhovany, J., Souza, J., Rojas, M., Duque, W., Campos, O., Torres, G., Castillo, D. y Arias, R. (2020). Responsabilidad Social Empresarial: experiencia y compromiso con los trabajadores y comunidades; Venezuela. Revista Naturaleza, Sociedad y Ambiente, 7 (1), 1-28 DOI: https://doi.org/10.37533/cunsurori.v7i1.48

José Yhovany Bastidas, Joao Leite de Souza, María Rojas, Winston Duque, Wison de Oliveira Campos, José Guillermo Torres, Darialys Castillo y Ranni Arias

\section{Universidad de Los Andes (ULA) Venezuela}

Recibido: 04 de marzo de 2020 / Aceptado: 06 de agosto de 2020

Disponible en internet el 10 de noviembre de 2020

*Autor para correspondencia, correo electrónico: jose.bastidas@paveca.com.ve

\section{Resumen}

La directiva de la empresa ha visto con preocupación, la situación de precariedad que viven algunas familias de las comunidades cercanas a Desarrollo Forestales San Carlos (DEFORSA) en el estado Cojedes, y Papeles Venezolanos (PAVECA) en el estado Carabobo; en aras de aliviar esa realidad y en el cumplimiento de la Legislación venezolana; DEFORSA ha implementado desde sus inicios la Responsabilidad Social Empresarial (RSE) a través de la Fundación Papeles Venezolano (FUNDAPAVECA) trabajando en tres líneas de acción: educativa, ambiental y social. El objetivo fue describir los programas de Responsabilidad Social Empresarial. La investigación es de campo, descriptiva no experimental. Los principales programas en orden cronológico son: Programa Visitas guiadas, Programa de Capacitación Profesional, Infraestructura vial, Dotación de Papel, Transporte a la comunidad, Biotrabajador, Buen vecino, Ración de Queso, Ración de Miel y Alimentos (Proteínas y carbohidratos). Se concluye que los programas vigentes están consolidados y han tenido un impacto importante en el entorno, así como la satisfacción personal de los trabajadores a través de la figura de voluntariado y su experiencia y compromiso con las comunidades y la empresa. Se recomienda consolidar los programas vigentes y estandarizar indicadores para evaluar los programas de RSE en DEFORSA.

Palabras clave: beneficiarios, compromiso, comunidades, DEFORSA, Venezuela

\section{Abstract}

The company's board of directors has seen with concern the precarious situation experienced by some families from the communities near Desarrollo Forestales San Carlos (DEFORSA) in the state of Cojedes, and Papeles Venezolanos (PAVECA) in the state of Carabobo; for the sake of alleviating that reality and in compliance with Venezuelan legislation; DEFORSA has implemented Corporate Social Responsibility (CSR) since its inception through the Venezuelan Papers Foundation (FUNDAPAVECA) working on three lines of action: educational, environmental and social. The objective was to describe the Corporate Social Responsibility programs. The research is field, descriptive, not experimental. The main programs in chronological order are: Guided Tours Program, Professional Training Program, Road Infrastructure, Paper Supply, Transportation to the community, Biotrajador, Good Neighbor, Cheese Ration, Honey Ration and Food (Proteins and carbohydrates). It is concluded that the current programs are consolidated and have had a significant impact on the environment, as well as the personal satisfaction of the workers through the figure of volunteering and their experience and commitment to the communities and the company. It is recommended to consolidate the current programs and standardize indicators to evaluate the CSR programs in DEFORSA.

Keywords: beneficiaries, commitment, communities, DEFORSA, Venezuela 


\section{Introducción}

Durante mucho tiempo, las empresas y la sociedad asumieron que la responsabilidad de las primeras era generar empleo y garantizar utilidades a sus propietarios o accionistas. En la actualidad esta visión no sólo es incongruente, sino que es criticada por la mayoría de los actores sociales vinculados a las organizaciones; además de generar utilidades, las empresas deben tomar en cuenta que todas las actividades que desarrollan afectan positiva o negativamente la calidad de vida de sus trabajadores y de las comunidades donde funcionan, así como a la sociedad en general y al ambiente. Consecuencia de este cambio en la concepción sobre la función de las empresas modernas, un creciente número de éstas perciben la necesidad de incorporar la responsabilidad social en su planificación interna como estrategia de negocio.

Es así, como el sector privado ha avanzado en la formulación y promoción de proyectos donde convergen intereses empresariales y las necesidades de la sociedad. Con el pasar del tiempo, las organizaciones han ido modificando su filosofía de gestión, es decir, ya no sólo parten de la práctica empresarial tradicional, como es la generación de trabajo para la sociedad y riqueza para los propietarios o accionistas, sino que ahora existe un valor agregado, como es la contribución que la empresa pueda hacer a las comunidades más que en el aspecto legal.

Las empresas modernas tienen una responsabilidad global más allá de la optimización de los beneficios, que involucra garantizar en la medida de lo posible; transparencia, controles, regulaciones; y, lo más importante, participación en la sociedad. En este contexto, surge la Responsabilidad Social Empre- sarial (RSE), como alternativa a los cambios socio-económicos presentes en el marco del proceso de globalización, donde se construye un nuevo concepto de negocio, como respuesta a las demandas que la sociedad hace a las organizaciones, particularmente a aquellas que han demostrado ser más exitosas.

La RSE a la que hace referencia este artículo, corresponde a la empresa Desarrollos Forestales San Carlos II S.A, (DEFORSA); esta fue fundada en el año 1987; posee una superficie de 13647 hectáreas (ha) de tierra, distribuidas en los Municipio Ezequiel Zamora (antiguo Municipio San Carlos), Tinaco y Rómulo Gallegos correspondientes a DEFORSA San Carlos con 10742 ha; $y$ en el Municipios Pao de San Juan Bautista correspondiente a DEFORSA Caño Benito con 2905 ha. Dicha superficie se distribuye en sistemas silvopastoriles de alta y baja densidad de población de eucalipto $(46 \%)$, bosques naturales (más del $20 \%$ ), entre otros usos como pastos naturales, lagunas, infraestructuras, cortafuegos y carreteras.

DEFORSA es una empresa forestal con plantaciones de Eucalyptus spp. principalmente, cuyo objetivo es garantizar la producción de madera para la elaboración de pulpa para papel; específicamente, papel tipo tisú o suave, entre otros usos madereros como la producción de madera para estantillos y carbón. EI procesamiento de la pulpa se realiza en la empresa PAVECA (en Guacara, estado Carabobo). A partir del año 2004 se implementaron plantaciones de eucaliptos con distanciamientos largos (baja densidad) en terrenos marginales, ocupadas por pastos naturales y establecidos con Brachiaria spp., para la incorporación de ganado bovino (vacuno y bufalino). Luego, se incorporaron rubros agríco- 
las entre las plantaciones, tales como: arroz, sorgo, maíz, café, patilla, frijol, entre otros, desarrollando de esta manera los Sistemas Agrosilvopastoriles y Silvopastoriles, el cual ha generado beneficios importantes para el cumplimiento de la RSE en las comunidades y trabajadores de la empresa.

En este contexto, la investigación se orienta en la descripción de los proyectos de Responsabilidad Social incorporados a la gestión empresarial de DEFORSA. En estos, se promueven valores éticos, políticas y programas diseñados para sustentar el trabajo de la organización, en una búsqueda constante de superar lo estrictamente económico a la preocupación por el impacto de la empresa en su entorno social y natural.

Es por esto, que se abordó como objetivo, describir los programas de Responsabilidad Social Empresarial (RSE), ejecutados por DEFORSA, pretendiendo mostrar los beneficios que los proyectos han generado de acuerdo a la experiencia y compromiso con los trabajadores y comunidades en el estado Cojedes y Carabobo, analizar el histórico, cronología y permanencia en el tiempo de los programas; y estudiar el impacto social de los programas banderas de la actualidad en relación con las comunidades e instituciones educativas y el grupo de beneficiarios al cual va dirigido.

\section{Referente teórico}

La Responsabilidad Social Empresarial, es un concepto que surge en Estados Unidos en la década de los cincuenta y sesenta, era considerada una obligación moral y responsabilidad personal del empresario (Alea, 2007). El carácter formal de la RSE se reconoce en Europa desde la publicación del llamado "Libro
Verde", cuyo objetivo era fomentar un marco europeo para la responsabilidad social de las empresas. Sin embargo, Sabogal (2008), hace referencia a una aproximación al concepto de RSE, así como también demanda algunos cuestionamientos al respecto.

La primera definición de RSE que estableció la Comisión Europea propone que la RSE es: "La integración voluntaria, por parte de las empresas, de las preocupaciones sociales y medio ambientales en sus operaciones comerciales y sus relaciones con sus interlocutores" según Monzón y Chaves (2018).

Esta concepción consideraba dos dimensiones: a) La interna de la empresa, entendida como las relaciones con los trabajadores, inversión en capital humano, salud y seguridad en el lugar de trabajo, reestructuración socialmente responsable de las plantas de producción, prácticas medioambientalmente responsables y b) la dimensión externa, que se extiende más allá del perímetro de la empresa, los empleados y los accionistas, teniendo en cuenta a la comunidad local y una amplia variedad de partes interesadas y otros afectados por la actividad empresarial: socios comerciales y proveedores, clientes, poderes públicos y ONG que representan a las comunidades locales y el propio medio ambiente (Monzón y Chaves, 2018).

En la actualidad existen diversas definiciones de RSE; en lo descrito en la Guía sobre Responsabilidad Social de la ISO 26000; una empresa es socialmente responsable si responde ante sus impactos en la sociedad. Estas empresas se caracterizan por realizar una contribución al desarrollo sostenible de las sociedades, así como por reconocer y 
considerar las aspiraciones de los diferentes grupos de interés. En el Libro Verde de la Comisión de las Comunidades Europeas (2001), establece que; una empresa no es responsable socialmente si cumple estrictamente con las imposiciones legales, sino que adicionalmente se preocupa por el bienestar de su capital humano, de su entorno más próximo y por cuidar las relaciones con sus principales interlocutores (Daza et al, 2018). En términos simples, la responsabilidad viene a ser la obligación (moral o legal) de responder ante hechos o situaciones.

Por asociación la Responsabilidad Social será entonces el compromiso de responder a las demandas de la sociedad y la Responsabilidad Social Empresarial constituye la capacidad de la empresa para empatizar con las necesidades de los grupos sociales con los cuales se relaciona y darles respuesta. En palabras de Cajiga (s/f): La Responsabilidad Social Empresarial, es el compromiso consciente y congruente de cumplir integralmente con la finalidad de la empresa, tanto en lo interno como en lo externo, considerando las expectativas económicas, sociales y ambientales de todos sus participantes, demostrando respeto por la gente, los valores éticos, la comunidad y el medio ambiente, contribuyendo así a la construcción del bien común.

En DEFORSA se ha enfocado la Responsabilidad Social Empresarial desde tres líneas de acción: Educativa, Ambiental y Social, contribuyendo con el desarrollo y fortalecimiento de sus trabajadores y comunidades aledañas, operando apegados a los principios éticos y morales, cumpliendo con la legislación venezolana y manteniendo siempre un clima de respeto y armonía.

\section{Metodología}

La metodología para llevar a cabo esta investigación fue de campo descriptiva no experimental (Hernández, Fernández y Baptista, 2014), donde se describieron los diferentes programas de Responsabilidad Social Empresarial más importantes, la permanencia en el tiempo y su relación entre número de beneficiarios e instituciones educativas y comunidades. El período de estudio comprendió 1995-2019.

Las técnicas de recolección de los datos y de la información se obtuvieron con la observación directa y el análisis documental. Las técnicas utilizadas fueron: el diario de campo y registros en informes técnicos e ilustraciones gráficas (Hurtado de Barrera, 2010). La ubicación general y la distribución de las comunidades atendidas se muestran en los anexos 1 y 2 respectivamente.

Los datos se analizaron a través de una línea de tiempo infográfica (Histórico de la RSE en DEFORSA) y una tabla cronológica donde se representa el análisis de la permanencia en el tiempo de cada programa.

El alcance geográfico (número de instituciones y comunidades atendidas en las adyacencias de DEFORSA en el estado Cojedes y en las adyacencias de PAVECA en el estado Carabobo) y número de beneficiados fueron analizados a través de la estadística descriptiva con tablas dinámicas y representaciones gráficas. El análisis de la estadística descriptica sólo se utilizó para los tres (3) programas más importantes en los dos (2) últimos años (2018 y 2019) como: el programa ración de queso, programa ración de miel y programa alimentos a base de proteínas y carbohidratos. 


\section{Resultados \\ Programas de Responsabilidad Social Empresarial}

\section{Línea de acción Educativa}

a. Programa de Capacitación Profesional: Desde el año 1995 hasta la actualidad, este programa ha contribuido al fortalecimiento de la educación técnica y especializada en las diferentes áreas del campo forestal, agropecuario y administrativo.

Es donde se complementan la capacitación práctica de las distintas instituciones educativas de educación media y universitaria a través del programa de pasantías de estudiantes desde técnicos medios, técnicos superiores hasta ingenieros o equivalentes.

b. Talleres Educativos en las Escuelas: se orientan al fortalecimiento de principios y valores de los niños en las escuelas cercanas a DEFORSA, a través de programas educativos sobre autoestima y motivación; los cuales fueron impartidos por los trabajadores y familiares en jornadas de voluntariado. entre los años 2011 y 2013 , dirigidos a estudiantes en los sectores "Luis Arias Andrade" y Conaima. Estos fueron denominados: "La Familia"; "Ventajas de permanecer en la Escuela" y "Ambiente, Conservación y Preservación"

c. Talleres educativos para las Comunidades: fue en el año 2013 donde se impartieron talleres en las comunidades organizadas con el fin de capacitar u orientar en oficios que permitieron a los participantes hacer uso de materiales disponibles o de re-uso; por ejemplo: reciclaje de envases plásticos, de vidrio, primeros auxilios, entre otros.

\section{Línea de acción Ambiental}

a. Visitas guiadas: se orientan a la concienciación en Educación Ambiental en niños, jóvenes y adultos hacia un cambio de conducta favorable a la conservación de los recursos ambientales.

Las visitas guiadas se realizan con estudiantes de todos los niveles de educación, trabajadores, familiares de los trabajadores y comunidades organizadas.

Este programa consta de tres etapas: primero se da cumplimiento a la normativa interna de seguridad, donde se les imparte una charla garantizando la integridad de los visitantes antes de dar inicio al recorrido; luego una segunda charla y videos alusivos a la conservación del ambiente; por último, se realiza el recorrido de campo por los senderos y lagunas naturales donde los visitantes pueden apreciar algunas especies de flora y fauna existente.

Los trabajadores también reciben inducción y capacitación en Educación Ambiental donde se comprometen al cuidado y conservación de los recursos ambientales en virtud de la biodiversidad de la flora y fauna silvestre presente en las áreas de reservas naturales como en el bosque plantado; además, realizan jornadas de liberación de aves, serpientes, morrocoyes, babas, entre otros. Este programa se inició en el año 1995 y sigue vigente en los actuales momentos, logrando alcanzar un número importante de visitantes entre los años 2010 - 2014. 
b. Programa Biotrabajador: este programa inició en el año 2012; busca que cada trabajador fomente el equilibrio entre el individuo y el ambiente, generando ideas y adoptándolas en prácticas ecológicas eficientes y eficaces que ayuden a proteger y conservar el ambiente tanto en la empresa como en su hogar.

El biotrabajador se convierte en "hombre biónico", transmite toda la energía positiva en pro del ambiente y de la biodiversidad. Algunas de las actividades tangibles que estos realizan son: clasificar los residuos en papel, vidrio, plásticos, desechos peligrosos en sus respectivos contenedores; utilización vaso y cubiertos (cuchillo, tenedor y cucharilla) personal para evitar utilizar desechables; apagar la luz en las horas de descanso o cuando se va a campo; entre otras actividades.

c. Programa "Buen Vecino": Se busca fortalecer lazos de cooperación en función de evitar la quema y los incendios forestales; además se crear concienciación en la conservación de los recursos y la fauna silvestre. Este programa es relativamente nuevo, se inició en el 2017 hasta la actualidad.

\section{Línea de acción Social}

a. Infraestructura vial (2000-2019): En cuanto a la infraestructura vial, DEFORSA constantemente realiza el mantenimiento de la vía que conduce desde la urbanización "Monseñor Padilla" Fundabarrios y Conaima pasando por DEFORSA hasta vía el Totumo.

b. Dotación de Papel (2005-2019): Consiste en la dotación de papel higiénico, toallín, servilletas y toallas para manos a instituciones de la localidad de San Carlos, en el estado Cojedes; así como en la ciudad de Valencia, en el estado Carabobo.

c. Transporte a la comunidad (2007-2019): DEFORSA provee el transporte de personal docente y administrativo a las tres instituciones educativas de la comunidad de Conaima, Fundabarrios y habitantes en general para un estimado de beneficiarios de 60 personas todos los días hábiles de la semana durante todo el año.

d. Infraestructura educativa (2011-2013): la empresa viene realizando grandes esfuerzos en fortalecer la educación en los niños de la comunidad más próxima a sus instalaciones, enfocando inicialmente la importancia que repercute la infraestructura escolar.

Por ello se logró la construcción de un módulo R2, con 03 aulas de clases donde actualmente funciona el Liceo "Luis Beltrán Prieto Figueroa" en la comunidad de Conaima, para beneficiar a un promedio de 40 niños.También se construyó una sala de telemática en la escuela de la comunidad de Fundabarrios, así como la dotación de utensilios para el comedor.

En la escuela "José Gregorio Hernández" (2012) se construyó el sistema de agua potable, el cual benefició a toda la comunidad estudiantil incluyendo a los niños de preescolar y del Liceo, y en el año 2013, se construyó el comedor y se logró la dotación de equipos (comedor del preescolar).

e. Alimentos DEFORSA: entre los años 2011 y 2013 , se creó la marca de productos alimen- 
ticios como: harina de maíz precocida y arroz marca DEFORSA. Estos productos fueron única y exclusivamente para el programa de RSE de DEFORSA (estado Cojedes) y PAVECA (estado Carabobo) destinados a las comunidades adyacentes y trabajadores, en el que se alcanzó beneficiar cerca de 2350 personas. Este programa fue mermando a partir del año 2014, cuando los insumos empezaron a escasear. En virtud de lo anterior, se generó una nueva alternativa; la producción de miel y leche en DEFORSA con el objetivo de dar respuesta a la sociedad. A finales del año 2017 y principios del 2018 es cuando se consolida el Programa de ración de queso y miel de abejas.

f. Programa Ración: Queso y Miel: en la actualidad, se está haciendo entrega de una ración de queso (50-100 gr) la cual resulta del proceso de transformación de toda la leche que se produce en DEFORSA; conjuntamente se suministran pequeñas dosis de miel (18$20 \mathrm{gr}$ ) a través de sachet o chupis como suplementos nutritivos, dirigido a niños en edad escolar, adulto mayor y personas en situación de calle, con la colaboración del equipo de trabajadores; con el fin de suplir la necesidad alimentaria.

Es de destacar que la miel es proveniente de los apiarios ubicados estratégicamente en los sistemas silvopastoriles y bosques naturales de la Empresa. Dicho producto se procesa y se destina toda la producción a la RSE.

g. Programa Alimentos (Carbohidratos y Proteínas): Otro de los programas que ha tenido impacto social desde finales del año 2017 hasta la fecha, ha sido el de alimentos a base de proteínas y carbohidratos, destinados a las instituciones educativas, comunidades más vulnerables y personas en situación de calle.

Adicionalmente, se tiene previsto para el año 2020, consolidar el Programa Cachama. Este programa, consiste en la siembra, cría y cosecha de cachamas en las lagunas naturales de DEFORSA con la finalidad de producir proteínas para incorporarla al programa de alimentación de responsabilidad social, el cual una vez alcanzado el peso ideal (600 gr) se procede a la pesca y eviscerado, seguidamente a la entrega en las comunidades.

\section{Histórico de la Responsabilidad So- cial Empresarial}

A continuación, se sintetiza en la ilustración 1 los programas de RSE de DEFORSA, a través de una línea de tiempo infográfica, en la que se denota con borde color negro, la línea de acción Educativa; la de color gris, la línea de acción Ambiental y la de color gris claro, la línea de acción Social. 


\section{Cronología de los programas de RSE}

Tabla No. 1, se presenta la cronología de los programas y su permanencia en el tiempo hasta la actualidad.

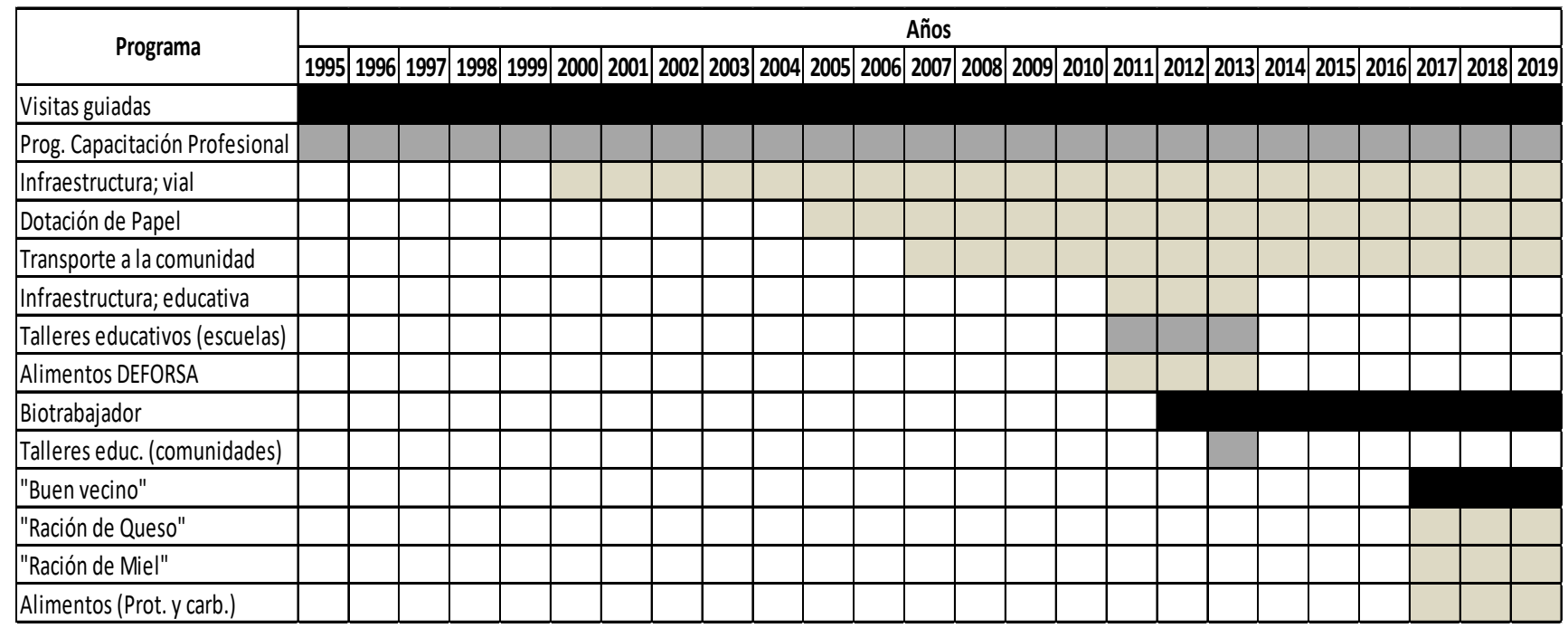

\section{Leyenda:}

Color Negro: Línea de acción Ambiental.

Color Gris: Línea de acción Educativa.

Color Gris claro: Línea de acción Social.

Fuente: elaboración propia a partir de los informes mensuales de la Superintendencia Interinstitucional y Ambiental de la empresa.

Se identifican los 14 programas más destacados; de los cuales 3 corresponden a la línea de acción Ambiental, 3 a la línea de acción Educativa; y 8 a la línea de acción Social. En cada programa se indica el año de inicio hasta el año de culminación en orden cronológico; así como los programas que se encuentran aún vigentes. De acuerdo con la cronología del cuadro 1, se analiza la permanencia en el tiempo de los programas: En la línea de acción Ambiental; es de resaltar, el programa "Visitas Guiadas"; fue el primero en iniciarse, y en la actualidad continua vigente con 25 años de trayectoria. El programa "Biotrabajador" tiene una vigencia desde hace 8 años; y el más reciente "Buen vecino", desde hace 3 años. Todos los programas en la línea de acción Ambiental se mantienen activos en la actualidad.
El Programa de Capacitación Profesional en la línea de acción Educativa tiene una permanencia en el tiempo de 25 años. Los talleres educativos, tanto para las escuelas como para las comunidades se ejecutaron solo en un período de tiempo determinado. En la línea de acción Social; el programa de "Infraestructura Vial" tiene una vigencia hasta la actualidad de 20 años, la "Dotación de papel" de 15 años y el servicio de "Transporte a la comunidad" de 13 años. Los programas "infraestructura educativa" y "Alimentos DEFORSA" tuvieron vigencia en el período 2011-2013. Recientemente, los programas "ración de Queso", "ración de Miel" y "Alimentos (proteínas y carbohidratos)" iniciaron hace 3 años y en la actualidad se han consolidado como los programas banderas en instituciones y comunidades de los estados Cojedes y Carabobo. 


\section{Principales programas de impacto social} Para este artículo, se hizo énfasis en 3 programas banderas basado en el impacto social de la actualidad; entre los que se mencionan: Ración de queso, ración de miel y alimentos (proteínas y carbohidratos).
Beneficiarios e instituciones educativas y comunidades

En las siguientes gráficas, se identifican las instituciones educativas, comunidades y el número de beneficiarios que gozan de los programas anteriormente mencionados, para los años 2018 y 2019 en el estado Cojedes (gráficas 1,2 , y 3 ) y en el estado Carabobo (gráficas 4, 5 y 6).

Figura No. 1 Beneficiarios por Institución Educativa y Comunidad. Programa "Ración de Queso" en el estado Cojedes. Año 2018 (a). Año 2019 (b).

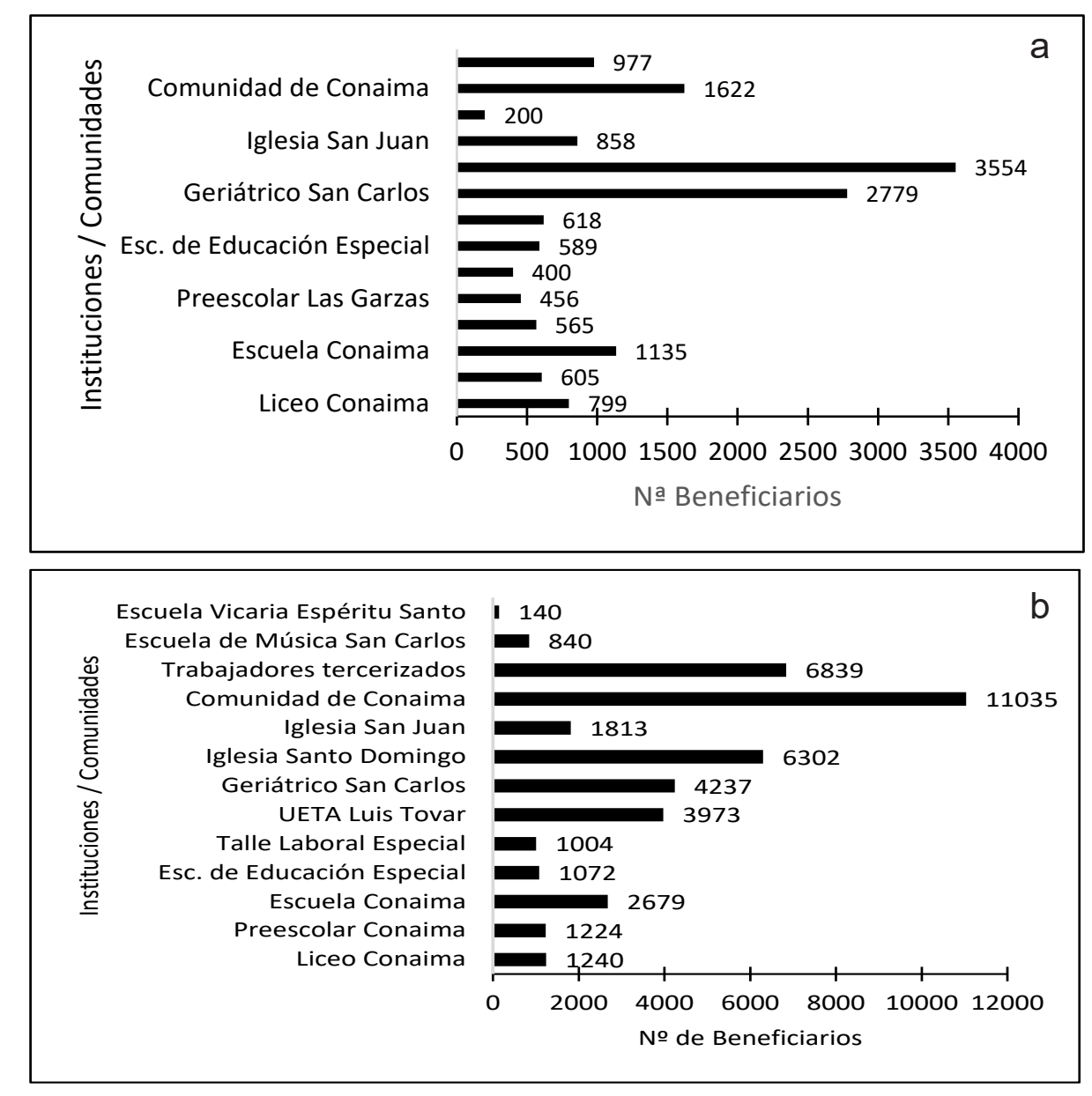

Fuente: elaboración propia a partir de los informes mensuales de la Superintendencia Interinstitucional y Ambiental de la empresa.

En el programa "Ración de queso" en el estado Cojedes (gráfica 1a y 1b), se incrementó el número de beneficiarios de 15157 a 42398 con respecto a los años 2018 y 2019; y el número de comunidades de 14 a 13 respectivamente. 
Figura No. 2 Beneficiarios por institución / comunidad. Programa "Ración de Miel" en el estado Cojedes. Año 2018 (a). Año 2019 (b).
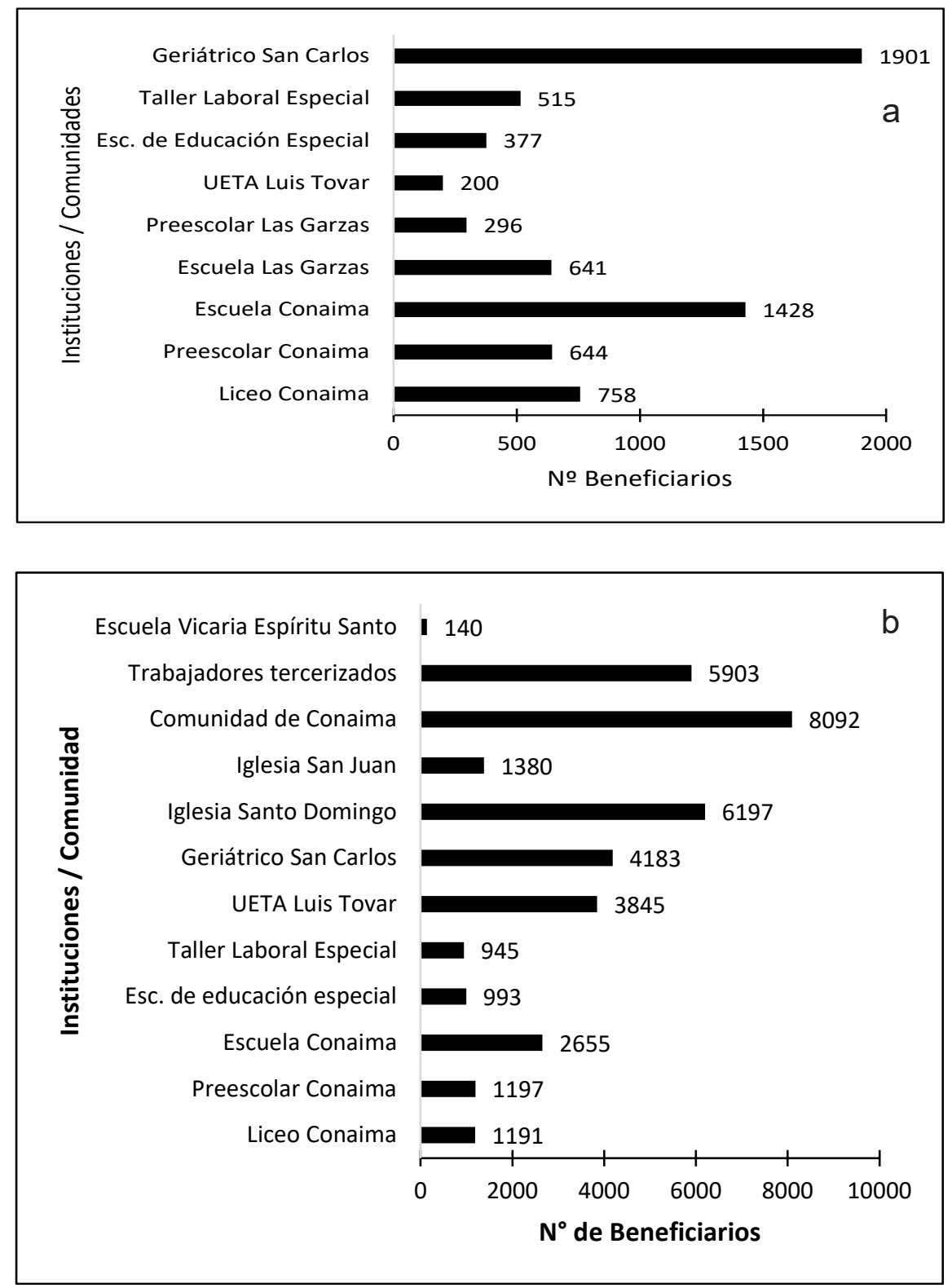

Fuente: elaboración propia a partir de los informes mensuales de la Superintendencia Interinstitucional y Ambiental de la empresa.

En el programa "Ración de miel" en el estado Cojedes (gráfica $2 a$ y $2 b$ ), se incrementó el número de beneficiarios de 6760 a 37510 con respecto a los años 2018 y 2019; y el número de comunidades de 9 a 12 respectivamente. 
Figura No. 3 Beneficiarios por institución / comunidad. Programa "Alimentos (Proteínas y carbohidratos)" en el estado Cojedes. Año 2018 (a). Año 2019 (b).
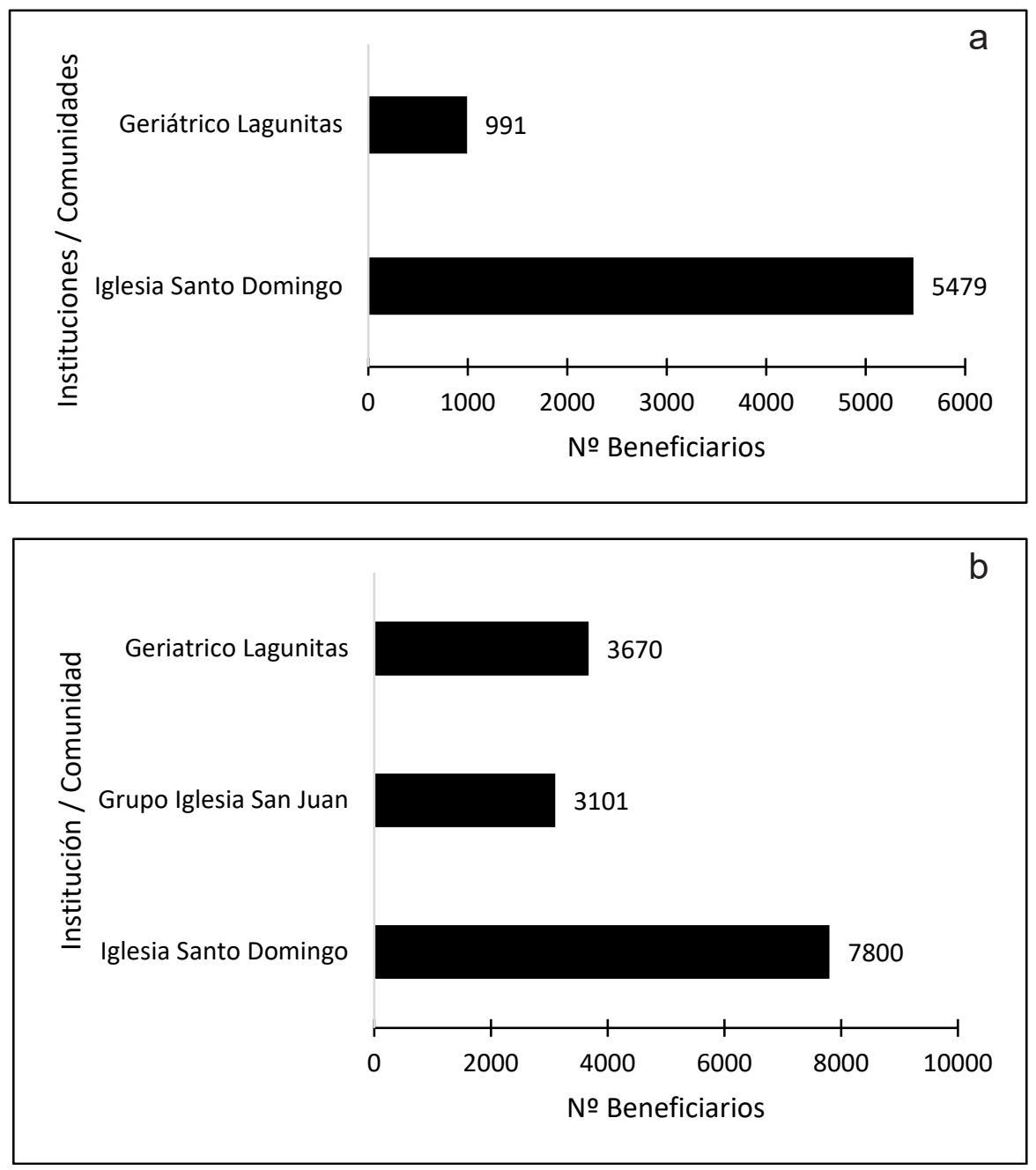

Fuente: elaboración propia a partir de los informes mensuales de la Superintendencia Interinstitucional y Ambiental de la empresa.

En el Programa "Alimentos (Proteínas y Carbohidratos)" en el estado Cojedes (gráfica 3a y $3 b$ ), se incrementó el número de beneficiarios de 6470 a 14571 con respecto a los años 2018 y 2019; y el número de comunidades de 2 a 3 respectivamente. 
Figura No. 4 Beneficiarios por institución / comunidad. Programa "Ración de Queso" en el estado Carabobo. Año 2018 (a). Año 2019 (b).
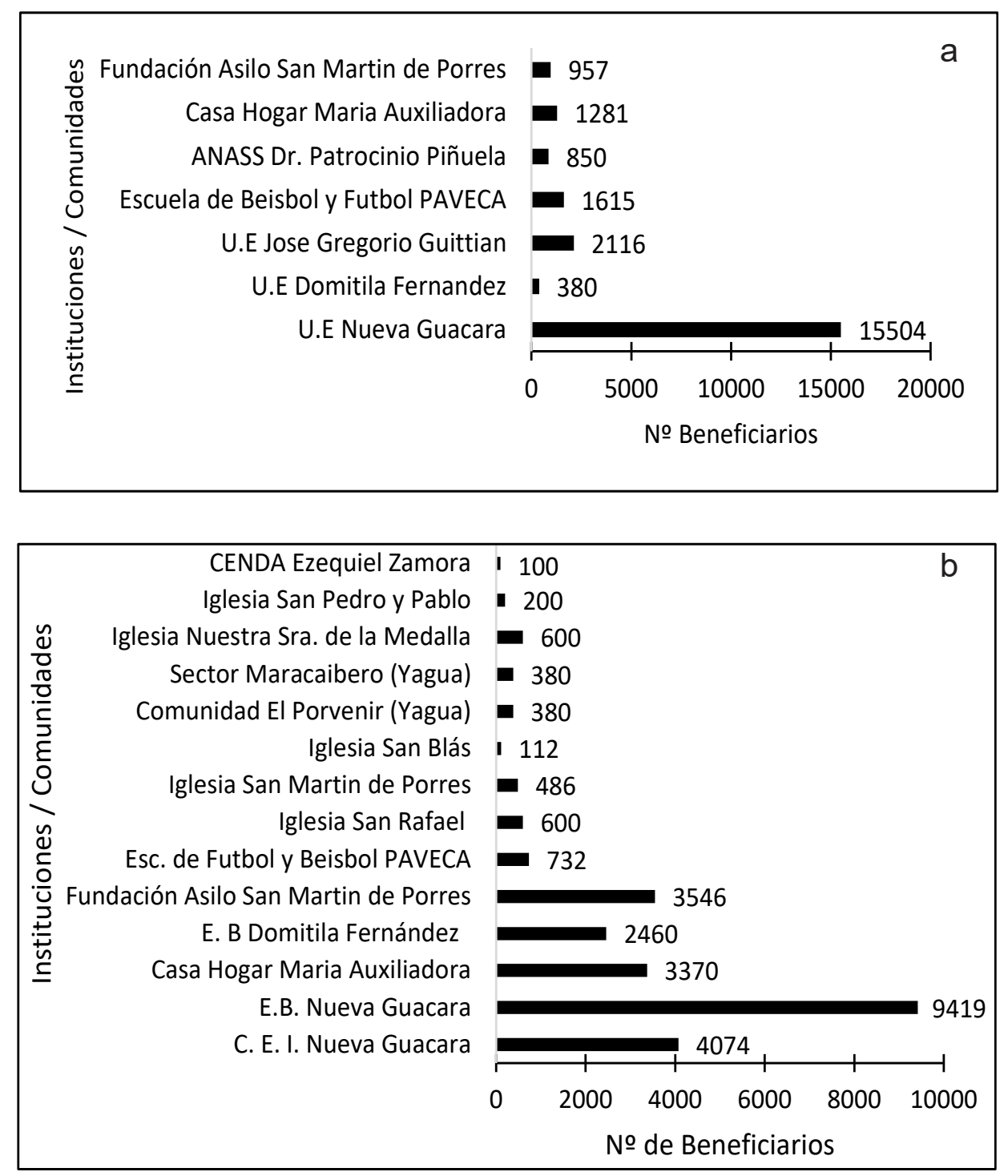

Fuente: elaboración propia a partir de los informes mensuales de la Superintendencia Interinstitucional y Ambiental de la empresa.

En el programa "Ración de queso" en el estado Carabobo (gráfica 4a y 4b), se incrementó el número de beneficiarios de 22703 a 26459 con respecto a los años 2018 y 2019 ; y el número de comunidades de 7 a 14 respectivamente. 
Figura No. 5 Beneficiarios por institución / comunidad. Programa "Ración de Miel" en el estado Carabobo. Año 2018 (a). Año 2019 (b).
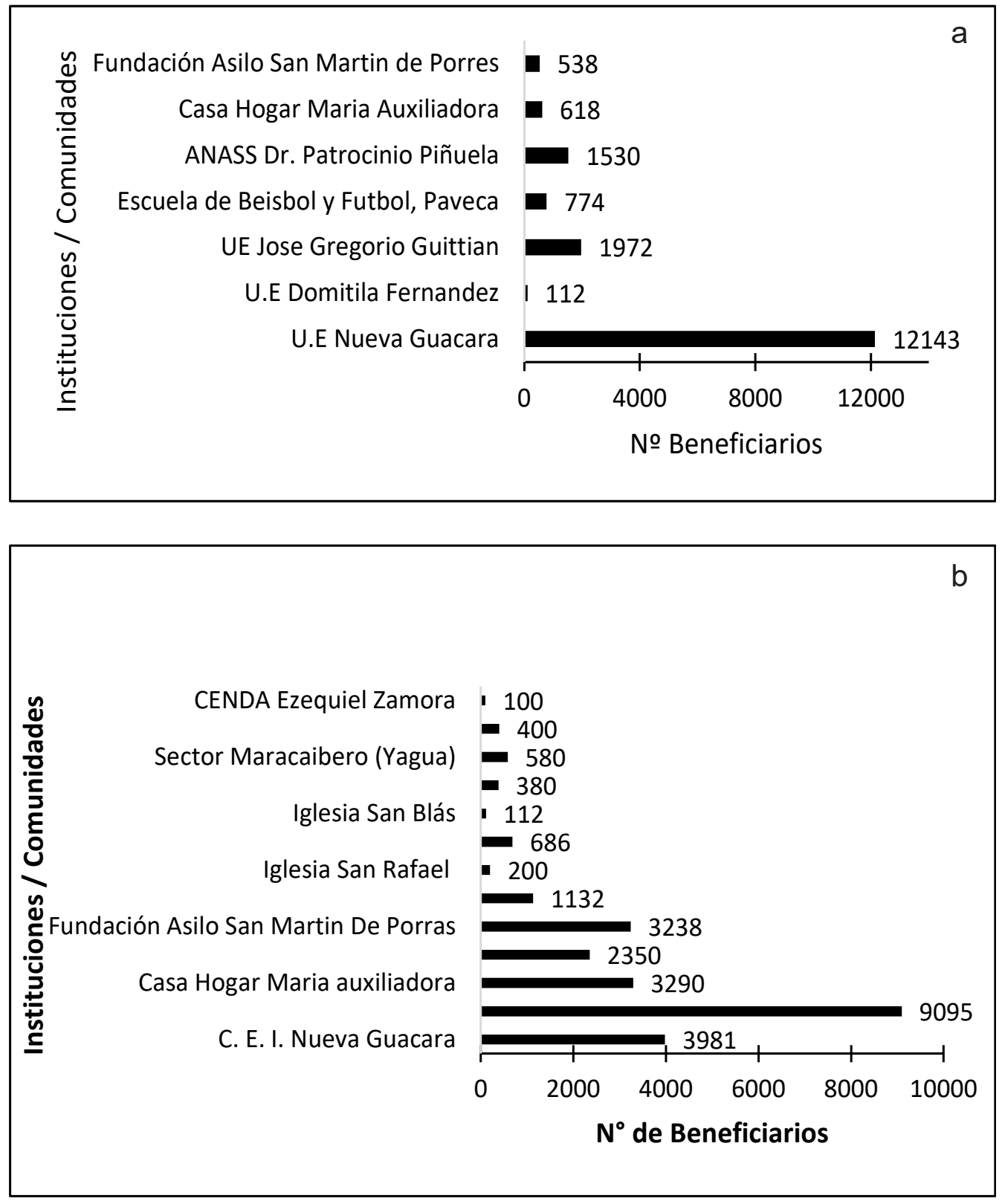

Fuente: elaboración propia a partir de los informes mensuales de la Superintendencia Interinstitucional y Ambiental de la empresa.

En el programa "Ración de miel" en el estado Carabobo (gráfica 5a y 5b), se incrementó el número de beneficiarios de 17687 a 25544 con respecto a los años 2018 y 2019; y el número de comunidades de 7 a 13 respectivamente. 
Figura No. 6 Beneficiarios por institución / comunidad. Programa "Alimentos (Proteínas y carbohidratos)" en el estado Carabobo. Año 2018 (a). Año 2019 (b).
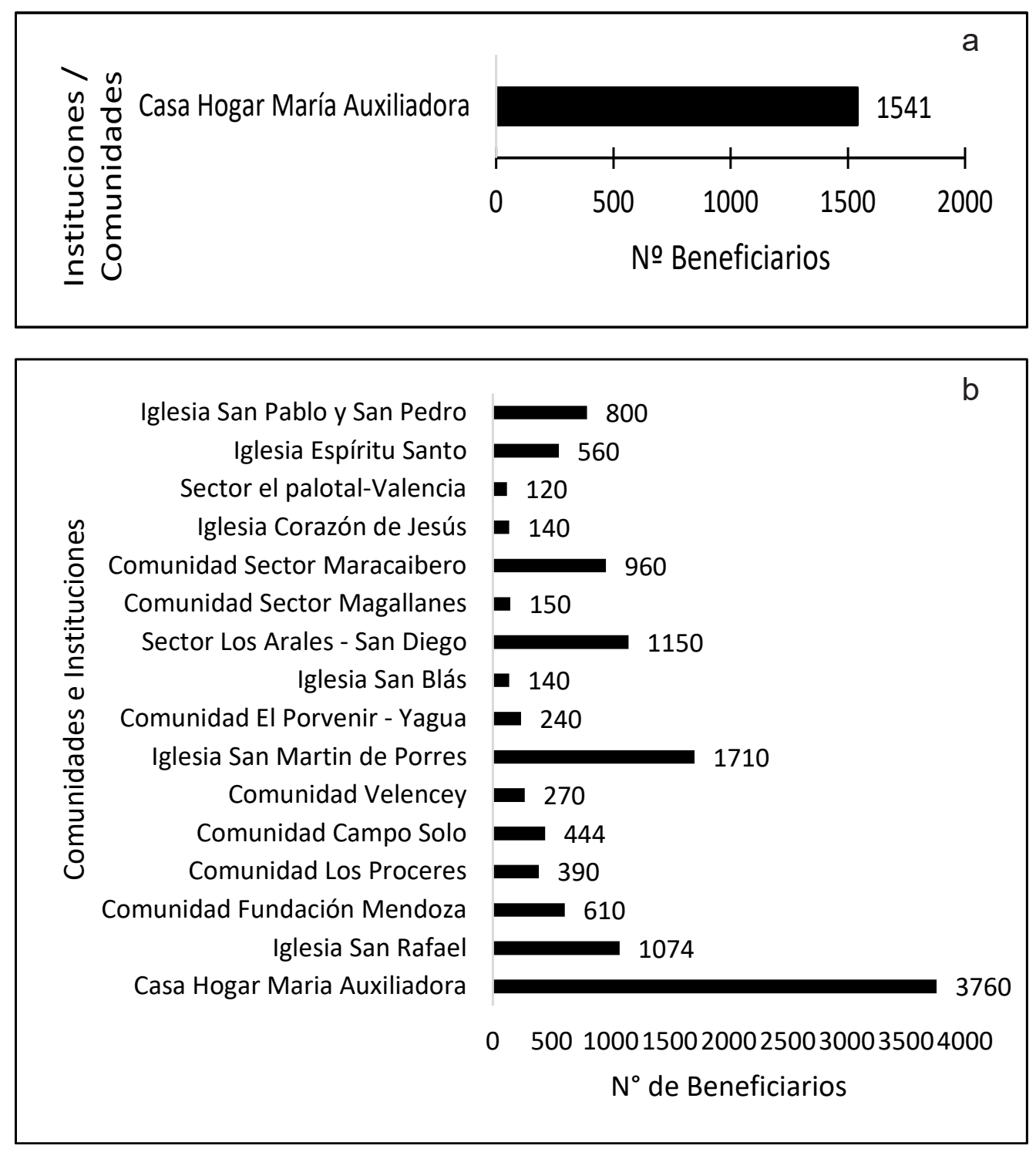

Fuente: elaboración propia a partir de los informes mensuales de la Superintendencia Interinstitucional y Ambiental de la empresa.

En el Programa "Alimentos (Proteínas y Carbohidratos)" en el estado Carabobo (gráfica 6a y 6b), se incrementó el número de beneficiarios de 1541 a 12518 con respecto a los años 2018 y 2019; y el número de comunidades de 1 a 16 respectivamente. 


\section{Grupo de beneficiarios}

En las gráficas 7, 8 y 9, se identifican los grupos de beneficiarios para los años 2018 y 2019 en cada una de las áreas de influencia.

Figura No. 7 Beneficiarios en el Programa "Ración de Queso" en el estado Cojedes (a) y estado Carabobo (b). Período 2018-2019).
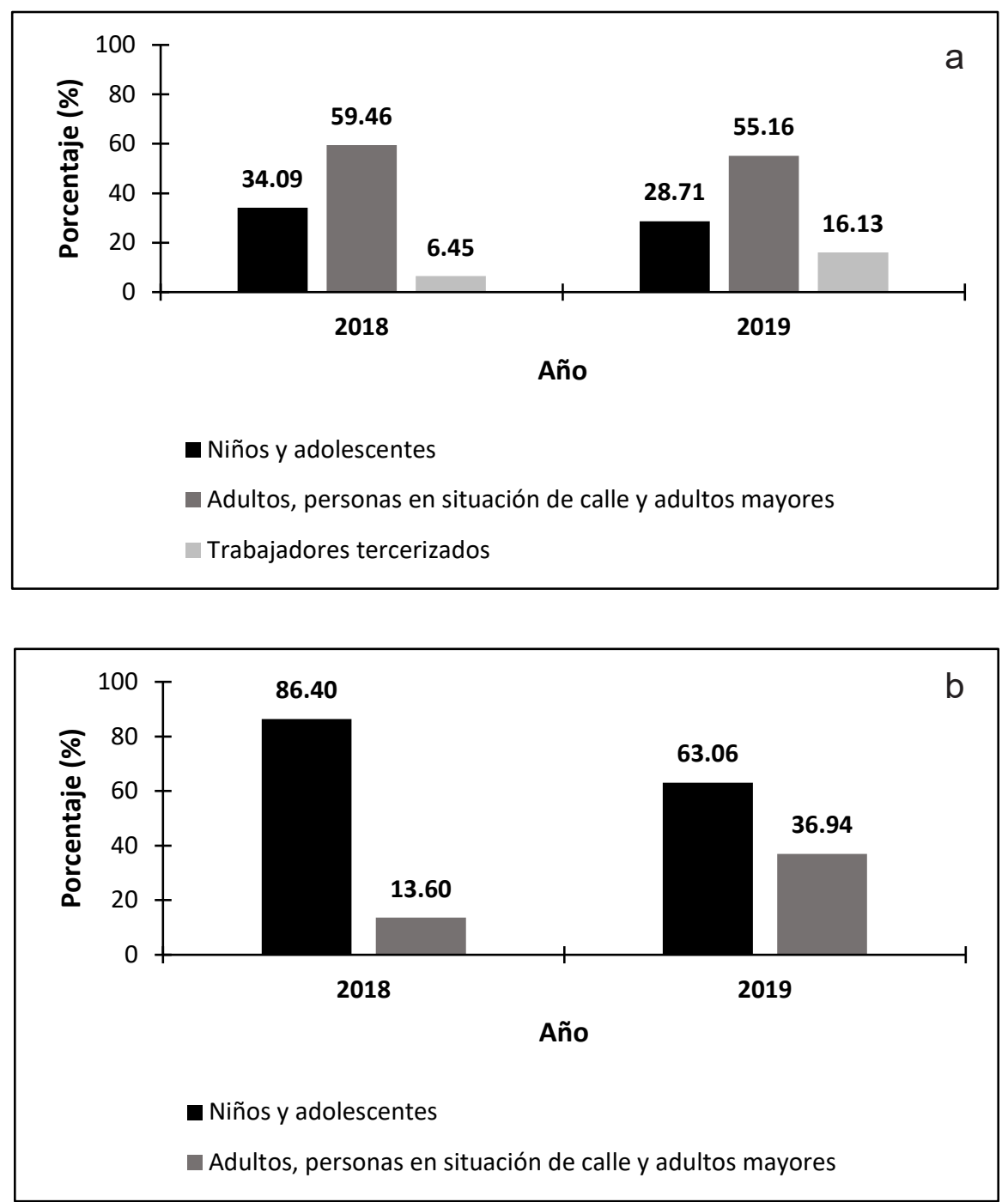

Fuente: elaboración propia a partir de los informes mensuales de la Superintendencia Interinstitucional y Ambiental de la empresa. 
Figura No. 8 Beneficiarios en el Programa "Ración de Queso" en el estado Cojedes (a) y estado Carabobo (b). Período 2018-2019).
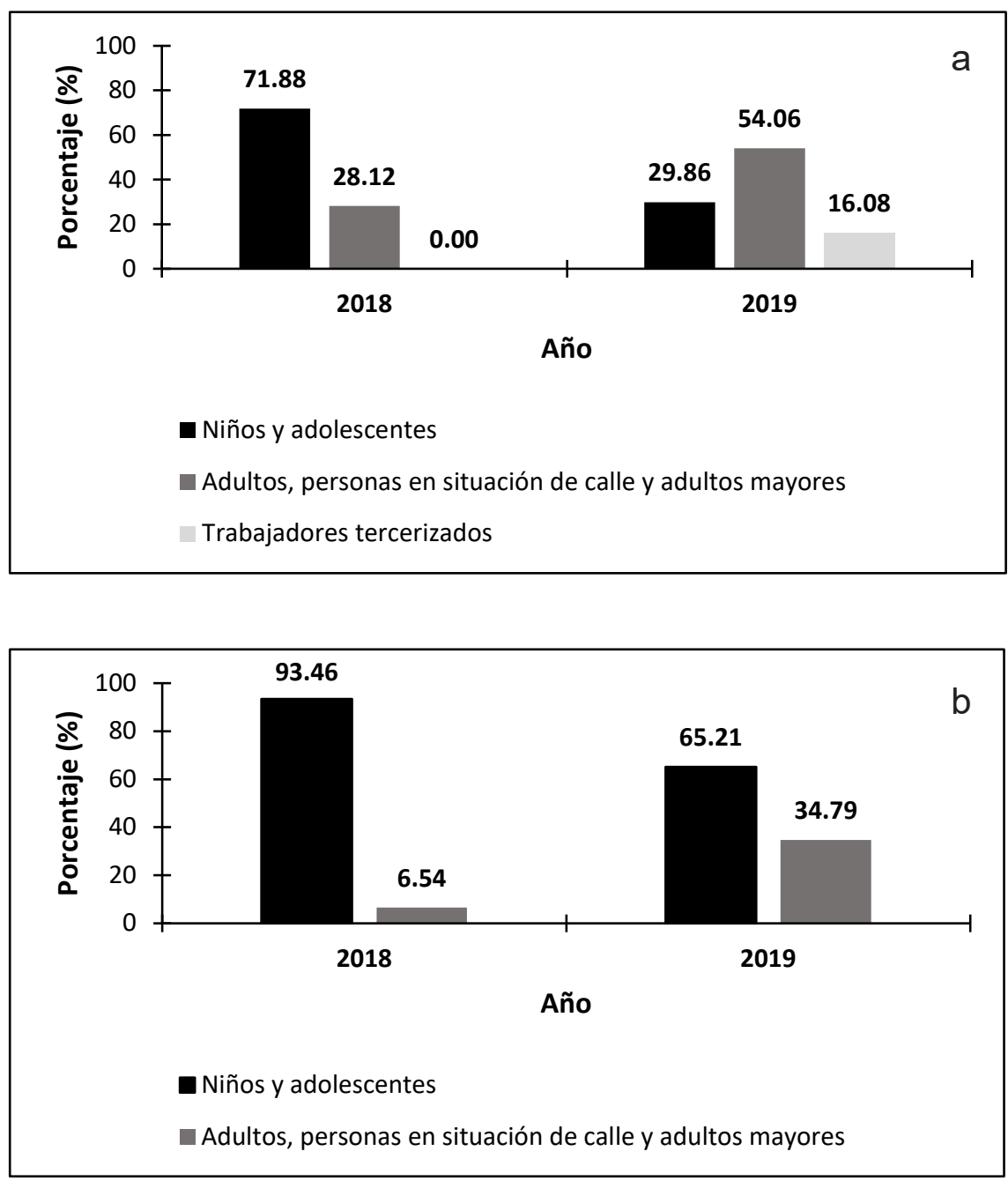

Fuente: elaboración propia a partir de los informes mensuales de la Superintendencia Interinstitucional y Ambiental de la empresa. 
Figura No. 9 Beneficiarios en el Programa "Alimentos (proteínas y carbohidratos) en el estado Cojedes (a) y estado Carabobo (b). Período 2018-2019).
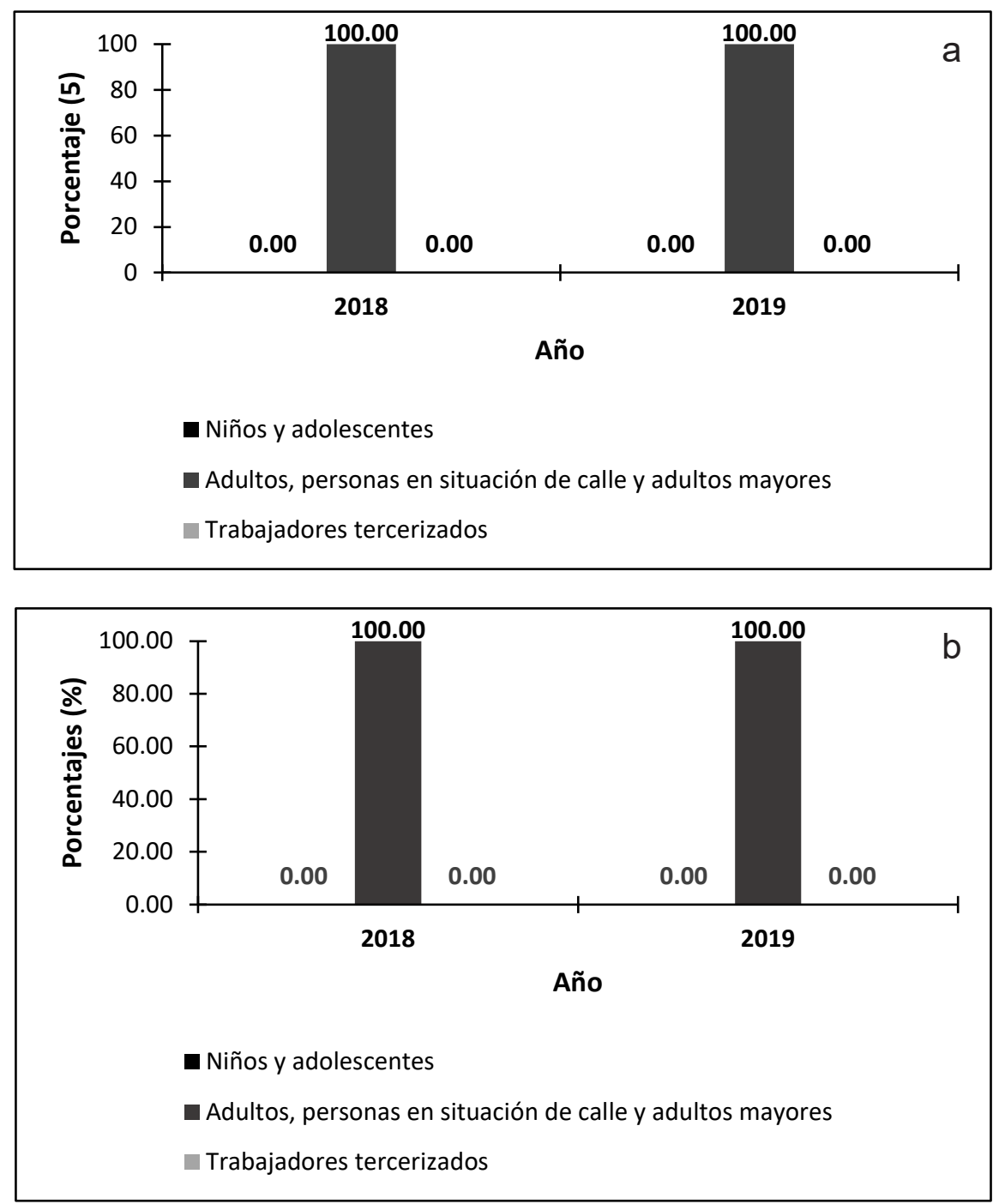

Fuente: elaboración propia a partir de los informes mensuales de la Superintendencia Interinstitucional y Ambiental de la empresa.

Para los programas, ración de queso y ración de miel; en el estado Cojedes, se prestó mayor atención a las comunidades con adultos, personas en situación de calle y adultos mayores. En segunda instancia, a los niños y adolescentes de las instituciones educativas (institutos educativos con matrículas baja); y luego, a los trabajadores tercerizados DEFORSA. Estos últimos, gozan del beneficio únicamente en el período de vacaciones de los institutos educativo; sin embargo, los niños se benefician en su comunidad (7a y 8a). Caso contrario sucede en el estado Carabobo, la mayor atención se presta a los niños y adolescentes y en segundo lugar; a los adultos, personas en situación de calle y adultos mayores. Esto se debe a que los institutos educativos poseen matrícula alta ( $7 \mathrm{~b}$ y $8 \mathrm{~b}$ ).Y en el programa Alimentos; solo los beneficiarios pertenecen al grupo de adultos, personas en situación de calle y adultos mayores (gráfica 9a y 9b). 


\section{Análisis global}

El análisis generalizado se representa en la gráfica 10 indicativa de la relación entre el número de comunidades e instituciones y el número de beneficiarios para los dos años (2018 y 2019) en los estados Cojedes y Carabobo; así como los grupos de beneficiarios (Gráfica 11).

Figura No. 10 Total de Beneficiarios e Institución / comunidad. Año 2018 y 2019; en el estado Cojedes (a) y en el estado Carabobo (b).
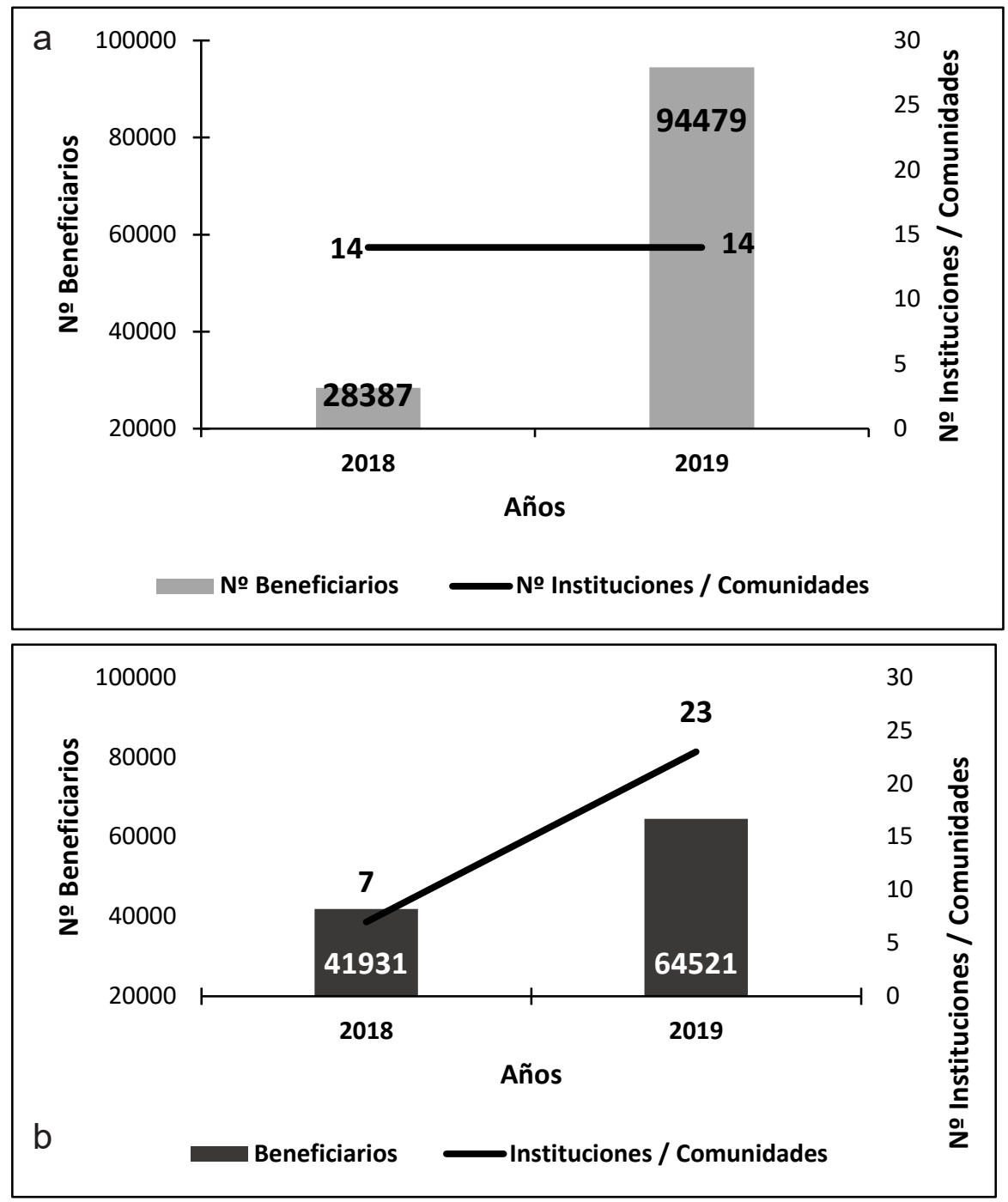

Fuente: elaboración propia a partir de los informes mensuales de la Superintendencia Interinstitucional y Ambiental de la empresa.

En el estado Cojedes, el número de Instituciones Educativas y Comunidades se mantuvo constante en 14 para los años 2018 y 2019 . El número de beneficiarios tuvo un incremento de 28387 a 94479; es decir, de 332,87\% infiriendo que para el último período del estudio hubo una "mejor" atención a las comunidades e instituciones; ya que se extendió el número de beneficiarios. Es de resaltar, que las comunidades e instituciones son de menores poblaciones 
favoreciendo la atención o el beneficio a un mayor número de personas de una comunidad (Gráfica 10a). En el estado Carabobo, el número de Instituciones Educativas y Comunidades incrementó de 7 a 23 para los años 2018 y 2019 respectivamente; y el número de beneficiarios de 41931 a 64521; es decir, un incremento de 153,84\%. En este caso la inferencia se sucede contrariamente al estado Cojedes; para el primer período del estudio (2018), hubo una mejor atención a las comunidades e instituciones con respecto al último año (2019) ya que se incrementó el número de comunidades en forma desproporcional, no siendo así el número de beneficiarios. Sumado a esto, es necesario considerar, que estas comunidades e instituciones son de mayores poblaciones; factor que no favorece la atención adecuada o el beneficio llega a pocas personas por comunidad (Gráfica 10b).

Figura No. 11 Porcentaje total de Beneficiarios en el estado Cojedes (a) y estado Carabobo (b). Período 2018-2019.

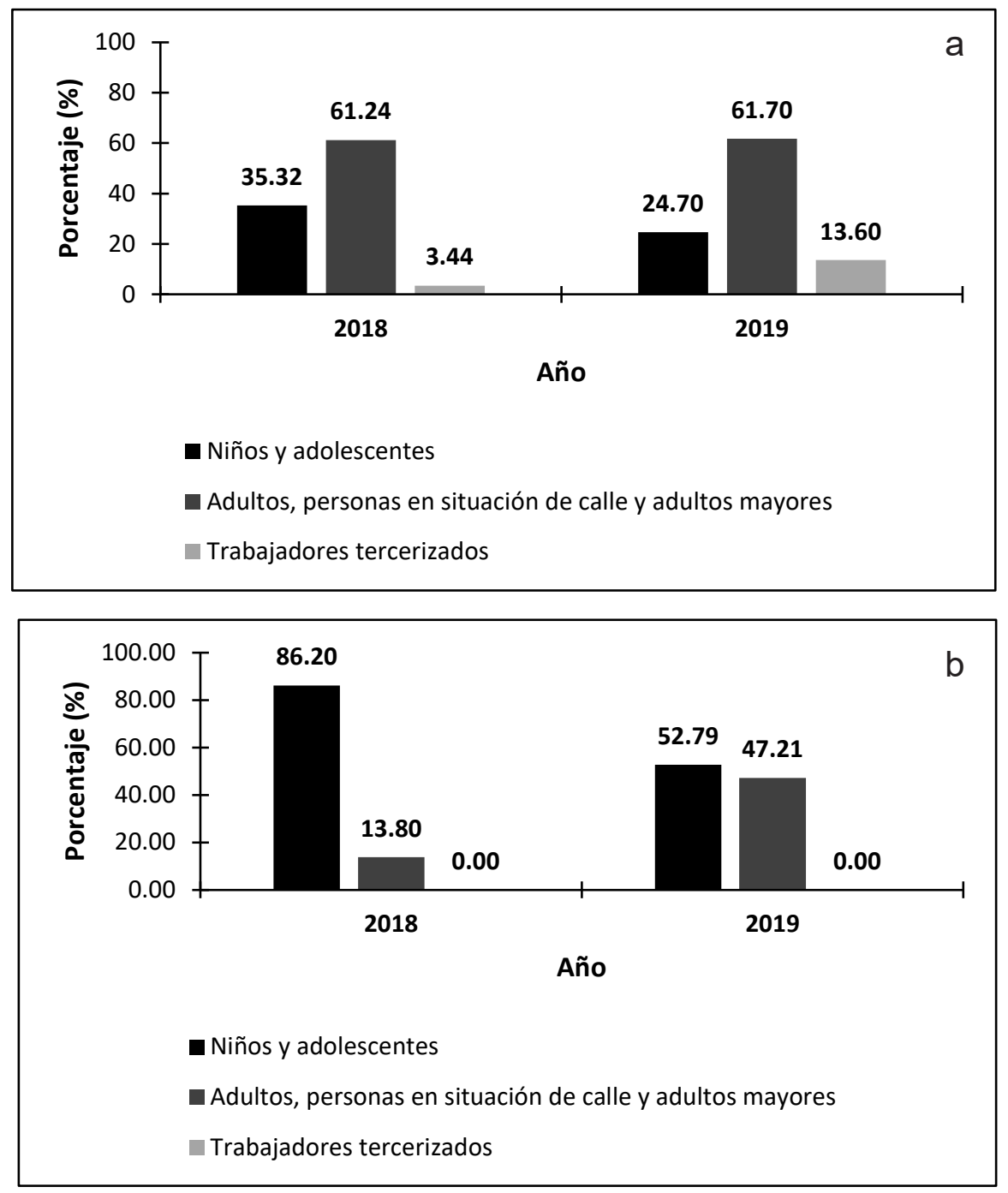

Fuente: elaboración propia a partir de los informes mensuales de la Superintendencia Interinstitucional y Ambiental de la empresa. 
En relación al grupo de beneficiarios en el estado Cojedes, predominó la atención a los adultos, personas en situación de calle y adultos mayores, mientras que en Carabobo fueron los niños y adolescentes de las instituciones educativas por ser los centros educativos de matrículas altas.

\section{Conclusiones}

La Responsabilidad Social Empresarial es un tema de gran interés en la actualidad y constituye una respuesta a la demanda social; es por ello que a partir del año 1995 se inicia la RSE en DEFORSA a través de 3 líneas de acción: Ambiental, Educativa y Social con 3 , 3 y 8 programas respectivamente; sumando un total de 14, de los cuales 10 permanecen en el tiempo; es decir, se han consolidado, destacándose los programas de la acción Ambiental: "Visitas guiadas", "Biotrabajador" y "Buen vecino"; en la acción Educativa; el programa de "Capacitación profesional"; y en la acción Social: "Infraestructura vial", "Dotación de papel", "Transporte a la comunidad"; y los más recientes: "ración de Queso", "ración de Miel" y "Alimentos".

Todos los programas se ejecutan con la experiencia y compromiso de los trabajadores a través de la figura de voluntariados y colaboradores externos. Se estimó el número de voluntariados en 14 pertenecientes a DEFORSA y PAVECA.

En relación a los programas recientes de impacto social como "ración de queso", "ración de miel" y alimentos (proteínas y carbohidratos); el número de comunidades incrementó de 21 a 37 con respecto a los años 2018 y 2019 para los estados Cojedes y Carabobo. Los beneficiarios de 70318 a 159000 para un total de 229318; que en porcentaje representa $226 \%$.
Para el período 2018 y 2019 (dos últimos años), en Cojedes se beneficiaron 122866 personas cuyo incremento porcentual representó $332,87 \%$ en 14 comunidades e instituciones educativas, siendo los adultos, personas en situación de calle y adultos mayores los más atendidos; sin embargo, la comunidad de Conaima cercana a DEFORSA, concentra la mayor cantidad de niños y adolescentes beneficiados.

En Carabobo, se beneficiaron 106452 personas cuyo incremento porcentual representó $153,84 \%$ en 23 comunidades e instituciones educativas, atendiendo principalmente a los niños y adolescentes de las instituciones educativas.

Se estima, en función de los bajos ingresos familiares y falta de ingesta por parte de algunos sectores marginales, así como personas en situación de calle; los programas ración de queso, ración de miel y alimentos (proteínas y carbohidratos) han tenido impacto positivo en las comunidades e instituciones educativas.

\section{Recomendaciones}

a. Seguir con los programas vigentes y atender un estándar manejable de comunidades e instituciones para lograr un beneficio eficiente y efectivo. 
b. Reactivar los programas talleres educativos para las escuelas y para comunidades a través del voluntariado o en su defecto, reajustar a las necesidades actuales tal como el caso Alimentos DEFORSA, que fue un programa de impacto a las comunidades más deprimidas y por la escasez de materia prima (fertilizantes, agroquímicos, etc.), se re-direccionó a través de los programas ración de queso, ración de miel y alimentos (proteínas y carbohidratos).

\section{c. Consolidar el programa cachamas.}

d. Establecer criterios de acuerdo al contexto para analizar los datos de la gráfica 10 y 11 en relación a la proporción entre $\mathrm{N}^{\circ}$ de comunidades, $\mathrm{N}^{\circ}$ de beneficiarios, tamaño de la comunidad (población) y grupo beneficiado.

e. Elaborar herramientas de monitoreo, que generen datos e información y se propongan indicadores que permitan evaluar la RSE de acuerdo a lo establecido por la Organización Internacional de Normalización, la norma ISO 26000 .

\section{Bibliografía}

Alea García, Alina. Responsabilidad Social Empresarial. Su contribución al desarrollo sostenible. Revista Futuros, vol. 5, núm.17 (2007). 25 de noviembre de 2019. http://www.revistafuturos.info/raw text/raw_futuro17/resp_social_empr.pdf

Cajiga Calderón, Juan. (s/f). El Concepto de Responsabilidad Social Empresarial (RSE). Centro Mexicano para la Filantropía. 27 de noviembre de 2019. https:// www.cemefi.org/esr/images/stories/pdf/ esr/concepto_esr.pdf
Chaves Ávila, Rafael y Monzón Campos, José. La economía social ante los paradigmas económicos emergentes: innovación social, economía colaborativa, economía circular, responsabilidad social empresarial, economía del bien común, empresa social y economía solidaria. CIRIEC-España. Revista de Economía Pública, Social y Cooperativa, núm. 93 (2018): 5-50.

Daza Corredor, Alexánder; Viloria Escobar, Javier, y Miranda Terraza, 'Luis. De la Responsabilidad Social Empresarial (RSE) a la Creación de Valor Compartido (CVC): Una reflexión crítica sobre los dos conceptos. Revista AGLALA. vol. 9, núm. 1 (2018). 4 de diciembre de 2019. http:// revistas.curn.edu.co/index.php/aglala/ article/view/1193.

Hernández, Roberto; Fernández, Carlos y Baptista, María. Metodología de la Investigación. (6ta ed.). Mc Graw Hill, México. 600 pp. 2014.

Hurtado de Barrera, Jacqueline. Metodología de la investigación. (4ta ed.). Ediciones Quiron. Universidad Nacional Abierta. Caracas. 146 pp. 2010.

Sabogal Aguilar, Javier. 2008. Aproximación y cuestionamientos al concepto responsabilidad social empresarial. Revista de la Facultad de Ciencias Económicas: Investigación y Reflexión. Vol.1 núm 16:179-195 (2008). 16 de Enero de 2020. https://www.redalyc.org/articulo. oa?id=90916113. 


\section{Sobre autor}

\section{José Yhovany Bastidas}

Ingeniero Forestal egresado de la Universidad de LosAndes(ULA). Venezuela. Maestrante de IngenieríaAmbiental delaUniversidad Nacional Experimental deLosLlanosOccidentales"Ezequiel Zamora" (UNELLEZ) Gestiona la Responsabilidad Social Empresarial por la Fundación Papeles Venezolanos (FUNDAPAVECA). Miembro activo de la Sociedad Venezolana de Ingenieros Forestales. Pertenece a la Red Forestal Silvopastoril. Ingeniero Forestal de Desarrollo Forestales San Carlos (DEFORSA) y Superintendente del área Responsabilidad Social Empresarial.

\section{Sobre coautor}

\section{Joao Leite de Souza}

Ingeniero Forestal egresado de la Universidade Federal Rural Do Rio de Janeiro. (UFRRJBrasil). Biólogo de la Univerdidade de Taubate (UNITAU-Brasil), Magíster Scientiarum en Ingeniería Ambiental de la Universidad Nacional Experimental de los Llanos Occidentales "Ezequiel Zamora" (UNELLEZ-Venezuela), Magister en Gerencia de Proyectos (CIU- Curazao), Ingeniero de Seguridad Laboral (ETEP- Brasil), Doctorando en Ambiente y Desarrollo (UNELLEZ). Ingeniero de Desarrollo Forestales San Carlos (DEFORSA-Venezuela) con una amplia experiencia de más de 39 años en la gestión de proyectos forestales sostenibles para la producción de materia prima para pulpa y papel, carbón vegetal y proyectos silvopastoriles.

\section{Sobre coautora}

\section{María Angélica Rojas}

Licenciada en Comunicación Social egresada de la Universidad Bicentenaria de Aragua (UBA-Venezuela). Magíster en Comunicación Organizacional de la Universidad José Antonio Páez (UJAP). Coordinadora de Comunicaciones Internas y Periodista de la fundación Papeles Venezolanos (FUNDAPAVECA), con la finalidad de fomentar la imagen corporativa de la organización y en sus distintos programas de Responsabilidad Social Empresarial a través de la redacción de comunicados, creación de vídeos corporativos y la edición de la revista Molino de Ideas.

\section{Sobre coautor}

\section{Winston Duque}

Profesional en Derecho de la Universidad Santa María de Caracas, Venezuela. Diplomado en Derecho Procesal Penal en la Universidad José Antonio Páez (UJAP). Desde el año 2004 forma parte de Papeles Venezolanos C.A. (PAVECA), ejerciendo funciones como Asesor Jurídico; director de Recursos Humanos y Asuntos Legales. Desde el 2009 hasta la actualidad ocupa el cargo de Vicepresidente de Asuntos Legales e Institucionales; y ha sido una pieza fundamental en la organización en el marco legal y en la Responsabilidad Social Empresarial, ya que en el 2010 crea la Fundación (FUNDAPAVECA), llevando los programas de alimentación y educativos en los Estados Carabobo y Cojedes. 


\section{Sobre coautor}

\section{Wilson de Oliveira Campos}

Ingeniero Forestal egresado de la Universidad Federal de Viçosa (UFV-Brasil). Tiene una trayectoria de 40 años en la investigación y gestión de proyectos forestales sostenibles para la producción de materia prima para pulpa y papel, carbón vegetal, aserradero y producción agropecuaria bajo la modalidad silvopastoril. Actualmente gerencia las operaciones forestales y agropecuarias en DEFORSA-Desarrollo Forestales San Carlos II C.A. (Venezuela).

\section{Sobre coautor}

\section{José Guillermo Torres}

Médico Veterinario egresado de la Universidad Centro Occidental "Lisandro Alvarado" (UCLA), Venezuela. Superintendente del Operaciones Agropecuarias de Desarrollo Forestales San Carlos (DEFORSA-Venezuela.) Miembro del Colegio de Médicos Veterinario de estado Cojedes- Venezuela.

\section{Sobre coautor}

\section{Darialys Castillo}

Licenciada en Administración, mención Informática egresada de la Universidad Nacional Experimental "Simón Rodríguez" (UNESR-Venezuela). Magíster en Administración del Trabajo y Relaciones Laborales de la Universidad de Carabobo (UC) y Analista del Departamento de Recursos Humanos de Desarrollo Forestales San Carlos (DEFORSA- Venezuela).

\section{Sobre coautor}

\section{Ranni Arias}

Médico Veterinario egresado de la Universidad Nacional Experimental Francisco de Miranda (UNEFM- Venezuela). Maestrante de Ingeniería Ambiental (UNELLEZ), Miembro del Colegio de Médicos Veterinarios del estado Cojedes. Trabaja en el Departamento de Operaciones Agropecuarias de Desarrollo Forestales San Carlos (DEFORSA-Venezuela).

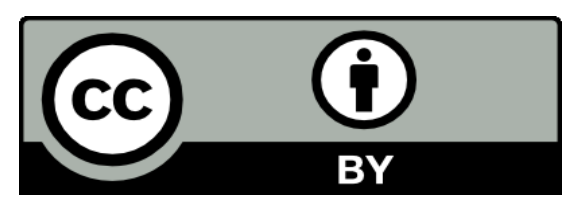

Este texto está protegido por una licencia CreativeCommons 4.0.

Esta licencia permite que otros distribuyan, mezclen, adapten y desarrollen su trabajo, incluso comercialmente, siempre y cuando le den crédito por la creación original. 



\title{
Ordenamiento Territorial en el Municipio de Jalapa
}

\author{
Territorial Planning in the Municipality of Jalapa
}

Como citar el artículo

Reyes, A. (2020). Ordenamiento Territorial en el Municipio de Jalapa. Revista Naturaleza, Sociedad y Ambiente, 7 (1), 29-39 DOI: https://doi.org/10.37533/cunsurori.v7i1.49

Ariel Oswaldo Reyes Donis

Centro Universitario de Sur Oriente (CUNSURORI), Universidad de San Carlos de Guatemala

Recibido: 08 de abril de 2020 / Aceptado: 07 de septiembre de 2020

Disponible en internet el 10 de noviembre de 2020

*Autor para correspondencia, correo electrónico: arielreyes07@hotmail.com

\begin{abstract}
Resumen
La implementación de un plan de Ordenamiento Territorial en la cabera municipal de Jalapa, si se concreta bajo las directrices establecidas, con conocimiento y aprobación de la Municipalidad de Jalapa, se convierte en una fuente de credibilidad ante la sociedad civil para los integrantes del Consejo Municipal de Desarrollo, a pesar de considerarse tendiente a la generación del conflicto, implementando de manera eficaz y tomando en consideración la opinión de los grupos organizados y de la sociedad en general ofrece la posibilidad de lograr el objetivo principal que consta del desarrollo sostenible tan necesario en la actualidad. En tal sentido existe el reto en este caso de lograr que quienes participen activamente en el proceso de Ordenamiento Territorial, logren consensuar los criterios e ideas en común las cuales les permita mejorar en términos de calidad del entorno en el que habitan y desarrollan sus actividades los ciudadanos, así como mejores las condiciones de convivencia, y en general, mayor seguridad territorial. Así se considera que un plan de Ordenamiento Territorial que ha sido concertado con los diversos actores logra que la población reconozca y comprenda la importancia de la ordenación y de su rol dentro del plan y si se realiza mediante una amplia participación, se estará contribuyendo a la implicación de la democracia y efectiva de gobernabilidad.
\end{abstract}

Palabras clave: ordenamiento Territorial, políticas de ordenamiento, subdesarrollo, solución de problemas, instrascendencia

\begin{abstract}
The implementation of a Land Use Plan in the municipal capital of Jalapa, if it is carried out under the established guidelines, with the knowledge and approval of the Municipality of Jalapa, becomes a source of credibility before civil society for the members of the Municipal Council of Development, despite considering itself tending to the generation of conflict, effectively implementing and taking into account the opinion of organized groups and society in general offers the possibility of achieving the main objective that consists of the much-needed sustainable development in today. In this sense, there is a challenge in this case to ensure that those who actively participate in the Land Management process, including the actors or sectors in conflict, manage to find common ground that allows them to improve the quality of the environment in which citizens live, better coexistence conditions, and in general, greater territorial security. Thus, it is considered that a Land Management plan that has been agreed with the various actors achieves that the population recognizes and understands the importance of planning and its role within the plan and if is carried out through broad participation, it will be contributing to the implication of democracy and effective governance.
\end{abstract}

Keywords: territorial planning, planning policies, underdevelopment, problem solving, inconsequential 


\section{Introducción}

En la actualidad surge la necesidad de crear normas que regulen la construcción de una planificación urbana y ordenamiento territorial que contribuyan a corregir dicha situación.

De acuerdo con Flores (2008), la historia de la planificación para el desarrollo en Guatemala, la cual en términos constitucionales comenzó el 1 de diciembre de 1954, indica que, con el transcurso del tiempo la planificación, las políticas públicas nacionales y políticas urbanas se dieron de manera débil, menciona que se vivieron tres experiencias que ejemplifican las modalidades bajo las cuales se han ensayado, planes y programas con fines de ordenamiento territorial como: 1) Esquema Director de Ordenamiento Metropolitano EDOM 1972-2000; 2) Plan de Desarrollo Metropolitano 2010 y 3) Plan 2020, presentado durante el primer semestre del año 2005 , lo que indica que si existen diversos intentos de ordenamiento territorial diseñados durante varios periodos de la historia urbana guatemalteca.

Las propuestas referentes al Ordenamiento Territorial en Guatemala son diversas y dependen exclusivamente de la visión sobre organización que posee cada dependencia edil, para llevar a cabo el proceso como lo estima el Código Municipal, siendo este el único documento a parte de la Constitución Política de la República de Guatemala, la que rige de manera directa el accionar de los planificadores de cada entidad de gobierno involucrado en el tema, cada uno de los departamentos que constituyen la República de Guatemala, en consideración a los datos del Instituto Nacional de Estadística (INE), consideran que para el año 2020 el crecimiento poblacional desmedido provocará aún más carencias en los diversos sectores del país en relación a los recursos que resultan necesarios para la sobrevivencia.

El desarrollo se ha convertido en la actualidad en un tema fundamental, para la capital, departamentos, municipios y comunidades del área rural de Guatemala, lugares que solicitan la intervención estatal y de entidades privadas para logra el avance hacia la estancia poblacional objetiva, que ofrezca estabilidad y garantías para la obtención de un nivel de vida deseado por la sociedad. Dentro del marco de desarrollo, surge la necesidad de enfocar con carácter prioritario el tema sobre "Ordenamiento Territorial", que representa en el medio estratégico para solventar a mediano y plazo, las carencias que presenta el país ante el crecimiento desmedido de la población guatemalteca, principalmente en los lugares catalogados como aptos para generar actividades de producción la cuales contribuyen al sostenimiento de las personas que las habitan.

El tema referente al Ordenamiento Territorial, conlleva cierta complejidad en su abordaje, pues la razón versa sobre la ineficiente información que sustenta los lineamientos correspondientes a la aplicación efectiva de las actividades inherentes al equilibrio de los sectores sociales, económicos, de salud, alimentarios, de infraestructura y medio ambientales, los cuales intervienen en el desarrollo integral de los pobladores mediante la efectiva implementación y aprovechamiento de los insumos y herramientas que se obtienen de estos.

El municipio de Jalapa cuenta con una cantidad representativa de recursos naturales considerable, los cuales son utilizados para generar cambios de carácter sostenible, es 
decir que hace falta entender a fondo cual es el verdadero objetivo de un ordenamiento territorial para que este se lleve a cabo de manera conjunta y equilibrada entre sectores, para generar el bienestar colectivo en la población.

Se estima que las limitantes principales asociadas a la inefectiva aplicación del proceso de ordenamiento son: 1) La disputa existente en el tema de tenencia de la tierra entre los pobladores de la comunidad de Santa María Xalapán y los representantes de la municipalidad de Jalapa, 2) La desinformación generalizada sobre los objetivos que contiene la aplicación de un ordenamiento territorial, 3) carencia de recursos económicos, que limitan la activación de propuestas de ordenamiento existentes, 4) La diversidad de ideologías políticas y sociales con respecto a la toma de decisiones a favor del desarrollo, 5) una inexistente voluntad referente al trabajo de en la políticas públicas.

\section{Referente teórico \\ Ordenamiento territorial}

El Ordenamiento Territorial no más que, la zonificación planificada del territorio, para lograr, a largo plazo del desarrollo equilibrado entre el sistema natural y el socioeconómico. El objetivo primordial del ordenamiento territorial desde el punto de vista investigativo, radica, en la generación de equilibrio sostenible entre los diferentes sectores en los que se desarrolla el ser humano, en el caso particular del municipio de Jalapa, este tema se encuentra condicionado básicamente por situaciones históricas ancestrales que denotan la división del territorio en dos puntos que debieran ser complementarios para lograr el desarrollo equitativo.
Martínez Toro, (2005) en el informe sobre Ordenamiento Territorial y Desarrollo Sostenible puntualiza sobre qué:

"Las definiciones más aceptadas universalmente sobre el significado del ordenamiento territorial apuntan a reconocerlo como "la proyección en el espacio de las políticas social, cultural, ambiental y económica de una sociedad" o "la expresión espacial las políticas económicas, sociales, culturales y ecológicas de la sociedad. Es a la vez una disciplina científica, una técnica administrativa y una política concebida como un enfoque interdisciplinario y global, cuyo objetivo es un desarrollo equilibrado de las regiones y la organización física del espacio" (p.14).

El Ordenamiento Territorial en el departamento de Jalapa de acuerdo con el Plan de Desarrollo Departamental (2011-2015) El departamento de políticamente se divide en siete municipios: Jalapa, San Pedro Pinula, San Luis Jilotepeque, San Manuel Chaparrón, San Carlos Alzatate, Monjas y Mataquescuintla. Según los acuerdos municipales los municipios, de los lugares poblados, Jalapa cuenta con seiscientos catorce lugares poblados, distribuidos en: área urbana sesenta poblados entre barrios, colonias y residenciales, el área rural con ciento sesenta y dos aldeas (Secretaria de Planificación y Programación de la Presidencia, 2010, p.12).

Según manifiesta Méndez (2015), qué en la cabecera municipal de Jalapa, existen planes de Ordenamiento Territorial pero solo en papel y lo ha realizado la Secretaria de Planificación y Programación de la Presidencia -SEGEPLAN-, por su parte la municipalidad no tiene la capacidad económica para ejecutar esos planes, debido a que dentro del 
presupuesto que se le asigna a la comuna, no se contempla que pueda ser utilizado para otros fines que nos sea el de pago a sus empleados y proyectos concretos.

Otro punto importante de explicar con respecto al tema del OT, es que la municipalidad debe negociar para que los comercios se ubiquen en áreas estratégicas, los centros de entretenimiento personal (prostíbulos), sean ubicados en áreas que no representan riesgos a las demás personas, la construcción de viviendas debe ser normalizada bajo estándares de dimensiones en acuerdo con la planeación que se tenga. El basurero municipal deber reubicarse en un lugar que sea apto y cuente con los requisitos en ley, que permitan actuar de manera correcta ante el tratamiento de desechos sólidos que produce la población jalapaneca.

La ausencia de acciones en referencia al tema de OT en la cabecera municipal de Jalapa, concuerdan en unanimidad los representantes de las diversas instituciones que debiera estar integradas para llevar a cabo el proceso, se debe categóricamente a la falta de voluntad política y sobre todo a la división de ideas en el caso de los funcionarios que representan los intereses del pueblo en el Consejo Municipal, además de que se prefiera cubrir proyectos de infraestructura que sirvan de apoyo en las campañas electorales y se descuida un tema como el Ordenamiento Territorial.

En consideración a Rodríguez (2003), es importante entender con claridad, las características propias del lugar donde convergen las personas para procurarse el desarrollo mediante la satisfacción de las necesidades, tales como:
"- un espacio apropiado, delimitado, productivo, ordenado en un entorno mayor, - un espacio de recursos, donde se cuente con recursos naturales, fuerza de trabajo, energía, capacidades y organización, y -un espacio productivo colectivamente" (p.13).

El Municipio de Jalapa, principalmente la cabecera, concentra diversidad de recursos naturales, que pueden ser aprovechados con fines de beneficio colectivo, pero existe a su vez, la posibilidad recurrente de desprotección y vulnerabilidad de ser destruidos por los mismos pobladores para obtención de ingresos económicos personales, sin importar el riesgo que representa ante los acontecimientos naturales que se presentan como ausencia de la deforestación, sumado a ello, se encuentra la contaminación del medio ambiente.

\section{Existencia de políticas sobre Orde- namiento Territorial en Jalapa}

El punto de partida de este proceso de planificación ha sido la información oficial del departamento porte del Instituto Nacional de Estadística -INE- y el Sistema de Información Territorial -SINIT- de SEGEPLAN, enriquecida con la información proporcionada por la Unidad Técnica Departamental, las instituciones de Gobierno y por representantes de la sociedad civil, con presencia en el departamento de Jalapa, durante 16 talleres y 7 reuniones técnicas del proceso de planificación (SEGEPLAN-CODEDE, 2010, p.7).

El proceso de planificación territorial para el municipio de Jalapa, se trata de un tema complejo de abordar, no únicamente por la diversidad de acciones que requiere para el cumplimento objetivo sino también por la cantidad de presupuesto que se requiere para la ejecu- 
ción, sumado a ello, la necesidad de realizar diálogos de negociación entre diversos sectores para que se obtengan los medios necesarios que garanticen la viabilidad del proyecto. En la cabecera municipal de Jalapa, el trabajo por la readecuación del municipio únicamente lo realiza la SEGEPLAN en apoyo de otras entidades de gobierno nacional, internacional y ONG's que se interesan por el desarrollo de los habitantes.

\section{Ventajas del Ordenamiento Territorial}

Para Morales, (2007). Hablar de ventajas en el sentido de búsqueda del desarrollo sostenible, comprende la determinación del cumulo de capacidades que tiene un individuo o grupo de colaboradores para lograr cambiar una situación, sin la utilización de medidas violentas, coercitivas o en el peor de los casos de conflicto y enfrentamiento entre sectores. Las ventajas constituyen la realización de un análisis exhaustivo de las condiciones en que se vive y a la vez la posibilidad de trabajar para dar un giro representativo, que genere cambio a través de la misma necesidad de los seres humanos para la obtención de los insumos necesarios que le permitan salir victoriosos de las necesidades que se presenta.

El ser humano desde tiempo inmemorables ha sido dotado de inteligencia y capacidad de transformación del entorno en el que se desarrolla, únicamente que en la actualidad se ha posicionado al hombre en el estado de dependencia generalizada, al haber permitido que el Estado a través de las instituciones lo convierta en el ser que debe esperar a que el gobierno responda y resuelva todas las necesidades y lo aísla del papel que le corresponde como principal actor para la generación de desarrollo.
Por tal razón, para que los pobladores se organicen de manera efectiva y promuevan cambios, necesitan en primer punto, definir exactamente qué es lo social, se debe recordar que la sociología, entres sus diferentes escritos y representantes en cientos de teorías, dicen abordar el tema social, pero hasta el momento, no se tiene un concepto claro, breve y preciso sobre lo que esto abarca y las formas en que incluye al individuo.

De acuerdo con el Programa de Fortalecimiento del Régimen Municipal (2010), se consideran las ventajas o beneficios siguientes con la implementación del ordenamiento territorial.

- "El ordenamiento territorial es el instrumento de planificación que permite organizar el territorio apropiadamente en términos políticos, económicos y administrativos.

- Garantiza la búsqueda de un mejor nivel de vida en los habitantes mediante una adecuada aplicación de las políticas sociales, económicas, culturales y ambientales.

-El Plan de Ordenamiento Territorial, tiene carácter prospectivo y garantiza la coordinación y armonía en la construcción de escenarios que abarquen varios períodos de gobiernos, resolviendo problemas de continuidad que presentan los planes de desarrollo" (p. 14).

\section{El Ordenamiento Territorial como solución a problemas territoriales}

Según Barrero (2008), El Ordenamiento Territorial busca minimizar los índices de corrupción, con la finalidad de dar protagonismo a personeros que están interesados en el desa- 
rrollo de la comunidad. por supuesto que tales acciones se prevén de ejecutar con apoyo necesario de las instancias de justicia. Posteriormente a la determinación de las principales debilidades en los sectores anteriores, se busca con la acción de los planteamientos en base a la realidad nacional, garantizar la calidad de vida a los habitantes del lugar donde se ejecuta el plan a fin de promover el cumplimiento de los objetivos de la estructura de la Constitución Política de la República de Guatemala.

La mayoría de los terrenos con características aptas para la vivienda de acuerdo a la vocación del suelo, se encuentran en la categoría de propiedad privada y estas a la vez se consideran ociosas o están destinadas al pastoreo de ganado principalmente. De allí que el Estado de Guatemala y los gobiernos Municipales principalmente deben trabajar por el fortalecimiento y restablecimiento de las relaciones con la sociedad civil para que atreves de la negociación consensuada se adquieran sitios que permitan el establecimiento de la población en lugares seguros y con el afán de evitar riesgos innecesarios y perjudiciales para el desarrollo efectivo.

Las diferentes municipalidades, especialmente la municipalidad de Jalapa, debe iniciar con los procesos de concertación social a través del dialogo, al considerar que el desmedido crecimiento de la población es cada día más alto en comparación al territorio que posee. Por tal razón, se debe buscar los medios y las herramientas necesarias que permitan sistemáticamente la reorganización y ubicación de los diferentes sectores dela sociedad, teniendo como base la consideración de la vocación del suelo.
El ordenamiento territorial no busca beneficiar a un sector en específico, más bien este pretende el beneficio colectivo de la región donde se implemente, el proceso de llevar a cabo de manera integral, lo que significa que en este punto se busca a la vez, desaparecer el favoritismo político, familiar y minimizar los índices de clientelismo político, de manera que las oportunidades sean generalmente de beneficio mutuo en pro de solventar las necesidades actuales. También ofrece en su aplicación el beneficio de armonía entre instituciones, que en el caso específico de la cabecera municipal de Jalapa resulta de urgencia en el trato.

Al fortalecer la integralidad y la participación, también se trabaja en la capacitación e información constante sobre la emisión de servicios profesionales y atención al usuario de manera efectiva, respetuosa, tolerante, ética y sobre todo solidaria, al considerar que las instituciones cuenten con colaboradores preparados y asignados de acuerdo al perfil que poseen. Por consiguiente, se requiere volcar la atención de la esfera gubernamental al promover que los planes de desarrollo sean sostenibles y continuos, sin importar si se dan o no cambios en el gabinete político. El proceso buscar establecer las normas que permitan incidir en la existencia de acciones de beneficios y resultados productivo hacia la población.

\section{Metodología}

Se realizó una entrevista a 45 personas que laboran en las diferentes instituciones, que se relacionan directamente con la necesidad de llevar a cabo el proceso de Ordenamiento Territorial de la cabecera municipal de Jalapa, 5 empleados de la Municipalidad de Jalapa, 5 de la Secretaria de Planificación de Pro- 
gramación de la Presidencia -SEGEPLAN-, 5 del Ministerio de Agricultura, Ganadería y Alimentación -MAGA-, 5 de la Coordinadora Nacional para la Reducción de Desastres CONRED-, 5 del Ministerio de Ambiente y Recursos Naturales -MARN-, 5 de Ministerio de Comunicaciones, Infraestructura y Vivienda -MICIVI-, 5 del Instituto Nacional de Estadística -INE-, 5 del Instituto Nacional de Bosques -INAB-, 5 de área Jurídica de Jalapa.

La información obtenida se tabuló en una página de Microsoft Excel, para poder generar una gráfica que permiten entender la información. Es importante recalcar que, en opinión de los entrevistados, se evidencia que no tienen participación activa en las reuniones que se planifican para el diseño de estrategias a través del ordenamiento territorial y aducen que se cumple con los requisitos de formalidad por parte de la entidad principal de ejecución, que, en este caso, es la municipalidad de Jalapa, a la que le corresponde guiar el proceso para su consecución.

\section{Resultados y discusión}

En cuanto a las labores que le corresponden a cada institución vinculadas al ordenamiento territorial, los representantes de las instituciones que fueron entrevistados indicaron cuáles son sus funciones por lo que se pudieron establecer los porcentajes presentados en la siguiente figura.

Figura No.1 Instituciones vinculadas al Ordenamiento Territorial en Jalapa

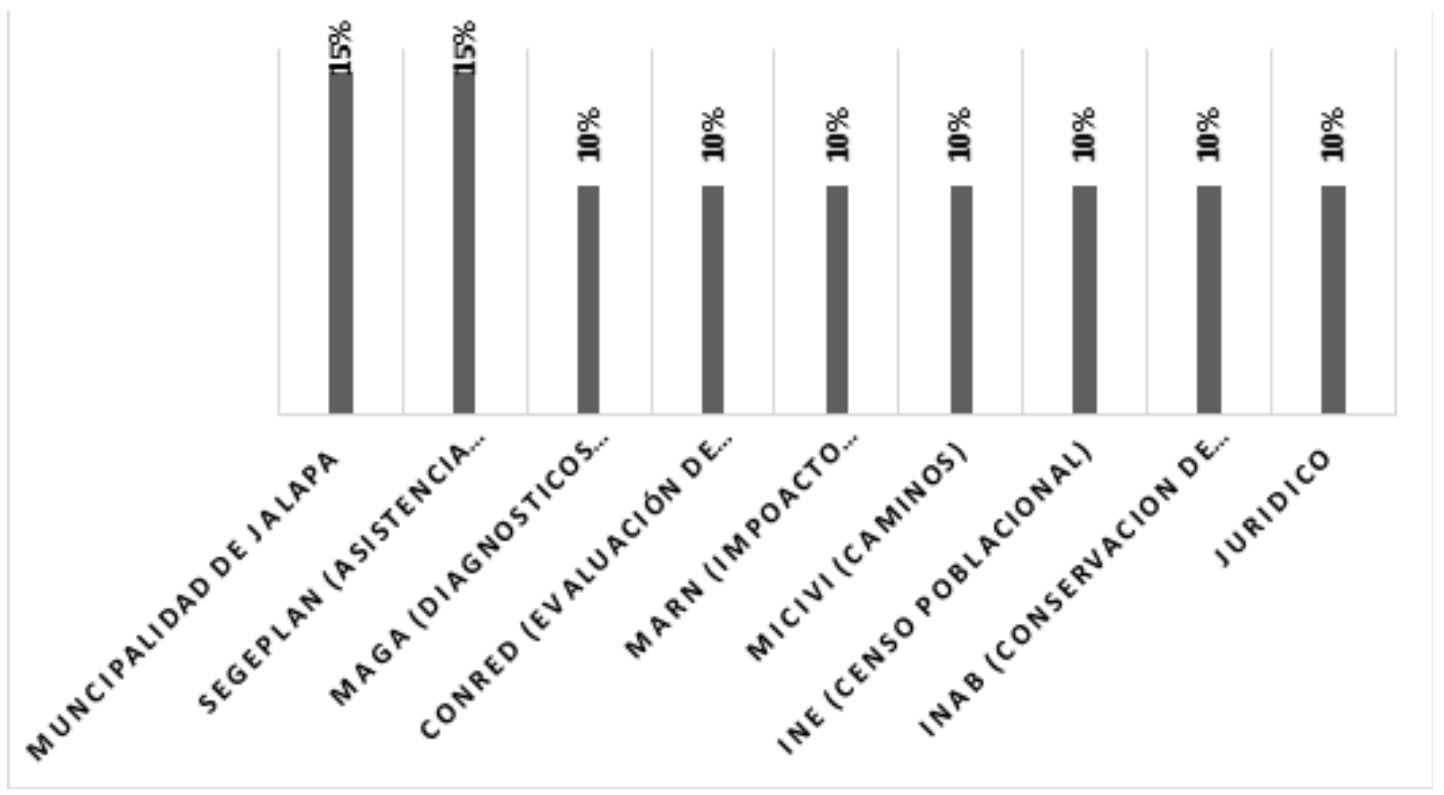

Las instituciones a través de los representantes que las coordinan, brindaron información referente a las funciones que les corresponde ante el tema de ordenamiento territorial, en primer lugar, la municipalidad de Jalapa a través de los actores que en ella intervienen, tienen claro que solo los principales protagonistas del inicio del proceso, conjuntamente brinda asesoría técnica, la Secretaria General de Planificación y Programación de la Presidencia SEGEPLAN, estas dos se encargan de hacer la convocatoria a las demás instituciones que se vinculan al proceso. 
Posteriormente a la identificación de los lugares en los cuales se pudiera establece la población, se solicita la intervención de la Coordinadora Nacional para la Reducción de Desastres CONRED, para que lleve a cabo estudios necesarios que determinen las áreas que representan riesgo ante los planes que se diseñan para el desarrollo de la población. Es este sentido se suma la presencia profesional del Ministerio de Ambiente y Recursos Renovables MARN, instancia que se encarga de verificar el impacto ambiental que los cambios que se proponen pueden generar sobre los recursos naturales, que son importantes en la sostenibilidad del territorio.

En apoyo a las instituciones mencionadas se encuentra el Ministerio de Agricultura Ganadería y Alimentación MAGA, el cual se encarga de la ubicación de las áreas con vocación de suelo para la producción. Así mismo, es necesaria la intervención de Ministerio de Comunicaciones infraestructura y Vivienda MICIVI, por medio de la oficina de caminos, para priorizar las pareas de transito con el fin de movilizar los recursos que permitan la factibilidad del proyecto.

Igualmente es necesaria la intervención del plano jurídico, pos de garantizar la efectiva delimitación del territorio, de manera que se eviten los conflictos para la tenencia de las tierras y se respeten los derechos de los pueblos indígenas que poseen terrenos en modalidad de lo comunal, a la vez es importante la participación de entidades que se encargan de la educación en el municipio para generar escenarios de participación e información sobre las disposiciones que se llevan a cabo para lograr mejoras al territorio.
Se determinó que, los representantes de las instituciones, conocen el termino Ordenamiento Territorial, pero no están involucrados de lleno en su implementación, la razón, no se interesan en participar en las actividades que se organizan en referencia al caso, pues consideran que en las sesiones de dan roces de carácter e interés político, lo que rompe con la armonía que debiese existir para la toma de decisiones efectiva y en consecuencia se obtienen, la desinformación de algunos sectores, convirtiéndose a mediano y largo plazo en un punto de desequilibrio para lograr concretar los objetivos que directamente le corresponden ejecutar.

La ausencia de comunicación e información entre los diferentes sectores e instituciones vinculadas al Orden del Territorio, provoca sustancialmente el alejamiento de la inversión pública y privada en la cabera municipal y por tal motivo se afecta directamente a la población que en el la mayor parte de los casos debe abandonar los hogares para buscar mejores oportunidades fuera de su lugar de origen a causa de la falta de empleo y el aumento de los índices de pobreza o bien verse afectados por desastres naturales ocasionados por condiciones climáticas adversas, al habitar áreas no aptas para dicha actividad.

En referencia al conocimiento de la existencia del marco legal para el Ordenamiento Territorial en el municipio de Jalapa, los diferentes actores entrevistados que se abordaron, indicaron que han escuchado del tema en cuestión, únicamente por la información teórica que ofrece -SEGEPLAN-, misma que es socializada mediante capacitaciones que se organizan, con el objetivo primordial de proveer a cada sector social de los datos específicos sobre el proceso que se propone para me- 
jorar las condiciones de vida de la población, es importante indicar que la terminología que se maneja a nivel institucional sobre el tema, es en diversas ocasiones vaga y confusa, debido a que la mayor parte de los entrevistados conocen la descripción del concepto de Ordenamiento Territorial, mas no lo verdaderos enfoques de este.

Es importante indicar que los representantes de las diferentes instituciones abordadas, por falta de información sobre las acciones que se llevan a cabo, realizan trabajo aislado de las planificaciones que corresponden, lo que se traduce en diversas ocasiones en el incremento de emisión de recursos dirigidos a lugares que no representan ningún problema, lo que genera que se inutilicen los recursos existentes que debieran llegar a los lugares catalogados en situación de riesgo. Bajo esta premisa es necesario que exista la instancia que regule el accionar conjunto de los sectores sociales de acuerdo a las funciones que le corresponden como parte de un grupo institucional que agilice la utilización de recursos para estudios de impacto ambiental y de riesgo.

Actualmente, aun no se tiene el carácter decisorio responsable de los actores involucrados en el proceso de ordenamiento territorial en la cabecera municipal de Jalapa, las razones obvias versan sobre la ausencia de comunicación, actuación ajena o en otra línea para concretar los objetivos, irresponsabilidad en el abordaje de temas relacionados con el desarrollo, violación de las leyes que protegen el medio ambiente, conflicto con la sociedad civil por cuestiones de tenencia de tierras, exclusión en la toma de decisiones y principalmente la politización de estrategias a conveniencia de grupos minoritarios.

\section{Conclusiones}

Es necesario implementar mecanismos que contribuyan a sentar las bases necesarias que permitan hacer un análisis concreto de las verdaderas necesidades que aquejan al municipio y de esta manera incidir en la importancia del trabajo en equipo consensuado en beneficio de la población que se encuentra al borde del colapso como consecuencia de la ineficiente administración de los recursos, la ausencia de voluntad política y recursos financieros inexistentes para la sostenibilidad del país.

La implementación de un plan de Ordenamiento Territorial en la cabera municipal de Jalapa, si se concreta bajo las directrices establecidas y con conocimiento del gobierno municipal, se convierte en la fuente de credibilidad ante la sociedad civil para los integrantes del Consejo Municipal de Desarrollo, a pesar de considerarse tendiente a la generación del conflicto, implementando de manera eficaz y tomando en consideración la opinión de los grupos organizados y de la sociedad en general ofrece la posibilidad de lograr el objetivo principal que consta del desarrollo sostenible tan necesario en la actualidad.

Uno de los beneficios principales puede ser, mejor calidad del entorno en el que habitan los ciudadanos, mejores condiciones de convivencia, y en general, mayor seguridad territorial. Así se considera que un plan de Ordenamiento Territorial que ha sido concertado con los diversos actores ogra que la población reconozca y comprenda la importancia de la ordenación y de su rol dentro del plan y si se realiza mediante una amplia participación, se estará contribuyendo a la implicación de la democracia y efectiva de gobernabilidad.

Durante el proceso se determinó que el sub- 
desarrollo es consecuencia de la inexistencia de Ordenamiento Territorial en la cabecera municipal de Jalapa, y es así que la población en análisis de los entrevistados concuerda en que los atrasos y la resistencia al cambio a través del tiempo han provocado que los recursos existentes se destinen a algunas acciones que no lo ameritan, dedicando esfuerzos a actividades improductivas, se minimiza la participación local, existe incertidumbre y desconfianza en la toma de decisiones, se acrecienta la falta de oportunidades, el territorio crece desordenado, no existe desarrollo económico y planificación y organización.

\section{Referencias bibliográficas}

Aldrey Vásquez, J.A. (2000). Legislación de incidencia territorial. Santiago de Compostela: Departamento de Geografía

Carrión Barrero, G.A. (2008). Debilidades del nivel Regional en el Ordenamiento Territorial desde la política administrativa y uso del suelo. Colombia: ACE

Centro Nacional de Análisis y Documentación Judicial. (2005). Ley de registro de información Catastral, decreto 41-2005. Guatemala: autor

López Noguero, F. (2002). El análisis de contenido como método de investigación. Revista de educación, 170.

Martínez Toro, P.M. (2005). Ordenamiento Territorial y Desarrollo Sostenible. España: Universidad del Valle.

Mayorga, F., \& Córdova, E. (2007), Gobernabilidad y Gobernanza en América Latina. Ginebra: Working Paper.

Meadowcroft, J. (2001). Participación y estrategias para el desarrollo sostenible. Estados Unidos de América: autor.
Melgar Ceballos, M. (2008), ¿Que Marco Legal se tiene en Guatemala para el desarrollo de los Planes de Ordenamiento Territorial? Guatemala: Empresa Consultora La Ceiba.

Municipalidad de Guatemala. (2014). Plan de Ordenamiento Territorial Metropolitano. Guatemala: autor

Ortega y Gasset, J. (1972). El hombre y la gente. Madrid, España: Espasa-Calpe, S.A.

Programa de Fortalecimiento del Régimen Municipal. (2010). Manual de Ordenamiento Territorial. Honduras: PFM AECID-AMHON

Sayquí, S. (2008). El triunfo, un reto a la juventud. Guatemala: Visión Juvenil.

Portillo, J.L. (1976). Génesis y Teoría General del Estado Moderno. México: Textos Universitarios S.A.

Programa de Desarrollo Rural Sostenible de GTZ. (2007). Ordenamiento Territorial, una herramienta para el Desarrollo. Perú: CONDENSAN-GTZ

Secretaría de Planificación y Programación de la Presidencia. (2010). Plan de Desarrollo Departamental 2011-2015. Jalapa, Guatemala: Autor

Secretaria de Planificación y Programación de la Presidencia. (2011). Guía para la Elaboración del Plan de Ordenamiento Territorial Municipal. Guatemala: Autor 


\section{Sobre autor}

\section{Ariel Oswaldo Reyes Donis}

Ingeniero Agrónomo en Sistemas de Producción Agrícola, Facultad de Agronomía, Universidad de San Carlos de Guatemala, Maestría en Docencia Universitaria con énfasis en Andragogía y pensum cerrado del Doctorado en Investigación para el Desarrollo Social, Centro Universitario de Sur Oriente. Docente del Centro Universitario de Sur Oriente, en las unidades académicas de Administración de Empresas y Zootecnia, y el Departamento de Estudios de Postgrado CUNSURORI, Publicaciones "Estrategias Andragógicas en la docencia universitaria para el aprendizaje significativo", en el libro: Docencia Universitaria Andragógica 2017, y "Políticas de desarrollo rural y su impacto en la región Sur Oriente de Guatemala", en revista Académica y Científica: Naturaleza, Sociedad y Ambiente, Portal de Portales LATININDEX, volumen 5, 2018.

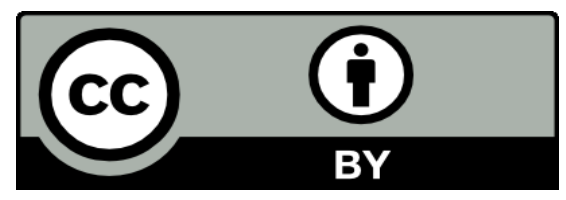

Este texto está protegido por una licencia CreativeCommons 4.0.

Esta licencia permite que otros distribuyan, mezclen, adapten y desarrollen su trabajo, incluso comercialmente, siempre y cuando le den crédito por la creación original. 



\title{
La validez de escalas NEP-R y ECS para medir comportamiento y preocupación ambiental en estudiantes del CUNSURORI, USAC
}

\section{The validity of NEP-R and ECS scales to measure behavior and environmental concern in students from CUNSURORI, USAC}

Como citar el artículo

Castro, J., y Velásquez C. (2020). La validez de escalas NEP-R y ECS para medir comportamientos y preocupación ambiental en estudiantes del CUNSURORI, USAC. Revista Naturaleza, Sociedad y Ambiente, 7 (1), 41-52. DOI: https://doi.org/10.37533/cunsurori.v7i1.50

Jerson Martínez Castro y Carlos Augusto Velásquez Rodríguez

Centro Universitario de Sur Oriente (CUNSURORI), Universidad de San Carlos de Guatemala

Recibido: 24 de febrero 2020 / Aceptado: 19 de agosto de 2020

Disponible en internet el 10 de noviembre de 2020

*Autor para correspondencia, correo electrónico: rrcastroll@yahoo.com

\begin{abstract}
Resumen
En la actualidad el deterioro del ambiente y el uso inapropiado de los recursos naturales es una preocupación creciente en las sociedades del mundo. Para medir esa preocupación respecto al tema ambiental, es necesario disponer de herramientas apropiadas para distinguir los comportamientos a favor o en contra respecto a este tema. Según algunos autores como Pato (2004), Castanedo (1995) y Bolzan (2009), los instrumentos más utilizados para evaluar el comportamiento ecológico y la preocupación ambiental son las Escala del Nuevo Paradigma Ecológico (NEP-R) propuesta por Dunlap, Van Liere y otros (2002) y la Escala de preocupación Ambiental (ECS) propuesta por Weigel y Weigel (1978). Para verificar la confiabilidad de estas escalas respecto a las variables de comportamiento y preocupación ambiental, se realizó un estudio con estudiantes de la carrera de Agronomía del CUNSURORI en 2019. El instrumento de investigación consistió en un consentimiento informado, las escalas NEP-R y ECS. La validez de las escalas conllevó el análisis del proceso de validación de contenido y validez aparente. Se evaluó la consistencia interna, a través la prueba de Kolmogorov- Smirnov. La validez de consistencia se calculó por el Coeficiente del alfa de Cronbach. Finalmente, se realizó validez del constructo, por la prueba de Keyser- Meyer- Olkin (KMO). Para realizar estas pruebas fue necesario utilizar los programas MS EXCEL y el SPSS.
\end{abstract}

Palabras clave: confiabilidad, escalas, alfa de Cronbach, Prueba de normalidad de Kolmogorov- Smirnof, Prueba de Keyser- Meyer- Olkin, interpretación estadística, comportamiento ecológico, preocupación ambiental, carrera de Agronomía del CUNSURORI, NEP-R, ECS

\section{Abstract}

At present, the deterioration of the environment and the inappropriate use of natural resources is a growing concern in the societies of the world. In order to measure this concern regarding the environmental issue, it is necessary to have appropriate tools to distinguish behaviors for or against this issue. According to some authors such as Pato (2004), Castanedo (1995) and Bolzan (2009), the most used instruments to evaluate ecological behavior and environmental concern are the Scale of the New Ecological Paradigm (NEP-R) proposed by Dunlap, Van Liere and others (2002) and the Environmental Concern Scale (ECS) proposed by Weigel and Weigel (1978). To verify the reliability of these scales with respect to the variables of behavior and environmental concern, a study was carried out with students of the Agronomy degree of CUNSURORI in 2019. The research instrument consisted of an informed consent, the NEP-R and ECS scales. The validity of the scales involved the analysis of the content validation process and apparent validity. Internal consistency was assessed through the Kolmogorov-Smirnov test. Consistency validity was calculated by Cronbach's alpha coefficient. Finally, the construct was validated by the Keyser-Meyer-Olkin (KMO) test. To perform these tests it was necessary to use the MS EXCEL programs and the SPSS. 
Keywords: reliability, scales, Cronbach's alpha, Kolmogorov-Smirnof normality test, Keyser-Meyer-Olkin test, statis tical interpretation, ecological behavior, environmental concern, CUNSURORI Agronomy career, NEP-R, ECS.

\section{Introducción}

Las escalas sobre el comportamiento ecológico (NEP-R) y la preocupación ambiental (ECS) son instrumentos útiles para entender las relaciones de las personas con el medio que les rodea y permiten recabar creencias y comportamiento de las personas sobre la naturaleza. Dichas escalas permiten medir las preocupaciones sociales en relación a procesos de contaminación y preservación del medio ambiente. Son instrumentos de investigación frecuentemente utilizados para estudios relacionados con el comportamiento ambiental de las personas. Los mismos fueron elaborados inicialmente por ecologistas norteamericanos como Dunlap y Van Liere, además de Weigel y Weigel. Pero actualmente adaptados al castellano para estudios ambientales en Europa y Latinoamérica. Con la ayuda de estas escalas se planea realizar una investigación para conocer el comportamiento y la preocupación ecológica ambiental en estudiantes universitarios del Centro Universitario - CUNSURORI- de la Universidad de San Carlos en la cabecera departamental de Jalapa. Para esto es necesario inicialmente realizar una prueba piloto que permita validar los instrumentos y encontrar algunas debilidades en los mismos que sean factibles de mejorar o bien determinar que las escalas no miden las variables de estudio. En cuyo caso, será necesario un nuevo estudio para validarse.

EI CUNSURORI es uno de los centros regionales de la Universidad de San Carlos con sede en la cabecera departamental de Jalapa. Fue creado por acuerdo de Consejo Superior Universitario del 28 de septiembre de 1977. Inició a funcionar en enero de 1978 con las carreras de Técnico frutícola, Técnico en producción de lácteos y Técnico en Trabajo Social. En la actualidad, dicho Centro imparte seis carreras profesionales: Agronomía, Zootecnia, Trabajo social, Administración, Derecho y Pedagogía. Éstas se desarrollan en plan diario; las primeras tres en horarios de 14:00 a 20:00 horas; Administración y Derecho en horario de 18:00 a 21:00 horas. Pedagogía se desarrolla en plan fin de semana, los días sábados y domingos en horario de 8:00 a 17:00 horas. Cabe indicar que esta carrera trabaja estos dos días, pero en forma individual, ya que hay una carrera de pedagogía para cada uno de estos días.

A través de las escalas NEP-R y ECS se pretende relacionar las creencias ecológicas y la preocupación ambiental con la formación universitaria que se desarrolla a medida que los estudiantes cursan los diferentes ciclos de su carrera profesional. Para poder obtener un título a nivel profesional, los estudiantes deben estudiar en promedio, cinco años y realizar un año más de Ejercicio Profesional Supervisado -EPS-. A medida que los estudiantes aprueban los cursos de su carrera, adquieren capacidades y destrezas que les permiten adquirir habilidades y competencias en su campo profesional. Una formación universitaria integral, les permite una mayor visión de su realidad y del ámbito profesional que se forman. Además, desarrollan habilidades y raciocinio sobre diferentes temas sociales, económicos, humanísticos y ambientales. Toda esta formación moldea el comportamiento de los estudiantes hacia los diferentes temas de su educación universitaria. Se espera que a medida que los estudiantes son formados en sus respectivas disciplinas, desarrollen racio- 
cinio y conciencia en aspectos ecológicos y ambientales. Según Páramo, los cambios de comportamiento de las personas depende de la estructura social, el conocimiento con que cuentan y creencias proambientales (Páramo, 2016). De manera que, al enfrentarse a una problemática en cualquiera de los campos de su formación, las personas tendrán la destreza suficiente para establecer alternativas de solución.

El comportamiento ambiental de los estudiantes, es la reacción voluntaria a diferentes aspectos que influyen en el entorno donde se desenvuelven. Hay varios factores que influyen en el comportamiento de las personas; una de ellas es la magnitud de la información que posean al respecto. Una educación apropiada provee de información oportuna para discutirla, analizarla y absorberla. La educación, a través de sus distintos medios provee de conocimientos, que propician un cambio de actitud y comportamiento positivo, ante diferentes temáticas y circunstancias del medio en general. Las personas en nuestro medio; independiente de su origen, estrato social, religión, género y demás aspectos sociales, tienen comportamientos parecidos. Los mismos son más visibles cuando se aborda el tema ambiental. Lo que puede deberse a que se comparte un contexto y cultura en común. Para Mata-Segreda (2004), la cultura, es el resultado de un proceso continuo de construcción colectiva; cambia con el tiempo dependiendo de los gustos, preferencias, modas o tendencias imperantes en el momento en que se desarrolla.

El comportamiento de los estudiantes universitarios, puede ser influido por la educación que reciben de los diferentes cursos de formación universitaria. Es apropiado determinar, si la formación que se recibe como parte de un proceso educativo, deja de lado el desarrollo cognoscitivo de sus estudiantes y por ende se les desvincula del raciocinio apropiado para el buen manejo ambiental. En opinión de Flores (2012), la investigación educativa orienta el análisis de una problemática ambiental; determina que la formación académica tiende a producir un cambio en el comportamiento de las personas que se involucran en el estudio de la problemática.

Existen diferentes metodologías para evaluar las actitudes y el comportamiento ambiental de personas en formación académica. Muchas de ellas contempla el uso de escalas psicométricas como la NEP-R y ECS (Moyano-Diaz \& Palomo-Velez, 2014; Pato, C.; Ros, M.; Tamayo, 2005). Las percepciones ambientales de estudiantes incluyen actitudes, preocupaciones, creencias, paradigmas, valores y puntos de vista respecto al ambiente (Isaac-márquez et al., 2011). El comportamiento ambiental respecto a las creencias generales de los individuos sobre el medio ambiente es posible medirse a través de la escala del Nuevo Paradigma Ecológico (NEP) propuesto por Dunlap, Van Liere y otros (Sanz, L.; Guillén, 2005). Para medir la preocupación ambiental se utiliza la escala del mismo nombre, que se toma de la original Environmental Concern Scale (ECS) de Weigel y Weigel de 1978 y su adaptación al castellano por Aragones y Amerigo en 1991, modificado por Américo y Gonzales en 1996, la más reciente adaptación es de Hernández, Suarez, Martínez-Tornisco y Hess en 1997 (Baena-Extremera \& Granero-Gallegos, 2013)

\section{Metodología}

Esta investigación se analiza desde el enfoque del paradigma Neopositivista. El mismo 
explica que el conocimiento se adquiere por medio de la probabilidad, fuera del alcance del ser humano. Se estudia la realidad al adquirir la cualidad de ser medible. La metodología se enmarcará en un diseño cuantitativo. Cuya finalidad es analizar la confiabilidad de las escalas NEP-R y ECS. El diseño cuantitativo puede ser experimental y no experimental (Velásquez, 2017). Esta investigación es no experimental. El diseño no experimental, no trata de replicar la realidad para la manipulación la manipulación de variables a manera de realizar y registrar influencia entre las mismas. En este tipo de diseño, el investigador recolecta datos, lo cual puede hacerlo en un momento determinado o bien realiza un estudio comparativo a través de los resultados que se le presenten en el tiempo (Bonilla, 2019).

Previo a la realización de una investigación compleja que involucra considerar diferentes aspectos, como los elementos de estudio, metodología, los instrumentos de medición, entro otros tantos factores. Es indispensable realizar una prueba piloto. La misma representa una investigación a menor escala de lo que se realizará a futuro. Esta prueba piloto permite reconocer si la metodología en general, como sus componentes son apropiados, pertinentes y objetivos de acuerdo a lo que se investiga. Dicha prueba permite realizar ajustes y tomar decisiones sobre los detalles de la investigación.

La prueba piloto que se realizó permitió inferir a partir de la teoría que describe que los componentes del ambiente social y natural están conformados por la cultura, recursos naturales, organización social y base económica (Bifani, 1984). El razonamiento deductivo prueba una teoría al reunir resultados de instrumentos de encuestas o censos que per- miten confirmar o rechazar una teoría (Best, 1982). De manera que el razonamiento del diseño de investigación que se plantea es deductivo.

Para esta prueba piloto el diseño cuantitativo tiene enfoque no experimental. A diferencia del experimental, este no tiene un grupo control y no utiliza la aleatorización en la elección de sujetos experimentales. La investigación no experimental puede ser de tipo transversal o longitudinal (Velásquez, 2017). La primera se aplica cuando la investigación pretende conocer un momento determinado del tiempo, es decir, describe el fenómeno en el rango de tiempo que tarda el estudio. Por otra parte, la segunda, busca describir el fenómeno de estudio en su desarrollo o evolución, es decir, en los diferentes momentos en que ocurre (Corona, 2016; Tamayo, 2007). Esta prueba se realizó en cuatro ciclos de la carrera de Agronomía en el segundo semestre del año 2019. De manera que esta investigación es Transversal, ya que solo recoge la información de los ciclos en un punto específico del tiempo y no describe su comportamiento cronológico.

Las investigaciones cuantitativas, no experimentales de tipo transversal pueden tener diferentes tipos de alcance como los siguientes: exploratorio, descriptivo, correlacional y explicativo (Velásquez, 2017). Para poder comprender dichos alcances algunos autores las definen como aparece a continuación (Hernández-Sampieri, 2014; Piloña, 2005; Velásquez, 2017). La investigación correlacional permite encontrar las relaciones entre variables dependientes e independientes y encontrar los aspectos de causa y efecto que las caracterizan (Piloña, 2005; Velásquez, 2017). En síntesis, la prueba piloto es el reflejo de una investigación que se planea realizar de diseño mixto, donde la parte cuantitativa es 
no experimental, de tipo transversal, con alcance correlacional.

La prueba piloto que se realizó representa un estudio sobre la evaluación de los conocimientos y percepciones de estudiantes de la carrera de Agronomía del CUNSURORI, respecto al paradigma ambiental. Esta prueba analiza la confiabilidad de las escalas utilizadas para medir las creencias ecológicas y la preocupación ambiental de los estudiantes de acuerdo a su formación académica universitaria. De manera que, las percepciones ambientales de estudiantes incluyen actitudes, preocupaciones, creencias, paradigmas, valores y puntos de vista respecto al ambiente (Isaac-márquez et al., 2011). Esas percepciones pueden ser moldeadas o aprendidas a través de un proceso formativo consciente de la realidad actual.

\section{Instrumento}

Se elaboró un instrumento que incluyó un consentimiento informado y las escalas NEP-R y ECS. El consentimiento informado permitió informarles a los encuestados sobre los propósitos de la investigación, los responsables y la metodología a seguir para el estudio. Para obtener la información sobre creencias ecológicas y preocupación ambiental se utilizan los instrumentos correspondientes a la Escala del Nuevo Paradigma Ecológico (NEP-R), la Escala de la Preocupación ambiental (ECS. La escala NEP-R representa una forma ecologista de entender las relaciones del ser humano con la naturaleza y recoge las creencias generales que las personas tienen sobre el medio ambiente (Moyano-Diaz \& Palomo-Velez, 2014). Actualmente conocida por NEP-R es una forma ecologista de entender las relaciones del ser humano con la naturaleza.
La escala NEP-R fue diseñada con la intención de obtener información sobre la intranquilidad del encuestado sobre aspectos ecológicos, equilibrio de la naturaleza y la posibilidad de que haya una crisis ecológica (Baena-Extremera \& Granero-Gallegos, 2013). La escala NEP-R fue creada por Dunlap y Van Liere en 1984 (Sanz, L.; Guillén, 2005), posee 16 ítems, los que fueron reducidos posteriormente a 15. Sin embargo, Moyano-Diaz y Palomo-Velez en 2014, realizaron las investigaciones respectivas y determinaron que de la escala de 15 ítems podían obviarse 4 de estos dejando un total de 11 ítems, sin que eso afectase significativamente la consistencia y confiabilidad de los datos. Utilizaron análisis multifactorial, las pruebas de confiabilidad a través del Alfa de Cronbach y determinaron que ese valor se mantiene representativo y constante con los 11 ítems únicamente. Lo que resulta en una escala mucho más práctica y fácil de responder para el encuestado. Para ser resuelto este instrumento por el encuestado, cada ítem posee una escala Likert donde se encuentran las respuestas numeradas del 1 al 5. Donde los extremos de respuestas son el "1" que indica que está muy de acuerdo y el " 5 " indica que está muy en desacuerdo, la opción " 2 " le indica que está de acuerdo, el " 3 " es intermedio; puede escogerlo cuando no tenga preferencia entre una u otra opción, el "4", indica que está en desacuerdo.

Para medir la preocupación ambiental se utiliza la escala del mismo nombre en su versión del idioma Inglés, que se toma de la original Environmental Concern Scale (ECS) de Weigel y Weigel de 1978 y su adaptación al castellano por Aragones y Amerigo en 1991, modificado por Américo y Gonzales en 1996, la más reciente adaptación es de Hernández, Suarez, Martínez-Tornisco y Hess en 1997 (Baena-Extremera \& Granero-Gallegos, 
2013). Es un instrumento fiable, breve y de uso fácil para determinar la preocupación actitudinal sobre la calidad del medio ambiente y los cambios en las actitudes públicas y el impacto de políticas medioambientales, legislativas y del esfuerzo educativo (Weigel \& Weigel, 1978). La escala mide la preocupación ambiental en torno a la conservación y la contaminación del medio ambiente. La escala ECS consta de 16 ítems politómicos en una escala Likert de 5 puntos que se encuentran en los rangos de "muy en desacuerdo" con valor de 1 y el otro extremo con "muy de acuerdo" con valor de 5. La misma posee niveles adecuados de consistencia interna y de validez medida por comparaciones entre grupos diferentes y por predicción de la conducta ecológica relevante (Gónzalez, 2002)

\section{Población de estudio}

Los elementos de estudio de la prueba piloto para validar las escalas NEP-R y ECS como herramientas necesarias para evaluar el entendimiento de las personas con el entorno, las creencias generales sobre el ambiente y la preocupación ambiental, la relación de la formación universitaria y su relación con el comportamiento, fueron los estudiantes de diferentes ciclos de la carrera de Agronomía. De manera que se solicitó a los estudiantes responder los ítems de estas dos escalas. Los estudiantes encuestados fueron de los ciclos $2^{\circ}$., $4^{\circ}$. $6^{\circ}$. y EPS, que son $18,7,9$ y 13 , respectivamente; para un total de 47 estudiantes. Para algunos especialistas en el tema, la educación ambiental debe ser enfocada desde las características propias de las comunidades; los estudios que se realicen deben permitir medir dichas variables para consolidar una cultura ambiental favorable (Miranda, 2013).

\section{Procedimiento}

La recolección de la información se realizó en los ciclos de formación de la carrera ya indicada. Esta carrera incluye diez ciclos teóricos que duran cinco años, más un Ejercicio Profesional Supervisado -EPS- con una temporalidad de 10 meses. La distribución anual de los ciclos es semestral, de manera que cada año se reciben dos ciclos. La recopilación de la información se realiza durante el mes de septiembre del año 2019, con los ciclos mencionados anteriormente. La prueba piloto contempla el rigor científico, al relacionar los aspectos teóricos y relacionarlos con elementos observables y medibles; si las propuestas no involucran observación y pruebas públicas, no constituyen propuestas científicas (Kerlinger \& Howard, 2002).

Para esta prueba se consideró el total de estudiantes en cada ciclo, lo que corresponde al total de estudiantes que se encontraban recibiendo sus cursos. El total de estudiantes encuestados fue de 47 alumnos. Sin embargo, para la escala NEP-R se analizarán 45 datos lo que se debe a que existen 2 estudiantes que no respondieron la encuesta. En cuanto a la escala ECS, se analizaron 46 datos ya que existe una boleta en blanco. Los ciclos que se consideraron en el estudio, se escogieron al azar y se tomó en cuenta la presencia de los estudiantes en el momento del muestro. Algunos ciclos reciben prácticas de laboratorio y de campo durante sus horarios de estudio, por lo que se buscó el momento oportuno para pasar los instrumentos de investigación. Para esta prueba piloto se solicitó y obtuvo la autorización del Coordinador de la carrera de Agronomía. Antes de llegar al salón de clase, se solicitó también, pero en forma verbalmente y con anticipación la autorización del docente encargado del curso y 
se hizo saber sobre la autorización y conocimiento del Coordinador de la carrera.

Una prueba piloto, consiste en administrar el instrumento a una muestra del estudio para probar su pertinencia y eficacia, para conocer las condiciones de la aplicación y los procedimientos requeridos (Hernández-Sampieri, 2014). Se solicitó a los estudiantes de los ciclos de la carrera de agronomía ya mencionados, que de forma voluntaria decidieran contestar las escalas NEP-R y ECS. En su mayoría los estudiantes que estuvieron de acuerdo en contestar dichas escalas, firmaron "un consentimiento informado". El mismo representa un acuerdo donde se explica la investigación, sus propósitos y los responsables de la misma. Los instrumentos o escalas de investigación, se llevaron en sobre cerrado y de igual manera se archivaron para un mayor control y proteger la confidencialidad de los datos obtenidos.

Los datos obtenidos a través de las encuestas, fueron tabulados a través de los programas MS Excel y SPSS versión 25. Se creó una base de datos con las respuestas de cada grupo de medición, es decir, de cada ciclo de las carreras en estudio, luego se unieron y se analizaron los datos en conjunto para cada una de las dos escalas. Se obtuvieron 45 datos para la escala NEP-R y 46 datos para la escala ECS. Esto indica que para la escala NEP-R existieron dos boletas que no se contabilizaron debido a que la encuesta no fue contestada y en el caso de la ECS exitió un dato perdido. Los resultados de la prueba piloto, fueron tabulados y se aplicaron las validaciones de contenido, aparente, constructo y validez.

\section{Resultados}

Los resultados que se presentan son productos de las encuestas que se practicaron a los estudiantes ya descritos. La redacción de varios ítems se revisó previamente a la prueba piloto y se castellanizo para su uso en los estudiantes de la carrera de Agronomía. Aun así, varios ítems presentaron necesidad de aclaración durante la prueba. Eso permitió revisar nuevamente las escalas, verificar su redacción en cuanto a su compresión y reconocer palabras que no son dominio popular y realizar las enmiendas respectivas. Algunas frases y palabras no son de uso común entre los encuestados, como el ítem 4 de la escala NEP-R donde hace referencia a la "inventiva humana", lo que refiere cambiarse por "los inventos de la humanidad", entre otros.

Para el consentimiento informado se realizó una prueba con el grupo del sexto ciclo de la carrera de agronomía. A la mitad del grupo se le proporciono dicho consentimiento antes de pasar la encuesta y a la otra mitad del grupo no se le dio ese consentimiento. Al final de la prueba se entrevistó a ambos grupos, sobre si los resultados de sus respuestas cambiarían al utilizar el consentimiento o no tenerlo. Las ideas de ambos grupos es que responderían de la misma forma. Al comparar los resultados no se presentan tendencias que puedan inclinar respuestas respecto al uso o no de dicho consentimiento. Por lo que es una mejor opción para el encuestado presentarle la información de la encuesta previamente y librarlo de toda responsabilidad al contestar las escalas.

Para analizar las escalas, se tomaron los datos obtenidas a través de estas. Los ítems de las escalas y los datos obtenidos de las mismas fueron evaluadas a través de los siguientes 
parámetros: validez de contenido, validez aparente, consistencia interna de las escalas y prueba de normalidad. Para la validez de contenido, se consideró que las pruebas NEP-R y ECS no son propias de Guatemala, por lo que se procedió a contextualizarlas de acuerdo al uso apropiado de nuestro lenguaje de acuerdo a palabras de uso común como "vehículo" en lugar de "coche", la moneda circulante como lo es "quetzal". Posteriormente las escalas fueron revisadas por dos docentes de la carrera de agronomía en su papel de expertos en el tema. Ambos son ingenieros agrónomos, docentes con titularidad $\mathrm{VI}$ y XI, responsables de cursos como Manejo de los recursos naturales, Estadística, Suelos, Granos básicos, entre otros. Los mismos consideraron algunos aspectos de redacción en los ítems.

La validación aparente se realizó al pasar la prueba a los estudiantes encuestados, donde existieron dudas en algunos ítems como el número 4 de la escala NEP-R donde los estudiantes no entendían del todo la "inventiva humana" que se cambió posterior mente a "los inventos de la humanidad", entre otros. Con el consentimiento informado, no existieron mayores dudas y se asume que se entendió a plenitud. Como se mencionó anteriormente, existió un grupo de estudiantes que contestaron el instrumento sin tener previamente el consentimiento informado y un grupo que si lo tuvo. Al evaluar sobre los resultados y opiniones de los encuestados. Los mismos respondieron que no se sintieron influidos en sus respuestas al tener o no tener el consentimiento informado para contestar las encuestas. Tampoco los resultados reflejaron un cambio de respuestas en los mismos.
Para evaluar la consistencia interna de las Escalas NEP-R y ECS y determinar la fiabilidad y valides de estas escalas, se le aplicó el Coeficiente desarrollado por J.L. Cronbach a los datos de cada escala. El alfa de Cronbach debe presentar valores entre 0.70 y 0.90 para que el instrumento tenga confiabilidad de que mide los aspectos que lo conforman (Hernández-Sampieri, 2014). Originalmente, la escala NEP-R contiene 16 ítems, a los que le fueron agregados 2 ítems adicionales redactados por el investigador. El número total de ítems de la escala NEP-R fue de 18. Con esta cantidad de ítems se obtuvo un Alfa de Cronbach de 0.918; lo que sobrepasa el 0.70 aceptable para la confiabilidad. Eso indica que la escala es muy confiable y valida, los aspectos para los que fue diseñada como lo son el entendimiento las creencias de las personas con el ambiente. Según MoyanoDiaz (2014), recomienda que la confiabilidad puede mantenerse y es factible de eliminar de la prueba original los ítems $1,8,11,12$; los autores de esta escala también decidieron eliminar el ítem 16. Se realizó un nuevo análisis de los datos tabulados dejando únicamente los 11 ítems recomendados por el autor mencionado; se obtuvo un Alfa de Cronbach de 0.858 . En cuanto a la escala ECS que presenta 16 ítems en la escala, presentó un Alfa de 0.885 , el cual también supera el índice de 0.70 que requiere la confiabilidad de este coeficiente. Por lo que también esta escala mide la preocupación ambiental, para lo que fue diseñada.

La estadística es un instrumento útil del investigador que le capacitar para hacer deducciones de sus observaciones y hacer estimaciones con probabilidades de error conocidas (Best, 1982). . Por lo que para este estudio en particular se recomienda utilizar la escala NEP-R completa y los dos ítems adicionales 
redactados por el autor de la investigación. Para un uso confiable de la escala ECS con un Alfa de Cronbach aceptable pueden utilizarse los 16 ítems que la conforman.

A los datos de las escalas NEP-R y ECS se les realizó la proyección del comportamiento normal de los datos a través de los momentos estadísticos, como son los cálculos de media, moda, mediana, desviación estándar, curtosis, asimetría, coeficiente de variabilidad, valor máximo y mínimo, rango. Por medio del programa MS EXCEL se determinó que los datos no son normales, pero se acercan mucho a los valores de la normalidad. Pueden normalizarse a través de aplicarles algunos factores a los datos como la raíz cuadrada o el logaritmo natural. Eso no cambiaría la naturaleza de los datos, solo serían interpretados a través de un factor de ajuste (Levin, 1989; Merk, 1996). Según el valor de la curtosis que es de -0.33 , los datos se encuentran distribuidos en los extremos de la curva normal, por lo que la curva recibe el nombre de platicurtica (Dicovskiy-Rioboo, 2008; Pardinas, 1975).

Otra forma de analizar la normalidad de los datos en la escala NEP-R fue a través de la prueba de Kolmogorov- Smirnov (KS), realizada por medio de MS EXCEL. Esta prueba toma en cuenta la Media y la Desviación estándar como parámetros de distribución normal, también los valores mínimo y máximo de los datos (García, R.; González \& Net, 2010). El valor KS indica que los datos se comportan de manera normal con significancias de 0.10 y 0.05 , no así con significancia de 0.01 .

Para realizar la validez del constructo, es decir, los aspectos de comportamiento y pre- ocupación de las escalas NEP-R y ECS, respectivamente; se realizó un análisis factorial exploratorio de los datos de dichas escalas. Para esto se aplicó la prueba Kaiser- MeyerOlkin (KMO) y la Prueba de esfericidad de Bartlett, que permiten medir la adecuación muestral para factorizarse de forma eficiente. Esto, permite determinar si los datos son factibles de realizarse análisis factorial y determinar si algunos ítems pueden analizarse en forma conjunta. Para que esta prueba sea validad el valor KMO debe ser mayor de $0.60 \mathrm{y}$ el índice de Bartlett debe ser mayor de 0.05 . Para la escala NEP-R el valor de KMO fue de 0.773 y el índice de Bartlett fue de 0.000 . Lo que indica que los datos obtenidos a través de esta escala son factibles de realizarse análisis factorial. En cuanto a la escala ECS el índice KMO fue de 0.776 y el índice de Bartlett fue de 0.000 , por lo que también los datos de esta escala son factibles de realizarse análisis factorial.

La aplicación de las escalas NEP-R y ECS permitirán analizar el comportamiento y preocupación ambiental de los estudiantes en las diferentes carreras del CUNSURORI. Es necesario que estudiantes y profesionales desempeñen en un rol protagónico ante la sociedad, con la intención de establecer una relación de armonía con la naturaleza (UNESCO, 1977). Por lo que, los estudiantes, a medida que avanzan en su carrera profesional, pueden denotar mayor manejo de conocimientos generales y se afianzan los conocimientos específicos del área de su formación. Desarrollan una mayor conciencia de la realidad de los aspectos relevantes de la preservación medio ambiental, del contexto en que se relacionan y del mundo en general. 
Al aplicar las escalas NEP-R y ECS en diferentes carreras y ciclos de formación puede medirse la manera que la educación, favorece cambios de comportamiento en los sujetos que aprenden, lo que repercute en cambios de sentimientos, pensamientos que se ven ejecutados en acciones (Tyler, 1986). Esto permitirá evaluar si la población universitaria en el CUNSURORI es consciente y con capacidades suficientes para explicar, promover y desarrollar acciones, actividades y proyectos que favorezcan una comunidad con un mejor cuidado de sus recursos. De esta manera, se estará contribuyendo con la sostenibilidad y sustentabilidad de la naturaleza en la comunidad.

En síntesis, las escalas NEP-R y ECS son herramientas necesarias para analizar la formación universitaria y su influencia sobre el comportamiento ambiental de los estudiantes. $\mathrm{Si}$ el individuo no se informa o se capacita, corre el riesgo de que tome actitudes fuera de su realidad y su entorno. Algunos investigadores, coinciden en que las actitudes y las intenciones de actuar influyen sobre el comportamiento de las personas, cuando otros factores, como el comportamiento individual de consumo y de participación ambiental, no lo impiden (Gomez, Noya, \& Panigua, 1999). La persona reconoce, que hay buenos hábitos y malas costumbres que no necesariamente deben continuarse y puede aprender a desaprender. Esto crea un cambio positivo para el individuo, su cultura y la sociedad en general donde se desenvuelve.

\section{Referencias}

Baena-Extremera, A., \& Granero-Gallegos, A. (2013). Estudio cuasi- esperimental de un programa de supervivencia en el medio natural. Revista Internacional de Medicina y Ciencias de La Actividad Física y El Deporte, 13(51), 551-567.

Best, J. (1982). Como investigar en educación (Novena edi). Madrid, España: Ediciones Morata, S.A.

Bifani, C. (1984). Desarrollo y medio ambiente. Madrid, España: Publicaciones del Ministerio de Obras Públicas y Urbanismo.

Bolzan, C. ., \& Pol, E. (2009). Sistemas de gestión ambiental y comportamiento ecológico: una discusión teórica de sus relaciones posibles. Aletheia 29, 103-116.

Bonilla, G. (2019). Investigación científica; Métodos, técnicas e instrumentos. Guatemala: Editorial Servi prensa.

Castanedo, C. (1995). Escala para la evaluaicón de las actitudes pro- ambientales (EAPA) de alumnos universitarios. Revista Complutense de Educación, 6(2), 253-278.

Corona, J. (2016). Apuntes sobre métodos de investigación. Medisur, 14(1), 81-83. Retrieved from http://scielo.sld.cu

Dicovskiy-Rioboo, L. (2008). Estadística Básica (U. N. de Ingeniería, Ed.). Esteli, Nicaragua.

Flores, R. C. (2012). Investigación en educación ambiental. Revista Mexicana de Investigación Educativa, 17(55), 1019-1033.

García, R.; González, J. . J., \& Net, J. (2010). SPSS: Pruebas no paramétricas. (U. de Valencia, Ed.). Valencia, España: InnovaMIDE, Grupo de Innovación educativa.

Gomez, C., Noya, F., \& Panigua, A. (1999). Actitudes y Comportamientos hacia el medio ambiente. Madrid, España. 
Gónzalez, A. (2002). La peocupación por la calidad del medio ambiente, un modelo cognitivo sobre la conducta ecológica. Universidad Complutense de Madrid.

Hernández-Sampieri, R. (2014). Metodología de la Investigación (Sexta Edic; M. Rocha, Ed.). México, D.F.: Mac Graw Hill education.

Isaac-márquez, R., Salavarría, O., Eastmond, A., Ayala, M., Arteaga, M., Isaac-Márquez, A., ... Manzanero, L. (2011). Cultura ambiental en estudiantes de bachillerato . Estudio de caso de la educación ambiental en el nivel medio superior de Campeche. Revista Electrónica de Investigación Educativa, 13(2), 100.

Kerlinger, F., \& Howard, L. (2002). Investigación del comportamiento. Métodos de investigación en ciencias sociales (Cuarta edi; Mc Graw Whill Ineramericana Editores, Ed.). México, D.F.: Mc Graw Hill.

Levin, R. (1989). Estadística para administradores (Sexta edic). Mexico, D.F.: Prentice Hall.

Mata-Segreda, A. (2004). Transformación de la cultura ambiental mediante la docencia universitaria. Revista Biocenosis, 129-135.

Merk, J. (1996). Estadística y Prácticas primarias. (Unidad de practicas de Ingenieria y EPS., Ed.). Guatemala: Facultad de Ingenieria, USAC.

Miranda, L. (2013). Cultura ambiental: un estudio desde las dimensiones de valor, creencias, actitudes y comportamientos ambientales. Producción Mas Limpia, 8(2), 94-105.

Moyano-Diaz, E., \& Palomo-Velez, G. (2014). Propiedades psicométricas de la Escala Nuevo Paradigma Ecológico (NEP-R) en
Poplación chilena. Psicología Ambiental, 45(3), 415-423.

Páramo, P. (2016). Reglas proambientales: una alternativa para disminuir la brecha entre el decir-hacer en la educación ambiental. Suma Psicológica, 4, 1-17. https://doi.org/10.1016/j.sumpsi.2016.11.001

Pardinas, F. (1975). Metodología y técnicas de Investigación en ciencias sociales. Mexico, D.F.: Siglo XXI Editores, S.A.

Pato, C.; Ros, M.; Tamayo, A. (2005). Creencias y comortamiento ecológico: un estudio empírico con estudiantes brasileños. Medio Ambiente y Comportamiento Humano, 6(1), 5-22.

Pato, C. (2004). Comportamiento edcológico: relacionado con valores personales y creencias ambientales. Universidad de Brasilia. Brasília, DF.

Piloña, G. (2005). Guía práctica sobre métodos y técnicas de investigación documental y de Campo. (Sexta edic). Guatemala: Editorial CIMGRA.

Sanz, L.; Guillén, C. (2005). Escala nuevo Paradigma Ecológico: propiedades psicométricas con una muestra española obtenida a través de Internet. Medio Ambiente y Comportameinto Humano, 6(1), 37-49.

Tamayo, M. (2007). El proceso de la investigación científica (4a. edició; E. Limusa., Ed.). México, D.F.

Tyler, R. (1986). Principios básicos del currículo. Buenos Aires, Argentina.: Troquel.

UNESCO. (1977). Conferencia intergubernamental sobre educación ambiental. Tibilisi, URSS.

Velásquez, C. (2017). La investigación cientifica, un acercamiento didáctico (Se- 
gunda). Villa Nueva, Guatemala: ECO ediciones.

Weigel, R., \& Weigel, J. (1978). environmetal concern: The deveolpment of a measure. Environment and Behavior, 10(1), 3-15.

\section{Sobre autor}

\section{Jerson Martínez Castro}

Profesor Titular del Centro Universitario de Sur Oriente -CUNSURORI- de la Universidad de San Carlos de Guatemala -USAC-, con sede en la ciudad de Jalapa. Con estudios a nivel de licenciatura en Agronomía y Administración de empresas. Graduado de la Maestría en Docencia Universitaria y actualmente estudia el Doctorado en Educación en la USAC. Es Coordinador de la Práctica Profesional Supervisada -PPS- y del Ejercicio Profesional Supervisado -EPS- de la carrera de Agronomía en el CUNSURORI. Ha producido texto de apoyo a la docencia como Introducción al estudio de los nombres de las plantas y Descripción taxonómica del grupo de plantas: Pinophytas y Magnoliophytas. Además de realizar investigaciones en el tema ambiental.

\section{Sobre Coautor}

\section{Carlos Augusto Velásquez Rodríguez}

Doctor en investigación didáctica por la Universidad de Almería, España, en noviembre 19 de 2019. Como parte del curso de Seminario de Investigación V, del doctorado en Educación de la Facultad de Humanidades, USAC.

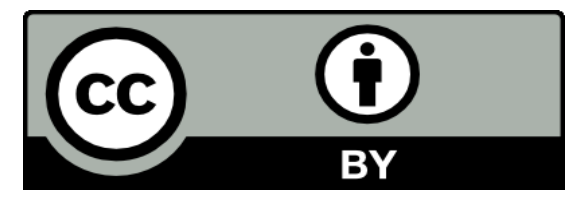

Este texto está protegido por una licencia CreativeCommons 4.0.

Esta licencia permite que otros distribuyan, mezclen, adapten y desarrollen su trabajo, incluso comercialmente, siempre y cuando le den crédito por la creación original. 


\title{
Estudio de prevalencia de Salmonella sp. en palomas domesticas (Columba livia) en parque zoológico minerva, Quetzaltenango
}

\section{Prevalence study of Salmonella sp. in domestic pigeons (Columba livia) in minerva zoo, Quetzaltenango}

\section{Como citar el artículo}

Amado, V. y Fuentes, H. (2020). Estudio de prevalencia de Salmonella sp. en palomas domesticas (Columba livia) en parque zoológico minerva, Quetzaltenango. Revista Naturaleza, Sociedad y Ambiente, 7 (1), 53-56. DOI: https:// doi.org/10.37533/cunsurori.v7i1.51

Victor Amado Soto y Héctor Fuentes Rousselin

Facultad de Medicina Veterinaria y Zootecnia, Universidad de San Carlos de Guatemala

Recibido: 04 de febrero de 2020 / Aceptado: 28 de agosto de 2020

Disponible en internet el 10 de noviembre de 2020

*Autor para correspondencia, correo electrónico: amadosoto90@gmail.com

\begin{abstract}
Resumen
El estudio consistió en la captura de 30 palomas domésticas, sin importar rango de edad o sexo, situadas en el parque Zoológico Minerva en Quetzaltenango. El objetivo fue determinar la prevalencia de Salmonella sp. en las mismas, a través del método de aglutinación rápida en placa. Investigaciones recientes han reportado que la infección por Salmonella causa 2.8 mil millones de casos de diarrea anualmente en todo el mundo. Salmonella, es considerada la zoonosis con mayor importancia en las enfermedades bacterianas capaz de ser transmitidas por la paloma doméstica. Esta enfermedad ha estado involucrada en morbilidad y mortalidad en aves de zoológicos y de centros de rehabilitación de fauna silvestre en todo el mundo. Sin embargo, no se obtuvieron anticuerpos contra Salmonella $\mathrm{sp}$. en las 30 muestras procesadas, por lo que se concluye que no existe prevalencia de Salmonella sp en palomas domesticas en el zoológico minerva.
\end{abstract}

Palabras clave: Salmonella, Palomas domésticas, Zoológico, Quetzaltenango

\begin{abstract}
The study consisted of capturing 30 domestic pigeons, regardless of age range or sex, located in the Minerva Zoological Park in Quetzaltenango. The objective was to determine the prevalence of Salmonella sp. in them, through the fast plate agglutination method. Recent studies have reported that Salmonella infection causes 2.8 billion cases of diarrhea annually worldwide. Salmonella, is considered the most important zoonosis in bacterial diseases capable of being transmitted by the domestic pigeon. This disease has been involved in morbidity and mortality in birds of zoos and wildlife rehabilitation centers throughout the world. However, no antibodies were found against Salmonella sp. in the 30 samples processed, it concludes that there is no prevalence of Salmonella sp in domestic pigeons in Minerva zoo.
\end{abstract}

Keywords: Salmonella, Domestic pigeons, Zoo, Quetzaltenango 


\section{Introducción}

El género Salmonella pertenece al orden Enterobacteriales y a la familia Enterobacteriaceae que incluye más de 2,300 serotipos. (Herrera, 2015) Investigaciones han estimado que la infección por Salmonella causa 2.8 mil millones de casos de diarrea anualmente en todo el mundo. Se ha informado que Salmonella enterica serovar Typhi (S. Typhi), causa entre 16 y 33 millones de casos infecciosos, con un estimado de 500,000 a 600,000 muertes, mientras que las infecciones por Salmonella no tifoidea (NTS) representan 90 millones de casos y 155000 muertes en todo el mundo anualmente (Abraham, 2018). En los centros de control y prevención de enfermedades se ha estimado que hay aproximadamente 74, 000 casos de salmonelosis asociados a reptiles o anfibios cada año en los Estados Unidos (Bauwens, 2005).

Las aves domésticas y otras especies aviares constituyen el más grande reservorio de Salmonella en la naturaleza, así mismo puede estar presente en animales sanos o enfermos sin el acompañamiento de un cuadro clínico (Herrera. Yonairo, 2015).

Salmonella, es considerada la zoonosis con mayor importancia en las enfermedades bacterianas capaz de ser transmitidas por la paloma doméstica. (González-Acuña, 2007) La mayoría de palomas expuestas a la enfermedad, se recuperan completamente, ya sea mediante tratamiento o a través de mecanismos de defensa naturales (González-Acuña, 2007).

En el parque, Zoológico de Minerva, situado en Quetzaltenango se observa la proliferación de palomas domésticas, las cuales se aprovechan de la comida brindada a los animales mantenidos en cautiverio. Además, las palomas defecan dentro de las jaulas, comederos y/o bebederos, aumentando el riesgo de infección de salmonela a los animales de la colección. El objetivo del estudio fue determinar la prevalencia de Salmonella sp. En palomas domesticas en el parque Zoológico Minerva en la Ciudad de Quetzaltenango, a través del método de aglutinación rápida en placa

\section{Materiales y métodos Área de estudio}

El estudio se realizó en el parque zoológico minerva que se encuentra en la ciudad de Quetzaltenango, localizada a los $14^{\circ} 50^{\prime} 40^{\prime \prime}$ de latitud Norte y $91^{\circ} 30^{\prime} 05^{\prime \prime}$ de longitud oeste, a $206 \mathrm{~km}$ al Noroeste de la ciudad de Guatemala. La ciudad se encuentra ubicada en un valle montañoso en el altiplano occidental con una altitud media sobre el nivel del mar de 2333 metros. Posee tres clases de bosques: latifoliado con 299.72 hectáreas, bosque conífero con 18.88 hectáreas y bosque mixto con 683.38 hectáreas. (Orantes, 2014)

\section{Criterio de inclusión}

Treinta palomas capturadas destinadas a eutanasia como método de control de plagas, sin importar rango edad o sexo.

\section{Técnica de captura}

El parque zoológico minerva realiza controles de plagas (roedores, aves) cada seis meses como una medida para reducir los problemas que las plagas producen. Se utilizaron dos métodos de captura: 1) una canasta de mimbre, un palo de madera, y se colocara alimento para pollos como cebo; y 2) una trampa de red de caída. 


\section{Pesaje}

Se utilizó una balanza electrónica para obtener el peso en gramos de las palomas capturadas.

\section{Toma de muestra}

Se utilizó una jeringa de $3 \mathrm{ml}$ con una aguja 23G para la obtención de sangre de la vena ulnar, humedeciendo el área con alcohol; la sangre se colocó en tubos al vació sin anti coagulante. Luego se separó el suero del coagulo centrifugándolo a 4,000 rpm por cinco minutos, colocándolo en viales de eppendorf para evitar hemolisis.

\section{Técnica de Eutanasia}

Luego de la toma de muestra se administró pentobarbital a dosis de $4 \mathrm{mg}$ por kilo de peso vivo por vía intravenosa en la vena ulnar.

\section{Traslado de la Muestra}

Se enviaron las muestras en una hielera de plástico con hielo seco a una temperatura de cuatro grados centígrados para mantener la cadena de frio, al Laboratorio Regional De Referencia De Sanidad Animal (LARSSA) que se encuentra ubicado en la ciudad de Guatemala.

\section{Procesamiento de la muestra}

Para determinar la presencia de Salmonella sp. en el suero se empleó la prueba de aglutinación rápida en placa.

\section{Resultados y discusión}

En este estudio no se detectó anticuerpos séricos contra Salmonella sp. en ninguna de las 30 muestras de paloma doméstica. Uno de los factores que puede estar asociado en obtener resultados negativos es que la prueba de aglutinación rápida en placa presenta bajos porcentajes de sensibilidad (70.58\%) y especificidad (83.34\%) (Torre-Cisneros, 2010). El fundamento de la prueba se basa en la formación y reconocimiento de complejos antígeno-anticuerpo (Tizard, 2009). Por lo cual si las palomas no han cursado la enfermedad no presentaran anticuerpos contra Salmonella sp.

comportamiento de cada enfermedad en una población depende de múltiples factores, que se han clasificado en tres grandes grupos: factores del propio agente biológico, del medio ambiente y del hospedero. (Marlen Barreto, 2016).

El peso promedio de las palomas domesticas muestreadas fue de 320 gramos, siendo el peso más bajo 210 gramos y el máximo 423 gramos. En la evaluación física presentaban una condición corporal promedio 4 de 9 , según la tabla de índice de condición corporal (BCS). Lo cual puede relacionarse a que tengan un estado inmunitario adecuado y por lo cual no hayan manifestado la enfermedad.

\section{Bibliografía}

Abraham, M. G. T. V. Y. N. D., 2018. Salmonella infection - prevention and treatment by antibiotics and probiotic yeasts: a review. Microbiology Society.

Bauwens, F.-M. S. d. C., 2005. Isolation of salmonella from enviromental samples collected in the reptile department of antwerp zoo using different selective methods, s.l.: Journal of applied microbiology. 
González-Acuña, F. S. G. L. M. S. F. C. L. D. E. J. C. C. y. J. L. M., 2007. Detección de algunos agentes zoonóticos en la paloma(Columbia livia) en la ciudad de Chillán, Chile, Chillan, Chile: Revista chilena de infectologia.

Herrera. Yonairo, M. P. A. S. A. J., 2015. Psitacosis y Salmonelosis: Zoonosis que involucran a las aves. Revista colombiana de Ciencia animal, p. 108.

Herrera, B. Y. J. R. L., 2015. Salmonelosis, zoonosis de las aves y una patogenia muy particular, s.I.: Revista Electronica Veterinaria.
Marlen Barreto, M. C.-R. R., 2016. Salmonella enterica: una revisión de la trilogía agente, hospedero y ambiente, y su trascendencia en Chile, Chile: Infectologia al dia.

Orantes, M. r. m., 2014. Organizacion Empresarial(produccion de maiz), Quetzaltenango: s.n.

Tizard, I. R., 2009. Veterinary Immunology. Missouri: octava edicion.

Torre-Cisneros, R. J. J. C. A. M. A. D. D. R., 2010. Fiebre tifoidea y otras infecciones por salmonella, Cordoba,España: Unidad de Gestión Clínica de Enfermedades Infecciosas.

\section{Sobre autor}

\section{Victor Andrés Amado Soto}

Ejerce como asistente veterinario en el Parque Nacional Zoológico La Aurora, en Guatemala. Estudió la licenciatura de medicina veterinaria en la Universidad de San Carlos de Guatemala (USAC). Realizó su Ejercicio Profesional Supervisado (EPS) en el Parque Zoológico Minerva, en Quetzaltenango, Guatemala. También ha cursado diplomados en línea sobre el manejo, cirugía y medicina interna de animales exóticos y silvestres en el Instituto Mexicano de Fauna Silvestre y Animales de compañía (IMFAC), asimismo realizó prácticas en el Grupo de Rehabilitación Fauna Autóctona y su hábitat (GREFA) en Madrid, España.

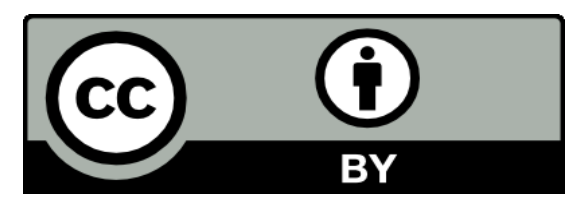

Este texto está protegido por una licencia CreativeCommons 4.0.

Esta licencia permite que otros distribuyan, mezclen, adapten y desarrollen su trabajo, incluso comercialmente, siempre y cuando le den crédito por la creación original. 


\section{Estrategias de enseñanza utilizadas en estudiantes en programas de equivalencias integrales}

\section{Teaching strategies used in students in comprehensive equivalency programs}

Como citar el artículo

Estrada, A. (2020). Estrategias de enseñanza en estudiantes en programas de equivalencias integrales. Revista Naturaleza, Sociedad y Ambiente, 7 (1), 57-70. DOI: https://doi.org/10.37533/cunsurori.v7i1.52

\section{Adán Estrada Chávez}

\section{Centro Universitario de Sur Oriente, Universidad de San Carlos de Guatemala}

Recibido: 17 de abril de 2020 / Aceptado: 11 de agosto de 2020

Disponible en internet el 10 de noviembre de 2020

*Autor para correspondencia, correo electrónico: adane01@yahoo.com

\section{Resumen}

Con el objetivo de establecer si en los procesos educativos se utilizan metodologías con enfoque andragógico o basadas en una teoría pedagógica conductista, que se caracteriza por el desarrollo de la relación docente-estudiante de forma vertical, que conlleva la realización de clases de tipo magistral o conferencias, planes de estudio rígidos, prácticas docentes tradicionales sustentadas en procesos educativos descendentes, que no permiten la participación de los estudiantes (Gamboa y Flores 2018), se procedió a investigar cuáles son las estrategias que se utilizan en la enseñanza de los estudiantes, en programas de equivalencias integrales, como modalidad de egreso de la universidad. Se utilizó el método de estudio de casos, el cual permitió construir la realidad tal como la observan los participantes en programas universitarios de equivalencias integrales, por medio de este método se analizaron los tipos de estrategias que se utilizan en la enseñanza de los estudiantes. Los resultados de la investigación aportan respuestas evidentes al objetivo planteado, debido a la aplicación de instrumentos en las diferentes fases de la investigación, lo cual permitió que las conclusiones proporcionaran un panorama que ayuda a visualizar de forma clara el proceso educativo en estos programas.

Palabras clave: estrategia, técnica, enseñanza, aprendizaje, programa

\section{Abstract}

With the objective of establishing whether in the educational processes methodologies with an andragogic approach or based on a behavioral pedagogical theory are used, which is characterized by the development of the teacher-student relationship in a vertical way, which entails the realization of master-type classes or conferences, rigid curricula, traditional teaching practices based on descending educational processes, which do not allow student participation (Gamboa y Flores 2018), We proceeded to investigate what are the strategies used in the teaching of students, in programs of integral equivalences, as a modality of graduation from the university. The case study method was used, which allowed the construction of reality as observed by the participants in university programs of integral equivalences, through this method the types of strategies used in teaching students were analyzed. The results of the research provide clear answers to the objective, due to the application of instruments in the different phases of the investigation, which allowed the conclusions to provide a panorama that helps to clearly visualize the educational process in these programs.

Keywords: reli Strategy, technique, teaching, learning, program 


\section{Introducción}

En varias universidades en la actualidad se enseña utilizando metodologías tradicionales que no estimulan el interés del estudiante y no consienten la participación de este en su proceso educativo, además, los estudiantes con cierre de pensum a nivel licenciatura se enfrentan a varias dificultades que no permiten que concluyan su proceso de titulación; esta situación trae como consecuencia el surgimiento de nuevas modalidades de egreso, como los programas de equivalencias integrales, ofrecidos por algunas universidades, con el objetivo de titular a los estudiantes a nivel licenciatura, por lo tanto, es importante establecer las estrategias que se utilizan en estos programas.

La educación superior por el interés que representa, demanda que en el proceso educativo se utilicen estrategias y técnicas adecuadas para la transferencia del conocimiento a los estudiantes. Derivado de la aplicación en el proceso educativo de nuevas tecnologías y a la implementación de nuevas modalidades de egreso, como los programas de equivalencias integrales, se hace necesario que en los procesos de enseñanza-aprendizaje del nivel superior, especialmente en los nuevos programas de egreso, que estos estén orientados hacia una metodología andragógica.

La investigación tiene como objetivo determinar las estrategias que se utilizan en la enseñanza de los estudiantes con cierre de pensum del nivel licenciatura, en programas de equivalencias integrales para concluir su formación profesional, por lo tanto, los resultados muestran la utilización de una variedad de metodologías, adicional, proporcionan información que ayuda a orientar las prácticas docenes hacia un enfoque andragógico, el cual puede ser utilizado desde la formulación de las planificaciones educativas.

\section{Marco teórico}

\section{Técnicas de estudio}

Las técnicas son actividades o acciones que se desarrollan en forma ordenada, para fortalecer, mejorar y ayudar a los estudiantes en su proceso de aprendizaje en las aulas, con lo cual se pretende potencializar las habilidades de los participantes en los salones de clase. Las técnicas también pueden considerarse como herramientas valiosas para realizar evaluaciones o autoevaluaciones de forma periódica, con el fin de establecer los avances de lo aprendido en los salones de clase. Las técnicas varían dependiendo de los contenidos impartidos en el curso, las metas que se deseen lograr, las limitaciones físicas y los conocimientos previos de los estudiantes (Crispín et al., 2012).

Desde otro punto de vista, se puede decir que las técnicas son todas aquellas acciones realizadas específicamente por los estudiantes en el desarrollo de su proceso educativo, pero que no son de su uso exclusivo. Las técnicas en muchos casos son utilizadas de forma mecánica por los estudiantes, lo que significa que, en el proceso de aprendizaje, se hace uso de dichas herramientas de forma automática, o dicho de otra marera, se utilizan determinadas técnicas de estudio por costumbre. Por medio de las técnicas los estudiantes se van apropiando de los procedimientos, con el fin de lograr el desarrollo y mejoramiento de sus habilidades (Molina y Lovera, 2008). 


\section{Clase magistral}

Esta técnica presenta significativas ventajas, dentro de las cuales están: Permite la enseñanza a grupos grandes, facilita la programación del tiempo del profesor, es barata, es muy conocida tanto por los docentes como por los estudiantes, los conocimientos se pueden transmitir de forma sistemática y rápida. Dentro de sus desventajas se encuentra que la atención de los estudiantes sólo se puede mantener por períodos cortos de tiempo, lo que provoca que los estudiantes se desconecten y dejen de poner atención. La clase magistral puede ser usada en los procesos educativos, pero no debería de ser la única actividad desarrollada como parte del proceso de enseñanza-aprendizaje (Lujan, 2013).

\section{Diálogos simultáneos}

Esta técnica se puede utilizar como apoyo a otras técnicas que necesiten una conversación previa, también puede ser utilizada de forma aislada. La participación del docente consiste en comunicar el tema, coordinar el tiempo, indicar el final del diálogo y solicitar las respuestas. En la aplicación de la técnica se procede a realizar una rueda de intervenciones, con el fin de aportar ideas que enriquezcan el tema tratado. Es útil para determinar los conocimientos previos, ayuda en la autoevaluación y la evaluación de los estudiantes. Permite que los estudiantes intervengan desde el inicio de la exposición del docente, es importante que no se abuse de su utilización (Herrán, 2011).

\section{Lluvia de ideas}

La técnica se caracteriza por ser creativa, flexible y espontánea, se utiliza en muchos casos para incentivar la reflexión y la reso- lución de problemas, en esta actividad no es aceptable la represión, reproche o rechazo, durante el espacio de la generación de las ideas, sino hasta que se ha finalizado con la producción de estas. La clave de esta técnica es su poder común, que quiere decir, el poder del grupo ejercitado libremente. Esta técnica tiene como propósito desarrollar en los estudiantes una actitud de exploración de argumentos, que sirvan para resolver determinadas situaciones. Con la lluvia de ideas se pretende potencializar la imaginación, la inteligencia e incentivar una actitud crítica (Prado, 2001).

\section{Trabajo en equipo}

Dentro de las características del trabajo en equipo se encuentra la colaboración, que significa aprender mediante un grupo de trabajo, en vez de realizar las tareas de forma individual. El aprendizaje en los grupos de trabajo consiste en que dos o más estudiantes comparten equitativamente la carga de trabajo, mientras avanzan hacia los resultados deseados. El objetivo principal de los equipos de trabajo en las aulas, es el de aumentar el rendimiento académico de los estudiantes, además, que muestren constancia y actitudes favorables al proceso de aprendizaje. Con esta técnica se benefician todos los estudiantes, tanto los que están en la etapa avanzada como los rezagados (Barkley et al., 2008).

\section{Foro}

Es una conversación abierta, se parte de un tema, que posteriormente se dialoga. El proceso debe ser moderado por un participante, quien fungirá como coordinador, además, se debe elegir un secretario quien llevará el orden de los participantes y realizará las anotaciones necesarias (Herrán, 2011). Los foros 
proporcionan los siguientes beneficios: a) Facilitan la solución de problemas, ya que se abordan de forma grupal; b) Permiten mejorar la habilidad de comunicación; c) Propicia que los participantes mantengan un papel activo durante el proceso educativo; d) Incrementan el número, así como la calidad de las intervenciones; y e) Desarrolla habilidades sociales (Castro et al., 2016).

\section{Seminario}

Consiste en realizar un estudio intenso sobre un tema determinado, los grupos trabajan de forma cooperativa, además, todos se encuentran al mismo nivel, su fin es intercambiar conocimientos y experiencias, posteriormente se presentan las conclusiones. Entre los objetivos del seminario están: Incentivar la lectura, examinar e integrar la información, que posteriormente se presenta por medio de una conferencia. El seminario puede ser aplicado por el docente como parte de su programa, quien debe participar como moderador. El seminario se puede utilizar para ampliar información a profundidad, generando con ello la especialización sobre un área determinada (Rodríguez, 2007).

\section{Estudio de caso}

El objetivo de esta técnica es que los estudiantes a partir de una situación aprendan a resolver circunstancias complejas, por medio de la indagación y el análisis de diversos puntos de vista. En esta técnica el docente debe: a) Fomentar el trabajo en equipo, debe propiciar en el aula un ambiente de colaboración de manera que los estudiantes puedan ayudarse en la solución del caso en cuestión; b) Facilitar la consulta; c) Ayudar a organizar la información; d) Ofrecer o proponer alternativas a los casos planteados; y e) Promover la exposición de resultados, es importante que al finalizar el estudio del caso, los estudiantes puedan presentar sus conclusiones (Aramendi et al., 2014).

\section{Aprendizaje basado en problemas}

En esta técnica el aprendizaje de los estudiantes se favorece enormemente con la interacción social, ya que el estudiante por medio de los problemas planteados en clase se dedica a la investigación, observando su comunidad con relación a la búsqueda de soluciones a los problemas. A partir de la implementación de esta técnica se puede mejorar la calidad del aprendizaje en diversos aspectos, entre las competencias que esta técnica ayuda a desarrollar se enfatizan las siguientes: a) Capacidad de resolución de problemas; b) Toma de decisiones; c) Trabajo en equipo; d) Habilidades de comunicación, tanto oral como escrita; y e) Desarrollo de actitudes de revisión (Bernabeu y Folch, 2013).

\section{Foros de debate virtual}

Estos foros son utilizados como herramienta en el proceso educativo, ya que permiten que los estudiantes articulen sus ideas y opiniones, con lo cual se pretende que el aprendizaje se realice desde varias formas de interacción. Dentro de los aportes de esta técnica se tiene el intercambio de trabajos académicos y la colaboración. Los foros hacen que la labor educativa se vuelva más dinámica, lo cual estimula la revisión diaria de las actividades a desarrollar, que trae como consecuencia dedicación a la formación. Esta técnica permite que se pueda participar en las discusiones, expresar inquietudes, con el propósito de recibir mayor información que en los espacios presenciales (Arango, 2011). 


\section{Estrategias}

La estrategia es un conjunto de acciones planificadas que integran los principales objetivos que se desean alcanzar, establece una secuencia coherente con las acciones a realizar, ayudando a poner en orden los recursos de una institución, con el fin de lograr una situación factible, además, define una base continua, con propósitos ampliamente concebidos. Las estrategias se pueden considerar de forma previa, como guías para la acción, que pueden permitir al docente organizar su plan de estudio con el fin de fortalecer las competencias de los estudiantes y que le pueda servir de guía en la implementación de las diferentes acciones a desarrollar dentro de los salones de clase (Mintzberg et al., 1998).

\section{Mapa mental}

Es una estrategia que persigue que los conocimientos adquiridos sean representados de forma gráfica, lo que proporciona una salida adecuada para los participantes al momento de expresar lo aprendido en los salones de clase. La estructura de los mapas mentales se compone de una imagen central, símbolos y palabras que se enlazan. Con la ayuda de los mapas mentales se puede convertir una larga lista de datos, en un diagrama ordenado, fácil de recordar, permitiendo con ello, que se tenga congregada una gran cantidad de información. La estrategia ayuda a organizar con facilidad los pensamientos y a utilizar al máximo la capacidad mental (Buzan, 2004).

\section{Mapa conceptual}

Esta estrategia se puede iniciar con una lluvia de ideas, la cual nace del estudio de un concepto determinado, que posteriormente se ordena de forma lógica y jerarquizada. Los mapas conceptuales son representaciones abreviadas y externas de un objeto o fenómeno de estudio, que ayudan al aprendizaje de los temas, que pueden plasmarse de diversas formas, por ejemplo: El modelo del sistema solar, los modelos económicos, etc. Los estudiantes en varios casos generan mapas mentales a partir de mapas o modelos conceptuales que les sean proporcionados por los docentes para desarrollar determinada tarea (Greca, 1997).

\section{Ensayo}

Se puede considerar como el instrumento en donde los estudiantes plasman sus opiniones o ideas personales sobre un tema polémico. Es a través de un ensayo que los estudiantes respaldan por medio de argumentos válidos su posición frente a un tema de actualidad. Los ensayos requieren de un alto nivel de reflexión, con el fin de generar ideas de alta calidad, las cuales se deben pulir, pensar y articular, para luego ser trasladadas de forma escrita, dicho en otras palabras, los ensayos representan no solo la posibilidad de aprender a pensar, sino de aprender a hablar y defender posiciones académicas (Alzate, 2009).

\section{El portafolio}

Se puede considerar como una herramienta que permite presentar el progreso logrado por los participantes durante el proceso educativo, además, estimula la experimentación, la reflexión, la investigación e incentiva el diálogo en la resolución de los problemas. Los portafolios contienen los logros alcanzados durante la formación educativa, presenta los temas investigados y las etapas del proceso de aprendizaje. Los docentes al utilizar esta estrategia deben ayudar a los estudiantes 
al momento de crear, analizar y valorar las áreas principales que forman parte de los portafolios, ya que esto les servirá para que posteriormente puedan realizar sus propias autoevaluaciones (Agra et al., 2003).

\section{Línea de tiempo}

Esta estrategia facilita la presentación visual de la información que se desea trasladar a los estudiantes en los salones de clase. Comúnmente las líneas de tiempo se representan por líneas rectas en las cuales se establecen de forma ordenada las fases de un proceso o hecho histórico. Una de las funciones de las líneas de tiempo es organizar y ordenar de forma visual una serie de eventos o hechos que requieren de un orden histórico, de manera que se pueda de forma visual tener acceso a la información. Las líneas de tiempo proporcionan una estructura lógica de los acontecimientos, y muestran de forma secuencial la temática abordada en las asignaturas (Villalustre y Del Moral, 2010).

\section{Infografía}

Se compone de elementos visuales que contribuyen a un despliegue de imágenes que representan la información que se desea abordar en los salones de clase. Las infografías son útiles para trasladar temas que tienen cierta complejidad, por lo tanto, se pretende brindar por medio de gráficos, imágenes y figuras, una exposición amigable que interese a los participantes. Entre las funciones de la infografía está el de trasmitir el conocimiento de manera clara, precisa y coherente, por medio de un lenguaje visual. La infografía acelera los procesos de compresión, debido a que utiliza menos cantidad de texto, lo que representa una mayor cantidad de información gráfica (Aguirre et al., 2014).

\section{Mentefacto}

Esta estrategia está compuesta por esquemas de pensamiento que se expresan a través de un ideograma, por ejemplo, las señales de tránsito, cuya finalidad básica es servir para el aprendizaje vial. Se puede decir que son diagramas que representan un concepto. Entre las ventajas de esta estrategia se destacan las siguientes: Incluye formas gráficas muy clarificadas, puede servir de guía en el aprendizaje, consigue ayudar a comprender y recordar (Herrán, 2011). Estos esquemas son una herramienta que permite representar el conocimiento propio de los conceptos, por medio de la utilización de bosquejos que condensan el conocimiento que se tiene sobre una noción (Vega, 2005).

\section{Metodología}

La investigación es de carácter cualitativa, el método de investigación empleado es el estudio de caso, el cual permitió determinar las estrategias que se utilizan en el proceso educativo de los estudiantes. Los sujetos de estudio que se tomaron fue el universo de docentes y estudiantes, que se encuentra en programas de equivalencias integrales, en la Universidad Panamericana, del Departamento de El Progreso. Las técnicas empleadas en el análisis de la información son las que se detallan a continuación: a) Encuesta; b) Revisión bibliográfica; y c) Observación. Los instrumentos empleados en la investigación son: Cuestionario y block de notas. 


\section{Resultados y discusión}

Resultados de la encuesta aplicada a estudiantes

Figura No. 1 Estrategias que se utilizan en los programas de equivalencias integrales

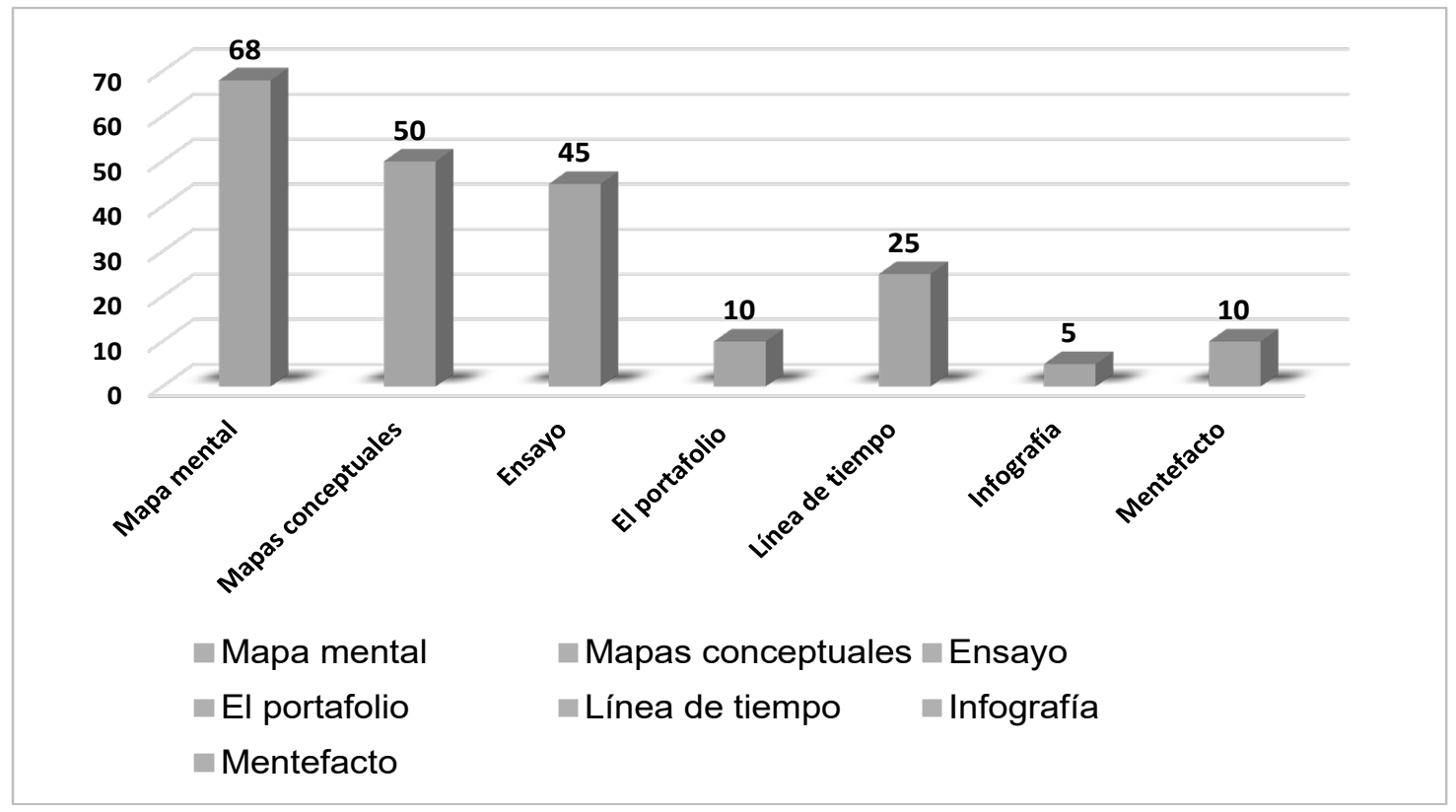

Fuente: Investigación de campo, año 2019.

Al analizar los resultados de la gráfica 1 se puede establecer que en los procesos educativos de los estudiantes se utilizan estrategias andragógicas en los salones de clase, al momento de que estos reciben sus respectivos cursos, tal como lo muestran los porcentajes siguientes, ordenados de mayor a menor de acuerdo a la frecuencia en los estudiantes: Mapa mental con $68 \%$, mapas conceptuales con $50 \%$, ensayo con $45 \%$, línea de tiempo con $25 \%$, el portafolio con $10 \%$, mentefacto $10 \%$ e infografía con $5 \%$. Esto permite establecer que los estudiantes en programas de equivalencias integrales, están conscientes de la implementación de estrategias andragógicas en su proceso formativo.

Este resultado viene a confirmar lo que dice Montes (2011), las estrategias se utilizan con mayor fuerza en los procesos educativos, por ello la necesidad de que los docentes dentro de sus planificaciones las incluyan, con el fin de potencializar el aprendizaje, lo cual está en acuerdo con Mintzberg (1998), que dijo que la estrategia es un plan que integra las principales metas de una institución y, a la vez, establece la secuencia coherente de las acciones a realizar, asimismo, otro autor como Acuña (2004), que dijo que los mapas mentales como estrategia ayudan a enfrentar de una manera diferente los procesos educativos. 
Figura No. 2 Técnicas de estudio que se utilizan en los programas de equivalencias integrales

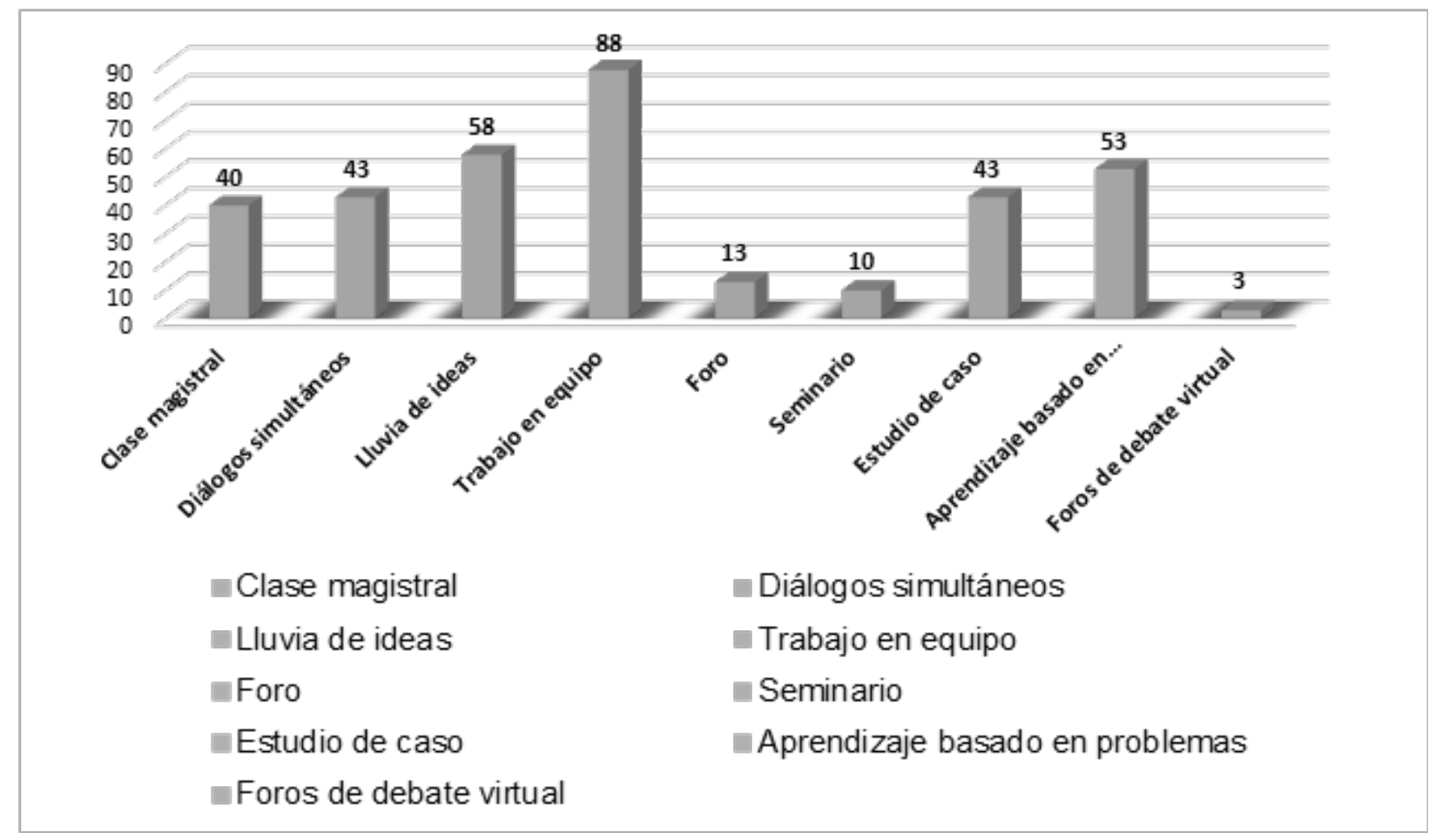

Fuente: Investigación de campo, año 2019.

Al analizar los resultados de la gráfica 2 se tiene, en primer lugar, la resolución de que en el proceso educativo de los estudiantes se aplican las técnicas andragógicas al momento de que estos reciben sus cursos, tal como lo muestran los porcentajes siguientes, ordenados de mayor a menor de acuerdo a la frecuencia en los estudiantes: Trabajo en equipo con $88 \%$, lluvia de ideas con $58 \%$, aprendizaje basado en problemas con $53 \%$, diálogos simultáneos con $43 \%$, estudio de caso con $43 \%$, clase magistral con $40 \%$, foro con $13 \%$, seminario con $10 \%$ y foros de debate virtual con $3 \%$.

Este resultado viene a confirmar lo que dice Crispín (2012), las técnicas son actividades o acciones que se desarrollan en forma ordenada, para ayudar a los estudiantes en su proceso de aprendizaje, y con ello potencializar sus habilidades, asimismo, otros autores como Molina y Lovera (2008), que dicen que las técnicas son los medios por los cuales los estudiantes se apropian de los procedimientos, con el fin de lograr el desarrollo de sus habilidades, lo cual está en acuerdo con Lujan (2013), cuando habla de la clase magistral, que puede ser usada en los procesos educativos, pero no debería de ser la única actividad desarrollada como parte del proceso de enseñanza-aprendizaje. 


\section{Resultados de la encuesta aplicada a docentes}

Figura No. 3 Las estrategias que se utiliza en el desarrollo de los programas de equivalencias integrales

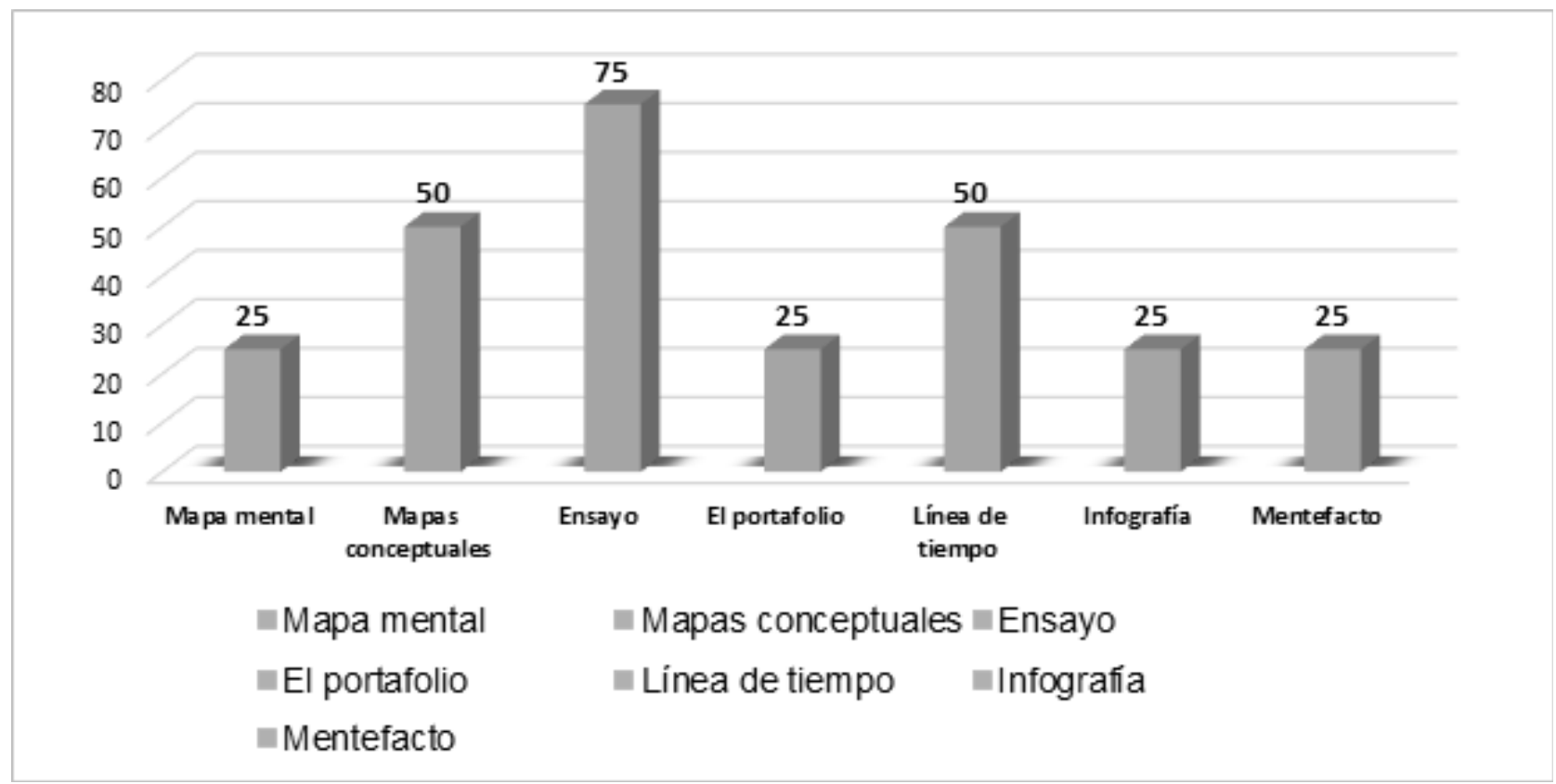

Fuente: Investigación de campo, año 2019.

Al analizar los resultados de la gráfica 3 se tiene, en primer lugar, la resolución de que el docente universitario utiliza estrategias andragógicas al impartir sus cursos, como lo muestran los porcentajes siguientes, ordenados de mayor a menor de acuerdo a la frecuencia en los docentes: Ensayo con $75 \%$, mapas conceptuales con $50 \%$, línea de tiempo con $50 \%$, mapa mental con $25 \%$, el portafolio con $25 \%$, mentefacto con $25 \%$ e infografía con $25 \%$. Esto permite establecer que los docentes universitarios en programas de equivalencias integrales, están conscientes de la importancia de la aplicación de estrategias con un enfoque andragógico en el proceso educativo.

Este resultado viene a confirmar lo que dice Montes (2011), las estrategias se utilizan con mayor fuerza en los procesos educativos, por ello la necesidad de que los docentes dentro de sus planificaciones las incluyan, con el fin de potencializar el aprendizaje, lo cual está en acuerdo con Mintzberg (1998), que dijo que la estrategia es un plan que integra las principales metas de una institución y, a la vez, establece la secuencia coherente de las acciones a realizar, asimismo, otro autor como Acuña (2004), que dijo que los mapas mentales como estrategia ayudan a enfrentar de una manera diferente los procesos educativos. 
Figura No. 4 Técnicas de estudio que se utilizan en los programas de equivalencias integrales

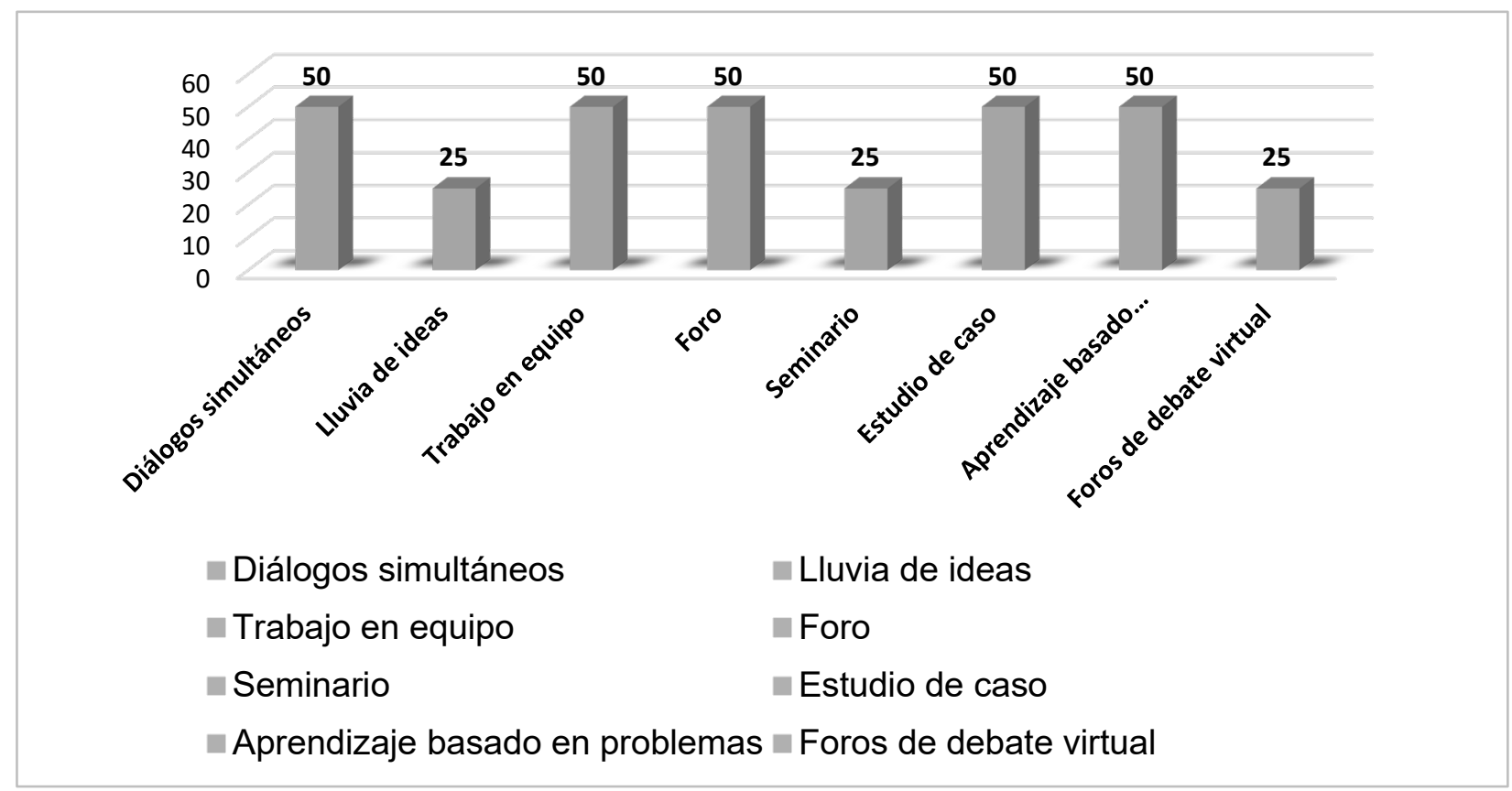

Fuente: Investigación de campo, año 2019.

Al analizar los resultados de la gráfica 4 se tiene, en primer lugar, la resolución de que el docente promueve la utilización de técnicas andragógicas al impartir sus cursos, como lo muestran los porcentajes siguientes, ordenados de mayor a menor de acuerdo a la frecuencia en los docentes: Clase magistral con $100 \%$, diálogos simultáneos con $50 \%$, trabajo en equipo con $50 \%$, foro con $50 \%$, estudio de caso con $50 \%$, aprendizaje basado en problemas con $50 \%$, lluvia de ideas con $25 \%$, seminario con $25 \%$ y foros de debate virtual con $25 \%$. Esto permite establecer que los docentes en programas de equivalencias integrales, están implementando técnicas con una orientación andragógicas.

Este resultado viene a confirmar lo que dice Crispín (2012), las técnicas son actividades o acciones que se desarrollan en forma ordenada, para ayudar a los estudiantes en su proceso de aprendizaje, y con ello potencializar sus habilidades, asimismo, otros autores como Molina y Lovera (2008), que dicen que las técnicas son los medios por los cuales los estudiantes se apropian de los procedimientos, con el fin de lograr el desarrollo de sus habilidades, lo cual está en acuerdo con Lujan (2013), cuando habla de la clase magistral, que puede ser usada en los procesos educativos, pero no debería de ser la única actividad desarrollada como parte del proceso de enseñanza-aprendizaje. 


\section{Análisis y discusión de resultados}

Del análisis de los resultados de las encuestas a los estudiantes, se obtuvieron las estrategias que se implementan en clase, siendo estas: Mapa mental con $68 \%$, mapas conceptuales con $50 \%$, ensayo con $45 \%$, línea de tiempo con $25 \%$, el portafolio con $10 \%$, mentefacto $10 \%$ e infografía con $5 \%$; por otra parte, de las encuestas a los docentes se obtuvieron las estrategias que aplican en clase, y son: Ensayo con $75 \%$, mapas conceptuales con $50 \%$, línea de tiempo con $50 \%$, mapa mental con $25 \%$, el portafolio con $25 \%$, mentefacto con $25 \%$ e infografía con $25 \%$. Esta información al contrastarla se obtiene que tanto docentes como estudiantes concuerdan con las estrategias que se desarrollan en clase.

La técnica de la observación permitió realizar un contraste entre los diferentes resultados que se obtuvieron, de los dos sectores encuestados, por lo tanto, se establece que no hubo discrepancias entre lo indicado por los estudiantes y docentes, ya que se pudo comprobar por medio de la observación que los docentes en los salones de clase, con los estudiantes que se encuentran en programas de equivalencias integrales, aplican estrategias andragógicas y no metodologías tradicionales.

De los resultados de la encuesta a los estudiantes se obtuvieron las técnicas que se han desarrollado en clase, entre ellas están: Trabajo en equipo con $88 \%$, lluvia de ideas con $58 \%$, aprendizaje basado en problemas con $53 \%$, diálogos simultáneos con $43 \%$, estudio de caso con $43 \%$, clase magistral con $40 \%$, foro con $13 \%$, seminario con $10 \%$ y foros de debate virtual con $3 \%$; por parte de los docentes se obtuvieron las técnicas que utilizan en clase, siendo estas: Clase magistral con
$100 \%$, diálogos simultáneos con $50 \%$, trabajo en equipo con $50 \%$, foro con $50 \%$, estudio de caso con $50 \%$, aprendizaje basado en problemas con $50 \%$, lluvia de ideas con $25 \%$, seminario con $25 \%$ y foros de debate virtual con $25 \%$.

La técnica de la observación permitió realizar un contraste entre los diferentes resultados que se obtuvieron, de los dos sectores encuestados, por lo tanto, se establece que no hubo discrepancias entre lo indicado por los estudiantes y docentes, ya que se pudo comprobar por medio de la observación que los docentes en los salones de clase, con los estudiantes que se encuentran en programas de equivalencias integrales, aplican técnicas andragógicas y no modelos tradicionales.

Todo lo anterior se comprobó al momento de realizar visitas a los salones de clase, en donde se desarrollaban los programas de equivalencias integrales con los estudiantes, en donde se logró observar y evidenciar que se realizaban discusiones, foros, lluvias de ideas, líneas de tiempo, mapas mentales, ensayos, infografías, etc., por lo tanto, se concluye, que los resultados son positivos, ya que concuerdan con los datos proporcionados por las encuestas de los dos sectores. Además, es importante hacer notar que dichas estrategias y técnicas fueron implementadas, acondicionándolas de acuerdo con la etapa adulta de los estudiantes.

En la investigación de las estrategias y técnicas que se utilizan en los programas de equivalencias integrales, se considera satisfactorio en relación con los objetivos planteados, tratándose de un tema interesante, de mucha importancia por el valor que representa para los docentes que deseen retroali- 
mentación. Se observó la implementación de las estrategias y técnicas en el proceso educativo, por parte de los docentes, así como la aceptación de estas por los estudiantes.

\section{Conclusiones}

Las estrategias utilizadas en el proceso de enseñanza-aprendizaje de los estudiantes, en programas de equivalencias integrales para concluir su formación profesional, son las que a continuación se enlistan: Mapa mental, mapa conceptual, ensayo, línea de tiempo, portafolio de evidencias, mentefacto e infografía.

Las técnicas de estudio que se utilizan o aplican en los procesos educativos de los estudiantes en programas de equivalencias integrales para concluir su formación profesional, son las siguientes: Trabajo en equipo, lluvia de ideas, aprendizaje basado en problemas, clase magistral, diálogos simultáneos, estudio de caso, foro, seminario y foros de debate virtual.

La investigación establece que en los programas de equivalencias integrales no siguen una metodología basada en una teoría pedagógica conductista, como única metodología para el proceso educativo, ya que en los salones de clase se llevan a cabo procesos educativos participativos, favoreciendo una educación basada en principios andragógicos.

\section{Agradecimientos}

Agradezco a Yeshúa (Jesús) por darme la vida, las fuerzas y los conocimientos, para llevar a cabo la investigación, a mi querida y amada esposa Rosbith Estefany Argueta Lima de Estrada por ser mi soporte y a mi hijo Adán Estrada Argueta por ser la alegría que me anima para seguir adelante. Además, agradezco a la Universidad de San Carlos de Guatemala, a todo el personal docente-administrativo de postgrados por ser los intermediarios del conocimiento.

\section{Referencias bibliográficas}

Acuña, L. (2004). "Los mapas mentales: ¿otra forma de aprender?". Revista Horizontes Pedagógicos, No. 01, pp. 40-46.

Agra, M.; A. Gewerc y L. Montero (2003). "EI portafolios como herramienta de análisis en experiencias de formación on line y presenciales". Revista Enseñanza \& Teaching, No. 21, pp. 1-09.

Aguirre, C.; E. Menjívar y H. Morales (2014). "Elaboración de infografías: Hacia el desarrollo de competencias del siglo XXI". Revista Día-logos 15, pp. 23-37.

Alzate, T. (2009). "Hay que enseñar a hacer ensayos". Revista Iberoamericana de Educación.

Aramendi, P. et al. (2014). "Estudio de caso y aprendizaje cooperativo en la universidad". Revista de Currículum y Formación del Profesorado, No. 01, pp. 413-429.

Arango, M. (2011). "Foros virtuales como estrategia de aprendizaje". Revista Comunidades Virtuales para la Formación de Maestros.

Barkley, E.; K. Cross, y C. Maior (2008). Técnicas de aprendizaje colaborativo. Madrid. Morata.

Bernabeu, M. y M. Folch (2013). "Innovación curricular con el aprendizaje basado en problema en estudios universitarios: Estudio de caso". Revista Docencia e Investigación, No. 23, pp. 7-21. 
Buzan, T. (2004). Como crear mapas mentales. Barcelona (España). Ediciones Urano.

Castro, N.; X. Suárez y V. Soto (2016). "El uso del foro virtual para desarrollar el aprendizaje autorregulado de los estudiantes universitarios". Revista Innovación Educativa, pp. 23-41.

Crispín, M. et al. (2012). Guía del docente para el desarrollo de competencias. México. IBERO.

Gamboa, I., y A. Flores (2018). Dimensión pedagógico-didáctica. Modelo educativo de la Universidad de San Carlos de Guatemala. Guatemala. Universidad de San Carlos de Guatemala.

Greca, I. (1997). "Modelos mentales, modelos conceptuales y modelización". Revista desarrollo docente.

Herrán, A. (2011). Técnicas didácticas para una enseñanza más formativa. Camagüey (Cuba). Universidad de Camagüey.

Lujan, S. (2013). "De la clase magisterial tradicional al MOOC". Revista de docencia Universitaria REDU.

Mintzberg, H.; J. Quinn y J. Voyer (1998). El proceso estratégico, conceptos, contextos y casos. México. Pearson, Prentice Hall.
Molina, D. y Z. Lovera (2008). "Significado que le otorgan los docentes a las estrategias de evaluación". Revista Ciencias y Cognicao, pp. 82-93.

Montes, N. (2011). "Estrategias docentes y métodos de enseñanza aprendizaje en educación superior". Revista Humanidades Médicas.

Prado, D. (2001). Torbellino de ideas por una educación participativa y creativa. Santiago de Compostela. Universidad de Santiago de Compostela.

Rodríguez, R. (2007). Compendio de estrategias bajo el enfoque por competencias. Sonora (México). Mexicana.

Vega, P. (2005). Gestión de aula experiencia del proyecto de mejoramiento, proceso de enseñanza - aprendizaje. Barranquilla (Colombia). Fundación Promigas.

Villalustre, L. y E. Del Moral (2010). "Mapas conceptuales, mapas mentales y líneas temporales". Revista Latinoamericana de Tecnología Educativa, pp. 15-27.

\section{Sobre autor}

\section{Adán Estrada Chávez}

Licenciado en Contaduría Pública y Auditoria, Maestro en Artes en Docencia Universitaria con Énfasis en Andragogía, egresado de la Universidad de San Carlos de Guatemala. Coordinador de Presupuesto de la Dirección Departamental de Educación El Progreso, docente de la Universidad Panamericana de Guatemala. Anteriormente docente del Centro Universitario de El Progreso, Universidad Da Vinci de Guatemala, Confederación Deportiva Autónoma de Guatemala. También ha ocupado los puestos de Directivo de la Cooperativa Guayacán RL, Auditor Interno de la Fundación Visión Mundial de Guatemala y Contador General de Plan Internacional Guatemala. Realizo la investigación Estrategias de enseñanza utilizadas en estudiantes en programas de equivalencias integrales. 


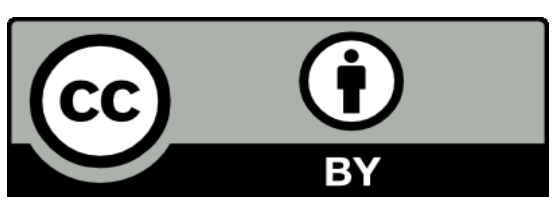

Este texto está protegido por una licencia CreativeCommons 4.0.

Esta licencia permite que otros distribuyan, mezclen, adapten y desarrollen su trabajo, incluso comercialmente, siempre y cuando le den crédito por la creación original. 


\title{
La ficción de método (reconstrucción del pasado) en Jinetes en el cielo del escritor guatemalteco, Mario Roberto Morales
}

\section{The fiction of method (reconstruction of the past) in Riders in the sky by the Guatemalan writer, Mario Roberto Morales}

Como citar el artículo

Alarcón, A. (2020). La ficción de método (reconstucción del pasado). Revista Naturaleza, Sociedad y Ambiente, 7 (1), 71-91. DOI: https://doi.org/10.37533/cunsurori.v7i1.53

\section{Daniel Alarcón Osorio}

\section{Facultad Latinoamericana de Ciencias Sociales (FLACSO), Argentina}

Recibido: 08 de abril de 2020 / Aceptado: 16 de julio de 2020

Disponible en internet el 10 de noviembre de 2020

*Autor para correspondencia, correo electrónico: dalarcon@fahusac.edu.gt

\begin{abstract}
Resumen
"El escritor que quiere decir el mundo se erige, a su manera, en investigador" (Jablonka, Introducción, 2016). " La tarea más urgente de la Crítica literaria actual es establecer las estrategias que ilustren las condiciones de comunicación entre la estructura material del texto y la de su constitución psicológica, imaginaria y sentimental, proyectada" (Antonio García Berrio, 2008). La literatura, es la postura ontológica y epistémica del escritor, cuya construcción cualitativa está fundamentada en y desde lo sociológico, antropológico, histórico y político. Jinetes en el cielo (Editorial Cultura, Guatemala, 2019), en las tres partes de la novela: El rumor de la noche. El tropel y la fuga. La luz en la sombra, desafía y cuestiona la veracidad relacionada y presentada a la sociedad guatemalteca sobre las negociaciones de los Acuerdos de Paz. Desafío que busca hacer comprender el presente y el pasado mismo que hacen presente y futuro, dentro de la sociedad guatemalteca producto del cuestionamiento que reclama lugar para el debate crítico-reflexivo y construcción de democracia y ciudadanía. La ficción de método o la reconstrucción del pasado, es la teoría postulada por Ivan Jablonka en La historia es una literatura contemporánea. Manifiesto por las ciencias sociales (FCE, Argentina, 2016), la cual es utilizada para el análisis de Jinetes en el cielo.
\end{abstract}

Palabras clave: literatura, ficción de método, reconstrucción, pasado

\section{Abstract}

"The writer who means the world becomes, in its own way, a researcher" (Jablonka, Introduction, 2016). "The most urgent task of current Literary Criticism is to establish the strategies that illustrate the conditions of communication between the material structure of the text and that of its projected psychological, imaginary and sentimental constitution" (Antonio Garcia Berrio, 2008). Literature is the writer's ontological and epistemic position whose qualitative construction is based on the sociological, anthropological, historical and political aspects. Riders in the Sky (Editorial Cultura, Guatemala, 2019), in the three the parts of the novel: The Rumour of the Night, The Throng and the Escape, The Light in the Shadow challenges and questions the veracity related and presented to Guatemalan society about negotiations of the Peace Accords. Challenge that seeks to make understand the past and the present that make present and future within Guatemalan society, product of the questioning that claims a place for critical-reflective debate and construction of citizenship. The fiction of method or the reconstruction of the past, theory postulated by Ivan Joblonka in the story is contemporary literature. Manifesto for the social sciences (FCE, Argentina, 2016), which is used for the analysis of Riders in the Sky.

Keywords: literature, method fiction, reconstruction, past 


\section{Introducción}

"Cada obra es una forma concreta de respuesta a solicitaciones de la realidad, producto de la vinculación del escritor con el medio" (Verdugo, 1984).

Toda lectura, de igual manera la escritura, convoca ejercicio crítico y del criterio, que al final de las páginas del género literario que se escriba o lea, el lector y escritor cuestionarán lo real, la realidad, lo simbólico, ya sea de forma inmediata a sí mismo, o de los otros, o de los propios registros de la Historia.

El siglo XXI, donde la inmediatez y la levedad de los hechos predomina, toda investigación relacionada con las ciencias sociales o las Humanidades, el especialista, debe contar con rigor académico y estar en la capacidad de construir puentes humanos y cognitivos dado que la literatura, la cultura y la educación, parten de supuestos éticos, estéticos y políticos., los cuales rigen dentro de la tradición social, cultural histórica, sin olvidar el necesario tránsito hacia y con las nuevas generaciones.

Cada generación debe y tiene que revalorizar, así como reinterpretar la historia y la literatura, con las luces y sombras de su propio aprendizaje, así como por sus propias experiencias, cuestionando al propio sistema educativo y sociedad a la que pertenece.

Si se ha dejado de recordar una fecha o hechos valiosos para la sociedad y todo es valorado a partir de su 'tendencia' en las deplorables redes sociales o a partir de su nula aparición en cualquier plataforma virtual, un estudio acerca de una obra literaria debe ser a la par de requisito de graduación, proyecto de investigación o artículo científico, una respuesta al analfabetismo cultural, político, histórico, estético y ético, al que toda una generación ha sido doblegada desde el pensamiento posmoderno y único como verdad absoluta.

Mario Roberto Morales, escritor guatemalteco, cuenta con una producción inicial marcada por la violencia ejercida por los regímenes dictatoriales de la segunda mitad del siglo XX. En sus primeras obras se escuchan ecos de la caída del gobierno democrático de Jacobo Árbenz. Hecho que desató años sombríos de la guerra interna para todos los sectores de la sociedad guatemalteca.

De esa cuenta, "la obra de Mario Roberto Morales, ha sido estudiada tomando en cuenta los acontecimientos históricos de la segunda mitad del siglo pasado o tomando como punto de referencia las manifestaciones estéticas de la literatura latinoamericana de la misma época" (Tohom, 2020).

\section{Historia, antropología, sociología, política = literatura}

"La obra literaria es en sí misma un agente y un artefacto de la historia, es en sí misma un acontecimiento histórico condicionado por circunstancias históricas, que también condiciona" (Zamora, Prefacio, 2004).

La literatura es un objeto social, de conocimiento y literario, cuyo aporte contribuye en la construcción social en la propia interrelación e interacción cultural y educativa desde lo local, nacional, mundial. 
A veces, los escritores han hecho transitar la literatura por caminos del arte por el arte, otras como el arte para el cambio social. Jinetes en el cielo, es literatura que propugna, cambio social.

En ese sentido, "la relación entre novela y política, o entre novela e historia, o realidad, difícilmente se agota en América Latina" (Ramírez, 2019). La relación entre novela y política y realidad, constituyen escenarios permanentes en la literatura guatemalteca.

Dentro de ese devenir e históricamente, "la narrativa ha sido una de las herramientas primarias del conocimiento y es la que determina la estructura y la forma en que se presentan los hechos reales o imaginarios, en otras palabras, la narrativa revela tanto la realidad histórica como la esfera de la ficción en la historia y en la literatura" (Fumero, 2004).

A través de la ficcionalización cuyos matices con sus diversas perspectivas humanas, son recogidos por el lenguaje narrativo, lugar desde donde el escritor enfrenta la historia local, nacional, mundial y circunstancias conexas, entre otros elementos de su interés, mediante la subjetividad, transubjetividad y objetividad, como hecho comunicativo y medio de conocimiento.

Con relación a la ficcionalización, de entrada, se hace necesario deshacer los dudosos conceptos de la misma, puesto que, "por lo común, suele cometerse a la hora de especificar la dimensión semántica de ficción. Las acepciones más comunes con que este término se define abundan en expresiones como "acción de fingir", "cosa simulada", "cosa inventada" o "imaginada" y, lo que es más grave, por este cauce se equipara la ficción con valores como "fantasía" o "ilusión", conceptos con los que, desde luego nada tiene que ver (a pesar de rótulos como "ciencia ficción", que ahondan aún más en la dimensión de lo maravilloso) (Redondo, Concepto de ficción, 1994).

En todas las culturas y sociedades, el ser humano construye narraciones cual modelos aclaratorios, interpretativos, hermenéuticos, para conocerse, analizarse, juzgarse, mediante la ficción. Papel determinante por la conjunción que se establece entre la historia y la literatura al compartir esfuerzos teóricos, metodológicos y epistémicos.

Es decir, la "ficción no es lo contrario a lo real, sino precisamente la imagen que de lo real puede constituirse. Es más: la ficción es la única imagen que de lo real puede constituirse. O lo que daría igual: a través de la ficción, el individuo puede ponerse en contacto con la realidad que le rodea" (Redondo, Concepto de ficción, 1994).

De igual forma el ser humano como sujeto social dentro de la sociedad, " (...) se constituyen inter-subjetivamente, en la constante exposición a la alteridad; esta inter-subjetividad sólo es posible en y por la comunicación, y esta comunicación, por ende, es esencialmente un intercambio de narrativas" (Benjamin, La catástrofe de la experiencia, 2008).

\section{La literatura: manifestación local, nacional, universal}

“(...) la literatura está dotada de una aptitud histórica, sociológica, antropológica" (Jablonka, Introducción, 2016). 
La literatura es la actividad artística e intelectual cuyos aportes representan universalidad del pensamiento, mediante obras literarias como testimonios culturales locales, nacionales, latinoamericanos, mundiales.

La llíada, La Odisea, El Quijote de la Mancha, Popol Vuh, el Rabinal Achí, El señor presidente, son algunos ejemplos concretos humanos, locales, nacionales, culturales, universales. Asimismo, dentro del sistema educativo, en el currículo, la literatura es un medio y herramienta importante de aprendizaje para el fortalecimiento de capacidades y habilidades en cuatro áreas para la vida: leer, escribir, hablar y escuchar, cuando ontológica, teórica, metodológica y epistémicamente es asumida como medio y no como fin.

Ganar y recuperar lectores para la vida, es determinante dentro de las instituciones educativas y culturales, sin importar si es primaria, básico, diversificado, Universidad.

Sin embargo, visiones decimonónicas son una constante dentro del sistema educativo por profesores y por las mismas autoridades educativas y culturales: $¡$ si no rima la poesía, no es poesía!; ¡si no tiene mensaje no es un cuento!, etc.; cuando el desarrollo de dichas capacidades y habilidades lo que persiguen es coadyuvar con el ser humano dentro de la sociedad como parte del código letrado.

Para muchos profesionistas de la cultura y educación, la literatura es solo arte; con lo cual se deja de distinguir el que la comprensión e interpretación de la realidad, contiene registros éticos, estéticos y políticos.
La estética se refiere no solo a "las emociones y las sensaciones, sino también a las ideas e incluso las acciones. Existe también una estética general, universal, filosófica. La estética aborda dos ámbitos: el de las obras concretas y el de las ideas" (Blanco, 2001).

\section{Qué es literatura}

"La literatura, como parte de la ideología, está claramente situada dentro de la superestructura de una formación social dada" (Liano, La literatura como arma ideológica, 1979).

Partir sobre lo que se entiende por literatura, se hace necesario: "La literatura es un hecho concreto humano, registro estético de las mentalidades, ideologías, culturas, situaciones y relaciones humanas en un momento histórico dado, por medio de la escritura" (Morales, Las palabras y los hechos. Curso de literatura hispanoamericana, 1994, 1994).

Es decir, la literatura aporta a la experiencia humana, cotidiana, los eventos, hechos y acontecimientos, desde distintas formas y perspectivas que suceden y podrán suceder en el mundo y la realidad desde siempre.

Todo a través del lenguaje narrativo. El lenguaje es el proceso que construye, crea y recrea realidades.

La naturaleza de la literatura, se manifiesta, así:

- "La literatura trae «a primer plano» el lenguaje.

- La literatura integra el lenguaje.

- La literatura es ficción. 
- La literatura es un objeto estético.

- La literatura es una construcción intertextual o autorreflexiva" (Culler, 2019).

\section{¿Qué es la literatura guatemalteca?}

"La literatura no es la realización de la potencia sin normas de la poeticidad sino en la medida en que es "expresión de la sociedad" (Ranciére, El libro de la vida y la expresión de la sociedad, 2009).

Debe entenderse que "la literatura guatemalteca es aquella escrita en español, por personas pertenecientes a la nueva entidad cultural que nació de la fusión de elementos indígenas e hispanos y que ha ido construyéndose y sigue creándose a partir del proceso de la Conquista" (Barrios, 1986).

La literatura guatemalteca, como parte de la cultura y de lo social, se enlaza de manera directa e indirecta, y a través de diversas instancias, a los procesos generales y particulares de la sociedad.

La literatura guatemalteca, "por su particular desarrollo, está inmersa en los procesos históricos del país. A partir de dicha relación confiere a la literatura guatemalteca su especificidad y los rasgos característicos y distintivos que de ella derivan" (Liano, Prólogo, 1997).

La literatura guatemalteca es un campo permanentemente virgen para realizar investigación, cuando es asumida como medio y no como fin.

Las Universidades y los profesores, así como autoridades educativas y culturales, tienen una gran deuda al respecto, inclusive de realizar investigación educativa propia y apropiada.

\section{Literatura guatemalteca, siglo $\mathrm{XX}$}

"El tiempo tiene huecos en los que el pasado y el futuro trazan, para la conciencia, un presente siempre a punto de ser descifrado, esto es, de mostrarse más allá de sus símbolos" (Maillard, 1992).

Poner en entredicho "la existencia de una literatura (caso de la guatemalteca) que, en rigor, existe como tal desde hace cinco siglos, desde el Popol Vuh y las crónicas de Bernal Díaz, hasta la última generación de escritores, que se expresa en blogs y cuelga sus primicias en páginas personales de la web, puede también parecer una broma, si no una provocación" (Rivera, 2017).

Producto de su propio devenir político, social, económico, cultural, desde lo local, nacional y mundial, la literatura guatemalteca, ha estado atravesada desde distintas perspectivas, universos, ideologías, cosmovisiones, modelos, representaciones sociales, entre otros aportes de su diversa producción artística y estética o por influencias.

Mario Roberto Morales con Los demonios salvajes, junto a Marco Antonio Flores, con Los compañeros y Edwin Cifuentes con El pueblo y sus atentados y Después de las bombas de Arturo Arias (Menton, 1985), son los forjadores de la nueva novela guatemalteca del siglo XX.

De forma que, en su devenir, "la literatura guatemalteca de los últimos años ha contribuido significativamente a conocer situaciones que 
marcaron los derroteros de la guerra interna. En ese sentido, Jinetes en el cielo es una novela excepcional, debido a la sugerente revelación de las relaciones internas (conflictos internos) que establecieron quienes integraban los grupos guerrilleros" (Saúl Hurtado-Heras, 2017).

En ese sentido, analizar el aporte de Mario Roberto Morales, a la cultura y educación, como intelectual orgánico por medio de su producción literaria y ensayística, así como periodística, se hace necesario. El caso, de Jinetes en el cielo.

\section{Literatura versus humanismo aristocrático}

"La literatura "es social"; expresa la sociedad ocupándose de sí misma, es decir de la manera como las palabras contienen un mundo" (Ranciére, el libro de vida y la expresión de la sociedad, 2009).

Visualizada por un profundo desconocimiento e ignorancia tanto por el humanismo aristocrático (elite) como por el posthumanisno neoliberal producto de una "educación líquida en un mundo líquido con profesionistas líquidos e instituciones también líquidas" (Bauman, 2013), la literatura no es aceptada ni valorada.

De igual forma es "enseñada": 'pedagógica y psicologizante", como fin y no como medio. Dichos 'profesionistas posmodernos', consideran y creen que la literatura es innecesaria e improductiva al no aportar nada al desarrollo social.
Los "profesionistas y autoridades educativas y culturales líquidos" a puro CV, consideran y creen que la literatura es innecesaria e improductiva porque no aporta nada al desarrollo social, desde cuyas "posiciones idealistas y románticas imaginan al arte un fenómeno espiritual ajeno a las condiciones sociohistóricas y reducen sus estudios a las obras, los estilos y los artistas" (Canclini, 2014). Sucede también con los profesionistas de las ciencias sociales. Ven a la literatura como arte por el arte. De igual manera, es enseñada y se vea solamente a los que son 'genios'.

Del mismo modo, "la teoría posmoderna tiende a deshistorizar los artefactos culturales, a tratarlos sin respeto por el motivo o el propósito histórico" (Zamora, La construcción del pasado. La imaginación histórica en la literatura americana reciente, 2004).

A dichos 'profesionistas posmodernos que también incluye autoridades educativas y culturales', solo les importa el comercio, la ganancia, negando que la democracia con la cual se vive es solo la administración formal electorera, mientras el crecimiento y desarrollo económico excluye permanentemente a las mayorías.

Este tipo de 'profesionistas', burócratas, sectaristas hipócritas, reproductores del conocimiento que abundan en las instituciones educativas y culturales, mucho menos les interesa e importa que el surgimiento de la literatura guatemalteca proviene de la fusión indígena e hispánica, salvo para lo folclórico.

La visión monodisciplinaria de la cultura y la educación, hace dejar de considerar que "en términos más generales, las humanidades 
y las ciencias de la naturaleza comparten la misma epistemología, consistente en resolver problemas" (Popper, 1988).

Limitar la comprensión e interpretación que la literatura como construcción artística y estética (contenido, ideas, recursos literarios, etc.), reduce la posibilidad de la misma literatura de contribuir y constituirse en parte del soporte de la realidad y el mundo, al asumir desde la escritura, géneros, perspectivas, universos, ideologías, cosmovisiones, como objeto social, de conocimiento y literario.

\section{Literatura y realidad}

"Reiteremos que cada fenómeno literario (lo mismo que todo fenómeno ideológico) está determinado simultáneamente desde fuera y desde dentro" (Medvedev), 1994).

El escritor mediante el discurso literario adelanta e incluso llega a anticipar el mundo y la realidad, vía la historia, narración, tiempo, espacio, personajes, narradores, modos o puntos de vista, a través de diferentes técnicas literarias, y que la crítica e investigación social como literaria deben examinar concienzudamente. Investigación literaria que desafortunadamente en Guatemala, no cuenta con una tradición fuerte.

Es decir: "por el universo crítico-reflexivo toda obra literaria es una rica estancia de silencio, una defensa firme y una alta muralla contra esa inmensidad hablante que se dirige a nosotros alejándonos de nosotros. Si toda literatura dejara de hablar, es el silencio lo que faltaría en ese Tíbet originario donde los signos sagrados ya no se manifestarían en nadie, y es la falta de silencio lo que revelaría tal vez la desaparición de la palabra literaria" (Blanchot, 1959).

\section{Jinetes en el cielo y la ficción de método como reconstrucción del pasado}

"Los jinetes eran la furia, su furia. El cielo era el infierno" (Morales, El tropel y la fuga, 2019).

Jinetes en el cielo, forma parte de la fuerte e intensa producción literaria del Premio $\mathrm{Na}$ cional de Literatura, Miguel Ángel Asturias, 2007, Mario Roberto Morales.

Jinetes en el cielo, novela, donde se cuestiona lo real, la realidad y lo simbólico. Situaciones que el investigador y lector deben captar para tener la esencia que transita por la historia, narración, personajes, tiempo, espacio, narradores y puntos de vista.

Elementos que lo harán caminar desde el asombro en El rumor de la noche, la incertidumbre en El tropel y la fuga y la sorpresa en La luz en la sombra, hasta el final de la novela.

Así, como lo refiere el narrador protagonista, Fabián Algara:

"(...) nadie que no conoce los intestinos de un país tiene derecho de apropiárselo" (Morales, La luz en la sombra, 2019).

Se debe tener presente que dentro de la reconstrucción del pasado o ficción de método, "el pasado es la suma de las modificaciones y las transformaciones narrativas de la conciencia actual, una suma que nunca dismi- 
nuye, que crece continuamente" (Zamora, La angustia de los orígenes, 2004).

La articulación de la ficción de método indica que "constitutivas del razonamiento, las ficciones de método son a la vez más ficcionales, más conceptuales y más indispensables que la imaginación. Difieren de la ficción novelesca en tres aspectos: se presentan como tales, es decir que se autodenuncian, solo se alejan de lo real para retornar a él con más fuerza, y no son ni lúdicas ni arbitrarias, sino que están gobernadas por el razonamiento. Las ficciones de método pueden agruparse en cuatro familias conceptuales: el extrañamiento, la plausibilidad, la conceptualización y el procedimiento narrativo" (Jablonka, Las ficciones de método, 2016).

\section{Extrañamiento}

"La vocación de ciertas novelas es socavar la posibilidad misma de la verdad: si los hechos no existen, si no hay más que interpretaciones, si la historia solo es la propaganda del vencedor, la ficción es entonces la única verdad" (Jablonka, El extrañamiento, 2016).

"Lo verdadero puede, a veces, no ser verosímil" (Maupassant, 1971).

Develar lo real, la realidad y lo simbólico, proceso y acción que el escritor emprende como pregunta diacrónica y sincrónica, con lo cual cuestiona y discute los hechos, elimina hipótesis y crea nuevas.

Al principio de Jinetes en el cielo, el autor, realiza la Advertencia oportuna: Los personajes, las situaciones y los narradores de esta historia están basados, como ocurre en toda ficción acerca de sucesos colectivamente conocidos, en hecho y personas reales. Pero, como elementos de la trama novelesca, tanto ellos como la historia son enteramente imaginarios (página 7 ).

La Advertencia oportuna en Jinetes en el cielo, plantea el extrañamiento como alejamiento ficcional y el investigador o lector empiecen a dudar si dentro de los elementos de la historia, narración, tiempo, espacio, personajes, narradores, modos o puntos de vista, e incluso cuestionen si lo que comprenden como ficción o realidad, lo es, y poco a poco, también vayan reconstruyendo lo que saben o les han dicho, frente a lo que les aporta la novela como hecho social, de conocimiento y literario.

Todo escritor es un historiador que revisa y cuestiona lo que ha sucedido a través del tiempo.

Todo escritor es un actor social cuya participación se mueve con base en su compromiso ético, estético y político, en un momento determinado con relación a la historia local, nacional, mundial, desde la literatura misma. Para comprender hay que comparar, someter la Historia a prueba de confrontaciones.

En ese sentido, Guatemala, Centroamérica, Latinoamérica, Europa, son espacios y tiempos culturales, psicológicos, escriturales y geográficos desde donde cada autor, nacido o radicado, observa, analiza, y lo pacta como sueño que redime la vida desde una posición más íntima y esencial y, por lo tanto, subjetiva. 
De esa manera, cada lector y la sociedad, debe entender que "la novela (como género literario serio y responsable) es una respuesta dada por el sujeto a su situación en la sociedad burguesa o burguesamente estructurada. Esta respuesta supone una operación textual sobre lo real, que es tomado en un relato implicando a uno o a varios narradores. La figura del narrador es un doble del autor-sujeto, o es una estructura intermedia dialectizada entre el autor-sujeto y la realidad" (Krysinski, El árbol modelizante y los datos históricos de la novela, 1997).

Jinetes en el cielo, como parte del universo de la literatura guatemalteca, es un proceso escritural que contesta a la realidad concreta e histórica y responde a cuestiones complejas y cerradas para la mayoría.

Entendiendo que "la realidad, la cual se designa como una cualidad propia de los fenómenos que el individuo reconoce como independientes de su propia volición y que a partir del conocimiento de la misma como certidumbre que los fenómenos son reales y que poseen características específicas" (Luckman, 1972).

La novela como creación estética, política y ética, representa el espíritu de la complejidad desde la visión del escritor.

Cada novela cuya relevancia abre caminos, le dice al lector: "Las cosas son más complicadas de lo que tú crees". Esa es la verdad eterna de la novela que cada vez se deja oír menos en el barullo de las respuestas simples y rápidas que preceden a la pregunta y la excluyen" (Kundera, El arte de la novela, 2000).

\section{Plausibilidad}

"La plausibilidad estructura, pues, un espacio de evaluación donde, en una suerte de escala descendente lo probable prevalece sobre lo posible, más aceptable que lo dudoso. Entra plenamente en la lógica del contraargumento, que consiste no tanto en administrar la prueba como en destruir hipótesis" (Jablonka, La plausibilidad, 2016). Siempre en la Advertencia oportuna, refiere:

Por eso mismo, no resulta pertinente equiparar la ficción a la que el lector está a punto de entrar, con los hechos y las personas que la inspiraron. Y mucho menos lo es establecer grado alguno de veracidad histórica en las inevitables coincidencias (página 7).

La Advertencia oportuna, plantea como parte de la plausibilidad, hipótesis con variables independientes y dependientes dentro de la estructura narrativa que la historia, narración, personajes, tiempo, espacio, narradores y puntos de vista, irán aportando o revisando o cuestionando dentro del asombro, incertidumbre y la sorpresa.

Hipótesis y variables independiente y dependiente que la historia, la narración y los diversos personajes mostrarán para que el lector establezca las relaciones de poder y subordinación y los subterfugios a los cuales son sometidos o apercibidos. Incluso el mismo lector como sujeto social.

Tanto el investigador como el lector, tendrán que revisar si lo real, cuya existencia es verdadera y efectiva y lo simbólico con su capacidad de transmitir ideas, han, y son intervenidas de forma relativistas, posmoder- 
namente, en la sociedad guatemalteca, para distraer, confundir, hacer dudar, desde distintas ópticas la realidad, sin ver la totalidad ni el hecho concreto en la relación concreta: la Historia.

Por ello, con relación a la historia hay varios grados de verosimilitud: lo plausible es una posibilidad más sólida que las otras (o sea, la hipótesis que mejor ha resistido) (Jablonka, La plausibilidad, 2016). Es decir, no se puede separar la relación realidad-ficción, verdad-fabulación (hipótesis y variables). Hacerlo es repudiar y negar el aporte de las ciencias sociales y la misma literatura. Quien maneja la 'verdad' y la repite en distintas formas y a través de distintos interlocutores, hace creer $y$, por lo tanto, influye de forma poderosa en la sociedad.

Ejemplo concreto son el pobre abordaje de la Historia en los libros de texto del sistema educativo y las humanidades, así como la enseñanza de las mismas, incluso en las Universidades. En cambio, en las redes sociales el exceso de 'información' para tener entretenidas a las masas y se 'manifiesten libremente', sin incidir en cambios sociales y colectivos.

Parte de ello, es lo que ha venido sucediendo con el colapso de las instituciones responsables de generar nuevos horizontes y certeza frente a los hechos, donde la normalización de la mentira no conlleva consecuencias ni reacciones de la sociedad y todo sea asumido como real y verdadero para que todo cambie sin que pase nada para lo social y lo colectivo, a través de medidas como la privatización, cooptación de profesionistas, reducción de presupuesto, como parte del sistema neoliberal.
A partir de eso, Jinetes en el cielo, cuestiona las maneras o formas utilizadas como distorsión de la verdad para influir en las personas frente a la realidad como conjunto de comportamientos y como parte de la reconstrucción del pasado siempre necesario de analizar y cuestionar para un presente más concreto y digno, enfrentando al pensamiento único como única verdad.

Veamos, un ejemplo:

"-Mire, Fabián, esto de la paz es una gran puesta en escena. Los militares y los guerrilleros teníamos ya casi quince años de estar jugando al gato y al ratón porque la guerrilla fue derrotada militarmente a los tres meses de iniciada la campaña de "tierra arrasada" (El rumor de la noche, página 106).

Dentro de la ficción de método, la plausibilidad estructura, o es en sí misma, "un espacio de evaluación donde, en una suerte de escala descendente, lo probable prevalece sobre lo posible... Entra en la lógica del contraargumento, que consiste no tanto en administrar la prueba como en destruir hipótesis que compiten" (Jablonka, Las ficciones de método, 2016), tal como ocurrió con los grupos guerrilleros y la firma de los Acuerdos de Paz.

\section{Conceptualización}

"Por tener como fin la aprehensión de lo real, su conceptualización más allá de lo dado fenomenológico, las ficciones de método son ficciones reales. Superan con mucho el dominio de las ciencias sociales" (Jablonka, Conceptos y teorías, 2016). 
Tomar en cuenta que por tener como medio e incluso fin, la aprehensión de lo real, "la conceptualización va más allá de lo dado fenomenológicamente, las ficciones de método son ficciones reales" (Jablonka, Conceptos y teorías, 2016).

Recordemos, lo que dice, la Advertencia oportuna: Los personajes, las situaciones y los narradores de esta historia están basados, como ocurre en toda ficción acerca de sucesos colectivamente conocidos, en hecho y personas reales. Pero, como elementos de la trama novelesca, tanto ellos como la historia son enteramente imaginarios (página 7).

Jinetes en el cielo, con base en la conceptualización, es un "edificio jerarquizado en el cual el lenguaje está sometido a la ficción, el género al tema y el estilo a los personajes y situaciones representados" (Ranciére, De la representación a la expresión, 2009).

Lo anterior, para enfrentar y cuestionar el pasado, tal el caso de los Acuerdos de Paz, como pensamiento único referido a la sociedad guatemalteca, ya que "la recuperación de la historia perdida se vuelve una parte esencial del proceso de liberación, puesto que un pasado que no se analiza opera como destino más que como revelación" (Zamora, La angustia de los orígenes, 2004).

Asimismo, "la novela que no descubre una parte hasta entonces desconocida de la existencia es inmoral. El conocimiento es la única moral de la novela" (Kundera, La desprestigiada herencia de Cervantes, 2000).
Jinetes en el cielo, enfrenta desde la conceptualización que plantea la ficción real, de esa historia, de ese pasado, y los discursos hegemónicos sean cuestionados dentro del espacio y el tiempo, eliminando la concepción que el lenguaje y la historia son privadas o exclusivas de un grupo social.

Por la complejidad que asume "la novela (como género literario), esta se convierte en la cima de un saber epistémico estéticamente mediatizado, en el que la relación entre el narrador y el referente resulta esencial" (Krysinki, 1997). De ahí, la importancia de la comprensión e interpretación de la realidad con pensamiento crítico como elemento vital para relacionar lo que la historia y la literatura, dicen, presentan, dentro del tejido narrativo de la novela, Jinetes en el cielo.

En otras palabras: "la novela signa la perplejidad del sujeto -el individuo aislado en medio de la pletórica existencia" (Benjamin, La diferencia melancólica de técnica y artesanía, 2008).

\section{Procedimientos narrativos}

"Uno de los procedimientos más fecundos es la narración por símbolos, consistente en encapsular el fenómeno, un período o un acontecimiento en un individuo o un objeto considerados representativos. Esta concentración del razonamiento tiene por efecto la vivificación del relato, a la vez que induce un reflejo de identificación en el lector" (Jablonka, Procedimientos narrativos, 2016).

El escritor mediante el discurso literario adelanta y hasta puede llegar a anticipar el mundo y la realidad, por medio de la historia, narración, tiempo, espacio, personajes, 
narradores, modos o puntos de vistas, todo como parte de los procedimientos narrativos, para no perder de vista el todo y las partes de Jinetes en el cielo.

Dentro de los procedimientos narrativos, "uno de los procedimientos más fecundos es la narración por símbolos, consistentes en encapsular un fenómeno, un periodo o un acontecimiento en un individuo o un objeto considerados representativos (Jablonka, Las ficciones de método, 2016).

Los diversos y diferentes personajes, como parte de los procedimientos narrativos, representan en la narración, la síntesis, tesis y antítesis simbólica de la historia en Jinetes en el cielo. La semejanza de los personajes de la novela con personajes de la vida real, proporcionan a los mismos procedimientos narrativos, la fuerza que conlleva la ficción, tornándose real.

En razón de ello, "lo que atrae al lector a la novela es la esperanza de calentar su vida que se congela al abrigo de una muerte, de la que lee" (Benjamin, Consideraciones sobre la obra de Nikolai Leskov, 2008). Entre los procedimientos narrativos, los personajes, la narración, la historia, entre otros recursos del lenguaje narrativo, aportan intensidad en el proceso de escritura como de la lectura de las novelas o los relatos.

El o los personajes constituyen un eje esencial de la lectura en el relato o la novela. A la vez, pueden ser factor de recuerdo y de progresión y ofrecen al lector la posibilidad de construir su interpretación. Así, cada quien descubre y puede llegar a cerciorarse que "cada lector es un personaje que se ignora (a sí mismo)" (Osorio, 2016), o a los otros, por las características de los mismos dentro de la sociedad, sobre todo cuando la narración mediada por la historia permite establecer la relación de actitudes, conductas y mentalidades que muestran los personajes en Jinetes en el cielo.

\section{Farol de la calle y oscuridad de su casa (El rumor de la noche, página 91)}

"(...) toda literatura auténtica es literatura comprometida, al menos en la medida en que toda literatura auténtica aspira a cambiar el mundo cambiando la percepción del mundo del lector, que es la única forma en que la literatura puede cambiar el mundo" (Cercas, 2016).

En Jinetes en el cielo, los personajes son determinantes para interpretar y comprender lo que el escritor cuestiona. Es decir, los personajes reciben y confrontan tiempos, espacios humanos, individuales, colectivos.

Aprendizaje cuyo impacto en los lectores también hace cuestionar el pasado en el presente que se vive, así como lo que se ha denominado lo real, la realidad y lo simbólico: "(...) crear a un personaje 'vivo' significa: ir hasta el fondo de su problemática existencial. Lo cual significa: ir hasta el fondo de algunas situaciones, de algunos motivos, incluso de algunas palabras con las que está hecho" (Kundera, Diálogo sobre el arte de la novela, 2000). De manera más concreta, los personajes revisten diferentes funciones: 
1. "Una representación (o función mimética), particularmente a través de la descripción del personaje, la constitución de sus retratos.

2. Una función informativa, puesto que el personaje vehicula índices y valores transmitidos al lector.

3. Una función simbólica: el personaje supera muy a menudo el campo estrictamente individual y sirve para representar una capa más o menos amplia de la población, un campo más o menos amplio de convicciones, de posiciones morales e ideológicas.

4. Una función de regulación del sentido: en efecto, en gran parte, a través del personaje se distribuye y se constituye la significación del relato o la novela.

5. Una función pragmática, en la medida en que el personaje, sus comportamientos, pueden influir sobre el comportamiento del lector y sus representaciones del mundo (efectos catárticos y de identificación).
6. Una función estética, porque existe un arte de la composición del personaje, de sus aspectos, de sus actos, de su psicología, de sus especificidades, así como un arte de distribuirlos o instilarlos a lo largo del relato o novela" (Miraux, 2005).

Los diversos personajes de Jinetes en el cielo, cuya dicotomía y contradicción debe ser matizada por los lectores e investigadores y su relación posible y hasta concreta con la realidad como parte constitutiva de la ficción real, pero con una lógica de la sospecha, aunque lo narrado le parezca anécdota, sacudida o referencia literaria y el velo caiga como coágulos descubiertos ante las mentiras y confabulaciones dentro del espacio de lo llamado real, de la realidad y lo simbólico, sobre las negociaciones de los Acuerdos de Paz, como fin de la guerra interna que padeció Guatemala, y porque nada ha cambiado en lo colectivo y social.

Figura I. Personajes dicotómicos en Jinetes en el cielo

\begin{tabular}{|ll|}
\hline Fabián & Narrador protagonist \\
\hline Monseñor Alberti & Monseñor Gerardi \\
\hline Maldonado & Capitán Lima \\
\hline Cuevas Ruiz & ¿Efraín Ríos Montt? \\
\hline Melchor & Rodrigo Asturias \\
\hline Guerrilleros & Militares \\
\hline Oscar Ramírez & ¿Alfonso Portillo? \\
\hline Música & Boleros \\
\hline Gumersinda Coyoy & Rigoberta Menchú \\
\hline Juancho & ¿Mincho? \\
\hline General Reinosa & ¿Otto Pérez Molina? \\
\hline
\end{tabular}

Fuente: elaboración propia. 


\section{Conclusiones}

"Los críticos latinoamericanos tampoco se apresuraron a entrar en el análisis crítico de la posmodernidad, en parte a causa de su ahistoricismo latente, en parte porque la posmodernidad es vista como una ideología diseñada en otra parte en respuesta a otras necesidades históricas" (Zamora, La construcción del pasado. La imaginación histórica en la literatura reciente, 2004).

"El pasado no puede recuperarse, pero el proceso de su reconstrucción narrativa proporciona los consuelos de la conclusión y la continuidad que a menudo nos niegan los acontecimientos" (Zamora, Para que quede registrado, 2004)

La ficción de método como ficción real, a través del extrañamiento, la plausibilidad (hipótesis), la conceptualización y el procedimiento narrativo" (Jablonka, Las ficciones de método, 2016), sitúan en perspectiva la reconstrucción del pasado, mediante la relación de la literatura y la historia en Jinetes en el cielo, principalmente.

Al respecto, Mario Roberto Morales, en una entrevista, respondió: "La paz se firmó porque el capital corporativo transnacional necesitaba entrar aquí, y para eso necesitaba de olas privatizadoras que recibieran las inversiones extranjeras y permitieran que la oligarquía local quedara como social minoritaria en el sector telefónico, eléctrico y demás. Eso fue lo que hizo Arzú exactamente. Tienen pendiente la educación y la salud públicas. Si no hubiera habido ese interés capitalista, el simulacro de guerra que se venía desarrollando desde junio del 92, que fue cuando la guerrilla quedó militarmente derrotada, hubiese conti- nuado indefinidamente enriqueciendo a los chafas de los grupos paralelos (La Cofradía y El Sindicato) y permitiendo que los comandantes de cinco estrellas siguieran recibiendo la menguante ayuda extranjera que recibían" (Morales, Entrevista con Mario Roberto Morales en torno a Jinetes en el cielo, su obra finalista del Premio Herralde de Novela, 2013).

Los diferentes personajes, son presentados en la narración con sus propias historias y filosofías por la función que desempeñan bajo el entramado histórico y social.

La sociedad enfrenta, el peligro permanente inclusive de la posverdad, la cual consiste en que las personas, lentamente, dejen a un lado la honestidad y el pensamiento objetivo, para darle lugar a la credibilidad a las noticias falsas y sin sentido (https://www.significados. com/posverdad/, 2020).

La historia no es espacio exclusivo de los vencedores. Pertenece también a los vencidos. Jinetes en el cielo, cuestiona y reinterpreta, abriendo caminos desde la verosimilitud para otras interpretaciones posibles y necesarias sobre las negociaciones de los Acuerdos de Paz y la historia guatemalteca.

Por ello, la literatura es un objeto social, de conocimiento y literario, con lo cual cada obra literaria es y será diferente, lo que causa desconcierto, indicando con esta actitud que la sociedad no está preparada culturalmente para recibirla y las más de las veces, decepciona e incluso ofende, perdiendo de vista el que: "Literatura/ Sociedad, es (son) una relación y que los términos que ella articula no son dos entidades recíprocamente externas, sino mutuamente implicadas, una relación 
que varía según los períodos y las culturas" (Sarlo C. A., 2001).

De esa cuenta, cada lector y la sociedad, debe entender que "la novela es una respuesta dada por el sujeto a su situación en la sociedad burguesa o burguesamente estructurada. Esta respuesta supone una operación textual sobre lo real, que es tomado en un relato implicando a uno o a varios narradores. La figura del narrador es un doble del autor-sujeto, o es una estructura intermedia dialectizada entre el autor-sujeto y la realidad" (Krysinski, El árbol modelizante y los datos históricos de la novela, 1997).

Mario Roberto Morales, como intelectual comprometido, en Jinetes en el cielo, hace revisión del contexto local, nacional, mundial, a través del código y la obra, y los lectores se pregunten sobre lo que suponen saben sobre lo que ocurrió antes, durante y después del conflicto armado y la firma de los Acuerdos de Paz con la participación de agentes fácticos poderosos, así como de innombrables expresidentes, mostrando los hechos y acciones humanas mediante diversos personajes cuya posición ideológica dentro de la conformación de los hechos y sus circunstancias, oscilan como el péndulo tal cual axioma político, donde los pactos se rompen a cada instante ante el devenir de los intereses y conflictos desde el chisme y la intriga, el chantaje, la traición y la muerte.

Como parte del universo de la literatura guatemalteca y como proceso escritural, a través del extrañamiento, la plausibilidad (hipótesis negadas y propuestas como reconstrucción del pasado), la conceptualización y el procedimiento narrativo, Mario Roberto Morales, contesta y responde puntos complejos y ce- rrados para la mayoría de ciudadanos de la sociedad guatemalteca, mediante la ficción real (historia y literatura) en Jinetes en el cielo.

En esa línea, los procesos históricos políticos, así como sociales, en sus generalidades y sus particularidades, hacen de la literatura guatemalteca, universo abierto.

Mientras, en la óptica postmoderna "la historia es discontinua, sin una racionalidad interna, es decir, llena de incertidumbres respecto del futuro" (Edelberto Torres-Rivas, 2001).

De esa misma cuenta, los intelectuales de esta línea de pensamiento y acción, son: "los intelectuales que desmontan el rostro para explicarlo por pedazos, pero ya no ven la sonrisa" (Saint-Exupéry, 1999).

Es decir, la realidad, lo real, lo simbólico y la realidad concreta, son asumidas de otra manera para que nadie cuestione sobre la supuesta veracidad, repetida a la sociedad guatemalteca.

Jinetes en el cielo, dentro de su construcción narrativa, es un "edificio jerarquizado en el cual el lenguaje está sometido a la ficción, el género al tema y el estilo a los personajes y situaciones representados" (Ranciére, De la representación a la expresión, 2009). Todo como parte de la literatura como objeto social, literario y de conocimiento, responsablemente estructurada.

Jinetes en el cielo, enfrenta, desarrolla, cuestiona la Historia como pensamiento único referido a la sociedad guatemalteca, desde la 
cual, asume un compromiso ético, estético y político, considerando que "la novela que no descubre una parte hasta entonces desconocida de la existencia es inmoral. El conocimiento es la única moral de la novela" (Kundera, La desprestigiada herencia de Cervantes, 2000).

Dentro de lo referido "cada escritor construye su literatura, por íntima que sea, con el mundo que tiene a su alcance; la tajada de vida empírica que alimenta su imaginación es la savia secreta que justifica cada uno de los signos que estampa sobre el papel" (Saer, 2005).

La relación interdisciplinaria y cualitativa de "la historia y la literatura pueden ser, la una para la otra, algo más que un caballo de Troya" (Jablonka, Introducción, 2016). Es lo que permite la ficción de método como reconstrucción del pasado.

Historia y literatura complementos del saber humano y social a través de una poética del decir frente a lo que nos han dicho, revisando y develando hechos, personajes, acuerdos, polémicas, lo que efectúa en las 288 páginas, Jinetes en el cielo. Todo como un nuevo discurso-relato fundador de una nueva novela dentro de la tradición literaria guatemalteca.

En Jinetes en el cielo, la estructura narrativa y su articulación con la historia (local, nacional, mundial), narración, tiempo, espacio, personajes, narradores, le permiten a Mario Roberto Morales, explorar y manifestar dentro de sus propios postulados ontológicos, gnoseológicos y epistémicos, donde lo real, la realidad y lo simbólico del mundo junto a lo cotidiano, los cuales tienen que ser revisados o reaprendidos ante la sorpresa que la rea- lidad representa como forma de superar a la ficción.

De esa cuenta, cualquier "novela (los relatos, también) que ofrezca(n) una interpretación o explicación histórica, especialmente de las tragedias, conflictos o eventos mayores de la historia, invitan al análisis de su perspectiva histórica en la medida en que su retrato de esos eventos sustenta su visión moral" (Browitt, 2020).

Lo anterior, no puede ser visto como dicotomía de lo binario: exactitud/fidelidad, sino de perspectivas y posiciones socio históricas, a modo de cuestionamiento al revisar el pasado que hace presente y nubla o alumbra el futuro, en lo social, político, cultural, económico, donde los eventos son vistos de manera muy diferente a como lo han dicho y han hecho conocer.

Asimismo, los lectores y la metacognición que logren con base en su experiencia de lecturas y de vida, les corresponde determinar si lo que se narra o se describe en Jinetes en el cielo, mediante lo literal, lo inferencial y lo crítico contextual constituye la sociedad como realidad objetiva y subjetiva. Lo literal lo que dice la obra, lo inferencial y que reexige relectura y poslectura en el momento mismo de la lectura ante lo narrado (la historia, narración, tiempo, espacio, personajes, narradores, punto de vista) para situarlo y contextualizar los hechos y las circunstancias del momento histórico determinado cuya revisión y sospecha, convoca Jinetes en el cielo.

Lo literal, lo inferencial y lo crítico contextual son parte del proceso de interpretación y comprensión, al no funcionar ni desarrollarse 
de forma aislada como también se hace creer y se enseña.

Jinetes en cielo, incorpora en la complejidad de sus preguntas y respuestas "la participación de referentes, intertextos, valores e ideologías, pulsiones y estéticas" (Krysinski, Prefacio del autor a la edición española, 1997).

La experiencia de la lectura sensibiliza. Ante lo cual, se hace necesario, reconstruir y construir públicos lectores para conformar ciudadanía, sociedad y democracia, y realizar investigación, puesto que "la literatura, como toda serie socio-cultural, forma parte de la realidad que llamamos mundo -el único que nos concierne directamente al ser constituido por nosotros y al constituirnos, en un giro de boomerang ontológico a nosotros en cuanto tales, en cuanto hombres" (Oropeza, 1999) y enfrentar el pasado desde un presente que exige coherencia y ética, desde lo real, la realidad y lo simbólico, sin entregar el pasado ni el presente a los supuestos poseedores de la verdad.

\section{Referencias}

(s.f.). (editor), F. O. (2007). Epistemología de las Ciencias Sociales. Breve manual. Chile: UCSH.

Antonio García Berrio, T. H. (2008). Conclusión: Significado actual del formalismo para una crítica literaria globalizadora. En T. H. Antonio García Berrio, Crítica Literaria. Iniciación al estudio de la literatura (pág. 72). Madrid: Cátedra.

Barrios, F. A. (1986). Introducción. En F. A. Barrios, Historia de la literatura guatemalteca, tomo I (pág. 11). Guatemala: Editorial Universitaria.
Bauman, Z. (2013). Sobre la educación en un mundo líquido. España: Paidós.

Benjamin, W. (2008). Consideraciones sobre la obra de Nikolai Leskov. En W. Benjamin, El narrador (pág. 85). Chile: Metales pesados.

Benjamin, W. (2008). La catástrofe de la experiencia. En W. Benjamin, El narrador (pág. 13). Chile: Metales pesados.

Benjamin, W. (2008). La diferencia melancólica de técnica y artesanía. En W. Benjamin, El narrador (pág. 22). Chile: Metales pesados.

Blanchot, M. (1959). El libro por venir. París: Gallimard.

Blanco, P. (2001). Estéticas y bellezas. En P. Blanco, Estética de bolsillo (págs. 16, 18). Madrid: Colección Albatros.

Browitt, J. (2020). "Ese escurridizo objeto de deseo: la verdad histórica". http://istmo. denison.edu/n09/proyectos/verdad.html.

Canclini, N. G. (2014). Conclusión. En N. G. Canclini, La producción simbólica. Teoría y método en sociología del arte (pág. 62). México: Siglo XXI.

Cercas, J. (2016). El hombre que dice no. En J. Cercas, El punto ciego. Las conferencias Weidenfeld 2015 (pág. 118). Barcelona: Random House.

Culler, J. (Martes de Junio de 2019). file:///F:/ Fac. \%20Humanidades/Qué\%20es\%20 literatura/62650614-Que-es-la-literatura-Culler\%20(1).pdf. Obtenido de file:///F:/Fac.\%20Humanidades/Qué\%20 es\%20literatura/62650614-Que-es-la-literatura-Culler\%20(1).pdf.

Edelberto Torres-Rivas, I. W. (2001). Las ciencias sociales y el pesimismo. En I. W. Edelberto Torres-Rivas, Acerca del pesimismo en las ciencias sociales. Los in- 
telectuales en una época de transición. (pág. 34). Guatemala: FLACSO.

Fumero, P. (2004). Historia y Literatura: Una larga y compleja relación. http://istmo.denison.edu/n06/proyectos/historia2.html.

https://dle.rae.es/posverdad?m=form. (Martes de Marzo de 2020). https://dle.rae.es/ posverdad. Obtenido de https://dle. rae.es/posverdad: https://dle.rae.es/ posverdad?m=form

https://dle.rae.es/posverdad?m=form. (Martes de Marzo de 2020). https://dle.rae.es/ posverdad?m=form. Obtenido de https:// dle.rae.es/posverdad?m=form: https:// dle.rae.es/posverdad? $\mathrm{m}=$ form

https://www.significados.com/posverdad/. (Martes de Marzo de 2020). Obtenido de https://www.significados.com/posverdad/: https://www.significados.com/ posverdad/

https://www.significados.com/posverdad/. (Martes de Marzo de 2020). https://www. significados.com/posverdad/. Obtenido de https://www.significados.com/posverdad/: https://www.significados.com/ posverdad/

Jablonka, I. (2016). Conceptos y teorías. En I. Jablonka, La historia es una literatura contemporánea. Manifiesto por las ciencias sociales (pág. 211). Buenos Aires: FCE.

Jablonka, I. (2016). Conceptos y teorías. En I. Jablonka, La historia es una literatura contemporánea. Manifiesto por las ciencias sociales (pág. 211). Buenos Aires: FCE.

Jablonka, I. (2016). El extrañamiento. En I. Jablonka, La historia es una literatura contemporánea. Manifiesto por las ciencias sociales (pág. 205). Buenos Aires: FCE.
Jablonka, I. (2016). Introducción. En I. Jablonka, La historia es una literatura contemporánea. Manifiesto por las ciencias sociales. (pág. 11). Argentina: FCE.

Jablonka, I. (2016). Introducción. En I. Jablonka, La historia es una literatura contemporánea. Manifiesto por las ciencias sociales (pág. 12). Argentina: FCE.

Jablonka, I. (2016). Introducción. En I. Jablonka, La historia es una literatura contemoránea. Manifiesto por las ciencias sociales (pág. 11). Buenos Aires: FCE.

Jablonka, I. (2016). La plausibilidad. En I. Jablonka, La historia es una literatura contemporánea. Manifiesto por las ciencias sociales (págs. 210, 211). Buenos Aires: FCE.

Jablonka, I. (2016). La plausibilidad. En I. Jablonka, La historia es una literatura contemporánea. Manifiesto por las ciencias sociales (pág. 209). Argentina: FCE.

Jablonka, I. (2016). Las ficciones de método. En I. Jablonka, La historia es una literatura contemporánea. Manifiesto por las ciencias sociales (págs. 195, 206). Argentina: FCE.

Jablonka, I. (2016). Las ficciones de método. En I. Jablonka, La historia es una literatura contemporánea. Manifiesto por las ciencias sociales (págs. 210, 211). Argentina: FCE.

Jablonka, I. (2016). Las ficciones de método. En I. Jablonka, La historia es una literatura contemporánea. Manifiesto de las ciencias sociales (págs. 215, 216). Buenos Aires: FCE.

Jablonka, I. (2016). Procedimientos narrativos. En I. Jablonka, La historia es una literatura contemporánea. Manifiesto por las ciencias sociales (págs. 215, 216). Buenos Aires: FCE. 
Krysinki, W. (1997). Preliminar. En W. Krysinki, Encrucijada de signos. Ensayos sobre la novela moderna (pág. 10). Madrid: Arco/ Libros.

Krysinski, W. (1997). El árbol modelizante y los datos históricos de la novela. En W. Krysinski, Encrucijada de signos. Ensayos sobre la novela moderna (pág. 32). Madrid: Arco/Libros.

Krysinski, W. (1997). Prefacio del autor a la edición española. En W. Krysinski, Encrucijada de signos. Ensayos sobre la novela moderna (pág. 29). Madrid: Arco/ Libros.

Kundera, M. (2000). Diálogo sobre el arte de la novela. En M. Kundera, El arte de la novela (pág. 46). Barcelona: Tusquets.

Kundera, M. (2000). El arte de la novela. En M. Kundera, El arte de la novela (pág. 29). Barcelona: Tusquets.

Kundera, M. (2000). La desprestigiada herencia de Cervantes. En M. Kundera, El arte de la novela (pág. 16). Barcelona: Tusquets.

Liano, D. (1979). La literatura como arma ideológica. En D. Liano, Literatura hispanoamericana (pág. 9). Guatemala: Universitaria.

Liano, D. (1997). Prólogo. En D. Liano, Visión crítica de la literatura guatemalteca (pág. X). Guatemala: Editorial Universitaria.

Luckman, P. L. (1972). El problema del conocimiento. En P. L. Luckman, La construcción social de la realidad (pág. 13). Buenos Aires: Amorrortu editores.

Maillard, C. (1992). El cometido de la filosofía. En C. Maillard, La creación por la metáfora. Introducción a la razón-poética (pág. 22). Barcelona: Anthropos.
Maupassant, G. d. (1971). La novela. En G. d. Maupassant, Pedro y Juan. Bola de sebo (pág. 22). España: Biblioteca Básica Salvat.

Medvedev), M. B. (1994). Objeto y tareas de los estudios literarios marxistas. En M. B. Medvedev), El método formal en los estudios literarios (pág. 76). Madrid: Alianza Editorial.

Menton, S. (1985). Los señores presidentes y los guerrilleros: la nueva y vieja novela guatemalteca (1976-82) y sus antecedentes (1955-75. En S. Menton, Historia crítica de la novela guatemalteca (pág. 349). Guatemala: Universitaria.

Miraux, J.-P. (2005). Funciones. En J.-P. Miraux, El personaje en la novela (pág. 14). Buenos Aires: Nueva Visión.

Morales, M. R. (1994). Las palabras y los hechos. Curso de literatura hispanoamericana, 1994. Guatemala: Consucultura.

Morales, M. R. (6 de Agosto de 2013). Entrevista con Mario Roberto Morales en torno a Jinetes en el cielo, su obra finalista del Premio Herralde de Novela. (J. L. OreIlana, Entrevistador)

Morales, M. R. (2019). El rumor de la noche. En M. R. Morales, Jinetes en el cielo (pág. 11). Guatemala: Cultura.

Morales, M. R. (2019). El tropel y la fuga. En M. R. Morales, Jinetes en el cielo (pág. 141). Guatemala: Cultura.

Morales, M. R. (2019). La luz en la sombra. En M. R. Morales, Jinetes en el cielo (pág. 257). Guatemala: Cultura.

Oropeza, R. P. (1999). Introducciòn. En R. P. Oropeza, Literatura y realidad (pág. 10). México: FCE. 
Osorio, D. A. (2016). Teoría literaria I. En D. A. Osorio, De quién es el cielo, entonces (pág. 44). Guatemala: Arizandieta.

Popper, K. (1988). Conocimiento objetivo. Madrid: Tecnos.

Ramírez, S. (Domingo de Agosto de 2019). En las patas de los caballos. elPeriódico, suplemento elacordeón, pág. 5 .

Ranciére, J. (2009). De la representación a la expresión. En J. Ranciére, La palabra muda. Ensayo sobre las contradicciones de la literatura (pág. 35). Argentina: Eterna cadencia.

Ranciére, J. (2009). El libro de la vida y la expresión de la sociedad. En J. Ranciére, La palabra muda. Ensayo sobre las contradicciones de la literatura (pág. 70). Argentina: Eterna cadencia.

Ranciére, J. (2009). el libro de vida y la expresión de la sociedad. En J. Ranciére, La palabra muda. Ensayo sobre las contradicciones de la literatura (pág. 62). Buenos Aires: Eterna Cadencia.

Redondo, F. G. (1994). Concepto de ficción. En F. G. Redondo, El lenguaje literario. Teoría y práctica (págs. 126, 127). Madrid: EDAF.

Redondo, F. G. (1994). Concepto de ficción. En F. G. Redondo, El lenguaje literario. Teoría y práctica (pág. 128). Madrid: EDAF.

Rivera, L. E. (2017). ¿Existe realmente la literatura guatemalteca? En L. E. Rivera, Tierra Adentro. De Gómez Carrillo a la literatura de los setenta (págs. 43,49). Guatemala: Cultura.

Saer, J. J. (2005). El escritor argentino en su tradición. En J. J. Saer, Trabajos (pág. 67). Buenos Aires: Seix Barral.
Saint-Exupéry. (1999). VII. En Saint-Exupéry, Piloto de guerra (pág. 43). Colombia: Panamericana.

Sarlo, B. (2005). Tiempo pasado. En B. Sarlo, Tiempo pasado. Cultura de la memoria y giro subjetivo. Una discusión (pág. 9). Buenos Aires: Siglo XXI.

Sarlo, C. A. (2001). Introducción. En C. A. Sarlo, Literatura/Sociedad (pág. 8). Buenos Aires: Edicial S. A.

Saúl Hurtado-Heras, A. R. (2017). Visión crítica de la guerrilla guatemalteca en Jinetes en el cielo de Mario Roberto Morales. Revista Análisis de la realidad nacional, Universidad de San Carlos de Guatemala, 58, 85.

Tohom, G. C. (Miércoles de Marzo de 2020). Apuntes para la tesis. Jinetes en el cielo: entre los hechos y la ficción. Guatemala.

Verdugo, I. H. (1984). La literatura como petición de la realidad. En I. H. Verdugo, El carácter de la literatura hispanoamericana y la novelística de Miguel Ángel Asturias (pág. 30). Guatemala: Editorial Universitaria.

Zamora, L. P. (2004). En L. P. Zamora, La construcción del pasado. La imaginación histórica en la literatura americana reciente (pág. 44). México: FCE.

Zamora, L. P. (2004). La angustia de los orígenes. En L. P. Zamora, La construcción del pasado. La imaginación histórica en la literatura americana reciente (pág. 48). México: FCE.

Zamora, L. P. (2004). La angustia de los orígenes. En L. P. Zamora, La construcción del pasado. La imaginación histórica en la literatura americana reciente (pág. 66). México: FCE. 
Zamora, L. P. (2004). La construcción del pasado. La imaginación histórica en la literatura reciente. En L. P. Zamora, La construcción del pasado. La imaginación histórica en la literatura americana reciente (pág. 44). México: FCE.

Zamora, L. P. (2004). Para que quede registrado. En L. P. Zamora, La construcción del pasado. La imaginación histórica en la literatura americana reciente (pág. 99). México: FCE.

Zamora, L. P. (2004). Prefacio. En L. P. Zamora, La construcción del pasado (pág. 13). México: FCE.

\section{Sobre autor}

\section{Daniel Alarcón Osorio}

Profesor titular (2004), jornada nocturna, Departamento de Letras, Facultad de Humanidades, Universidad de San Carlos de Guatemala, tiene trece libros publicados: 4 de poesía, 8 de cuentos y 1 de Ejercicios de Lectura y Escritura. A la espera de publicar dos libros de educación, de 2006 a 2020, ha presentado alrededor de 35 ponencias en materia de educación y literatura, en congresos internacionales en Guatemala, Argentina,

México, Colombia, Venezuela, y participado en La Habana, Cuba y proyección social y cultural al fundar Clubes de Lectores y realizar Encuentros de Lectores en estadios, gimnasios, museos, bibliotecas, en Guatemala, recibió en 2006, la distinción como Embajador Universal de la Paz, del Círculo de Embajadores Universales de la Paz, Ginebra, Suiza.

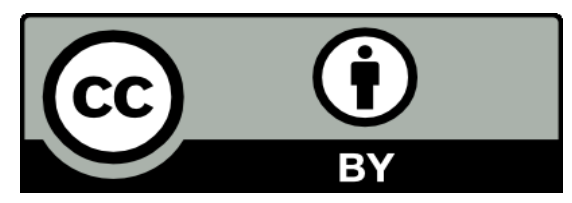

Este texto está protegido por una licencia CreativeCommons 4.0.

Esta licencia permite que otros distribuyan, mezclen, adapten y desarrollen su trabajo, incluso comercialmente, siempre y cuando le den crédito por la creación original. 



\title{
El aumento del uso de los medios de comunicación masivos por crisis del Coronavirus
}

\section{The increase in the use of mass media due to the Coronavirus crisis}

\section{Como citar el artículo}

Epinoza, L. (2020). El aumento del uso de los medios de comunicación masivos por crisis del Coronavirus. Revista Naturaleza, Sociedad y Ambiente, 7 (1), 93-101. DOI: https://doi.org/10.37533/cunsurori.v7i1.54

Linda Evelin Espinoza Recinos

\section{Centro Universitario de Oriente, Universidad de San Carlos de Guatemala}

Recibido: 29 de abril de 2020 / Aceptado: 09 de septiembre de 2020

Disponible en internet el 10 de noviembre de 2020

*Autor para correspondencia, correo electrónico: misslinda974@gmail.com

\begin{abstract}
Resumen
El presente año ha sorprendido a la humanidad con la aparición de una enfermedad altamente contagiosa llama Covid-19. Ante la posibilidad de frenar el avance de dicha enfermedad por el mundo con la práctica de medidas higiénicas y sanitarias, se suspendieron toda clase de actividades colectivas. Como resultado del confinamiento y del distanciamiento social, la mayoría de las personas ha recurrido al Internet como una forma de mantener el contacto con el mundo exterior sin poner en riesgo la salud. Esto hace más propensas a las personas de todas las edades a peligros tales como: campañas de desinformación, ciberataques, mal uso de datos personales y acciones de manipulación, ya que en el Internet las regulaciones brillan por su ausencia debido a que las gigantes tecnológicas esquivan la responsabilidad sobre los contenidos que circulan a través de sus plataformas. Esta situación lleva a repensar el papel que todos los involucrados tenemos en la actividad humana en Internet y lograr la colaboración entre las grandes corporaciones que comparten contenidos en Internet, acuerdos de cooperación entre países para regular dichos contenidos, pero también responsabilidad individual de impregnar de carácter bioético la red y definir buenas prácticas basadas en la cibernética de segundo orden.
\end{abstract}

Palabras clave: contacto, regulaciones, innovación, responsabilidad, colaboración

\section{Abstract}

This year has surprised humanity with the appearance of a highly contagious disease called Covid-19. Faced with the possibility of halting the advance of this disease around the world through the practice of hygiene and health measures, all kind of collective activities were suspended. As a result of social confinement and alienation, most people have turned to the Internet as a way to maintain contact with the outside world without putting their health at risk. This makes people of all ages more vulnerable to dangers such as: disinformation campaigns, cyber-attacks, misuse of personal data and manipulative actions, since regulations are conspicuously absent on the Internet as technological giants avoid responsibility for the content circulating through their platforms. This situation leads to a rethinking of the role that all of us, who are involved in human activity on the Internet have to play and to achieve collaboration between the large corporations that share content on the Internet, cooperation agreements between countries to regulate such content, but also individual responsibility for impregnating the network with a bioethical nature and defining good practices based on second-order cybernetics.

Keywords: contact, regulations, innovations, responsibility, collaboration 


\section{Introducción}

Los medios de comunicación social han ocupado un puesto relevante en la vida de las personas y lo siguen ocupando en la actualidad. Hay muchos medios de comunicación social. El termino medios de comunicación tradicionales se refieren a cualquier medio de comunicación masivo que apareció antes de la invención del Internet y las redes sociales. Unos de los más antiguos tipos de medios de comunicación social son los impresos. Esto incluye los periódicos, y las vallas publicitarias. Con el desarrollo de la tecnología, se agregaron la radio y la televisión a los medios de comunicación tradicionales.

Hoy, millones de personas usan las redes sociales para esparcir sus ideas y mensajes. Las redes sociales se refieren a cualquier sitio "web" o tecnología que permita a los usuarios crear y compartir información con una audiencia específica. También se les puede llamar medios de comunicación en masa, que es un tipo de medio de comunicación que alcanza un número muy grande de personas y que incluye los medios de comunicación tradicionales y las redes sociales. Hoy podemos decir que la tecnología ha crecido y que las maneras en las cuales recibimos los mensajes ha cambiado. Aunque leemos textos también miramos fotos, datos y cuadros. Miramos videos y escuchamos la radio, podcasts y otras grabaciones de audio. Para que podamos procesar correctamente toda esa información se necesita una adecuada alfabetización.

\section{La alfabetización en los medios de comunicación social}

La alfabetización según el contenido: "Can you separate fact from fiction?" del MOOC "English for Media Literacy" (2019) es la habilidad de leer, entender, analizar y crear usando el lenguaje escrito. Parte de la alfabetización es analizar texto. Analizar significa pensar sobre algo cuidadosamente para entenderlo. Alguien que es culto en los medios de comunicación abre el periódico o ve una publicación (un "post") en las redes sociales sabe hacer preguntas importantes sobre el mensaje y las personas que hicieron ese mensaje.

Las personas son inundadas con mensajes, no importa si llegan en línea, por televisión o por periódico.

La alfabetización sobre medios de comunicación se refiere a entender cómo y porqué los mensajes son propagados. Todo inicia con las preguntas correctas: ¿quién creó este mensaje?, ¿qué palabras o imágenes usaron y por qué? Y ¿cómo se supone que este mensaje me hace sentir?

a) ¿Quién creó el mensaje? Todos los mensajes son hechos por personas. Estas personas hacen elecciones sobre lo que incluirá o no un mensaje. Las imágenes y videos que vemos y las palabras que leemos nos cuentan una historia. Por lo cual es importante pensar en qué opciones fueron hechas y como afectan o cambian la historia que se cuenta.

b) ¿Qué técnicas usaron para atraer mi atención? Cuando los medios crean un mensaje usan ciertas técnicas para capturar la atención de su audiencia. Unas veces usan el humor - la comedia, también usan ciertos símbolos y palabras. La meta es que el usuario siga leyendo y viendo el mensaje en el futuro. 
c) ¿Qué puntos de vista y valores son incluidos u omitidos del mensaje? Por ejemplo, piensa en una persona que quiere participar en las elecciones para la presidencia de su país. Un mensaje puede decir que esa persona podría ser un gran presidente. Mientras otro podría decir que sería un terrible presidente. ¿Cómo puede la misma persona ser al mismo tiempo un excelente y un terrible presidente? No hay que olvidar que las organizaciones que crearon esos mensajes tienen creencias políticas y valores diferentes. Sin olvidar que las ideas o creencias que se omiten nos hacen perder de vista parte de la historia que los medios nos quieren hacer creer que no son importantes.

La alfabetización sobre medios de comunicación te enseña a pensar cuidadosamente sobre la información. Aprendes a hacer las preguntas correctas, mirar de forma diferente los puntos de vista y las conexiones entre nuevas y viejas ideas y estas preguntas no son solo importantes cuando miras televisión o revisas tu teléfono inteligente. El pensamiento crítico te ayuda muy bien en otras partes de la vida como el aula y la oficina. Recuerda que escuchas y ves más mensajes en los medios en un día que otras personas lo hicieron en el pasado. Debes poner mucha atención a lo que lees, miras y escuchas, ser consciente de su propósito así tomarás mejores decisiones y distinguirás entre los datos reales y la ficción.

La alfabetización en medios de comunicación te ayuda en dos destrezas necesarias para ser un ciudadano de una democracia: pensamiento crítico y autoexpresión sin caer en la trampa de las noticias falsas que son tan comunes en la actualidad.

\section{Tiempo dedicado al Internet}

En 2014 el promedio que las personas en América gastan en el Internet es de 7.4 horas. La gente de Filipinas, un país que se ubica en el Océano Pacifico ganó el primer lugar. Éstas personas gastaron 9.6 horas por día en Internet desde sus computadoras de escritorios, laptops y dispositivos móviles. De hecho, la gente ha estado gastando una enorme cantidad de tiempo en el Internet a través del mundo. Como resultado del confinamiento y del distanciamiento social debido al Covid-19, todavía más personas han recurrido al Internet como una forma de mantener el contacto con el mundo exterior sin poner en riesgo la salud.

El Internet ofrece acceso a mucha información las 24 horas del día. Las redes sociales son los contenidos más populares, pero también la gente gusta mucho de ponerse al día con las noticias del momento.

Las redes sociales son estructuras sociales compuestas de grupos de personas, las cuales están conectadas por uno o varios tipos de relaciones y mediadas por plataformas tecnológicas que constituyen el canal de intercambios que posibilitan las interacciones definidas, según Cobo y Romaní (2007) las redes sociales describen "aquellas herramientas diseñadas para la creación de espacios que promueven o faciliten la conformación de comunidades e instancias de intercambio social".

Actualmente, el uso de redes sociales es una actividad normal que cualquier persona puede realizar desde su dispositivo móvil, tableta o computadora. Las redes sociales más populares son: "Facebook, Twitter, Ins- 
tagram, Tmblr, Reddit, Linkedln and YouTube". El hecho es que, los seres humanos nos hemos vuelto adictos a este tipo de interacciones, debido exactamente a que dichas redes sociales están diseñadas para volverse adictivas.

Según Adam Alter (2018) para las grandes empresas de la tecnología masiva tales como: Google, Facebook, Netflix, entre otras existe una correlación directa entre atención y crecimiento, por lo cual éstas están diseñadas precisamente para volverse altamente adictivas. Aunque las tendencias adictivas aparecieron mucho antes que el Internet, los teléfonos inteligentes y las redes sociales han ampliado grandemente dichas tendencias.

- Recompensas variables: las redes sociales son como máquinas tragamonedas. Cada notificación, cada foto nueva, cada me gusta, es único y cambian a cada momento. La forma en que están diseñadas es muy difícil de resistir.

- Distracción: las redes sociales no son predecibles. A los seres humanos nos aburre la predictibilidad de nuestras vidas, es por eso que las redes sociales nos distraen y crean un circulo de retroalimentación que se vuelve más llamativo cuanto más lo usamos.

- Detener las señales: Las redes sociales usan vertiginosamente el video con desplazamiento infinito, es decir, el contenido nunca se detiene. Esto hace que cinco minutos se conviertan en treinta, sin que el usuario se dé cuenta.

- Métrica de vanidad: en las redes sociales puedes conseguir pequeñas victorias tales como: tienes más "likes" que tu mejor amiga, sobrepasaste a todos tus amigos por el "Snapstreak" más largo, tu foto o publica- ción tiene más comentarios que los de otras personas conocidas. Cada una de esas pequeñas victorias no significan nada, pero nos dan un golpe de dopamina cada vez, y su frecuencia cada vez mayor nos lleva a pasar más tiempo y esforzarnos aún más para alcanzar nuestros objetivos triviales de forma regular.

\section{Las redes sociales, una receta para la adicción}

Las redes sociales son una receta para la adicción, una muy potente por cierto y la parte más preocupante es que estos factores hacen que las personas eviten las interacciones cara a cara, pasen menos tiempo con familiares y amigos, e incluso arriesguen sus vidas (son conocidos los casos de jóvenes que arriesgan sus vidas por tomar "selfies" en lugares sumamente peligrosos para lograr la atención de miles de seguidores). Y aún hay más, estas adicciones nos hacen perder tantos momentos que nunca tendremos la oportunidad de revivir. Nos perdemos los mejores momentos de la vida real por pasar demasiado tiempo en los contenidos del Internet.

Pensando en esta adicción a los dispositivos electrónicos, se podría decir que la falta de conciencia sobre el tiempo que invertimos y la invasión en nuestras vidas que estos artefactos provocan, es la causa que más nos debería alarmar sobre el uso y abuso de ellos. Para poder ilustrar esa falta de conciencia sobre el tiempo que nos roba, pensemos por ejemplo que en promedio una persona normal revisa su teléfono móvil cada seis minutos (150 veces al día), la sola presencia del teléfono inteligente, aunque esté apagado, reduce nuestra capacidad cognitiva y, además, en menos de dos décadas, nuestro tiempo 
cara a cara con familiares y amigos ha disminuido en casi un treinta por ciento.

\section{Facebook, una de las redes sociales más populares}

Facebook es una red social creada por Marck Zuckerberg, quien de acuerdo con los datos de Bloomberg (compañía estadounidense de asesoría financiera), es la quinta persona más rica del mundo. Esta red social hace mucho dinero con nuestros datos mientras nos permite compartir, comentar y conectarnos con quien queramos. También tiene la capacidad de rastrear nuestra ubicación, nuestros desplazamientos y costumbres para almacenar esos datos y poder recrear un retrato robot lo más parecido a cada usuario. Recordemos que cada uno de nosotros somos dueños de nuestra privacidad y es precisamente eso lo que sacrificamos cuando usamos la red de tecnología móvil.

Con la reciente cuarentena por el Covid-19, Facebook tuvo un incremento de 105 millones de usuarios solo en el primer trimestre del 2020. Si tomamos en cuenta que la población mundial es de aproximadamente 7,800 millones de personas, que la mitad de esas personas no tienen acceso a Internet y que Facebook está prohibido en China y otras naciones, podemos darnos cuenta que su alcance activo de esta red social es absoluto. Aunque Facebook es una de las redes sociales más usadas, no podemos ignorar que existen otras muy importantes que han ganado popularidad entre los usuarios. Twitter, Tumblr and YouTube también tienen altos números de usuarios registrados obteniendo noticias de sus sitios web. Doug Bernard opina que el número de personas usando más de un sitio para obtener noticias es de solo el $26 \%$ y solo el $10 \%$ dice usar tres o más.
Los investigadores, de hecho, han encontrado que las noticias en de las cinco redes sociales más populares parecen ir dirigidas a diferentes tipos de personas. La gente que busca noticias en Twitter es la más joven. Los usuarios de las noticias en Facebook son en su mayoría del sexo femenino. Las personas con grados académicos buscan noticias en Linkedln.

\section{Las redes sociales y los rituales}

Pero el aumento del uso de las redes sociales no es la única consecuencia de la crisis del coronavirus, también dicha crisis está acabando con algo tan importante como lo son los rituales. Se está prohibiendo, por razones sanitarias, hasta el darse la mano. La pandemia está dando lugar a una sociedad de la cuarentena en la que se está perdiendo toda experiencia comunitaria. Aunque seguimos conectados digitalmente, seguimos comunicándonos, pero sin ningún acercamiento social que nos haga realmente felices. Incluso, antes del Covid-19, lo que conocemos y entendemos como comunidad ya se estaba extinguiendo con la desaparición de los rituales.

El filósofo alemán vivo más leído del mundo, Byung-Chul Han, señala que los rituales anclan la comunidad en el cuerpo ya que en ellos el cuerpo es un escenario en el que se inscriben los secretos, las divinidades y los sueños. La cortesía es un ejemplo de esos rituales. Cada día celebramos menos fiestas comunitarias, cada uno se celebra sólo a sí mismo. Debemos inventar nuevas formas de acción y juego colectivo que creen comunidad. La comunidad es fuente de felicidad. También la libertad tiene sus raíces en lo comunal, libertad y amigo tienen una etimología común. La libertad es la manifestación de una relación plena. Es por ello que debe- 
ríamos redefinir la libertad a partir de la comunidad. Por lo cual, según Han (1959), al desaparecer la comunidad ira desapareciendo también parte de nuestra libertad.

\section{La publicidad en los medios de co- municación social}

Pero aún hay más, en las redes sociales también vamos a ser bombardeados por otra herramienta muy popular para vendernos cualquier producto o servicio, "la publicidad". Las empresas de publicidad, según Nancy Bollinger (Directora Creativa), estudian a las personas, saben datos demográficos, la edad, residencia, ingresos, e información psicográfica realmente útil tales como estilo de vida, pasatiempos, intereses para captar clientes potenciales. Esto lo pueden hacer de varias maneras, por ejemplo, si ya hay clientes, ellos son la fuente de información más confiable. Si es un nuevo negocio, consideras cual será tu audiencia destinataria para encontrarlos y motivarlos a comprar.

La publicidad es motivación. No les venden un producto a las personas sino un estilo de vida, no satisfacen una necesidad sino crean necesidades para luego satisfacerlas. Por ejemplo, en 1930, no era común que las mujeres lucieran anillos de diamantes. En esa época De Beers Diamonds tuvo un exceso de diamantes de las minas del Sur de África y fue cuando inició una campaña para hacer creer a los hombres que la mejor manera de demostrar su amor por una mujer era regalando un hermoso anillo de diamantes, cuánto más grande y cara fuera la joya más grande era el amor que representaba y fue así como se convirtió en una tradición.

\section{La cibernética de segundo orden y el abordaje del tiempo y el uso del Internet}

Primero quiero que se tome en consideración que el hombre siempre ha tratado de dar una explicación al orden del mundo. Heráclito de Éfeso, Anaximandro, entre otros, descubrieron el mundo de la experiencia dando cuenta del orden del cosmos. Posteriormente René Descartes, llegó a la conclusión que para entender un fenómeno había que reducir a partes y procesos elementales, mirarlos aisladamente, para luego resolver la dificultad y creó la dualidad entre mente y cuerpo. Gracias al método de Descartes los eventos de análisis se redujeron a dos variables: causa-efecto.

Los términos científicos que se venían dando se referían a los efectos lineales, aunque el pensamiento de sistemas ya existía en Aristóteles, desaparece con Descartes y la realidad comienza a ser desmembrada y reducida a una creciente fragmentación.

A partir de la Segunda Guerra Mundial se comienza a consolidar un pensamiento cada vez más totalizador y menos fragmentado con Ludwig Von Bertalanffy. El emprendió la búsqueda de la unidad en la diversidad, dando origen a una nueva era en la ciencia, la que llamó sistemas. Bertalanffy inició el desarrollo del pensamiento sintético, el cual sostiene que todo sistema pertenece a un sistema más amplio (un sistema mayor) y que todo sistema es un todo organizado. Lo interesante es que la Teoría de sistemas estaba más interesada en integrar las cosas que en aislarlas, además propone unos modelos de sistema general como intento de unificar el conocimiento científico. 
La Cibernética se volvió en piedra angular de la Teoría de Sistemas, y juntos, Cibernética y Teoría de sistemas ofrecen al campo de las ciencias una nueva cosmovisión. En resumen, la Cibernética se basa en el supuesto según el cual las funciones de control, intercambio de información y procesamiento de la información, siguen los mismos principios, independientemente de que se apliquen a máquinas, organismos o estructuras sociales.

La Cibernética de Primer Orden es la ciencia que estudia los sistemas complejos: máquinas, organismos biológicos, grupos humanos, a través de los mecanismos de regulación interna y con especial atención a sus finalidades. En ella se postula que el observador se mantiene fuera del fenómeno observado, dando origen a la suposición de que aquél es capaz de manipular o controlar unilateralmente el sistema que está observando.

La Cibernética del Segundo Orden es el estado de las condiciones en que los sistemas humanos toman conciencia de los mecanismos de regulación interna y de sus finalidades, transformando de ese modo sus mismos mecanismos de regulación y esas finalidades. El observador es consciente, "se observa observar, y con ello transforma radicalmente el carácter de su observación" (Foerster, 1994).

La Cibernética de Segundo Orden es como el manifiesto aplicable a nuestra propia vida, dado que en el diario vivir construimos con el otro una nueva realidad cimentada en la libertad y la responsabilidad. Foerster lo destaca de la siguiente manera: "La cibernética de segundo orden abre un espacio para la reflexión sobre el propio comportamiento y entra directamente en el territorio de la res- ponsabilidad y la ética, fundamentado en la premisa de que no somos descubridores de un mundo exterior a nosotros, sino inventores o constructores de la propia realidad". Asumir esta posición se manifiesta en el quehacer científico, docente, empresarial, pero también en las relaciones de la vida diaria.

Según Jutoram (1994), si uno se considera un observador independiente "puede decir al otro cómo pensar y actuar: Tú debes, tu no debes. Este es el origen de los códigos morales. Si uno se considera un actor participante en el drama de la mutua interacción, del dar y recibir, en la circularidad de las relaciones humanas dada mi interdependencia, sólo puede decirme a mí mismo cómo pensar y actuar: Yo debo, yo no debo este es el origen de la ética".

Desde este punto de vista, soy yo como usuario de Internet quien debe reflexionar sobre la reflexión del uso que le estoy dando a mi tiempo en el Internet, ¿qué redes sociales son las que más utilizo?, ¿Qué tipo de información es la que comparto?, ¿qué tipo de fotografías estoy publicando?, ¿cuánto tiempo de mi vida le dedico a estar conectado/a?, ¿Qué cosas dejo de hacer?, ¿a quién le estoy negando el tiempo que le otorgo al Internet?, ¿qué experiencias dejo de vivir?, ¿es razonable lo que pierdo comparado con lo que gano usando el Internet?, ¿estoy consciente del efecto de la publicidad en mi vida?

Creo que es el momento de hacer una reflexión basada en la cibernética de segundo orden para poder establecer clara y razonablemente hasta donde estoy dispuesto a permitir la pérdida de mi privacidad, la poca convivencia familiar, renunciando a un tiempo que no volverá, el querer impresionar a gente 
que no conozco y que no me quiere, a sumar muchos amigos virtuales pero muy pocos 0 ningún amigo de verdad, a dejar morir los rituales comunitarios, hasta donde soy capaz de distinguir la verdad de la ficción en los textos que leo en las redes, a desarrollar una alfabetización que me ayude a desarrollar mi libertad y mi responsabilidad.

Por una parte, es importante colaborar para que existan regulaciones razonables a lo que se puede y se debe publicar en el Internet, ya que es un espacio que carece de regulaciones. Es sumamente fundamental evitar que el actual formato de innovación y desarrollo "corporativo e industrialista" atropelle y vuelva más precarios los derechos humanos de las poblaciones. Por otra parte, es muy deseable y conveniente la regulación pública para aprovechar mejor las tecnologías en la construcción de sociedades más justas, incluyentes y democráticas. De hecho, hay tres aspectos que degradan los derechos ciudadanos a escala global:

a) La privacidad. Existen varios informes y documentos a nivel internacional que describen un escenario de violación masiva de los derechos a la intimidad/privacidad reconocidos a los pueblos en las Constituciones nacionales y garantizados en instrumentos internacionales. Recordemos el caso de vigilancia masiva y ciberespionaje que algunos Estados-nación han construido a nivel global, que se volvieron de dominio público a través de las filtraciones de Chelsea Mannign y Edward Snowden.

b) Derecho de autor y derecho de copia. Las capacidades de copia se están distribuyendo a nivel internacional de una forma injusta $y$ asimétrica. No está claro aún cómo deben repensarse democráticamente las regulaciones sobre bienes y obras intelectuales, informaciones y datos. El derecho de copia y la disponibilidad de los bienes intelectuales deberían ser construidos y ejercidos como derechos humanos fundamentales.

c) Libertad de expresión y censura. Las libertades de expresión de la ciudadanía no pueden estar secuestradas por las condiciones de uso que plantean algunas corporaciones.

d) Debemos luchar por superar la "neutralidad", un concepto diseñado a la medida de los intereses de las grandes corporaciones de Internet. Debemos lograr el isomorfismo (igualdad ante la ley) para que podamos disfrutar justamente de los avances tecnológicos sin renunciar a nuestra privacidad y sin ser víctimas de los abusos que se pueden llevar a cabo por la falta de regulación en la red de redes.

Es lo que Friedman (2018) llama "el surgimiento de una innovación moral basada en valores sustentables, construidos y consolidados a través de la colaboración". Colaboración entre las grandes corporaciones que comparten contenidos en Internet, acuerdos de cooperación entre países para regular dichos contenidos, pero también responsabilidad individual de impregnar de carácter bioético la red y definir buenas prácticas basadas en la cibernética de segundo orden.

\section{Referencias bibliográficas}

Alter, A., 2018. La adicción a las pantallas avanza silenciosa. El país. 23/04/2018. Tecnología. Disponible en https://elpais.com/tecnologia/2018/04/24/actualidad/1524577831_486816.html 
Can You Separate Fact from Fiction? 2019. For the AETeacher Program, sponsored by the U.S. Department of State and administered by $\mathrm{FHI} 360$. This work is an adaptation of Can You Separate Fact from Fiction by ShareAmerica.gov. Adapted content is licensed under the Creative Commons. Disponible en Http:// Creativecommons.org/licneses/by/4.0/

Cobo Romaní C.; Pardo Kuklinski H. Planeta Web 2.0. Inteligencia colectiva o medios de fast food". Grup de Recerca d'Interaccions Digitals, Universitat de Vic. Flacso México. Barcelona. Disponible en https:// www. planetaweb2.0.net/
Foerster, V.,1994. Ética y cibernética de segundo orden. Santafé de Bogotá, pág. 89.

Friedman, T., 2018. Gracias por llegar tarde. Como la tecnología, la globalización y el cambio climático van a transformar el mundo en los próximos años. Barcelona. Deusto.

Han, B., 1959. La desaparición de los rituales. Barcelona, Herder Editorial.

Jutoram, S., 1994. El proceso de las ideas sistémico-cibernéticas. Sistemas familiares. Año 10, No 1. Buenos Aires. Pág. 20-21.

\section{Sobre autora}

\section{Linda Evelin Espinoza Recinos}

Secretaria Bilingüe, Licenciada en Pedagogía y Administración Educativa y Maestra en Investigación, cuenta con 22 años de experiencia como docente en el nivel medio, ciclo básico y diversificado enseñando Ciencias Sociales y Lenguaje y comunicación L3 (idioma inglés) y 8 años de experiencia laboral en la Carrera de Pedagogía del Centro Universitario JUSAC, de los cuales 6 han sido dedicados a cursos sobre Investigación. Se capacitó como Tutor Virtual en la Universidad Galileo. Actualmente se encuentra cursando el segundo semestre del Doctorado en Investigación en Educación en el Centro Universitario CUNORI.

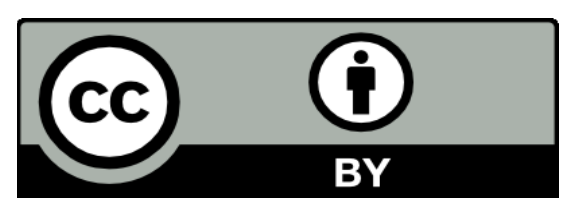

Este texto está protegido por una licencia CreativeCommons 4.0.

Esta licencia permite que otros distribuyan, mezclen, adapten y desarrollen su trabajo, incluso comercialmente, siempre y cuando le den crédito por la creación original. 



\title{
"El clima laboral en la empresa constructora CARMOR, del municipio y departamento de Jalapa"
}

\section{"The work environment in the construction company CARMOR, of the municipality and department of Jalapa "}

\section{Como citar el artículo}

Aragón, H. (2020). El clima laboral en la empresa constructora CARMOR, del municipio y departamento de Jalapa. Revista Naturaleza, Sociedad y Ambiente, 7 (1), 103-128. DOI: https://doi.org/10.37533/cunsurori.v7i1.55

Hugo Jovany Aragón González

\section{Centro Universitario de Sur Oriente, Universidad de San Carlos de Guatemala}

Recibido: 14 de abril de 2020 / Aceptado: 10 de septiembre de 2020

Disponible en internet el 10 de noviembre de 2020

*Autor para correspondencia, correo electrónico: jovanyaragon@gmail.com

\begin{abstract}
Resumen
El presente artículo sobre el estudio de caso realizado en la empresa constructora CARMOR del municipio y departamento de Jalapa, tiene como objeto principal exponer el compendio de datos sobre el clima laboral en la mencionada empresa. Se ha analizado cómo el manejo de la empresa influye en el comportamiento de sus empleados y poder determinar el grado de satisfacción laboral que ellos manifiestan. Para la obtención de esta información, se han tomado en cuenta temas importantes y de utilidad para diagnosticar los niveles en que se presentan las dimensiones del clima laboral. Los resultados obtenidos indican que el clima laboral no es completamente satisfactorio, puesto que existen ciertos parámetros que se han descuidado por parte de la organización, por lo que es necesario desarrollar e implementar en las áreas detectadas con alguna falla, estrategias de mejora en las insatisfacciones laborales encontradas.
\end{abstract}

Palabras clave: clima laboral, motivación, comunicación, liderazgo, satisfacción laboral

\begin{abstract}
The present article on the case study carried out in the company constructor CARMOR of the municipality and department of Jalapa, has as main object to expose the compendium of data on the work environment in the mentioned company. It has been analyzed how the management of the company influences the behavior of its employees and to determine the degree of job satisfaction they manifest. In order to obtain this information, important and useful topics have been taken into account to diagnose the levels at which the dimensions of the working environment are presented. The results obtained indicate that the work environment is not completely satisfactory, since there are certain parameters that have been neglected by the organization, so it is necessary to develop and implement in the areas detected with some failure, strategies for improvement in dissatisfactions labor found.
\end{abstract}

Keywords: work climate, motivation, communication, leadership, job satisfaction 


\section{Introducción}

En la actualidad las empresas desean brindar los mejores servicios, para lo cual necesitan el personal adecuado y capacitado para la ejecución de cada una de las actividades que se requieran, lo que se logra mediante un clima laboral adecuado. En Guatemala como en el mundo entero, las empresas enfocan sus esfuerzos en brindar productos y/o servicios de la mejor calidad, para poder lograr una aceptable participación competitiva en el sector donde se encuentran. Es importante recalcar que para el logro de dichos objetivos es necesario contar con el capital humano, quienes serán los encargados de realizar dichas actividades, poniendo en práctica técnicas y actitudes necesarias, aportando así a la empresa sus conocimientos y habilidades para generar ambientes agradables dentro de la organización.

La presente investigación tuvo como objetivo principal el análisis de los factores que afectan el clima laboral en la empresa constructora CARMOR , ubicada en el municipio y departamento de Jalapa. Siendo una investigación de tipo descriptivo, como fuente se presentan antecedentes de investigaciones sobre el clima laboral y un marco teórico en donde se incluye información sobre los indicadores utilizados, los cuales fueron: motivación, comunicación, liderazgo y satisfacción laboral. Los sujetos de estudio fueron 122, los cuales estaban conformados por 14 en el nivel administrativo y 108 en el nivel operativo. El instrumento utilizado para la recolección de información fue el cuestionario, con una escala que abarcó los criterios: nunca, algunas veces, frecuentemente y siempre.

Se logró concluir que el clima laboral de la empresa constructora CARMOR, es parcial- mente favorable, con las observaciones que, siempre existirán algunos empleados que no se sienten a gusto ni motivados con el trabajo que están desempeñando por situaciones de contratación, de incentivos, prestaciones y jornadas laborales. Por ello, es necesario fortalecer el indicador motivación, lo cual se puede realizar mediante un programa de reconocimientos y alicientes para el personal, recordando que la buena comunicación, las relaciones personales, el gusto por el trabajo, buena remuneración y la fomentación de desarrollo en los trabajadores, son factores importantes que influyen en el clima laboral e incrementan la productividad de la empresa.

\section{Referente teórico Clima laboral}

Katz y Kahn (1989), afirman que toda organización crea su propia cultura o clima organizacional. El clima o cultura refleja las normas y valores del sistema formal y la manera en que los interpreta el sistema informal. También es un reflejo de la historia de las luchas internas y externas, los tipos de personas que la organización atrae, sus propios procesos laborales, las formas de comunicación y como se practica la autoridad dentro del sistema. Robbins y Judge (2009), se refieren al clima laboral como la manera en que las personas actúan dentro de las organizaciones, encierra el impacto de los individuos, grupos y estructuras y que de él depende la conexión del sistema social.

Por otra parte, Chiavenato (2009), aborda al clima laboral en el contexto de los procesos de motivación dentro de los espacios organizacionales. Las personas se adaptan continuamente a diversas situaciones para satisfacer sus necesidades y mantener el equilibrio emocional. Para Méndez (2006), 
el origen del clima laboral está en la sociología; el concepto de organización dentro de la teoría de las relaciones humanas, destaca la importancia del hombre en la función del trabajo y la participación en un sistema social. El clima o comportamiento organizacional, es el estudio que se ocupa de las gestiones de los trabajadores.

\section{Motivación}

Según Ardouin et al., (2000), la motivación puede definirse como la voluntad que tienen los individuos para realizar esfuerzos hacia las metas que tienen las organizaciones, satisfaciendo al mismo tiempo necesidades individuales. Es de importancia en los colaboradores de una compañía, puesto que ellos darán todo de sí en pro de un objetivo organizacional y personal, aportando ideas creativas e innovadoras a la empresa. McGregor (1966), hace mención que en algunas ocasiones sucede que, aunque la necesidad no se satisfaga, tampoco existe frustración pues se transfiere a otra necesidad. Puede deducirse, que la motivación tiene diferentes niveles de estructura y desarrollo.

El clima laboral está ligado con la motivación, si los trabajadores están motivados el clima laboral es alto y proporciona satisfacción, animación, interés y colaboración entre el personal. Por su parte, García (2007), argumenta que si la motivación para los empleados es baja, existe frustración y se sienten insatisfechos, lo cual deteriora el ambiente interno de la institución. Es el deseo de esforzarse por alcanzar las metas, con la finalidad de satisfacer alguna necesidad individual. Debe entonces, concentrarse en metas a fin de reflejar el interés primordial por el comportamiento ligado con la motivación y el sistema de valores que rige la organización.

\section{Comunicación}

Amoros (2007), explica que es lógico que ningún grupo pueda existir sin la comunicación, entendiéndose ésta como la trasmisión y el entendimiento del significado. Con este punto de vista, es importante entender que una empresa no funciona si no existe una comunicación entre sus miembros. Tiene como base las redes de comunicación que existen dentro de la organización, así como la facilidad que tienen los empleados de hacer que sus comentarios sean escuchados y tomados en cuenta. La comunicación brinda un medio para la expresión emocional de los sentimientos y para satisfacer las necesidades sociales.

Proporciona información que los individuos y grupos necesitan para tomar decisiones por medio de la transmisión de datos. Adler (2005), indica que todos los colaboradores se comunican, sin importar cuál sea el campo de acción o cuanto se conozca el tema, el conocimiento especializado no es suficiente para alcanzar el éxito. Las habilidades para comunicarse son relevantes, puesto que una gestión eficaz y eficiente de la comunicación tiene mucho que decir en el momento de crear valor en las organizaciones, inmersas en un acelerado y competitivo mundo empresarial.

\section{Liderazgo}

Blanchard (2000), afirma que el liderazgo es la capacidad de influir en los demás por medio de la manifestación del poder y el potencial de las personas y organizaciones, para lograr mayores intereses. James y Lindsey (2008), definen al liderazgo como la habilidad de influir positivamente en la gente y los sistemas bajo la autoridad de uno a fin de tener un impacto significativo y lograr resultados importantes. El liderazgo permite a un gerente 
obtener una participación activa y consciente en la consecución de los objetivos institucionales. Por tal razón, debe crear un ambiente propicio, estable y tranquilo para que los colaboradores se desarrollen de forma satisfactoria para el bienestar de la empresa.

Sallenave (1994), resalta que la habilidad del liderazgo, es la capacidad para comprender que los seres humanos tienen diferentes fuerzas motivadoras, en distintos momentos y en diversas situaciones; habilidad para inspirar, y la fuerza para actuar de forma tal, que establezca un clima laboral apropiado, para responder y para despertar motivaciones, al implementar un estilo de liderazgo que integre el buen trato y respeto por las personas. Para Espinoza (1999), los directivos tienen que ser estrategas, organizadores y líderes. Es la capacidad que tiene una persona de formular planes de éxito y de motivar a los demás para que se lleven a cabo, a pesar de las dificultades y riesgos que se tengan que enfrentar.

\section{Satisfactores del trabajo}

De acuerdo con Dessler (2009), los satisfactores son un conjunto de elementos que condicionan el estado de bienestar psicológico en el trabajo. Algunas personas lo asocian con la motivación en el trabajo, a través de compensaciones monetarias, estímulos psicológicos y bienestar derivado de la asociación y el contacto con otras personas. La satisfacción del trabajo no solo es derivada de la interacción con las personas con las que se tiene contacto directo y activo en un momento determinado, sino que también por contacto de con quienes se estuvo relacionado directamente y que ahora se relaciona indirecta y ocasionalmente.
Para Landy y Conte (2005), la presencia de insatisfactores en el trabajo puede disminuir el desempeño en el trabajo. Su impacto sobre el cometido en el trabajo, tiene mayor fuerza que la satisfacción. Esto indica que si se desea aumentar la productividad en el trabajo como consecuencia de la satisfacción laboral, se debe trabajar los factores específicos asociados a las condiciones de trabajo en donde se producen insatisfacciones. La importancia relativa de un aspecto laboral en particular para el trabajador, influye en sus respuestas a ese aspecto laboral, es decir, que si se valora más el elogio de un jefe que la admiración de los compañeros, la satisfacción general con la empresa se verá más fuertemente influida por sus interacciones con el jefe que con la de los compañeros. 
Figura No. 1 Modelo de los determinantes de la satisfacción

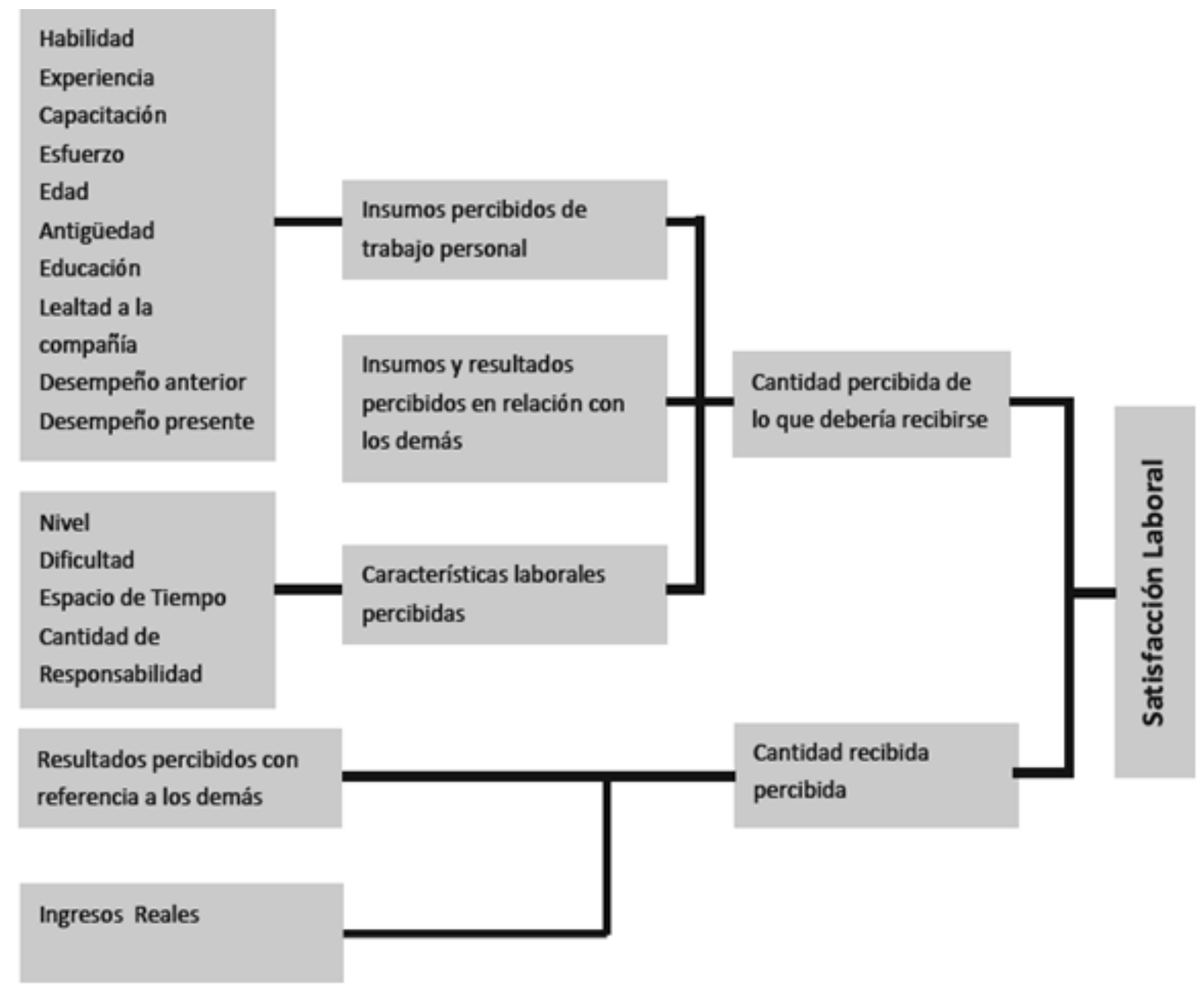

Fuente: Elaboración propia, con base a Landy y Conte (2005).

\section{Satisfacción laboral}

Según Robbins y Judge (2009), la satisfacción laboral se define como el pensamiento positivo respecto del trabajo propio, que resulta de una evaluación de sus características, representa una actitud en vez de un comportamiento. Rodríguez y Baker (2011), han encontrado una relación positiva con el rendimiento y la productividad, de modo que quienes están satisfechos con su trabajo presentan un mayor rendimiento y son más productivos. Las facetas de la satisfacción laboral son las siguientes: la satisfacción laboral propiamente dicha, la satisfacción con el salario, la satisfacción con los compañeros, la satisfacción con los jefes, y la satisfacción con los ascensos, cada faceta de la satisfacción en diferentes grupos contiene los elementos actitudinales de los componentes afectiva, cognitivo y del comportamiento. Adicionalmente se encontró que la relación entre la satisfacción laboral e inseguridad laboral, seguía siendo significativa después de tener en cuenta variables demográficas tales como la edad, permanencia en la organización y género. Para García (2007), es común pensar que hoy en día las empresas proporcionan espacios físicos de trabajo saludable, seguros, y cómodos y además proveer las 
herramientas para realizar su trabajo de la mejor manera posible. A medida que se investiga más sobre este aspecto se encuentra que aún las variaciones más modestas en temperatura, ruido, iluminación o calidad del aire, pueden ejercer efectos apreciables en el desempeño y las actitudes del empleado.

\section{Metodología}

Llevar a cabo una investigación implica considerar diferentes métodos, técnicas e instrumentos para la construcción del conocimiento científico. Esto significa un compromiso con la calidad del tipo de conocimiento que se produce.

\section{Método}

El estudio de casos es el método que fue utilizado para realizar la investigación del clima laboral en la empresa constructora CARMOR del municipio y departamento de Jalapa. Este proceso se caracterizó por analizar con profundidad el objeto y establecer cómo funcionan todas las partes que lo componen y las relaciones entre ellas, para formar un todo. En su realización se efectuó una encuesta de forma general en todas las áreas de la empresa, cubriendo el 83\% (122 trabajadores) de la población total; debido a que no se obtuvo el acceso a todos los empleados, porque algunos no se encontraban en la cabecera departamental de Jalapa, cumpliendo con sus labores en proyectos que la empresa realiza. Esto ocasionó que no se compartiera con todos los colaboradores de la constructora en las distintas áreas de trabajo, pero sí se logró trabajar con un alto porcentaje.

\section{Indagatoria}

Se llevó a cabo por medio de los procesos de recolección de información, directamente de las fuentes primarias (cuestionario a los empleados) y secundarias (libros y textos), de los cuales se obtiene los elementos necesarios para la elaboración del informe.

\section{Técnica}

Para la técnica de investigación, se utilizó una encuesta sobre el clima laboral para recolectar los datos, enfocada hacia la obtención de información acerca del compromiso y la satisfacción laboral de los colaboradores de la constructora en mención, dirigido al nivel administrativo, asistencial y operativo de la constructora CARMOR. Las 122 encuestas se distribuyen en las ocho áreas que cuenta la empresa, cubriendo de esta manera el $83 \%$ de la población total, con la que se midieron las variables siguientes:
a. Motivación.
b. Comunicación.
c. Liderazgo.
d. Satisfacción laboral.

\section{Instrumento}

El instrumento utilizado para la elaboración de la encuesta, fue un cuestionario, un formulario con un listado que contiene 15 preguntas que se formuló de idéntica manera para todos los encuestados con 4 diferentes opciones, con el cual se obtuvo información apegada a la realidad de los empleados de la empresa constructora CARMOR, para diagnosticar y analizar los datos adquiridos, que fueron de relevancia en la elaboración de las gráficas y la construcción de conclusiones y discusión de datos. Una de las ventajas de utilizar el cuestionario, es que se requiere relativamente de poco tiempo para reunir la información que se desea conseguir, especialmente en este caso, que es un grupo numeroso. Las 
cuatro diferentes opciones de cada pregunta, 2-Algunas veces contemplan los siguientes criterios: 3 - Frecuentemente 1 - Nunca 4 - Siempre

Tabla No. 1 Listado de colaboradores de la Constructora CARMOR

\begin{tabular}{|c|l|c|}
\hline No. & \multicolumn{1}{|c|}{ Área } & Cantidad \\
\hline 1 & Gerencia & 3 \\
\hline 2 & Recepción & 1 \\
\hline 3 & Diseño y planificación & 6 \\
\hline 4 & Jefe de operaciones & 1 \\
\hline 5 & Administración de proyectos & 3 \\
\hline 6 & $\begin{array}{l}\text { Maestros de obra (choferes, } \\
\text { operadores, peones, albañiles) }\end{array}$ & 117 \\
\hline 7 & Asistente de operaciones (mecánicos) & 14 \\
\hline 8 & Auxiliar de contabilidad & 2 \\
\hline & & 147 \\
\hline
\end{tabular}

Fuente: Elaboración propia, con base a información de la empresa.

\section{Resultados}

A continuación se presentan los resultados obtenidos de la investigación de campo realizada en la empresa constructora CARMOR, que reflejan las opiniones de los empleados del nivel administrativo y operativo, por medio del cuestionario "Clima laboral".

Figura No. 1 Motivación para realizar eficientemente las funciones

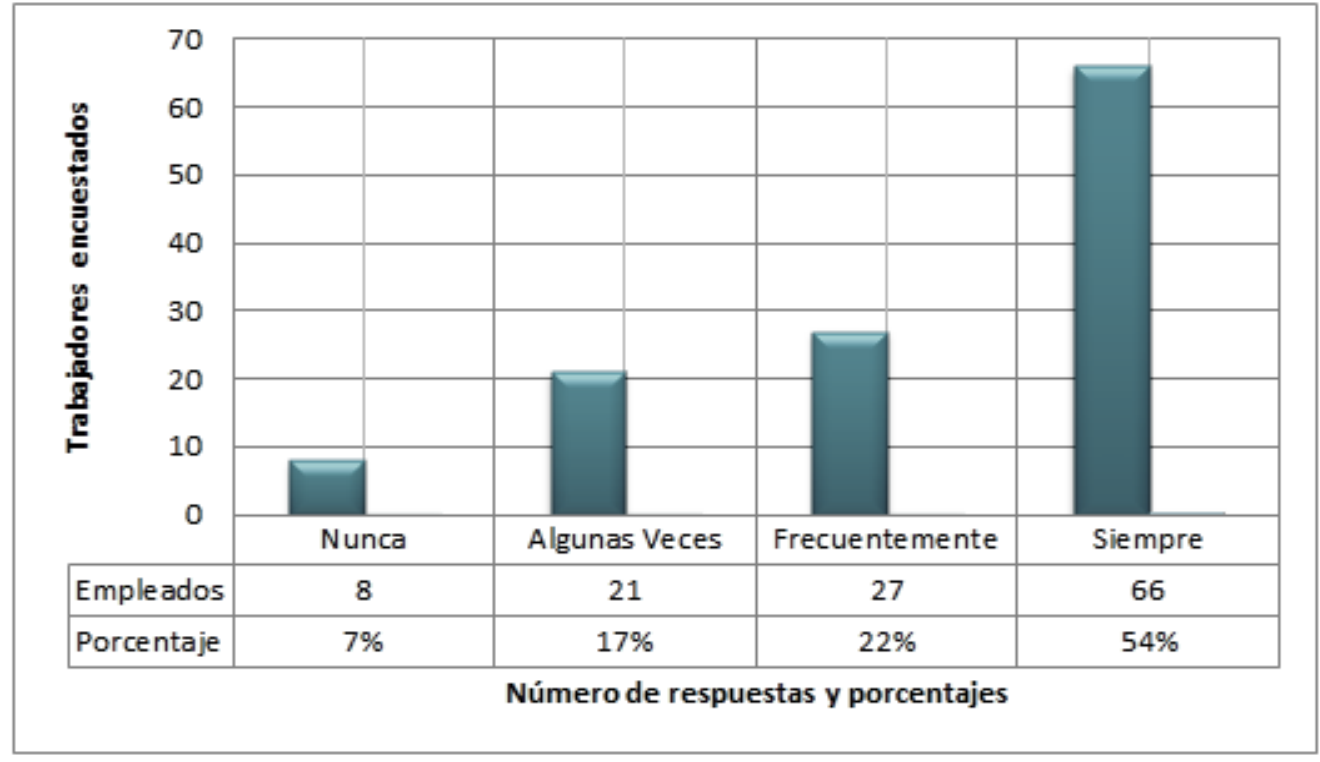

Fuente: Elaboración propia, con base a información de la empresa. 
La gráfica 1, indica que un $54 \%$ siempre está motivado dentro de la constructora. Existe un $22 \%$ que lo está frecuentemente, un $17 \%$ que lo manifiesta algunas veces, y un bajo porcentaje del $7 \%$ que nunca lo está. Estas cantidades deben analizarse puesto que no todos los empleados están altamente motivados en su labor y puede observarse que dentro de la constructora, existen causas que desmotivan a los empleados, como la falta de estímulos de diferentes tipos. En este punto, Robbins y Coulter (2005), hace notar que la motivación son todos los procesos responsables directamente del deseo de un individuo de realizar un gran esfuerzo para lograr objetivos organizacionales condicionados por la capacidad de satisfacer algún tipo de necesidades individuales. No siempre se logrará que los colaboradores realicen su trabajo con esfuerzo si estos no reciben la motivación necesaria por parte de los jefes.

Figura No. 2 Sentimiento de acogimiento entre compañeros de área

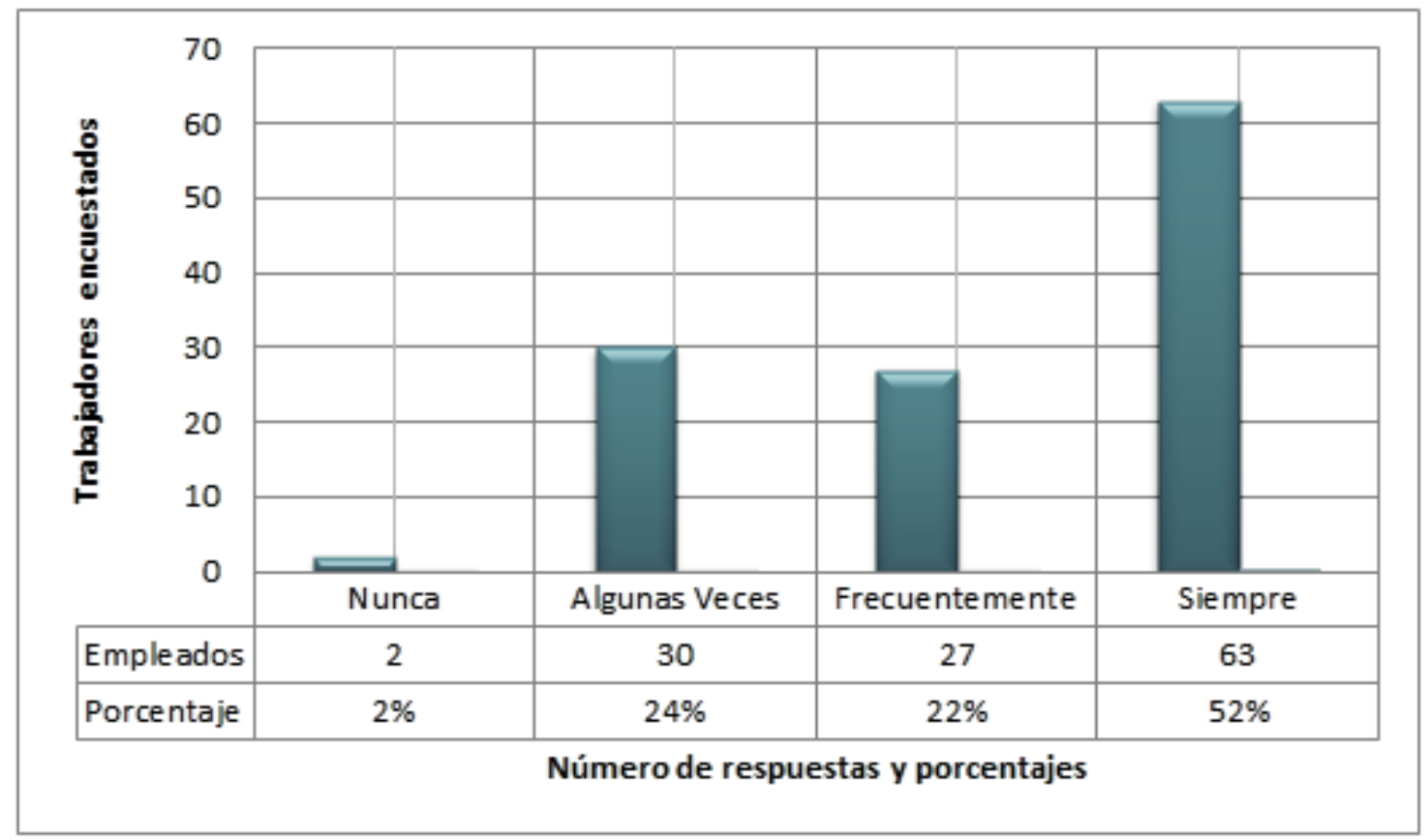

Fuente: Elaboración propia.

Se puede observar en la gráfica 2 , que un $52 \%$ de los empleados consideran que siempre existe buena relación con sus compañeros y con los superiores; un $22 \%$ perciben frecuentemente un acogimiento entre compañeros. El $24 \%$ de los encuestados piensan que algunas veces se han sentido bien recibidos en su área de trabajo, mientras que un $2 \%$ dicen que nunca han experimentado esta clase de relación armónica. Con estos resultados se puede deducir que dentro de la constructora existe un ambiente agradable para la mayoría, lo que hace que se facilite la convivencia, provocando que exista conformidad en el grupo de trabajo. Como lo dice García (2011), es importante tener en cuenta que la falta de comunicación genera problemas dentro de las organizaciones y torna difíciles los procesos. Por ello, la mayoría de los empleados logran los objetivos de cada departamento, al buscar trabajar en equipo y transmitir adecuadamente la información. 
Figura No. 3 Compatibilidad con el trabajo y los objetivos de la empresa

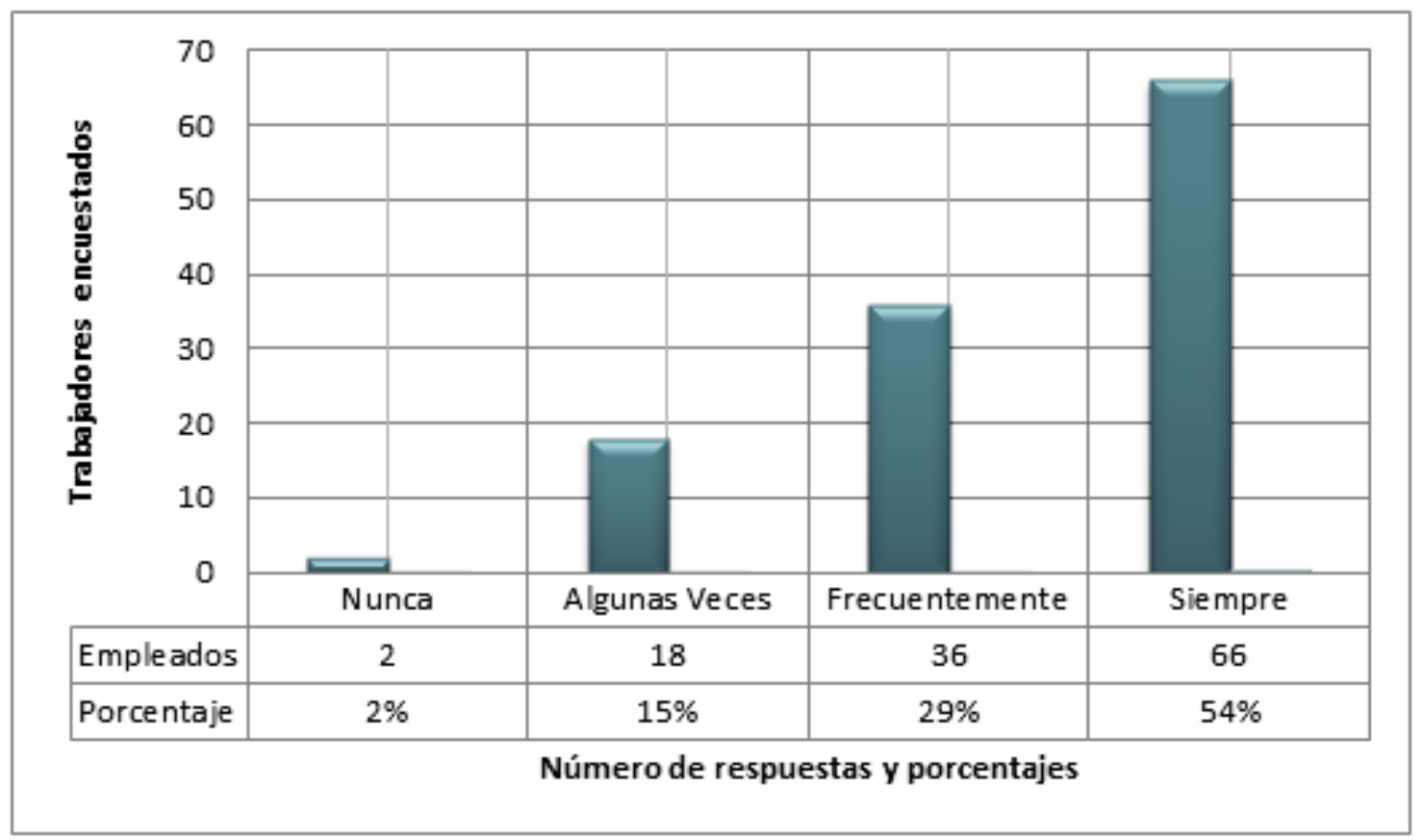

Fente: Elaboración propia.

El compromiso que cada colaborador tiene con la empresa, que es de suma importancia para el logro de las metas. La gráfica 3 muestra que un 54\% establece que siempre existe ese compromiso personal con la empresa para lograr cada uno de los objetivos establecidos; el $29 \%$ manifiesta que es frecuente su compatibilidad con lo que la empresa pretende. Un $15 \%$ de los empleados en algunas veces tienen un compromiso personal con la constructora, mientras que solamente un $2 \%$ de las personas encuestadas afirman que nunca han sido compatibles con la constructora. En este aspecto, es necesario señalar que aunque es muy bajo el porcentaje, existen personas que no se sienten parte de la empresa y su trabajo no tiene relación o vínculo alguno, un punto que para los objetivos de la empresa se convierte en un aspecto negativo. A ello se refiere Mitchell (1997), cuando aclara que en el centro de la teoría del establecimiento de metas se encuentra la idea de la acción con propósito. Las personas eligen las metas que se relacionan con la satisfacción de las necesidades, la aspiración y la búsqueda de deseos son parte central del proceso de la vida misma; por lo que la acción consciente y auto dirigida, es la responsable de casi todo lo que la gente hace. Por este motivo es que la constructora, en un alto porcentaje, cumple con sus objetivos gracias a los trabajadores que generalmente se encuentran motivados por parte de ella. 
Figura No. 4 Interés en los trabajadores por parte de jefes y supervisores

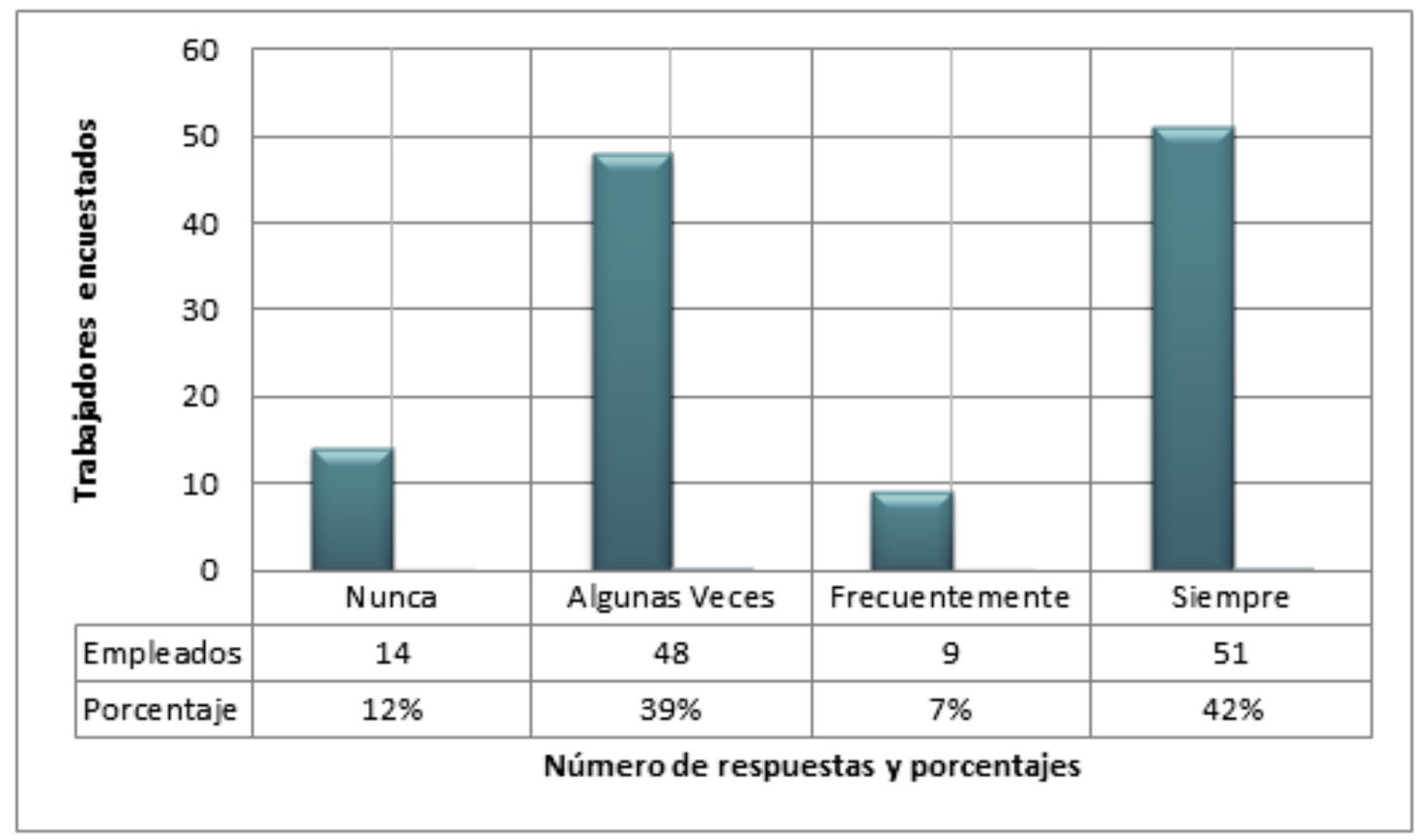

Fuente: Elaboración propia.

La interacción y la convivencia que existe entre jefe y empleado es un aspecto que debe de ser aplicado con ética y profesionalismo dentro de toda organización. Cada quien debe reconocer su cargo y por ende el puesto que le corresponde según el orden de jerarquía institucional. La gráfica 4 muestra que un $42 \%$ siempre sienten ese interés por parte de sus superiores. Solamente un $7 \%$ lo perciben frecuentemente, mientras que el $39 \%$ creen que en algunas veces hay muestras de interés por ellos, y un $12 \%$ aseguran que nunca lo han experimentado. En toda institución debe existir armonía y confianza entre jefe y empleado, para poder establecer bien los lazos de comunicación y estar al pendiente de qué es lo que necesitan los colaboradores, ya sea en materiales o recursos para que realicen su trabajo de una manera efectiva. Está claro que una parte considerable de los colaboradores no perciben ese interés por parte de sus jefes. Montes (2006), afirma que la mayoría de los trabajadores comprenden que es el supervisor quien a menudo controla el inicio y la longitud del intercambio, es decir que dependen de la actitud de las personas para poder interactuar con ellas. Existen personas que prefieren atención negativa a ser ignoradas, antes de que un supervisor o jefe se comunique con los trabajadores para impartirles las instrucciones laborales del día. 
Figura No. 5 Identificación positiva con el trabajo realizado

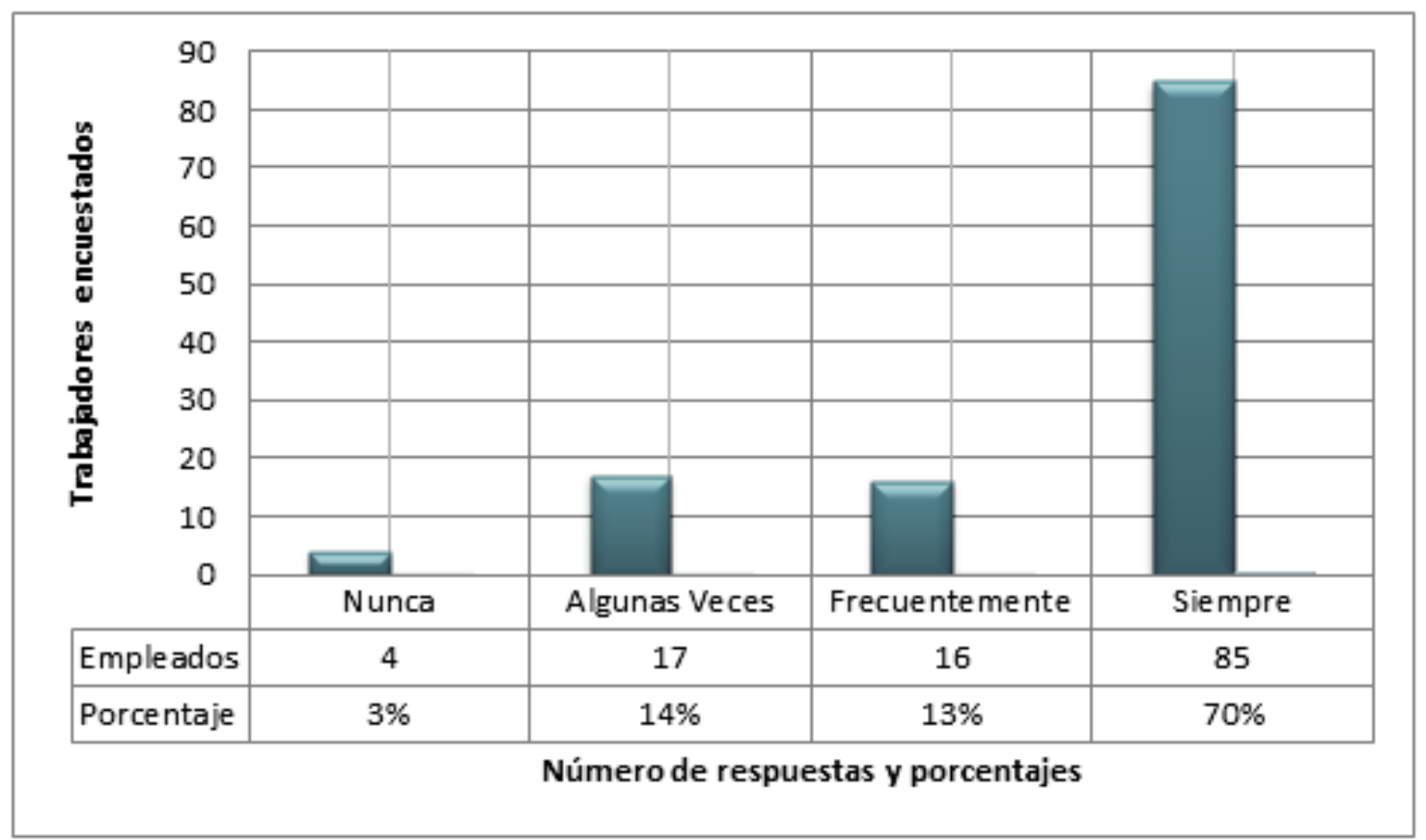

Fuente: Elaboración propia.

La gráfica 5 muestra una parte curiosa dentro de esta investigación, que el $70 \%$ de la población encuestada respondió siempre sentirse a gusto con su trabajo. El 13\% manifiesta que frecuentemente se identifica con su trabajo; el 14\% piensan que algunas veces se sienten cómodamente, mientras que un 3\% nunca están laborando con placer. Se dice que es curioso, porque según los resultados que muestran otras gráficas, un porcentaje considerable está pensando en otra clase de empleo. No es un porcentaje alto quien lo busca, pero sí existen algunas situaciones que pueden ser motivacionales que impulsen a algunos empleados a tomar estas decisiones. La constructora debe tomar importancia respecto al tema, como lo establece Cimpa (1990), que una empresa tiende a atraer y conservar personas que se adaptan a su clima. Los directivos deben percatarse de que el ambiente laboral forma parte del activo de la empresa, y como tal, deben valorarlo y prestar la debida atención, para lograr mayor tranquilidad y satisfacción por parte de los empleados. Debe considerarse también, que muchos de los colaboradores tienen tiempo laborando, lo que les induce a manifestar esa identificación laboral con la constructora, y que otros que inician en este trabajo, no se sienten completamente a gusto, o no se sienten cómodos en el área donde se desenvuelven. 
Figura No. 6 Recursos necesarios para poder desarrollar las funciones

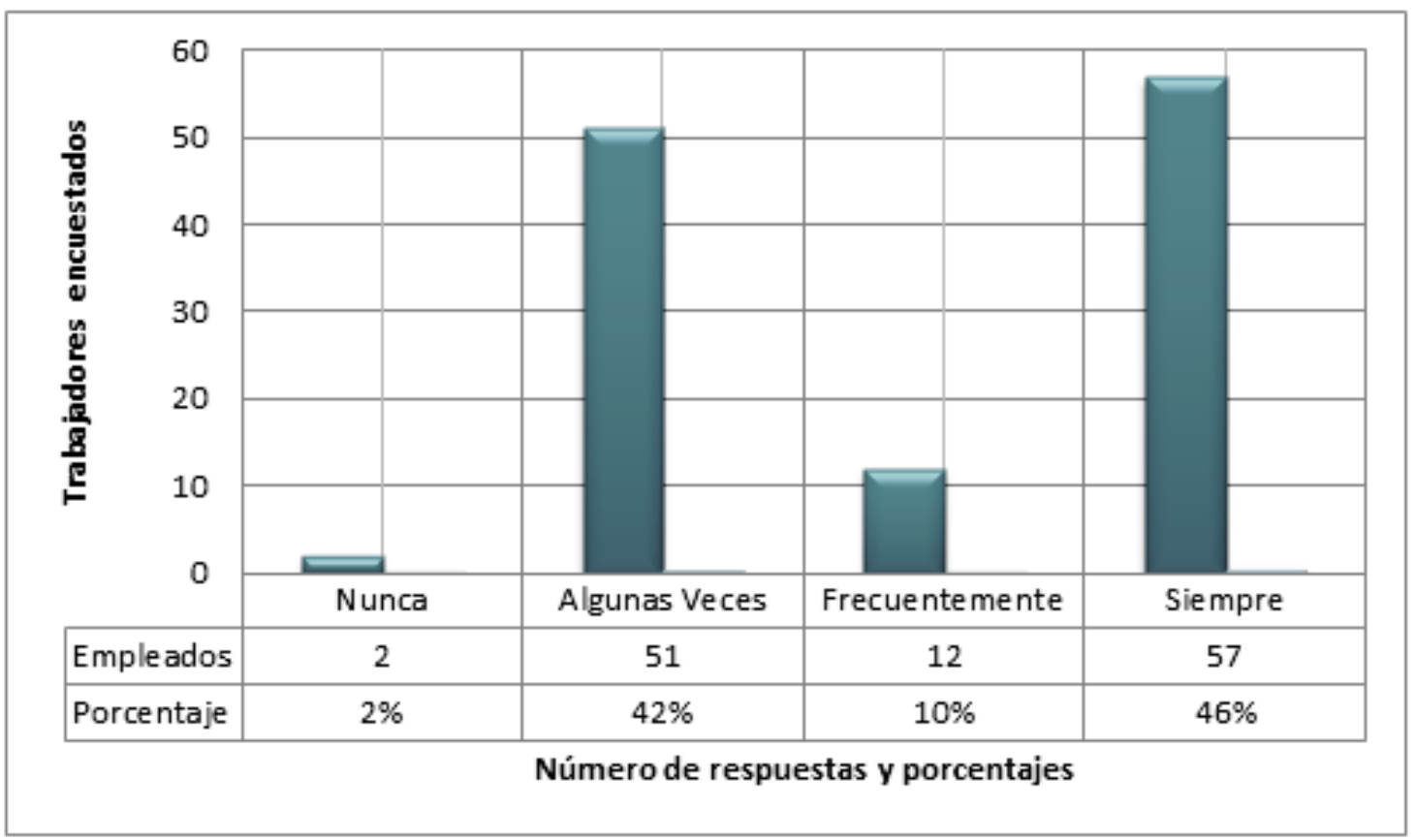

Fuente: Elaboración propia.

Puede observarse en la gráfica 6 que el $46 \%$ de las personas encuestadas dicen que siempre tienen los recursos necesarios en sus labores, mientras que un $10 \%$ aseguran que frecuentemente es que lo tienen. El $42 \%$ menciona que algunas veces sí lo tienen, y solamente el $2 \%$ respondieron que nunca tienen lo elemental para laborar. Este punto puede depender mucho del área o departamento donde se desenvuelven los empleados, pues dentro de las oficinas, la mayoría de personas cuentan con los recursos o herramientas necesarias para laborar, igualmente la mayor parte de los trabajadores de campo y los mecánicos. Lo que algunos colaboradores de campo expresan, es que no siempre tienen a tiempo los materiales o equipo para realizar sus labores. Según Lado y Wilson (1994), la diferencia en el rendimiento entre empresas se puede atribuir a la diferencia de recursos y capacidades existentes en las organizaciones. El objeto de cualquier empresa es generar una ventaja competitiva, con una rentabilidad superior a la de las empresas contendientes, por lo que utilizan recursos tangibles como intangibles en el desarrollo de sus estrategias. La situación en este marco apunta a que los jefes deben estar pendiente de su área de trabajo y que a sus subordinados no les falte o tengan a tiempo los instrumentos con los que elaborarán la tarea asignada. 
Figura No. 7 Actividades recreativas dentro de la constructora

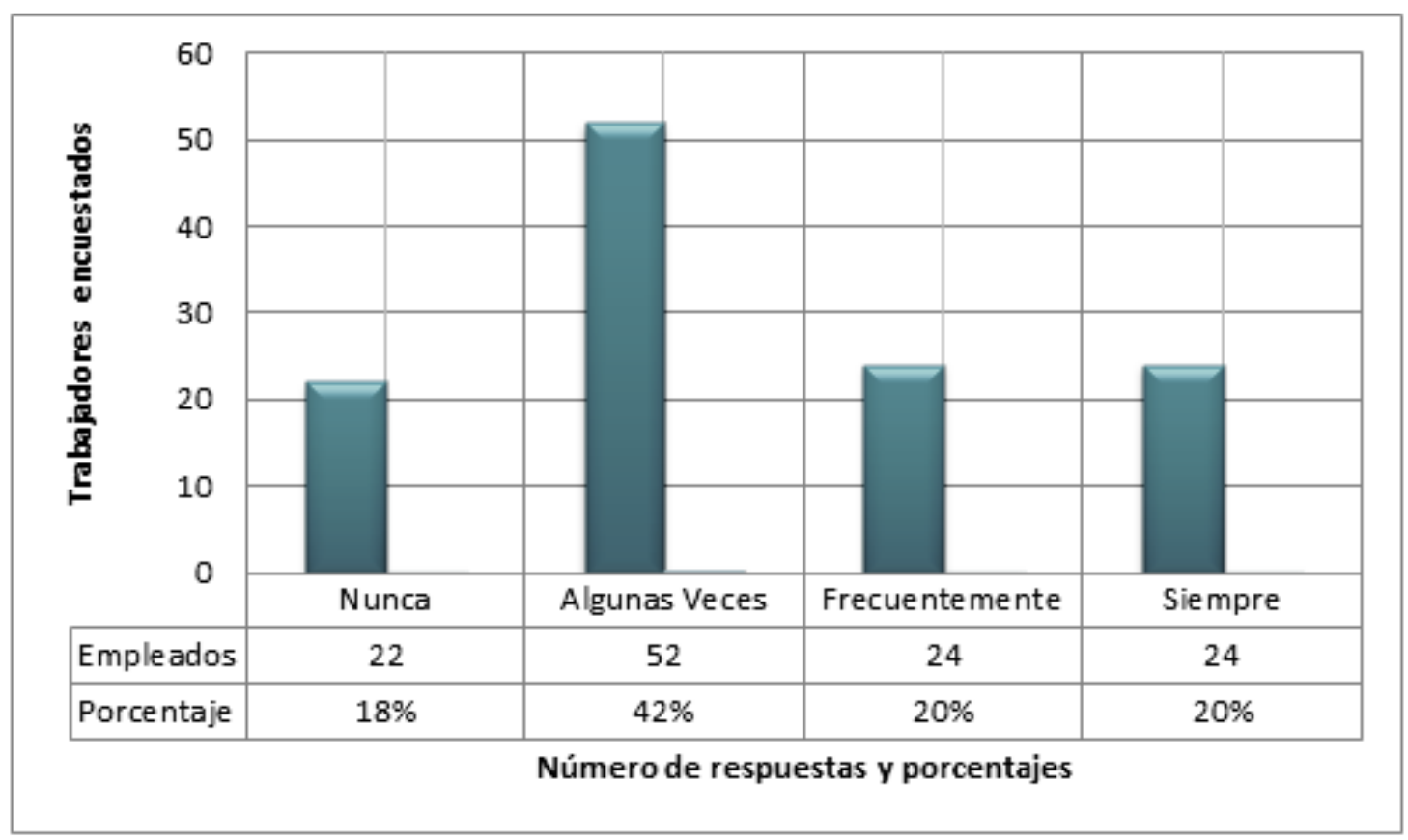

Fuente: Elaboración propia.

En la constructora puede observarse según la gráfica 7 , que no está definido a qué es lo puede nombrarse exactamente para todos los empleados, las actividades recreativas. Según pláticas con las personas de oficina, con quienes más contacto personal se mantuvo, mencionaron que celebraciones de cumpleaños y reconocimientos laborales o de estudios, sí se han realizado, pero que no se dan con tanta frecuencia. Por eso es que un $20 \%$ dice que siempre se realizan estas actividades, otro $20 \%$ indica que frecuentemente se llevan a cabo. El $42 \%$ menciona que en algunas veces se dan estas acciones, y el $18 \%$ aluden que nunca se ejecutan. Para Torres y Agulló (2002), la vida laboral se ve afectada no solo por factores intrínsecos al trabajo, sino también por todo lo que acontece en otras áreas extra laborales que conforman la vida diaria de los individuos, en este caso, las actividades recreativas. Los empleados de campo comentaron que por no estar presentes en ese momento, se pierden de esas diligencias, pero actividades recreativas que realmente sean utilizadas para motivar, agradecer o premiar a los trabajadores en general, no se realizan dentro de la constructora. La búsqueda de una vida laboral armoniosa, debe coincidir con los objetivos y metas de las empresas, para que de esta manera, lograr una estabilidad en el trabajo, beneficiando la productividad y eficiencia para ambas partes. 
Figura No. 8 Comunicación con superiores para solución a problemáticas

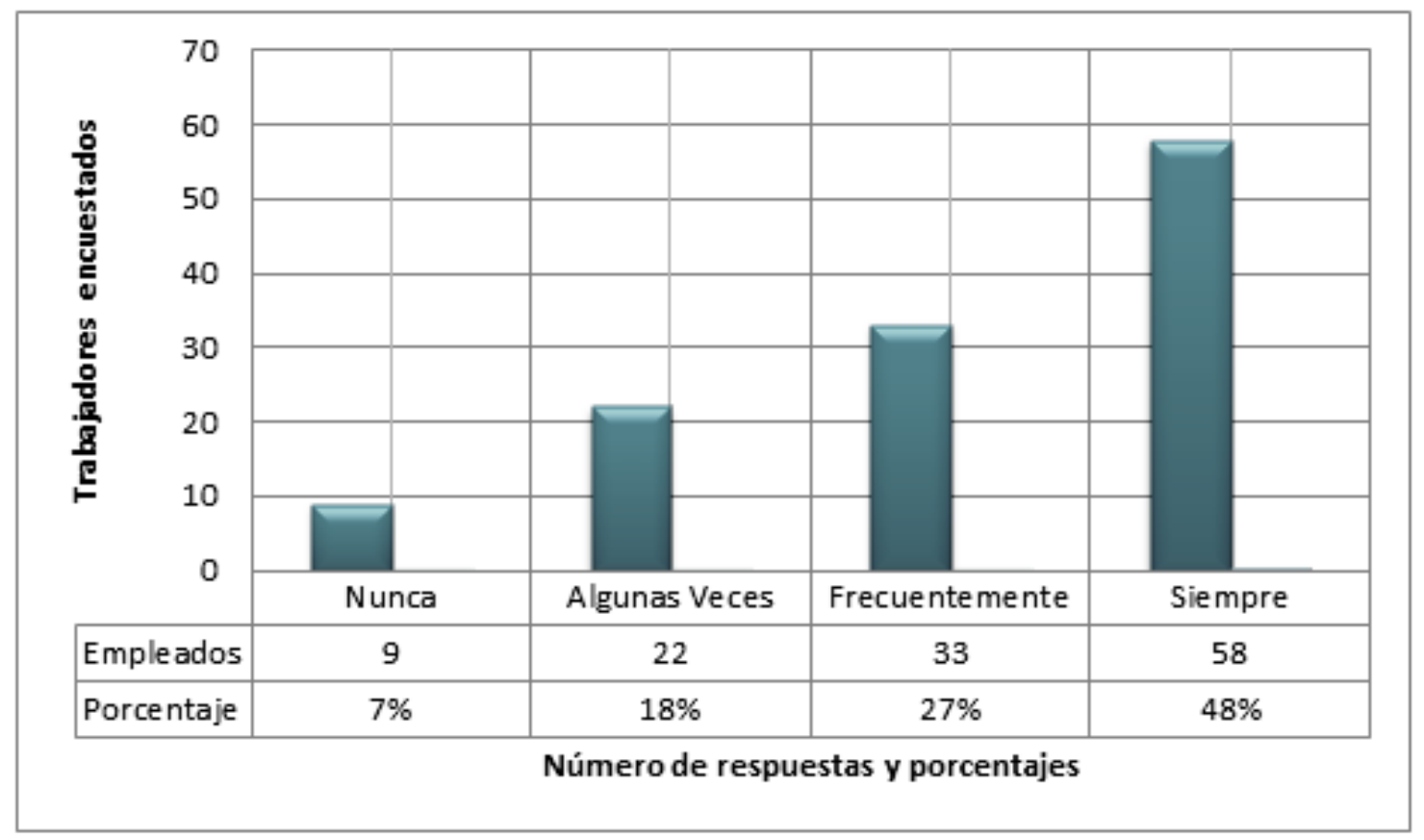

Fuente: Elaboración propia.

En la gráfica 8 , se refleja que un $48 \%$ de los empleados consideran que siempre pueden buscar el punto de vista de sus superiores o expresar algunas consultas con ellos. El $27 \%$ expresan que esto se da frecuentemente, mientras que el $18 \%$ opina que en algunas veces pueden tener esta comunicación, y el $7 \%$ afirman que nunca lo han establecido. Esto conduce a que algunos colaboradores se sientan satisfechos al ser escuchados, porque pueden preguntar, decir ideas y buscar mejorar en beneficio de la institución. Carretón (2007), hace referencia a que el boletín informativo o revistas, son los medios impresos más utilizados por las empresas, para mantener una relación informativa bidireccional con los trabajadores. Por tal razón, los colaboradores señalan que los medios escritos que se utilizan en la constructora, son eficaces para el traslado de la comunicación, puesto que las notificaciones de los altos mandos llegan a todo el personal. Pero existen también los trabajadores que indican que no tienen la confianza con el directivo de comentarle los problemas personales que afectan el rendimiento en el trabajo, con el fin de buscar soluciones y controlar las emociones; lo que puede provocar un mal desempeño y afectar a la organización. 
Figura No. 9 Satisfacción de los empleados con el puesto que desempeñan

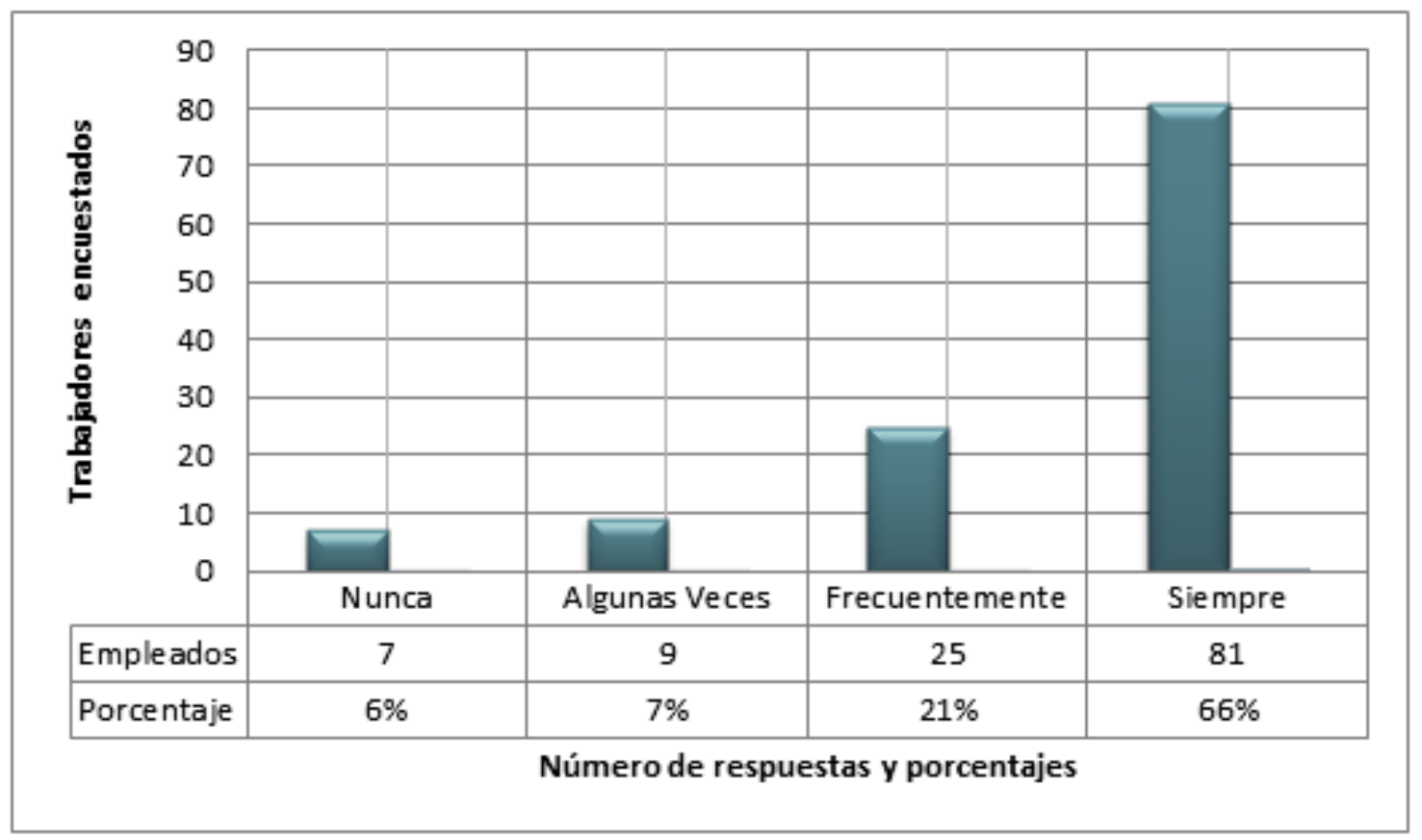

Fuente: Elaboración propia.

Lo que muestra la gráfica 9 , es que un $66 \%$ de los colaboradores de la constructora CARMOR siempre se sienten satisfechos con el puesto que tienen, mientras que un $21 \%$ creen que frecuentemente tienen ese sentimiento. El $7 \%$ piensan que algunas veces y solamente el $6 \%$ expresa que nunca está presuntuoso con su labor realizada. Muñoz (1990), define la satisfacción laboral como el sentimiento de agrado o positivo que experimenta un sujeto por el hecho de realizar un trabajo que le interesa, en un ambiente que le permite estar a gusto, dentro del ámbito de una empresa que le resulte atractiva y por el que percibe una serie de compensaciones acordes con sus expectativas. El éxito de una organización depende del desempeño de sus empleados, y por lo tanto, los trabajadores que expresan satisfacción son trabajadores productivos. La constructora debe obtener la perspectiva que necesita para asegurarse de estar haciendo todo lo posible para mantener al personal satisfecho y con su mejor desempeño. A pesar de que los otros porcentajes son bajos; deben de considerarse dentro de la empresa, puesto que existe algún motivo que esté dando estas manifestaciones de los empleados, al no sentirse a gusto con su puesto y poder conocer la postura de ellos para que ese sentimiento pueda reducirse. 
Figura No. 10 Satisfacción de necesidades básicas por el trabajo desempeñado

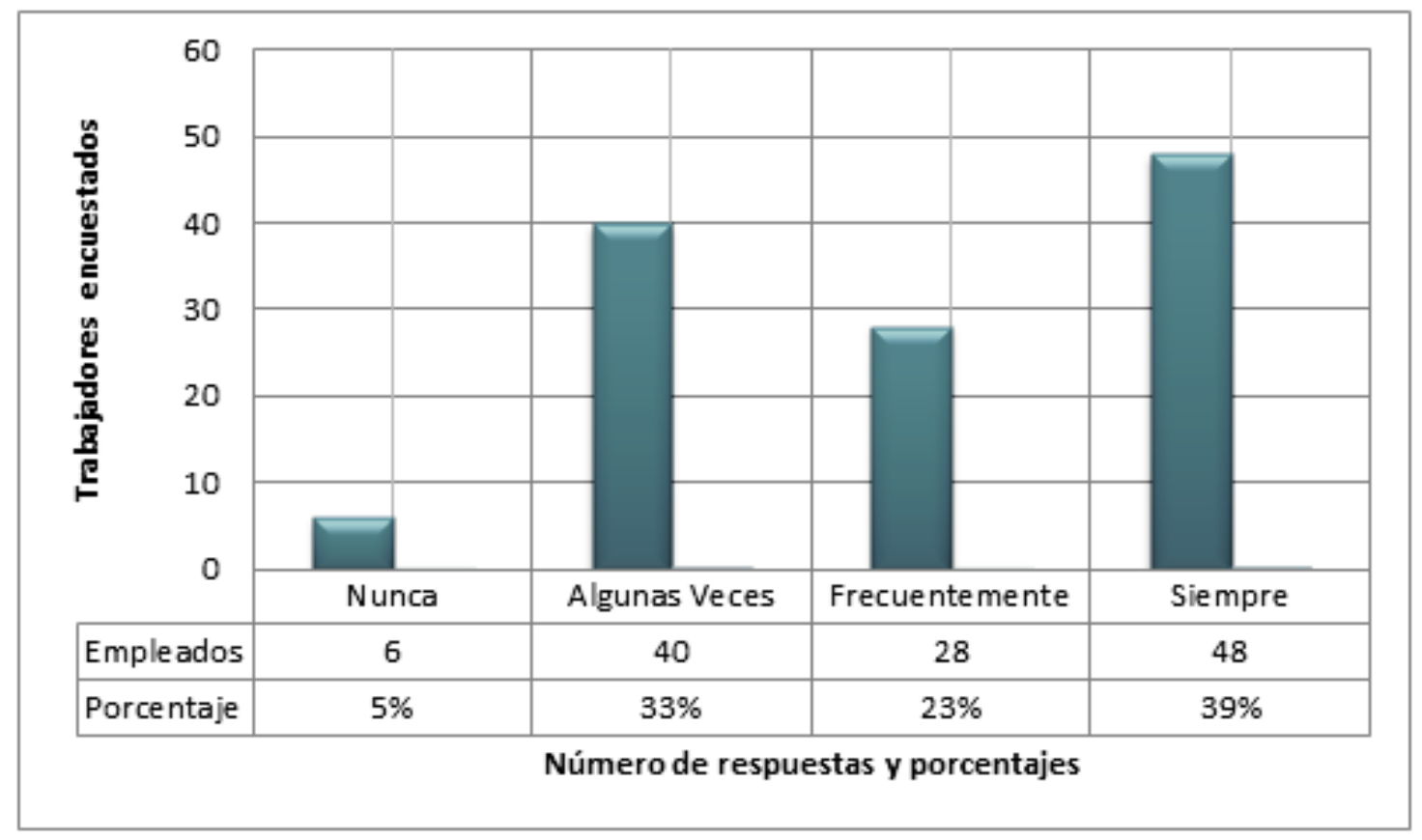

Fuente: Elaboración propia.

La gráfica 10 muestra efectivamente que solamente un 39\% siempre puede sentirse capaz de expresar que su trabajo en la constructora, le permite satisfacer sus necesidades. El $23 \%$ expresan que frecuentemente pueden obtener lo necesario; otro $33 \%$ piensan que algunas veces lo hacen, mientras que un $5 \%$ enmarca que nunca lo hace. Existen algunas teorías importantes alrededor de la motivación, como la teoría de la jerarquía de las necesidades, donde Maslow (1991), describe la importancia de suplir las necesidades básicas para posterior a ello, suplir las necesidades de orden superior, lo cual determina comportamientos en la conducta del ser humano, el cual trabaja por necesidad y no siempre por deseo. El enfoque en esta situación, es que los empleados no siempre se sienten motivados a trabajar como se espera, y aunque un bajo porcentaje expresa que nunca siente esa satisfacción, está presente y existe dentro de la empresa, sabedores que tienen otras necesidades que no logran satisfacer; provocando en cierta manera, un bajo rendimiento laboral que puede ser negativo para la productividad y el alcance de las metas propuestas. 
Figura No. 11 Formación necesaria para el desempeño de labores

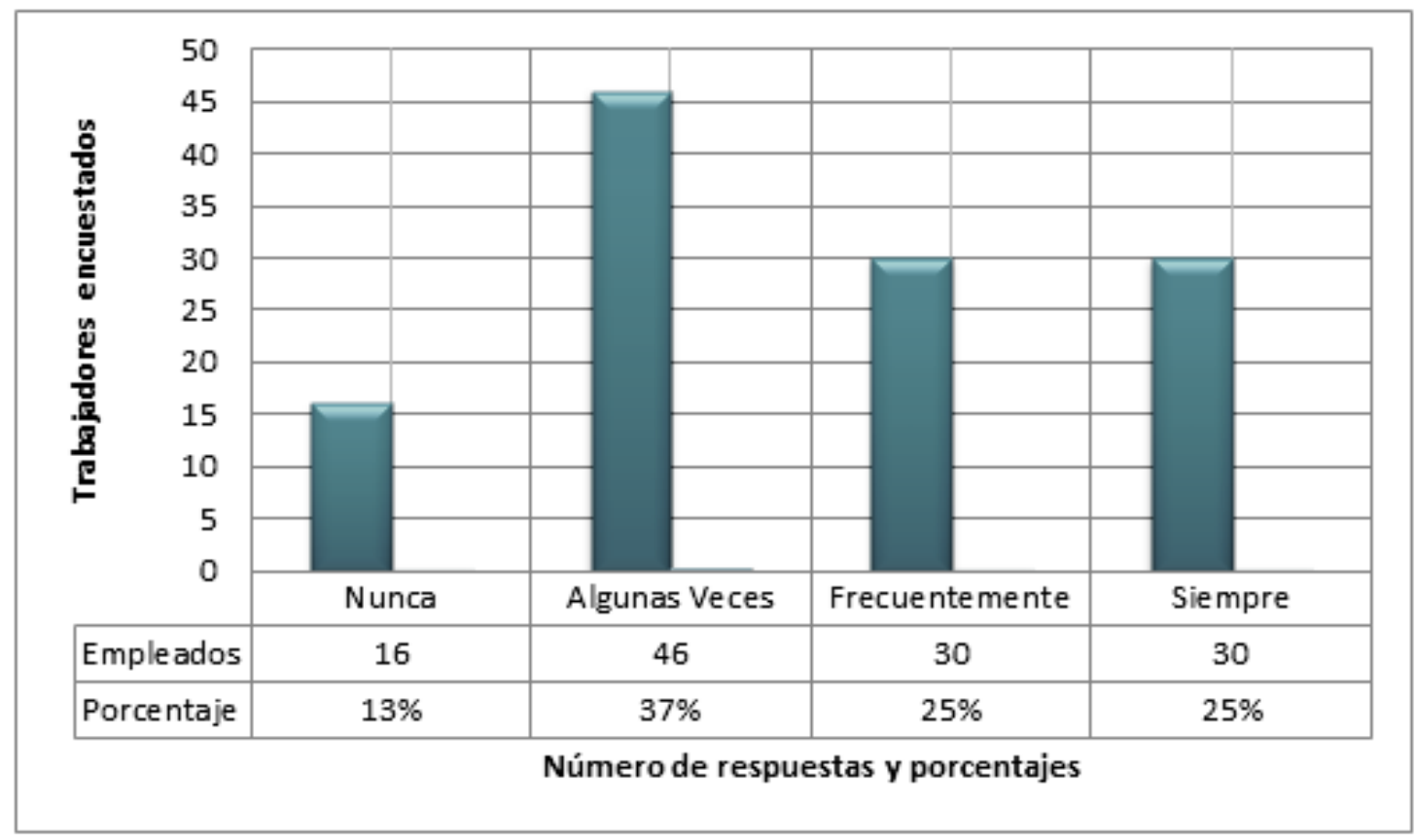

Fuente: Elaboración propia.

De acuerdo con los datos que muestra la gráfica 11 , se puede observar que el $25 \%$ de los empleados consideran que siempre los capacitan para desempeñar el trabajo, otro $25 \%$ opinan que frecuentemente reciben alguna inducción; mientras que un $37 \%$ expresan que en algunas veces las han recibido y el $13 \%$ afirman que nunca han tenido una formación para el desempeño de sus labores. Conversando directamente con algunos colaboradores, indicaron que en muchas ocasiones son los directivos quienes les brindan inducción de cómo realizar adecuadamente sus funciones. Como lo hacen ver Robbins y Judge (2009), el trabajo de una persona es más que solo realizar las actividades obvias, como ordenar papeles en la oficina o hacer el trabajo de campo; los trabajos requieren interactuar con los compañeros y jefes, seguir las reglas y políticas organizacionales, cumplir estándares de desempeño y estar en condiciones adecuadas. Deben existir mejoras en la constructora para que el trabajo permita satisfacer las necesidades de los empleados, en vista que es significativo tener en cuenta que ellos siempre buscan un crecimiento individual al lograr resultados y así tener oportunidades, pero para esto se deben recibir inducciones pertinentes y periódicas para un desarrollo laboral eficiente. 
Figura No. 12 Evaluaciones para conocer las necesidades de los trabajadores

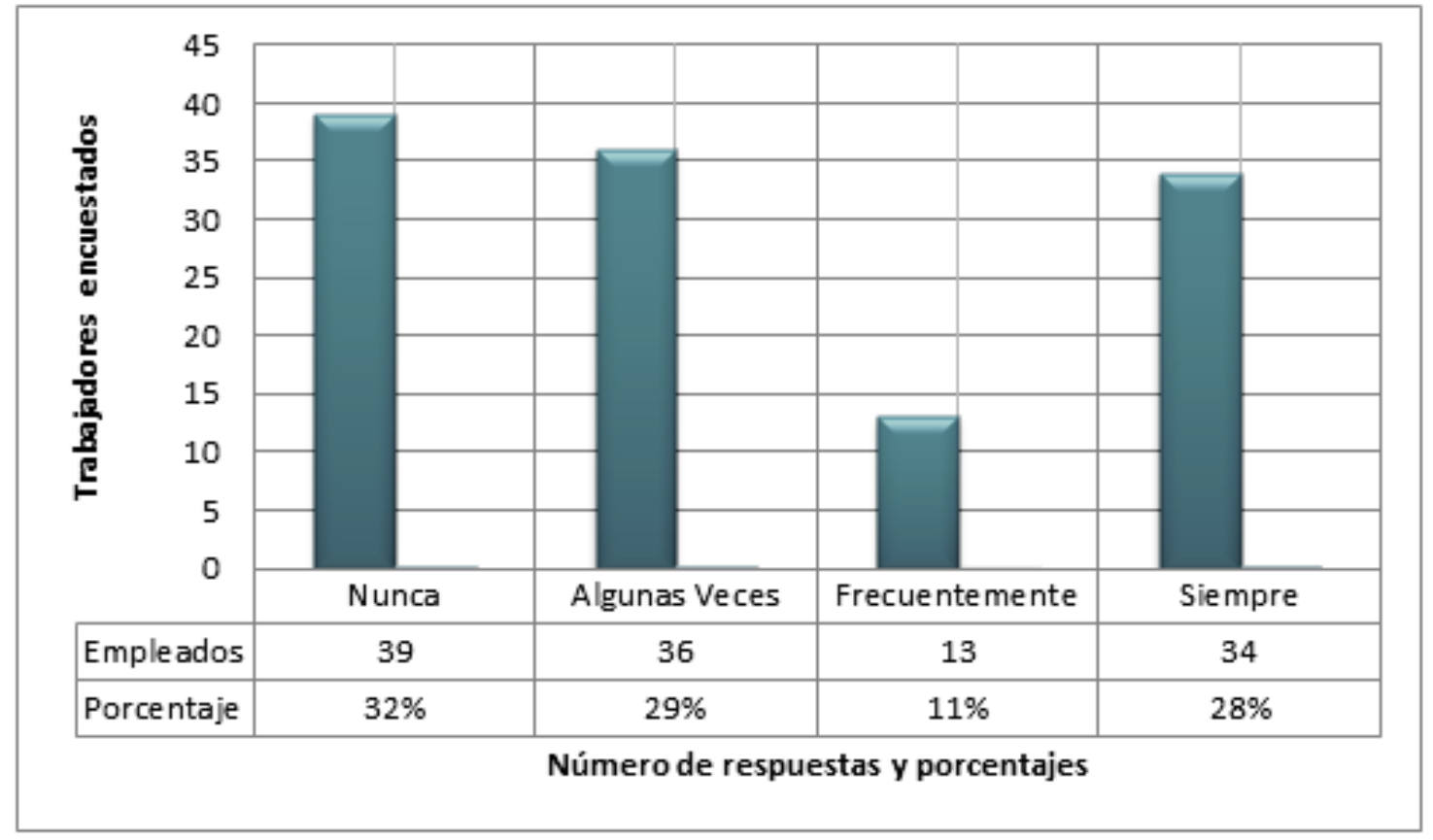

Fuente: Elaboración propia.

La opinión de los empleados en cuanto a si la empresa evalúa sus necesidades, la gráfica 12 muestra que el $28 \%$ de ellos expresan que siempre se han dado, el $11 \%$ opina que frecuentemente han observado estas actitudes; un $29 \%$ dicen que en algunas veces y un considerable $32 \%$ afirma que nunca han sabido de evaluaciones durante su estancia en la empresa. Robbins y Judge (2009), describen que la satisfacción laboral es un sentimiento positivo acerca de un puesto de trabajo que surge de la evaluación de las características. Por tal razón, es de importancia lo que se indica respecto a que las funciones y responsabilidades del puesto de trabajo estén bien establecidas, lo cual muestra que los directivos no brindan inducción del perfil ni del puesto con tanta claridad, y tampoco lo tienen definido, que ocupaciones y compromisos tiene cada integrante del equipo de trabajo. Debe mencionarse también, que el dueño y gerente general, siempre es la persona encargada de tomar las decisiones, no siempre está presente en la constructora y mucho menos compartiendo con los trabajadores de campo, lo que influye en ellos para entender realmente a que se refieren las evaluaciones en cuestión. La información de las necesidades de los empleados llega por los encargados de cada departamento, pero no puede considerarse como una evaluación en general. 
Figura No. 13 Influencia de la satisfacción laboral en la productividad

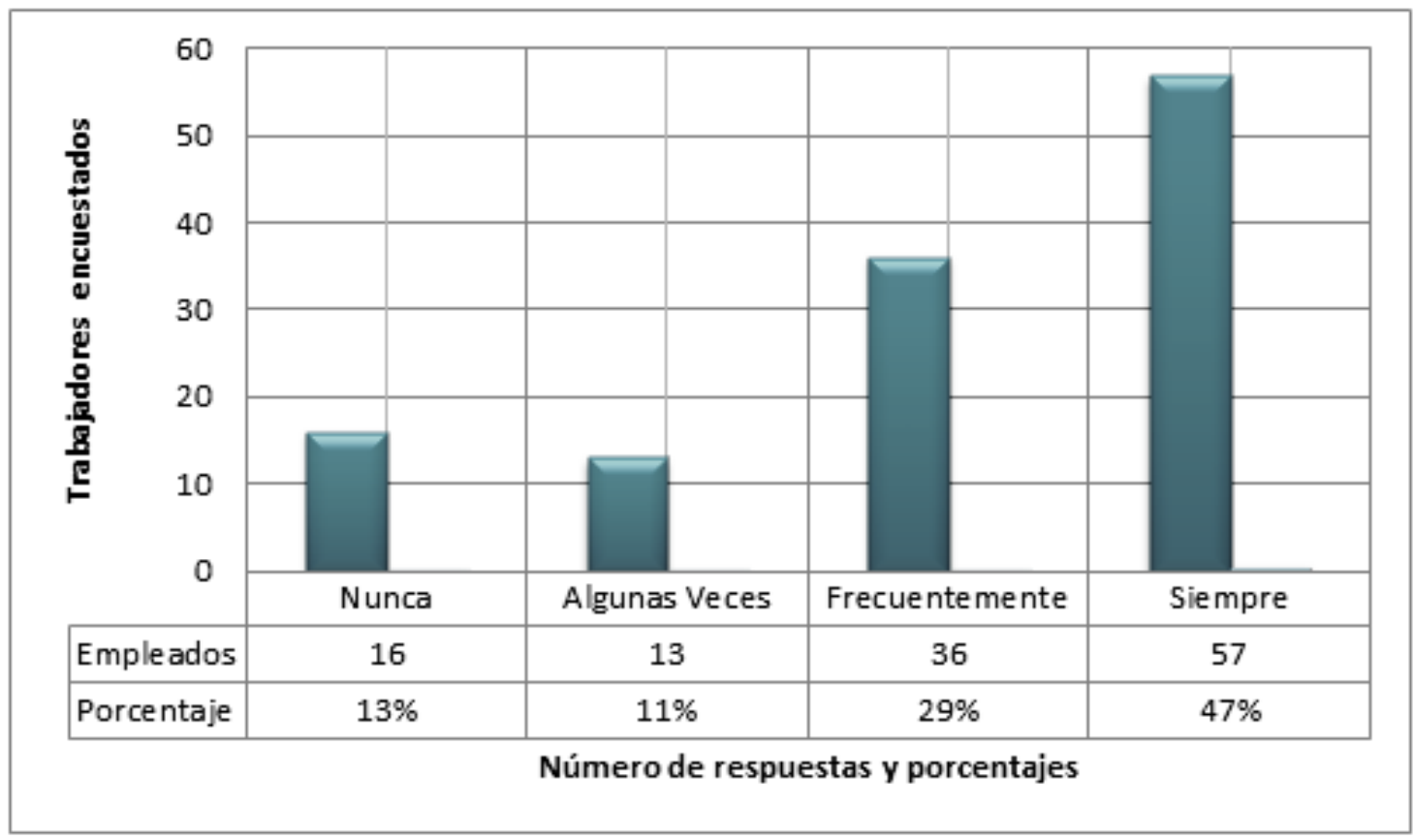

Fuente: Elaboración propia.

En lo que respecta a satisfacción y productividad, la gráfica 13 señala que el $47 \%$ de la población mostró que siempre se da este sentimiento dentro de la constructora, mostrando que, si el personal se encuentra satisfecho y motivado, rendirá productivamente. También hay un $29 \%$ que frecuentemente se encuentra satisfecho del trabajo que realiza mostrando resultados satisfactorios. No obstante un $11 \%$ manifiesta que algunas veces pueden manifestar satisfacción, y el $13 \%$ dice que nunca se sienten satisfechos; sin embargo, realizan su trabajo para producir tanto en cantidad como en calidad. En este aspecto, Davis y Newstrom (2003), identifican la satisfacción laboral, como el resultado de factores tanto internos como externos, en los que se puede mencionar la vida familiar y el trabajo y la relación que existe entre ellos. Así, pueden señalarse la motivación, el desarrollo profesional del personal, la pertenencia e identificación en la organización y la productividad que es una relación entre eficiencia y eficacia en la ejecución del trabajo individual y organizacional. La satisfacción laboral en los empleados es de suma importancia, sobre todo para la productividad y el logro de objetivos de la constructora, pues cada uno debe de estar conforme en el área donde desempeña su trabajo; de lo contrario pueden generar cierto fracaso en la empresa. 
Figura No. 14 Presencia de razones o causas que desmotivan a los empleados

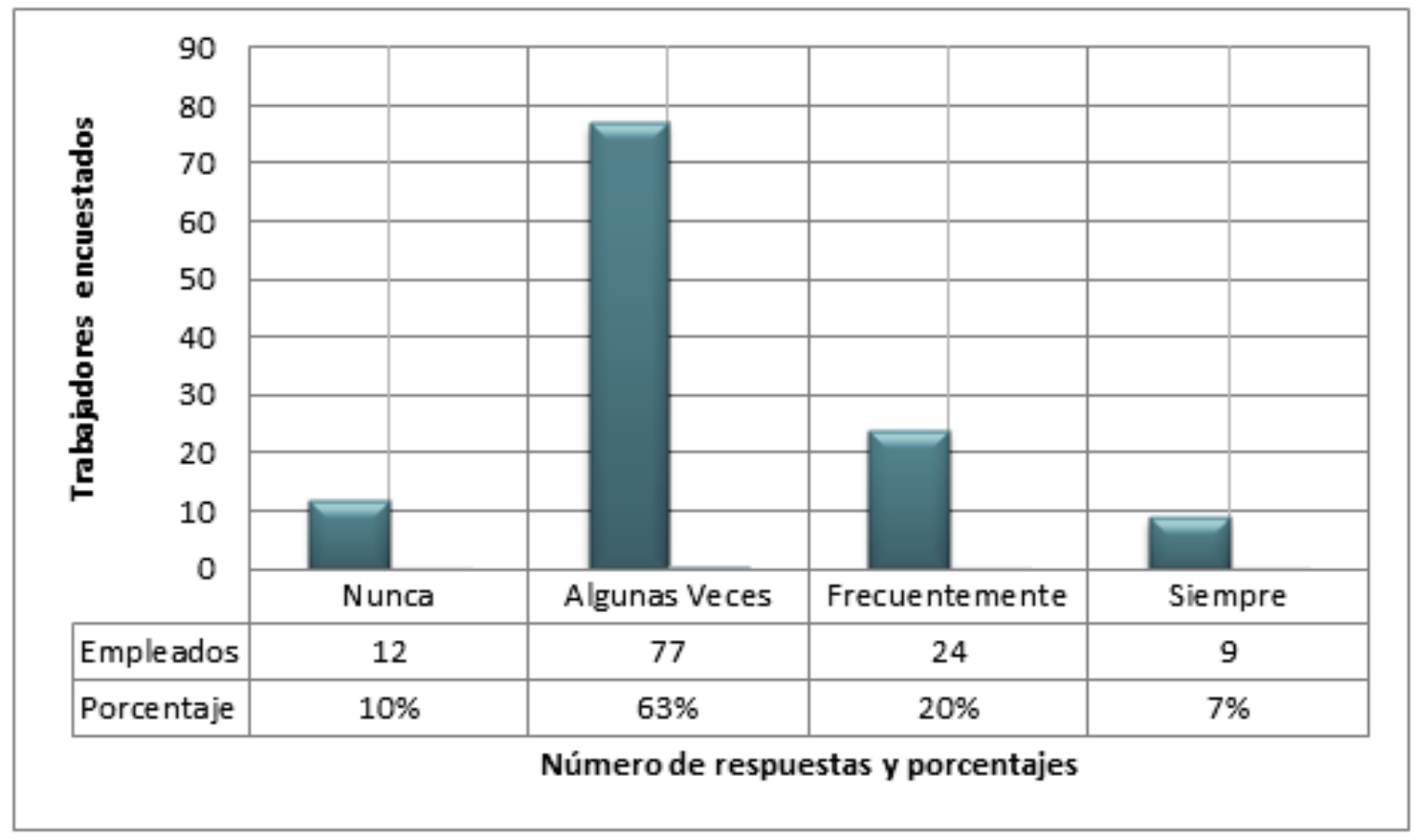

Fuente: Elaboración propia.

Con los datos de la gráfica 14 , se determinó que el $7 \%$ cree que siempre existen razones que desmotiven, un $20 \%$ manifestó que frecuentemente se viven estas situaciones de desmotivación. El $63 \%$ de la población establece que a veces existen causas que los desmotivan para realizar su trabajo con eficiencia, lo que provoca un desequilibrio en relación al clima laboral dentro de la constructora. El 10\% opina que nunca se dan estas razones. En estas circunstancias, Kreitner y Kinicki, (1997), establece que la motivación representa a todo el proceso psicológico que provoca la estimulación en las personas, lo que representa acciones voluntarias, persistencia y sobre todo, dirección hacia los objetivos. Una de las principales causas que desmotivan a los empleados dentro de la constructora, es la falta de incentivos de diferentes tipos, y a la vez, no brindarles apoyo en relación a las jornadas de trabajo. Otra causa, es la situación de contrataciones de trabajo, pues no siempre los trabajadores de campo son ingresados en la planilla correspondiente y en ocasiones deben de trabajar horas extras y los siete días a la semana. No puede lograrse que los colaboradores realicen su trabajo con esfuerzo si no reciben la motivación necesaria. 
Figura No. 15 Considerar la búsqueda de otro trabajo

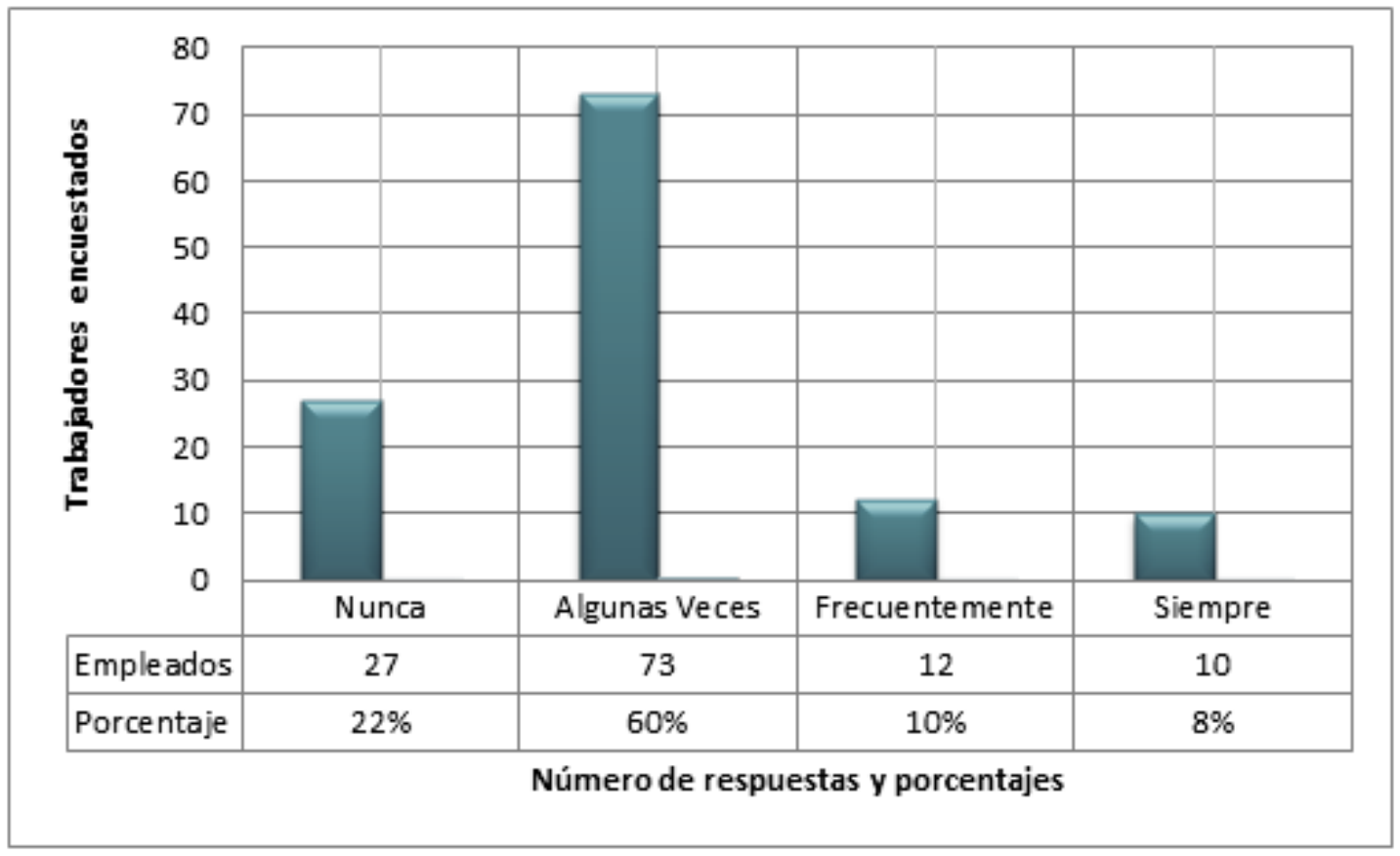

Fuente: Elaboración propia.

Los datos que se reflejan en la gráfica 15 , es que el $8 \%$ de los empleados, siempre considera buscar otro empleo, el $10 \%$ frecuentemente lo ha pensado; mientras que un $60 \%$ algunas veces ha considerado buscar otro trabajo, y un $22 \%$ nunca ha pensado en esa opción. Parecen porcentajes pequeños de quienes consideran esta opción, pero son datos que existen y están dentro de la organización. Sherman (1994), indica que las relaciones con los supervisores, injusticia en las revisiones de evaluación de desempeño y el clima laboral, son causas del por qué se van los trabajadores. Según lo establecido con los empleados con quienes se obtuvo la información, comparten (especialmente los de campo) que por no tener una plaza fija dentro de la empresa, siempre consideran o tienen otras opciones a la mano, en caso de que no puedan continuar en un proyecto, puesto que las necesidades personales siempre están presentes. Mientras que el personal de oficina o mecánicos, que tienen más tiempo laborando en la empresa, poseen un puesto estable dentro de la constructora, por lo que no consideran buscar otro trabajo. 
Figura No. 16 Valores en porcentajes por variables

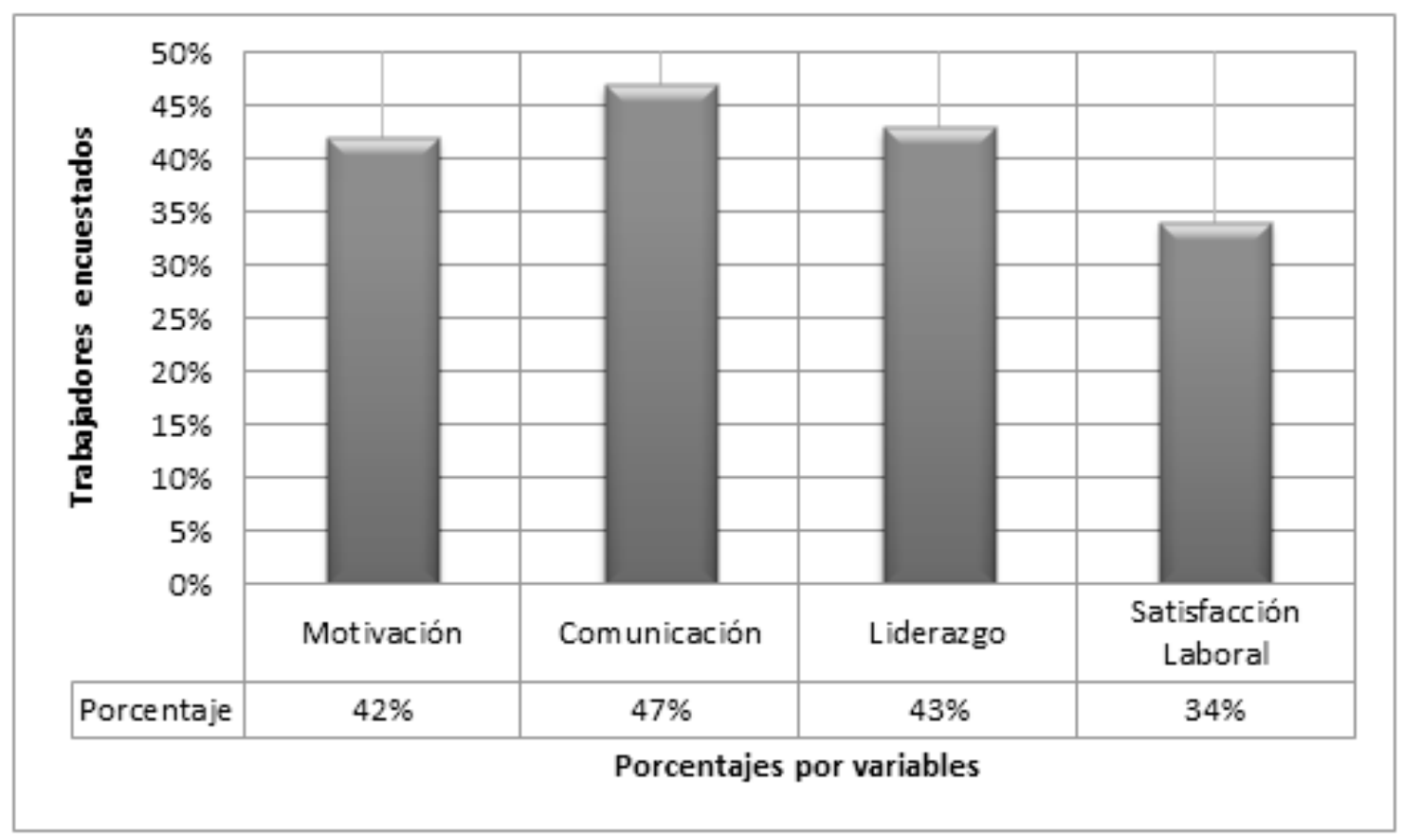

Fuente: Elaboración propia.

Según Gan (2007), el clima laboral de Likert mide las variables de motivación, comunicación, liderazgo y satisfacción laboral. En el caso de la empresa constructora CARMOR, puede comprobarse en cuanto a la motivación, que el $42 \%$ son quienes se sienten con entusiasmo dentro de la empresa al realizar sus labores. La comunicación puede decirse que ocupa el nivel más alto, con un $47 \%$, a pesar que en ocasiones, los empleados sienten que sus opiniones no cuentan en el momento de tomar decisiones. El liderazgo que se desarrolla en la constructora llega al $43 \%$, con lo que puede observarse una notable falta de organización dentro de la empresa y el manejo del personal.

En cuanto a la satisfacción laboral, que es el porcentaje más bajo con un $34 \%$, puede resaltar el punto, en que no todos los empleados realmente están satisfechos con lo que el empleo representa en su satisfacción; recordando que varios de los trabajadores consideran o piensan la opción de otro trabajo; situación que puede en alguna medida, perjudicar la productividad de la constructora, puesto que no todos los colaboradores se sienten satisfechos con lo que reciben por su labor. Puede entonces consolidarse que, la parte motivacional y de satisfacción dentro de los empleados de la constructora influye potencialmente en los porcentajes que se observan, lo que debe considerarse para que dentro de la organización pueda mejorar el clima laboral para un excelente funcionamiento de la misma. 


\section{Discusión}

En los resultados encontrados en la investigación aplicada a la constructora, puede observarse que respecto a los miembros de la empresa, tanto en trabajadores administrativos y personal obrero, existe un bajo porcentaje de satisfacción en el trabajo, a pesar que la mayoría viene laborando por varios años; es evidente que muchos expresaron no estar completamente a gusto con su labor desempeñada, por lo que la constructora trata de tener en cuenta su estabilidad, pero falta priorizar actitudes fundamentales en los trabajadores, como la dedicación al trabajo, el compromiso organizacional y un estado de ánimo en el trabajo, los cuales repercutirán en que los trabajadores puedan producir y rendir efectivamente en sus labores.

En el caso de los reconocimientos o incentivos que los jefes pueden brindar a sus empleados por su desempeño, muchos colaboradores manifiestan que no reciben esta clase de actitudes por parte de sus superiores, lo cual representa que el trabajador no se identifique con la empresa y que solamente la busque como una fuente de ingreso para el bienestar de su familia. Es bien sabido que la motivación es un factor importante para el buen desempeño de los trabajadores, por lo que la empresa debe considerar, que si desea generar la mejor productividad y mayor desempeño, debe mejorar la satisfacción de sus colaboradores, pensando en sus necesidades para que ellos puedan sentirse parte de la empresa y dar lo mejor de sí.

Sobre la comunicación se determinó que no en todas las ocasiones puede definirse como eficiente, por lo que podría generar problemas en la consecución de los objetivos tanto a corto, como a largo plazo de la constructora.
Además, la falta de comunicación influye en las relaciones personales, lo que puede perjudicar el desarrollo de la empresa y no alcanzar la competitividad de la misma. Los supervisores no siempre generan un adecuado ambiente de confianza que vaya relacionado con la manera de proponer decisiones a los responsables de cada área de trabajo, entablando una comunicación efectiva.

En relación con la información recolectada que tuvo como finalidad identificar los aspectos considerados para el liderazgo y la toma de decisiones en los diferentes niveles de la organización, se pudo determinar que estos son aceptables, lo cual indica que existe un respaldo de los altos niveles para el pro y mejoramiento de las actividades, así como también se consideran admisibles las decisiones que se toman por parte de los jefes y que existe una participación efectiva por parte de los colaboradores en el desarrollo de nuevos procesos y alternativas de mejora. Se hace la salvedad, que un buen porcentaje ha considerado buscar otras opciones, pues la satisfacción laboral no siempre creen que es la más adecuada, pero que se acepta porque es fuente de trabajo y sostenimiento familiar.

La constructora CARMOR hasta el momento, no cuenta con evaluaciones sobre el clima laboral ni necesidades de los empleados dentro de la empresa, lo que es indispensable para la obtención de datos relevantes sobre el ambiente profesional actual, para poder lograr una mejora en las distintas áreas de trabajo; por lo que esta investigación, ayuda para estar al pendiente de las situaciones que se viven y se avecinan dentro de la empresa, y llegar a alcanzar de la mejor manera posible, los objetivos propuestos. 


\section{Conclusiones}

El clima laboral dentro de la empresa Constructora CARMOR es parcialmente favorable, según los datos obtenidos sobre los distintos factores evaluados, en las escalas de: siempre, frecuentemente, algunas veces y nunca; dando los porcentajes en motivación con un $42 \%$, comunicación con un $47 \%$, liderazgo con un $43 \%$ y satisfacción laboral con un $34 \%$; observando una baja considerable en el aspecto de satisfacción en los empleados.

Se identificó que la motivación no siempre es buena por parte de la gerencia y los colaboradores en la empresa, aunque sí se estableció un alto prestigio para la organización por parte de los colaboradores. No reciben una constantes motivación proactiva por parte del jefe, o en algunas ocasiones incentivos no económicos; pero sí una satisfacción por parte de los colaboradores en su área de trabajo y también con sus compañeros de labor.

La comunicación en la constructora es aceptable, de acuerdo a la escala evaluada en cuanto a los canales de comunicación formal e informal, en donde se estableció que prevalece la comunicación verbal en los niveles en cuanto a la escrita, existiendo una retroalimentación acertada, considerando la asignación de actividades como justas y tienen definidos los objetivos a cumplir, brindando una ordenada toma de decisiones por parte del jefe y sus colaboradores; siempre teniendo en cuenta que las decisiones de mayor importancia son tomadas por los niveles superiores. La satisfacción laboral de los empleados es el factor más bajo encontrado en la investigación del clima laboral en la constructora con un $34 \%$, aspecto que tiene que ver en cuanto a que el personal obrero (que es la mayoría con 117 empleados), son quienes no tienen las mismas prestaciones e incentivos económicos y/o de otra índole, así como también, sus jornadas y horarios laborales son distintos y más amplios que los de otros departamentos. Estos contextos son los que vienen a afectar la satisfacción de los colaboradores en torno a su situación salarial, que provocan esta baja emocional y puede en gran parte afectar a la productividad de la empresa, al tomar ellos su empleo como algo meramente necesario para subsistir.

\section{Referencias}

Adler, R. (2005). Comunicación Organizacional. Principios y Prácticas para negocios y Profesionales. (Octava Ed.) McGraw Hill Interamericana. México, D.F.

Amoros, M. (2007). Calidad de vida en el trabajo. Ed. Libreros Unidos. Maracaibo, Venezuela.

Ardouin, et al., (2000). Diseño organizacional. Organización y métodos para la excelencia. CECSA. México, D. F.

Blanchard, K. (2000). El Ejecutivo al minuto en forma. Edit. MacGraw-Hil. Barcelona, España.

Carretón, C. (2007). Las relaciones públicas en la comunicación interna de la Banca española. España (España): Netbiblo.

Chiavenato, I. (2009). Comportamiento organizacional. La dinámica del éxito en las organizaciones. $2^{\mathrm{a}}$. Edit. McGraw Hill. Bogotá, Colombia.

Cimpa, D. (1990). Liderazgo industrial. $2^{\mathrm{a}}$. Edición. Editorial: Legis. Bogotá, Colombia.

Davis, K. y J. Newstrom (2003). Comportamiento humano en el trabajo. $11^{\mathrm{a}}$. Ed. México: McGraw- Hill. 
Dessler, G. (2009). Administración de recursos

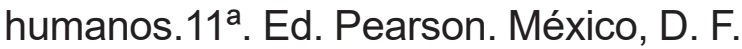

Espinoza, M. (1999). Líderes del Tercer Milenio. Edit. EDIAS. Lima, Perú.

Gan, F. (2007). Manual de recursos humanos. Edit. UOC. Barcelona, España.

García, S. (2007). El clima laboral depende sobre todo del jefe. Tesis Doctoral, Universidad de Granada. México, D.F.

García, J. (2011). Comunicación Interna. Madrid (España): Díaz de Santos.

James, E. y W. Lindsey (2008). Administración y control de la calidad. Edit. Thomson. México, D. F.

Katz, D. y R. Kahn (1989). Psicología social de las organizaciones. Trillas, $2^{\mathrm{a}}$. Ed. México, D. F.

Kreitner, R. y A. Kinicki, (1997). Comportamiento de las ornganizaciones. Madrid (España) McGraw-Hill.

Lado, A. y M. Wilson, (1994). "Human resource systems and sustained competitive advantage: A competency-based perspective". Academy of Management Review. 19, 4 ABI/INFORM. Global pg. 699.

Landy, F. y J. Conte (2005). Introducción a la psicología industrial y organizacional. McGraw Hill. México, D. F.

Maslow, A. (1991). Motivación y personalidad. Días de Santos S. A. Casa de Libro. Madrid, España.

McGregor, D. (1966). The human side of Enterprise, Leadership and motivation. Cambridge. The MIT Press. Reino Unido.

Méndez, C. (2006). Clima organizacional en Colombia El IMCOC: Un método de análisis para su intervención. Colección de lecciones de administración. Bogotá: Universidad del Rosario de Colombia.
Mitchell, T. (1997). "Matching motivational strategies with organizational contexts". In L.L. Cummings and B. M. Staw (Eds.), Research in organizational behavior. Vol. 19, 57-149. Greenwich, CT: JAI Press Inc. 1997.

Montes, R. (2006). Relaciones interpersonales en el trabajo. Editorial Merced. California.

Muñoz, A. (1990). Satisfacción e insatisfacción en el trabajo. F. de Psicología. Universidad Complutense, Madrid, España.

Robbins, S. (1999). Comportamiento Organizacional. McGraw-Hill Interamericana. México D. F.

Robbins, S. y M. Coulter (2005). Administración. Octava Edición. Pearson Educación. México, D. F.

Robbins, S. y T. Judge (2009). Comportamiento Organizacional. Decimotercera Edición. Pearson/Prentice Hall. México.

Rodríguez, A. y A. Bakker (2011). El Engagement en el Trabajo. Editorial Erasmus. Madrid, España.

Sallenave, J. (1994). La gerencia integral. Editorial Norma. Bogotá, Colombia.

Sherman, B. (1994). Administración de Recursos Humanos. 10 ${ }^{\mathrm{a}}$. Edición. South Western College Publishing, Cincinnati, Ohio, EUA.

Torres, A. y E. Agulló, (2002). "Calidad de vida laboral: hacia un enfoque integrador desde la Psicología Social". Psicothema. ISSN 0214 - 9915 CODEN PSOTEG. Vol. 14. N ${ }^{\circ} 4$, pp. 828-836. 


\section{Sobre autor}

\section{Hugo Jovany Aragón González}

Tiene una Maestría en Gerencia Administrativa de Recursos Humanos, en el Departamento de Estudios de Postgrado, USAC, CUNSURORI, Jalapa, 2019. Es Licenciado en Pedagogía y Desarrollo Educativo, en la Facultad de Ciencias de la Educación, Universidad Panamericana, sede Jalapa, 2016. Posee un Profesorado Universitario en Educación con Especialidad en Didáctica de la Comunicación y la Matemática, en la Facultad de Ciencias de la Educación, Universidad Panamericana, sede Jalapa, 2014. Es Maestro de Educación Primaria Urbana. Posee Diplomados Universitarios en Educación y Tecnología. Ha trabajado como Locutor, Docente Universitario, Docente en el Nivel Medio, Ciclo Básico y como Maestro de Primaria. Ha sido facilitador en conferencias, talleres y capacitaciones a otros docentes.

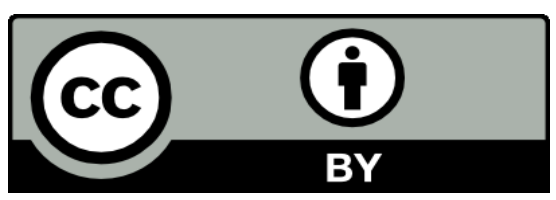

Este texto está protegido por una licencia CreativeCommons 4.0.

Esta licencia permite que otros distribuyan, mezclen, adapten y desarrollen su trabajo, incluso comercialmente, siempre y cuando le den crédito por la creación original. 


\section{Normas de la revista académica y científica del CUNSURORI}

La revista Naturaleza, Sociedad y Ambiente, es una publicación del Centro Universitario de Sur Oriente de la Universidad de San Carlos de Guatemala, creada para difundir trabajos originales de interés en el campo de las ciencias naturales, ciencias sociales y ciencias ambientales producto de las mejores investigaciones y tesis desarrolladas en las carreras a nivel de licenciatura, de los Programas de Postgrado del CUNSURORI, y de otras unidades académicas a nivel nacional e internacional. El presente normativo describe los objetivos, organización, proceso de arbitraje, políticas, temática y lineamientos editoriales de la revista.

La revista está registrada con el código estándar internacional: International Standard Serial Number, ISSN, bajo el número 2313-786X.

\section{Objetivo de la revista}

El objetivo de la revista Naturaleza, Sociedad y Ambiente es publicar y difundir trabajos originales producto de las investigaciones realizadas en las carreras a nivel de licenciatura y en los Programas de Postgrado que se imparten en el CUNSURORI, así como también, publicar los aportes realizados por otras entidades académicas guatemaltecas e internacionales con la finalidad de contar con investigaciones del más alto contenido científico. Los artículos pueden ser el resultado de investigaciones que hayan aplicado metodologías cuantitativas, cualitativas o mixtas, además de aportes teóricos y críticos que permitan el avance académico y científico al más alto nivel.

\section{Aspectos administrativos y sis- tema de arbitraje}

La revista tiene como instancias administrativas y de gestión a: Consejo Editorial, Editor de la revista, Equipo Editor, Grupo de Revisores Externos producto de gestiones y convenios con otras unidades académicas nacionales e internacionales y la Secretaria Administrativa.

\subsection{Consejo Editorial. El Consejo Editorial estará constituido por:}

\section{a) EI Director del CUNSURORI \\ b) El Director del Departamento de Post- grados del CUNSURORI}

c) El Coordinador Académico del CUNSURORI

d) El Coordinador del Departamento de Investigación

e) El Editor de la revista

f)Colaboradoresdeotrasunidadesacadémicas y de investigación externas producto de convenios realizados entre las autoridades de turno.

\subsection{Editor de la revista}

El Editor de la revista será el encargado de coordinar y supervisar todas las diligencias necesarias para la aceptación, revisión, edición y publicación de la revista.

\subsection{Sistema de Arbitraje, equipo editor y revisores}

Para cada edición de la revista se cuenta con un equipo multidisciplinario de académicos reconocidos a nivel nacional e internacional en el campo de las ciencias naturales, sociales y ambientales que apoyarán en la acreditación y edición de los artículos. Se tiene 
además un equipo de revisores externos de los artículos que se asignan por pares según sea el tema. Para el efecto, se tienen convenios con unidades académicas nacionales y de diferentes latitudes a nivel internacional por lo que se cuenta con una base de datos amplia de revisores que evalúan con rigurosidad cada una de los aportes académicos. Los pares de revisores tienen la responsabilidad de sugerir las correcciones mayores (de fondo o contenido) y correcciones menores (de forma o estilo) de cada artículo.

Al tener el listado de correcciones mayores y menores por parte de los revisores, se les hace llegar a los autores para que realicen las respectivas modificaciones. Luego de hacer las correcciones sugeridas, los artículos se remiten nuevamente a los revisores quienes dan un dictamen con fecha para la aprobación y aceptación final y por lo consiguiente el artículo estará apto para su publicación.

\subsection{Secretario (a) Administrativo (a)}

Será el o la profesional responsable de recibir los artículos y aportes académicos para luego trasladarlos a los pares revisores, equipo editor y finalmente a la dirección de la revista para su publicación.

\section{Política de la revista}

La revista Naturaleza, Sociedad y Ambiente considera las siguientes directrices:

- La finalidad de la revista es la publicación y difusión de trabajos originales de interés prioritariamente producto de las mejores investigaciones y tesis realizadas en las carreras a nivel de licenciatura y de los programas de postgrado del Centro Universitario de Sur Oriente de la Universidad de San Carlos de
Guatemala. También se aceptan aportes académicos de otras unidades académicas nacionales e internacionales para ser difundidas y avanzar en el conocimiento científico.

- El Consejo Editorial considerará para cada edición de la revista, los artículos que pueden ser sometidos al arbitraje del grupo revisor para poder ser publicados.

- La revista se publicará en los primeros 5 años en español para luego publicarse también en inglés.

- La publicación de los artículos considerará particularmente la calidad, originalidad e interés general de los mismos, según los estándares impuestos por su Consejo Editorial para cada edición de la revista.

- La revista se publicará una vez por año y de ser necesario se hará de forma semestral según los recursos económicos con que se cuente para el efecto.

- La revista constará de tres secciones: Naturaleza, Sociedad y Ambiente

- La revista está registrada con el número de serie estándar internacional: International Standard Serial Number, ISSN 2313-786X.

- La revista estará a cargo del Departamento de Postgrados del CUNSURORI y la Coordinación Académica y se buscará financiamiento en otras instancias para su mayor difusión.

- La revista deberá seguir cuidadosamente los criterios establecidos por las agencias e instituciones de acreditación a nivel internacional. 


\section{Temática de la revista}

La apertura para aceptar artículos es amplia pues, la revista está enmarcada en las ciencias naturales, sociales y ambientales por lo cual los aportes académicos se ordenarán según el área temática dentro de la revista en tres secciones: Naturaleza, Sociedad y Ambiente. Los aportes académicos también podrán ser notas técnicas, artículos de análisis, artículos de revisión y presentaciones de libros. Se dará prioridad a la calidad y la rigurosidad académica y para que un artículo pueda ser publicado es indispensable contar con el dictamen de los pares revisores.

\section{Lineamientos editoriales para los autores}

a) Los artículos deben ser inéditos y originales.

b) Los artículos deben ser escritos en español y deben considerar una extensión máxima de 7500 palabras.

c) El texto debe ser escrito a $1 \frac{1}{2}$ de espacio con tipo y tamaño de letra Arial 11 , incluyendo todo tipo de gráficos o cuadros.

d) Los artículos deben estar escritos en párrafos, máximo de ocho líneas.

e) La presentación de los artículos debe ser en Word.

f) Los artículos deben ser escritos en líneas corridas y no en columnas para someterse a revisión. (El editor se encargará posteriormente de adaptarlo en formato de columnas).

g) Las notas a pie de página serán en Arial 10 y deberán utilizarse únicamente para aclarar o ampliar un término.

h) Los encabezamientos de las diferentes secciones estarán numerados, y serán también en Arial 11. i) Toda contribución debe incluir un resumen, con una extensión no mayor a 200 palabras, y su correspondiente traducción en inglés.

j) Todos los artículos incluirán 5 palabras clave y su traducción al inglés.

k) Los títulos deben ser cortos, con un máximo de 12 palabras y de ser necesario se debe considerar un subtítulo.

I) Los artículos deben incluir una página con el título del artículo, el nombre del autor, su ocupación, afiliación institucional y dirección electrónica (debe colocarse al final del artículo).

m) Eliminar todo subrayado o negrilla del texto.

n) En caso de palabras con "extra sentido", palabras "adoptadas", palabras en otro idioma usar "comillas".

o) Como notas a pie de página, solo van las notas aclaratorias, ampliaciones, etc. Se debe minimizar su uso.

p) En el caso de Tablas, Figuras o Gráficos, usar alta resolución de los mismos.

q) Se recomienda que las Figuras sean en blanco, negro y grises.

r) Se deben evitar las tablas muy grandes. Se recomienda dividirlas en varias tablas.

s) En la medida de lo posible, los datos que den lugar a figuras se deberán presentar al final del artículo en forma de Tablas, en el correspondiente Anexo.

t) Los contenidos mínimos que deberá contener un artículo son: Introducción, referente teórico, metodología, resultados, conclusiones y referencias bibliográficas.

u) Cuando se cita y se hace referencia se hace de la siguiente forma (Leff, 2007).

v) Las referencias bibliográficas deben estar regidas bajo el estilo Harvard. 
Los artículos y aportes académicos deberán dirigirse al Mtro. Ludwing Enrique Ortíz López, Editor de la revista o bien a la Maestra Yadira Abigail Ishlaj Conde de González Secretaria Administrativa en los siguientes correos electrónicos:

postgradoscunsurori@gmail.com revistacunsurori@gmail.com

La revista puede consultarse en: https://www. revistacunsurori.com/ 



\section{USAC TRICENTENARIA Universidad de San Carlos de Guatemala}

Id y enseñad a tadas

UNIVERSIDAD
PONTIFICIA
DE SALAMANCA

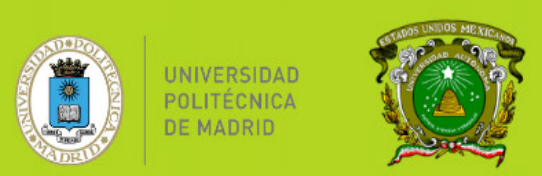

$\therefore$

10 경혀대대학교

iños

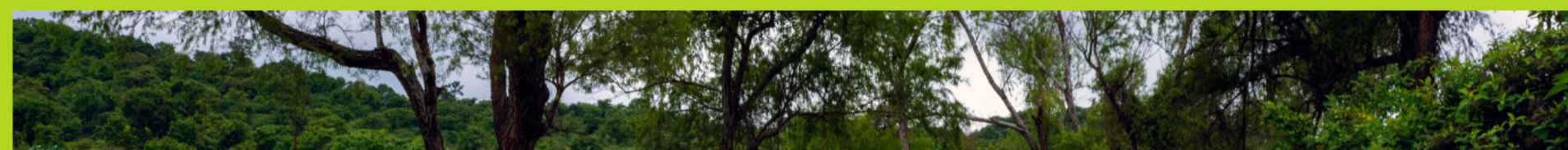

mas bosqueas mas vida

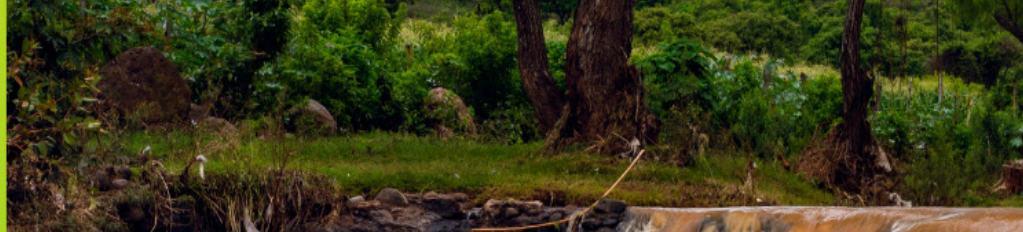
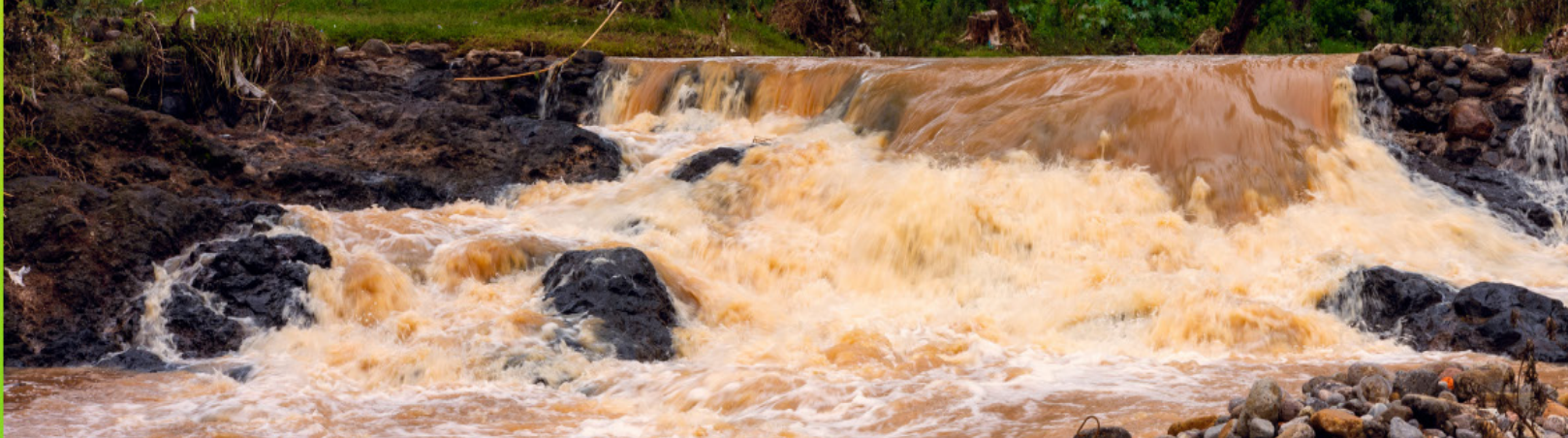

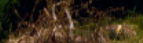
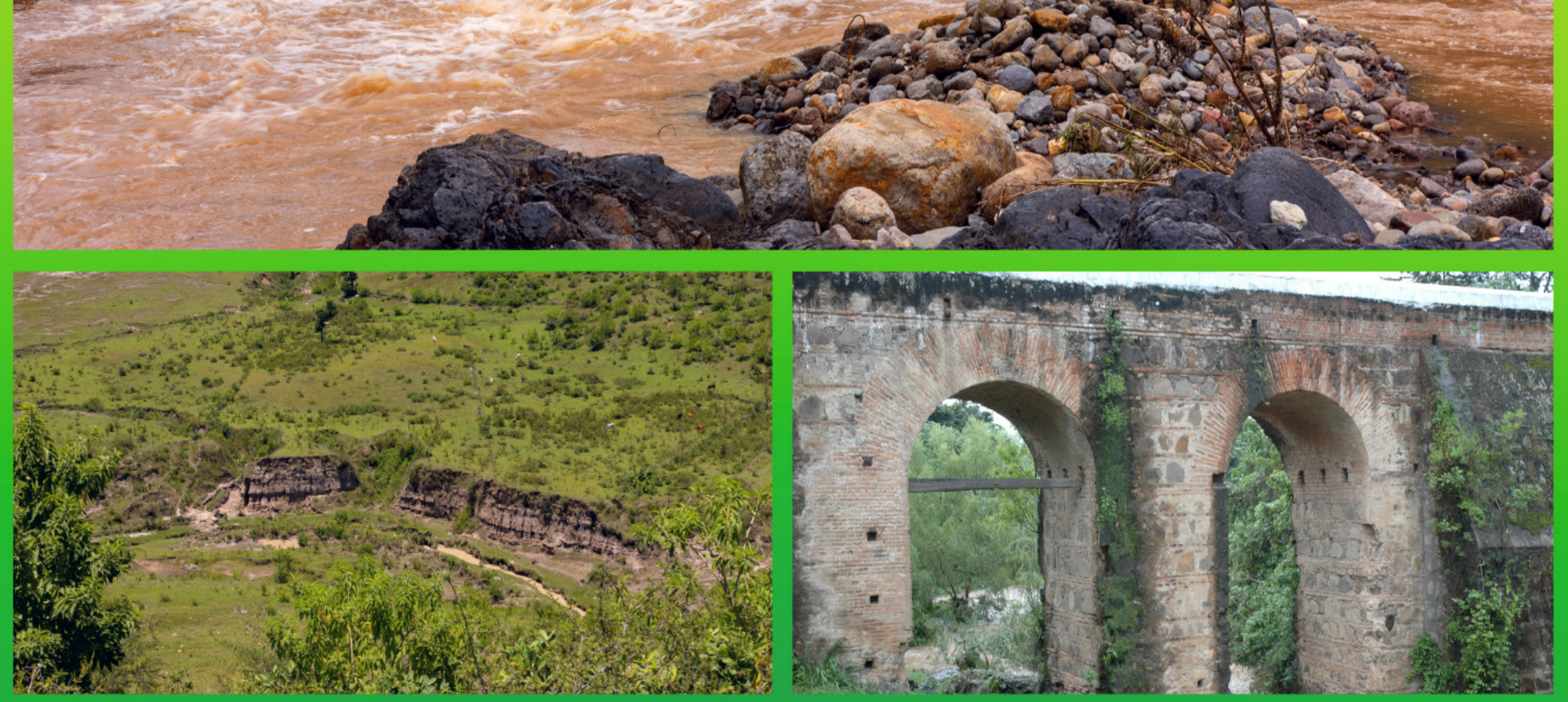

\section{Disponible en:}

\section{http://revistacunsurori.com/}

3a. calle final 1-69, zona 5 Bo. Chipilapa, Jalapa, Guatemala 